\title{
Removal and Recovery of Carbon Disulfide Emitted by the Viscose Process:
}

Final Report

Energy Systems Division

Argonne National Laboratory

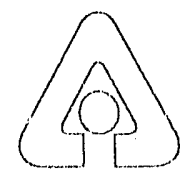

Operated by The University of Chicago.

under Contract W-31-109-Eng-38, for the

$P+3$

United States Department of Energy 


\section{Argonne National Laboratory}

Argonne National Laboratory, with facilities in the states of Illinois and ldaho, is owned by the United States govemment, and operated by the University of Chicago under the provisions of a contract with the Department of Energy,

This technical memo is a product of Argonne's Energy Systems (ES)

Division. For information on the division's scientific and engineering activities, contact:

Director, Energy Systems Division

Argonne National Laboratory

Argonne, Illinois 60439-4815

Telephone (708) 252-3724

Presented in this technical memo are preliminary results of ongoing work or work that is more limited in scope and depth than that described in formal reports issued by the ES Division.

\section{Disclaimer}

This report was prepared as an account of work sponsored by an agency of the United States Govermment. Neither the United States Govemment nor any agency thereof, nor any of their employees, makes any warranty, express or implied, or assumes any legal liability or responsibility for the accuracy, completeness, or usefulness of any information, apparatus, product, or process disclosed, or represents that its use would not infringe privately owned rights. Reference herein to any specific commercial product, process, or service by trade name, trademark, manufacturer, or otherwise, does not necessarily constitute or imply its endorsement, recommendation, or favoring by the United States Govemment or any agenoy thereof. The views and opinions of authors expressed herein do not necessarily state or reflect those of the United States Government or any agency thereof.

Available to DOE and DOE contractors from the Office of Scientific and Tochnical Information, P.O. Box 62, Oak Ridge, TN 37831; prices available from (615) $576-8401$, FTS 626-8401.

Available to the public from the National Technical Information Service, U.S. Department of Cominerce 5285 Pc.: Royal Road, Springfield, VA 22161 


\section{Removal and Recovery of Carbon Disulfide Emitted by the Viscose Process:}

\section{Final Report}

by M.J. Mclntosh

Energy Systems Division,

Argonne National Laboratory, 9700 South Cass Avenue, Argonne, Illinois 60439

February 1992

Work supported by Hazardous Waste Research and Information Center (Illinois Department of Natural Resources); Teepak, Inc.; and Illinois Challenge Grant Office (Illinois Department of Commerce and Cornmunity Affairs). 


\section{CONTENTS}

1 BACKGROUND AND SUMMARY $\ldots \ldots \ldots \ldots \ldots \ldots \ldots \ldots \ldots \ldots \ldots$

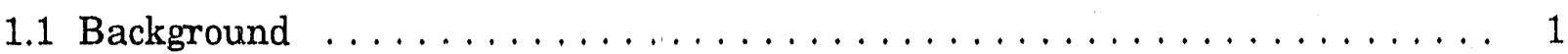

1. Summary $^{2}$ Work Completed $\ldots \ldots \ldots \ldots \ldots \ldots \ldots \ldots \ldots \ldots \ldots \ldots$

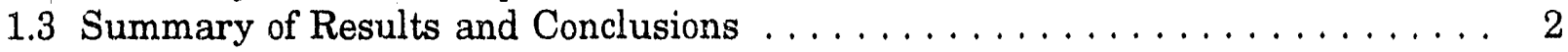

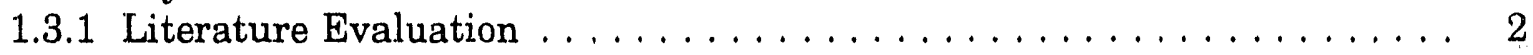

1.3 .2 Laboratory Testing . . . . . . . . . . . . . . . . . . . . 2

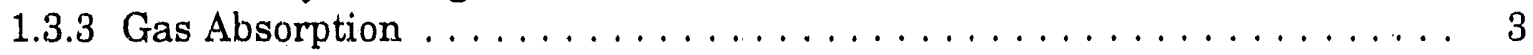

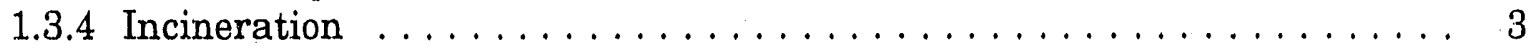

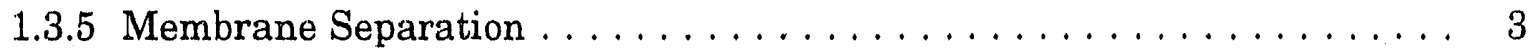

1.3.6 Noncarbon Adsorption . . . . . . . . . . . . . . . . . . . . . 4

1.3.7 Activated Carbon Adsorption $\ldots \ldots \ldots \ldots \ldots \ldots \ldots \ldots \ldots \ldots \ldots$

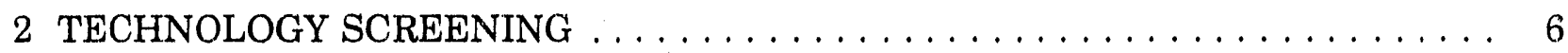

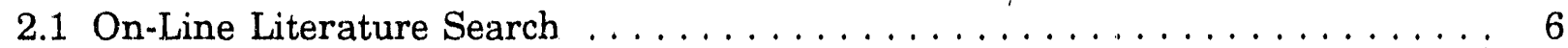

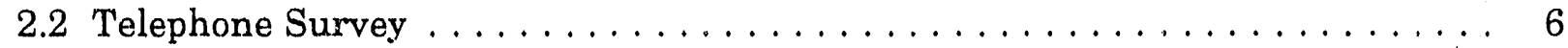

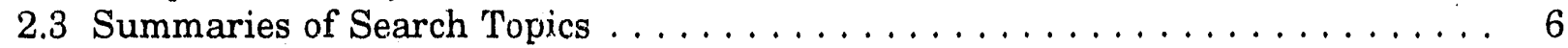

2.3.1 Noncarbon Adsorbents for $\mathrm{CS}_{2} \ldots \ldots \ldots \ldots \ldots \ldots \ldots \ldots \ldots$

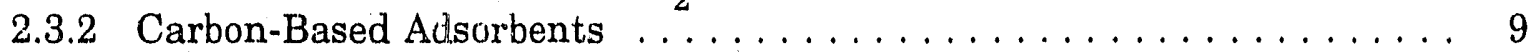

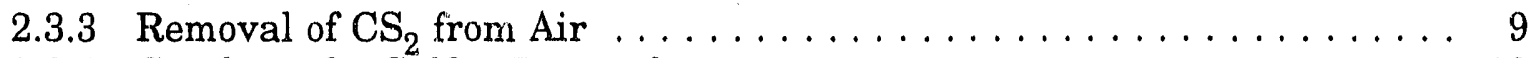

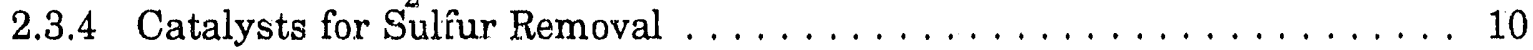

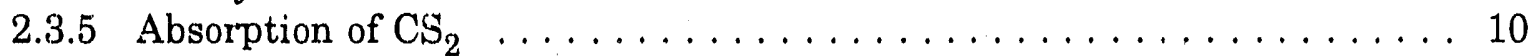

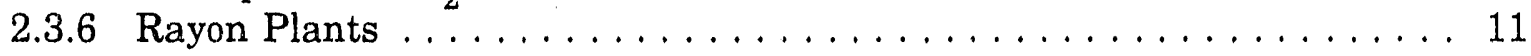

2.3.7 Vapor-Liquid Equilibrium of $\mathrm{CS}_{2} \ldots \ldots \ldots \ldots \ldots \ldots \ldots \ldots \ldots \ldots \ldots$

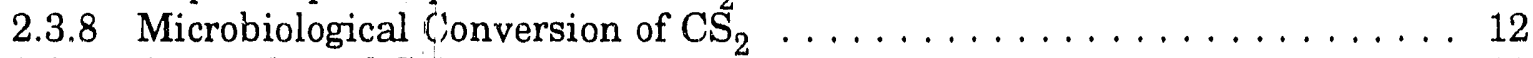

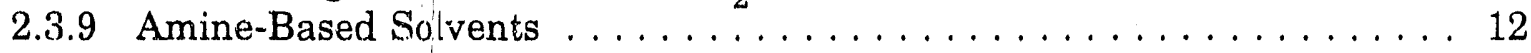

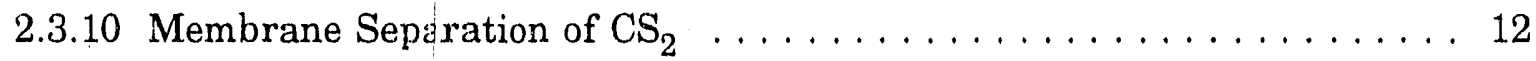

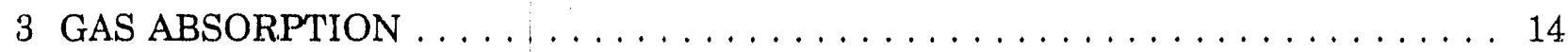

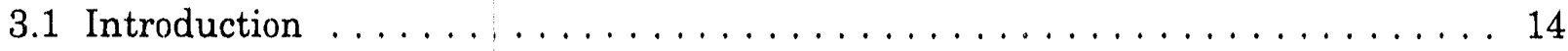

3.2 Absorption Liquid $\ldots \ldots \ldots \ldots \ldots \ldots \ldots \ldots \ldots \ldots \ldots \ldots \ldots$

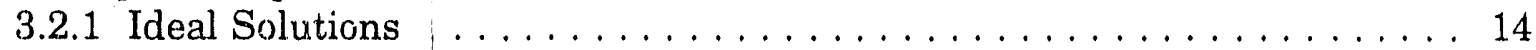

3.2.2 Solubility Parameter as a Criterion for Absorbent Selection . . . . . . . 16

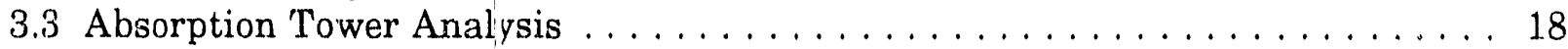

3.3 .1 Tower Diameter . . . . . . . . . . . . . . . . . . . . . 19

3.3 .2 Superficial Velocity . . . . . . . . . . . . . . . . . . . 19

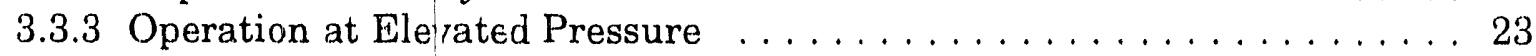

3.3.4 Reduction in Air Rate by Concentrating $\mathrm{CS}_{2} \ldots \ldots \ldots \ldots \ldots \ldots$

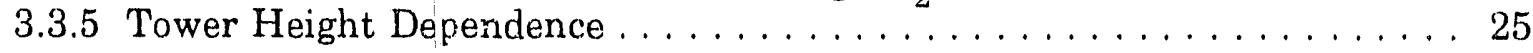

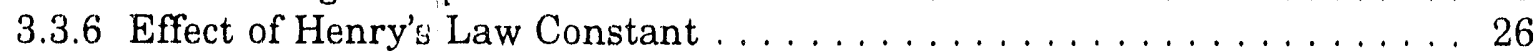

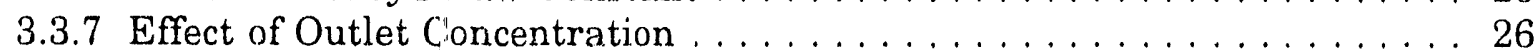

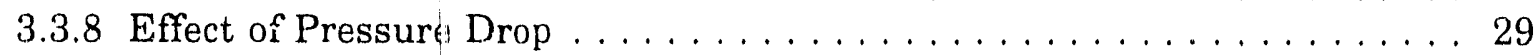

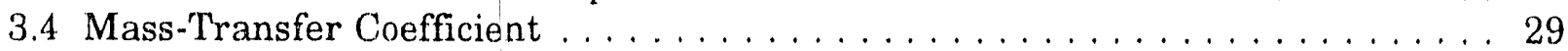

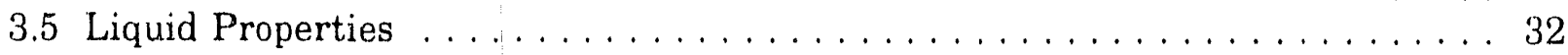

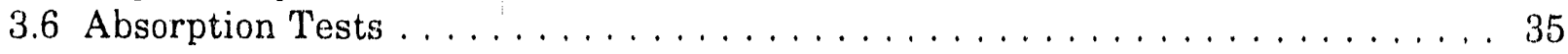




\section{CONTENTS (Cont'd)}

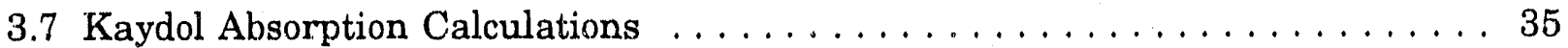

3.8 System Requirements for Gas Absorption . . . . . . . . . . . . . . . 47

3.8.1 Liquid Pumping .......................... 47

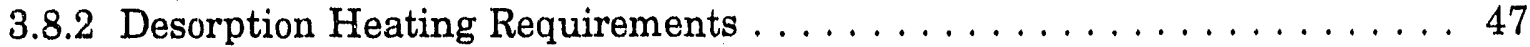

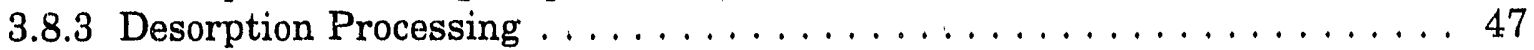

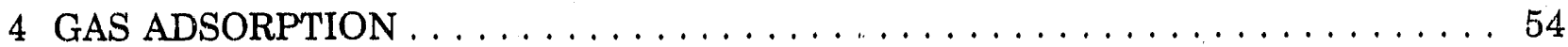

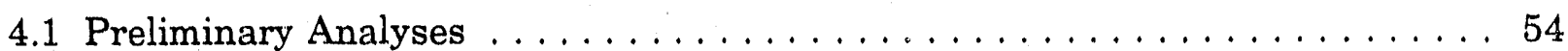

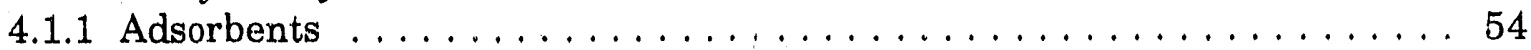

4.1 .2 Adsorbent Test Rig Design $\ldots \ldots \ldots \ldots \ldots \ldots \ldots \ldots \ldots \ldots \ldots$

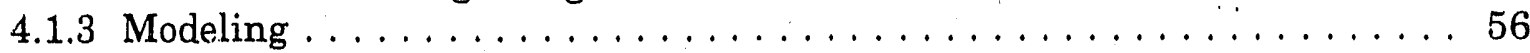

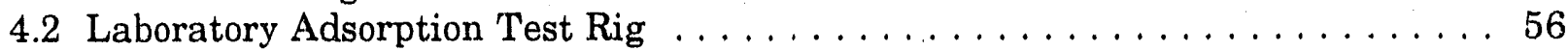

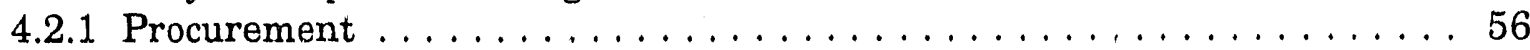

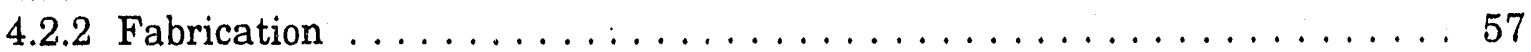

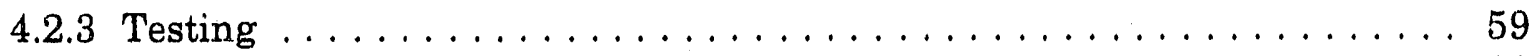

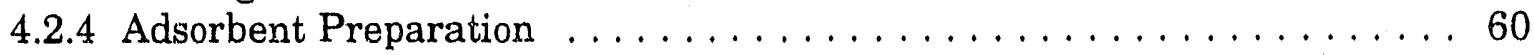

4.3 Data Collection ................................. 61

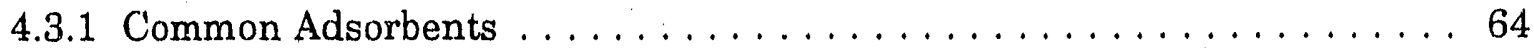

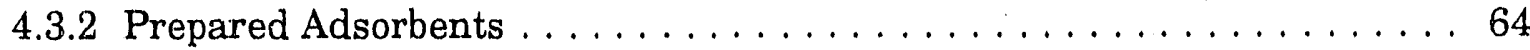

4.3.3 Polymeric Adsorbents . . . . . . . . . . . . . . . . . . . . . 67

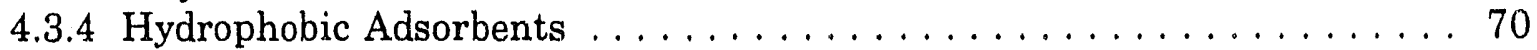

4.3.5 Activated Carbon Adsorbents $\ldots \ldots \ldots \ldots \ldots \ldots \ldots \ldots \ldots \ldots$. . . . . . . 70

4.4 Data Correlation ............................... 73

4.4.1 Gas Adsorption Process Description $\ldots \ldots \ldots \ldots \ldots \ldots \ldots \ldots \ldots$

4.4 .2 Solid Adsorbents and Isotherms $\ldots \ldots \ldots \ldots \ldots \ldots \ldots \ldots$

4.4 .3 Adsorption Tower Design $\ldots \ldots \ldots \ldots \ldots \ldots \ldots \ldots \ldots \ldots \ldots . \ldots 9$

4.4 .4 Effect of Maximum Loading $\ldots \ldots \ldots \ldots \ldots \ldots \ldots \ldots \ldots$

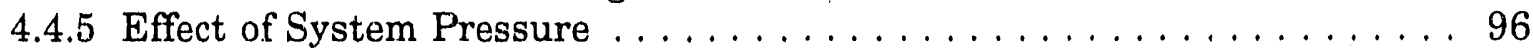

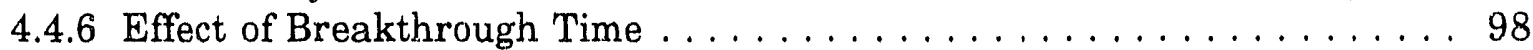

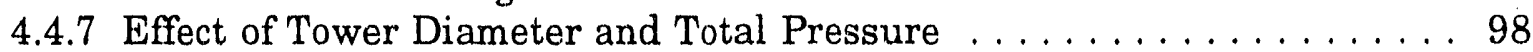

4.4 .8 Effect of Pressure Drop . . . . . . . . . . . . . . . . . . . . . . . 102

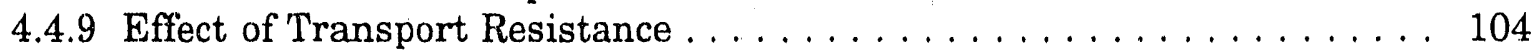

4.5 Concluding Remarks on Adsorption $\ldots \ldots \ldots \ldots \ldots \ldots \ldots \ldots \ldots \ldots$

5 GAS ADSORPTION COST STUDY $\ldots \ldots \ldots \ldots \ldots \ldots \ldots \ldots \ldots \ldots \ldots$

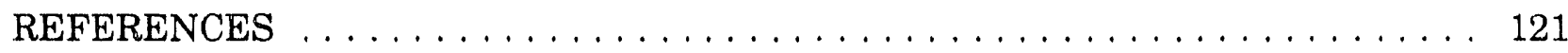

APPENDIX A: Gas Absorption Tower: Sample Calculation .............. 125

APPENDIX B: Gas Adsorption Tower: Sample Calculation $\ldots \ldots \ldots \ldots \ldots \ldots 143$

APPENDIX C: Publications Identified from Literature Search $\ldots \ldots \ldots \ldots \ldots \ldots$ 


\section{FIGURES}

3,1 Schematic of Gas Absorption Tower $\ldots \ldots \ldots \ldots \ldots \ldots \ldots \ldots \ldots$

3.2 Generalized. Flooding and Pressure Drop Correlations for

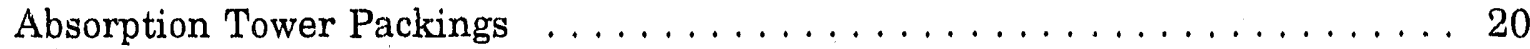

3.3a Absorption Bed Depth vs. Tower Diameter ..................... 22

3.3b Number of Absorption Towers vs. Diameter for 1, 5, 20, and $100 \mathrm{psig} \ldots \ldots 22$

$3.3 \mathrm{c}$ Superficial Velocity vs. Diameter $\ldots \ldots \ldots \ldots \ldots \ldots \ldots \ldots \ldots \ldots \ldots$

3.4 Cost of Compressors (millions of dollars) and Power Consumption

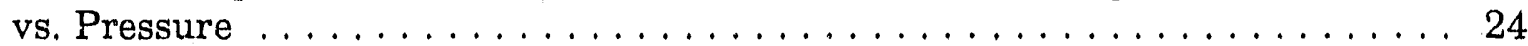

3.5a Absorption Bed Depth vs. Inlet Concentration .................. 24

3.5b Number of Absorption Towers vs. Inlet Concentration for 1, 5, 20, and

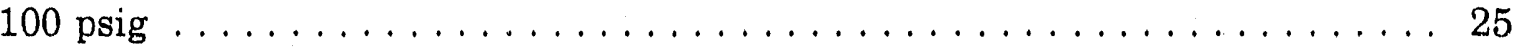

3.6a Absorption Bed Depth vs. Henry's Law Constant . . . . . . . . . . . . . . . 27

3.6b Number of Absorption Towers vs. Henry's Law Constant . . . . . . . . . . 27

3.6c Superficial Velocity vs. Henry's Law Constant . . . . . . . . . . . . . . 28

3.7a Absorption Bed Depth vs. Outlet Concentration at 1, 5, 20,

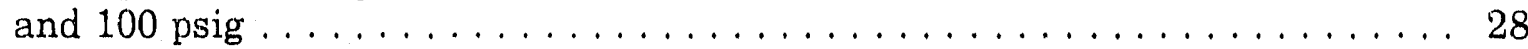

3.7b Number of Absorption Towers vs. Outlet Concentration . . . . . . . . . . . 29

3.8a Absorption Bed Depth vs. Available Pressure Drop . . . . . . . . . . . . . . 30

3.8b Number of Absorption Towers vs. Available Pressure Drop . . . . . . . . . . 30

3.8c Superficial Velocity vs. Available Pressure Drop . . . . . . . . . . . . . . 31

3.9 Variation of Tower Height with Mass-Transfer Coefficients $\mathrm{k}_{\mathrm{g}}$ and $\mathrm{k}_{\mathrm{l}} \ldots \ldots 33$

3.10a Variation of Tower Height with Liquid Properties $\ldots \ldots \ldots \ldots \ldots \ldots \ldots$. . . . 34

$3.10 \mathrm{~b}$ Variation of Number of Towers with Liquid Properties . . . . . . . . . . . 34

3.11a Schematic of Bubbler System for Gas Absorption Tests . . . . . . . . . . . 36

3.11b Rate Curve for Absorption of $\mathrm{CS}_{2}$ by Kaydol $\ldots \ldots \ldots \ldots \ldots \ldots \ldots \ldots \ldots$ 


\section{FIGURES (Cont'd)}

3.12a Absorption Bed Depth vs. Henry's Law Constant, Based on Kaydol Properties . . . . . . . . . . . . . . . . . . . . . 38

3.12b Number of Absorption Towers vs. Henry's Law Constant, Based on Kaydol Properties $\ldots \ldots \ldots \ldots \ldots \ldots \ldots \ldots \ldots \ldots \ldots$

3.13a Absorption Bed Depth vs. Henry's Law Constant, Based on Propylene Carbonate Properties . . . . . . . . . . . . . . . . . . . . . . 40

3.13b Number of Absorption T'owers vs. Henry's Law Constant, Based on Propylene Carbonate Properties . . . . . . . . . . . . . . . . . 40

$3.14 \mathrm{a}$ Absorption Bed Depth vs. Liquid Viscosity . . . . . . . . . . . . . 41

3.14b Number of Absorption Towers vs. Liquid Viscosity . . . . . . . . . . . . . . 41

3.15a Absorption Bed Depth vs. Liquid Viscosity . . . . . . . . . . . . . . 42

3.15b Number of Absorption Towers vs. Liquid Viscosity . . . . . . . . . . . . . . . 42

3.16a Absorption Bed Depth vs. Liquid Viscosity and Molecular Weight . . . . . . 43

3.16b Number of Absorption Towers vs. Liquid Viscosity and Molecular Weight ........................... 43

3.17a Absorption Bed Depth vs. Liquid Viscosity and Molecular Weight . . . . . . . 44

3.17b Number of Absorption Towers vs. Liquid Viscosity and Molecular Weight ............................44

3.18a Absorption Bed Depth vs. Liquid Viscosity ard Molecular Weight . . . . . . 45

3.18b Number of Absorption Towers vs. Liquid Viscosity and Molecular Weight .......................... 45

3.19a Absorption Bed Depth vs. Liquid Viscosity and Molecular Weight . . . . . . 46

3.19b Number of Absorption Towers vs. Liquid Viscosity and

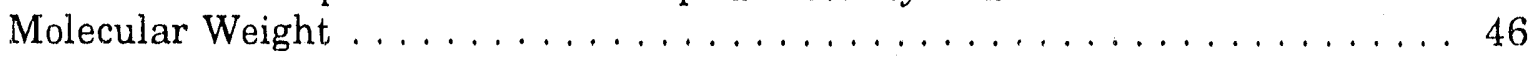

3.20 Clausius-Clapyron Extrapolation of $\mathrm{CS}_{2}$ Vapor Pressure Data . . . . . . . . 49

3.21a Variation of Percentage of $\mathrm{CS}_{2}$ Recovered with Temperature and Pressure of Vacuum Stripper 


\section{FIGURES (Cont'd)}

$3.2 \mathrm{lb}$ Variation of Percentage of $\mathrm{CS}_{2}$ Recovered with Temperature and

Pressure of Vacuum Stripper $\ldots \ldots \ldots \ldots \ldots \ldots \ldots \ldots \ldots \ldots \ldots$

3.21c Variation of Percentage of $\mathrm{CS}_{2}$ Recovered with Temperature and

Pressure of Vacuum Stripper $\ldots \ldots \ldots \ldots \ldots \ldots \ldots \ldots \ldots \ldots, \ldots \ldots$

3.21d Variation of Percentage of $\mathrm{CS}_{2}$ Recovered with Temperature and

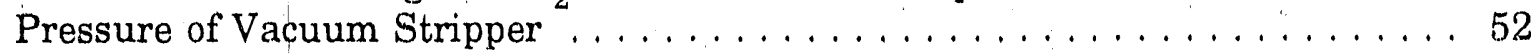

$3.21 \mathrm{e}$ Variation of Percentage of $\mathrm{CS}_{2}$ Recovered with Temperature and

Pressure of Vacuum Stripper $\ldots \ldots \ldots \ldots \ldots \ldots \ldots \ldots \ldots \ldots$

4.1 Schematic of Adsorption Column Dynamic Testing Rig . . . . . . . . . . 58

4.2 Infrared Spectrum of Untreated Alumina $\ldots \ldots \ldots \ldots \ldots \ldots \ldots \ldots \ldots \ldots$

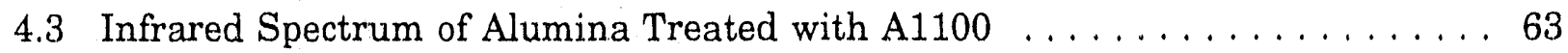

4.4 Breakthrough Plots for $\mathrm{CS}_{2}$ with Common Adsorbents $\ldots \ldots \ldots \ldots \ldots$

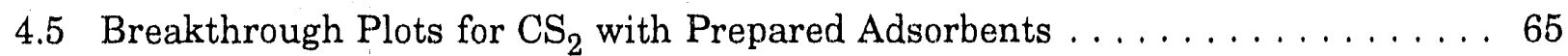

4.6 Adsorption and Desorption of Aminosilane/Silica:

Off-Gas Concentration in ppm vs. Time in Minutes $\ldots \ldots \ldots \ldots \ldots \ldots 6$

4.7 Breakthrough Plots for $\mathrm{CS}_{2}$ with Polymeric Absorbents $\ldots \ldots \ldots \ldots \ldots \ldots$

4.8 Adsorption and Desorption of XUS-40285 Polymer: Off-Gas

Concentration in ppm vs. Time in Minutes $\ldots \ldots \ldots \ldots \ldots \ldots 6 . \ldots \ldots$

4.9 Adsorption and Desorption of XUS-40323 Polymer: Off-Gas

Concentration in ppm vs. Time in Minutes . . . . . . . . . . . . . . 69

4.10 Breakthrough Plot for $\mathrm{CS}_{2}$ with Amberlite $\ldots \ldots \ldots \ldots \ldots \ldots \ldots \ldots \ldots$

4.11 Adsorption and Desorption of Amberlite: Off-Gas Concentration

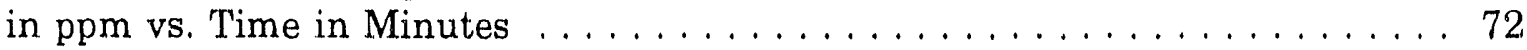

4.12 Breakthrough Plot for $\mathrm{CS}_{2}$ with Silicalite $\ldots \ldots \ldots \ldots \ldots \ldots \ldots \ldots \ldots$

4.13 Adsorption and Desorption of Silicalite: Off-Gas Concentration

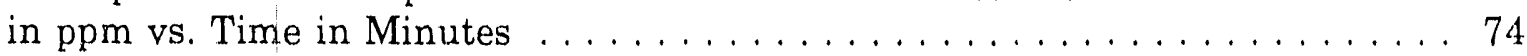

4.14 Breakthrough Plot for $\mathrm{CS}_{2}$ with Activated Carbon $\ldots \ldots \ldots \ldots \ldots \ldots \ldots$ 


\section{FIGURES (Cont'd)}

4.15 Adsorption and Desorption of Xtrusorb-700 Carbon: Off-Gas

Concentration in ppm vs. Time in Minutes . . . . . . . . . . . . 76

4.16 Adsorption and Desorption of PCB Carbon: Off-Gas Concentration

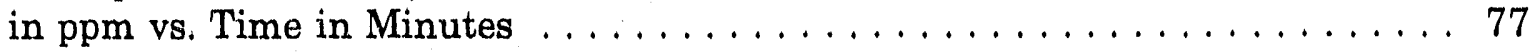

4.17 Adsorption and Desorption of GBAC Carbon: Off-Gas Concentration

in ppm vs. Time in Minutes $\ldots \ldots \ldots \ldots \ldots \ldots \ldots \ldots \ldots \ldots$

4.18 Adsorption of BPL Carbon: Off-Gas Concentration in ppm vs.

Time in Minutes . . . . . . . . . . . . . . . . . . . . . . 79

4.19 Breakthrough Curve for Adsorption $\ldots \ldots \ldots \ldots \ldots \ldots \ldots \ldots \ldots \ldots \ldots$

4.20a Mole Percent $\mathrm{CS}_{2}$ Recoverable vs. $\mathrm{CS}_{2}$ Concentration in $\mathrm{N}_{2}$

Desorption Gas for Various Condensation Temperatures ............ 82

4. 20b Mole Percent $\mathrm{CS}_{2}$ Recoverable vs. $\mathrm{CS}_{2}$ Concentration in $\mathrm{N}_{2}$

Desorption Gas for Various Condensation Temperatures $\ldots \ldots \ldots \ldots \ldots 82$

4.21a Phase Diagram for $\mathrm{CS}_{2} / \mathrm{H}_{2} \mathrm{O}$ System at 1 atm $\ldots \ldots \ldots \ldots \ldots \ldots$

4.21b Phase Diagram for $\mathrm{CS}_{2} / \mathrm{H}_{2} \mathrm{O}$ System at 2 atm $\ldots \ldots \ldots \ldots \ldots \ldots$

4.22 Isotherms for $\mathrm{CS}_{2}$ Adsorption and Desorption on

Activated Carbon $\ldots \ldots \ldots \ldots \ldots \ldots \ldots \ldots \ldots \ldots \ldots$

4.23 Expanded View of a Representative Carbon Isotherm $\ldots \ldots \ldots \ldots \ldots \ldots$

4.24 Variable Isotherm Definition $\ldots \ldots \ldots \ldots \ldots \ldots \ldots \ldots \ldots \ldots \ldots \ldots \ldots \ldots . \ldots \ldots$

4.25 Curve Fit of Breakpoint Loading with Maximum Loading for the

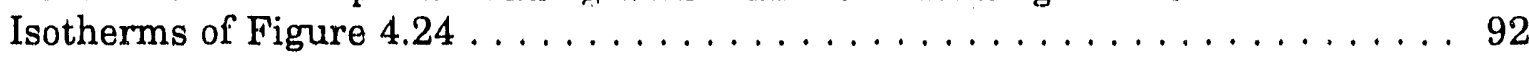

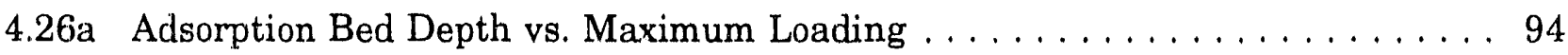

4.26b Number of Adsorption Towers vs. Maximum Loading . . . . . . . . . . . . 94

$4.26 \mathrm{c}$ Superficial Velocity vs. Maximum Loading $\ldots \ldots \ldots \ldots \ldots \ldots \ldots \ldots$ y5

4.27 Estimated Effect of Relative Humidity on $\mathrm{H}_{2} \mathrm{O}$ and $\mathrm{CS}_{2}$ Loading $\ldots \ldots \ldots 95$

4.28a Adsorption Bed Depth vs. Breakthrough Time . . . . . . . . . . . . . 99

$4.28 \mathrm{~b}$ Number of Adsorption Towers vs. Breakthrough Time . . . . . . . . . . . . 99 


\section{FIGURES (Cont'd)}

$4.28 \mathrm{c}$ Superficial Velocity vs. Breakthrough Time $\ldots \ldots \ldots \ldots \ldots \ldots \ldots \ldots$

4.29a Adsorption Bed Depth vs. Tower Diameter . . . . . . . . . . . . . . . . 100

$4.29 \mathrm{~b}$ Number of Adsorption Towers vs. Tower Diameter . . . . . . . . . . . . . . 101

$4.29 \mathrm{c}$ Superficial Velocity vs. Tower Diameter Time . . . . . . . . . . . . . . . 101

4.30a Adsorption Bed Depth vs. Pressure Drop ... . . . . . . . . . . . . . . 103

$4.30 \mathrm{~b}$ Number of Adsorption Towers vis. Pressure Drop . . . . . . . . . . . . . . 103

4.30c Superficial Velocity vs. Pressure Drop Time . . . . . . . . . . . . . . . . . 104

4.31 Bed Depth, Number of Towers, and Superficial Velocity vs. Particle

Diffusion Coefficient . . . . . . . . . . . . . . . . . . . . . . . . 105

5.1 Carbon Disulfide Adsorption Process Flow Diagram . . . . . . . . . . 108

5.2 Capital Costs for Adsorption Plant Cases Shown in Table 5.1. . . . . . . . 119

A.1 Diagram for Absorption Tower Material Balance $\ldots \ldots \ldots \ldots \ldots \ldots \ldots$

A.2 Relationship of Interfacial Concentrations to Bulk Gas and

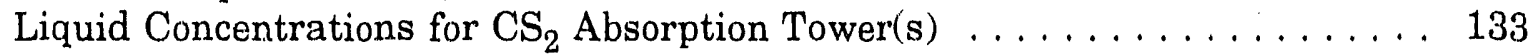

B.1 Expanded View of Carbon Isotherm $\ldots \ldots \ldots \ldots \ldots \ldots \ldots \ldots \ldots \ldots$

B.2 Pressure Drop for Adsorption Towers Packed with Calgon BPL Activated Carbon $\ldots \ldots \ldots \ldots \ldots \ldots \ldots \ldots \ldots \ldots \ldots \ldots, \ldots \ldots$

B.3 Basmadjian Graph for Adsorption Bed Depth Design . . . . . . . . . . . . . . . 149

\section{TABLES}

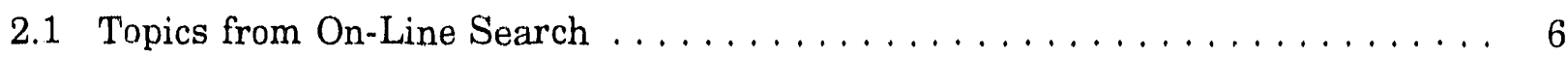

3.1 Solubility Parameters and Henry's Law Constants for Various Solvents . . . . . 17

3.2 Estimated Gas Absorption Losses for Various Absorbents . . . . . . . . . . . . 18

3.3 Values Used in Gas Absorption Calculations $\ldots \ldots \ldots \ldots \ldots \ldots \ldots \ldots . \ldots \ldots$ 


\section{TABLES (Cont'd)}

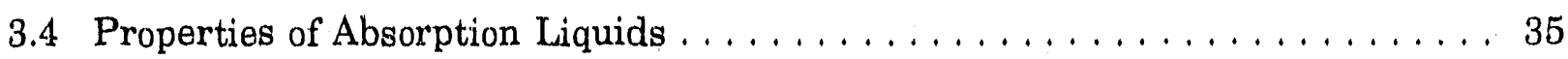

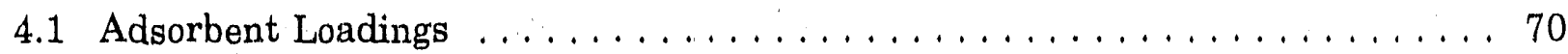

4.2 Input for Adsorption System Calculation, Nominal Case $\ldots \ldots \ldots \ldots$. . . . 92

4.3 Carbon Disulfide Loading at 100 ppm Vapor Concentration as a Function of Relative Humidity . . . . . . . . . . . . . . . . . . 97

4.4 Estimated Tower and Bed Depth Requirements for Activated Carbon and Hydrophobic Zeolite for Dry and Wet Gas Cases . . . . . . . . . . . 97

5.1 Cases Assumed for TSA Cost Study . . . . . . . . . . . . . . . . . . . 109

5.2 Carbon Disulfide Recovery System Cost Estimate: Base Case . . . . . . . . . 110

5.3 Carbon Disulfide Recovery System Cost Estimate: Nitrogen Desorption . . . 111

5.4 Carbon Disulfide Recovery System Cost Estimate: Wet Gas at 50\% Relative Humidity . . . . . . . . . . . . . . . . . . . . . . . . . 112

5.5 Carbon Disulfide Recovery System Cost Estimate: Wet Gas with

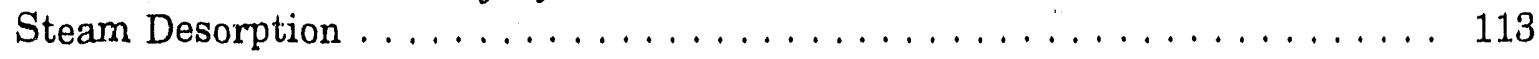

5.6 Carbon Disulfide Recovery System Cost Estimate: Very Wet Gas with Nitrogen Desorption and 80\% Relative Humidity ................. 114

5.7 Carbon Disulfide Recovery System Cost Estimate: Very Wet Gas with Steam Desorption ................................ 115

5.8 Carbon Disulfide Recovery System Cost Estimate: High Pressure with Dry Gas . . . ............................... 116

5.9 Carbon Disulfide Recovery System Cost Estimate: High Pressure with

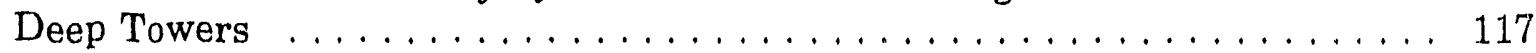

5.10 Summary of all $\mathrm{CS}_{2}$ Recovery System Cost Estimates $\ldots \ldots \ldots \ldots \ldots \ldots$

A.1 Iteration for Bed Depth of Absorption Tower . . . . . . . . . . . . . . 135

B.1 Iteration for Bed Depth of Adsorption Tower . . . . . . . . . . . . . 150 


\title{
REMOVAL AND RECOVERY OF CARBON DISULFIDE EMITTED BY THE VISCOSE PROCESS: FINAL REPORT
}

\author{
by
}

Michael J. McIntosh

\section{BACKGROUND ^IND SUMMARY}

\subsection{BACKGROUND}

Teepak, Inc, which manufactures cellulose food casings by means of the viscose process, has a plant in Danville, Illinois, that emits approximately 400,000 cubic feet per minute (cfm) of water-saturated air containing approximately 100 parts per million (ppm) of carbon disulfide $\left(\mathrm{CS}_{2}\right)$. Both Teepak and the state of Illinois desire to reduce these emissions as soon as possible; however, the large air flow and very small $\mathrm{CS}_{2}$ concentration result in a difficult and costly separations problem without an obvious economically viable solution. One possibility is to incinerate the $\mathrm{CS}_{2}$, but a more environmentally and economically acceptable alternative is to recover the $\mathrm{CS}_{2}$ for recycle to the process. The recovered $\mathrm{CS}_{2}$ would be worth about $\$ 700,000$ annually to Teepak.

This situation, although it involves an important Illinois industry, is much more than a serious local problem. The same problem exists at all plants that use the viscose process to manufacture rayon or cellulose products. These plants are located throughout the world (two in Illinois, including Teepak). As a result of upcoming clean-air laws, all such plants in the United States eventually will be shut down (with severe loss to local economies) unless a viable method is found to recover or remove small amounts of $\mathrm{CS}_{2}$ from wet air.

Teepak has sponsored, with the Hazardous Waste Research and Information Center (HWRIC) of the Illinois Department of Natural Resources, a research project at Argonne National Laboratory (ANL) to evaluate current gas-purification and recovery technology and to suggest a route of development that will lead to a $\mathrm{CS}_{2}$ recovery process. The Illinois Departmeit of Commerce and Community Affairs later provided an Illinois Challenge Grant to allow laboratory studies to supplement this effort. This report is a result of all those studies.

\subsection{SUMMARY OF WORK COMPLETED}

A literature search covering all aspects of $\mathrm{CS}_{2}$ removal and recovery produced 10,380 citations. Further sorting narrowed this group to 855 pertinent references; 235 were selected for further study. Of these, more than half were used directly in developing the results of this report. 
Design models for $\mathrm{CS}_{2}$ /air separations were developed for gas adsorption and gas absorption. A cost model was developed for gas adsorption. Sorption of $\mathrm{CS}_{2}$ in more than 20 sorbents, both liquid and solid, was measured in the laboratory, and the results were translated into equilibrium data. The laboratory data, supplemented with literature data, were used in design and cnst models to develop information regarding $\mathrm{CS}_{2}$ recovery at Teepak.

A wide range of U.S. experts in separations engineering, plant design and costing, and $\mathrm{CS}_{2}$ chemistry were contacted for comment on the information and rationale developed from the literature search and modeling efforts. Their suggestions were compiled and incorporated into revised models and reported information.

\subsection{SUMMARY OF RUSULTS AND CONCLUSIONS}

\subsubsection{Literature Evaluation}

The general literature contains a large number of reports related to $\mathrm{CS}_{2}$ recovery from air. Many of these were generally useful, but a majority were found to be quantitatively inapplicable to the Teepak case for one or more of the tollowing reasons:

- They relate to concentrations of $\mathrm{CS}_{2}$ often an order of magnitude or more larger than the Teepak case.

- They do not address the important process issues related to the Teepak case, such as the very high flow rate of air requiring treatment, mandated by the Occupational Safety and Health Administration (OSHA) personal exposure limits and product quality/process specifications.

- They do not provide quantitative data or results upon which an objective evaluation can be based.

\subsubsection{Laboratory Tesiing}

Both equilibrium data and rate data (or estimates) are required to evaluate any separations process. In all the data and literature searches associated with this project, only one set of applicable equilibrium data was found: adsorption isotherms for $\mathrm{CS}_{2}$ on activated carbon.

Additional adsorption and absorption equilibrium data for a variety of sorbents were measured at ANL and at Teepak. These data were used to determine the feasibility of $\mathrm{CS}_{2}$ sorption processes based on the use of specific sorbents. 


\subsubsection{Gas Absorption}

In the absence of applicable vapor-liquid equilibrium data for $\mathrm{CS}_{2}$ solvents, gas absorption was first studied on the basis of theoretical projections and assumptions (e.g., Henry's law coefficients obtained from solubility parameter data and rate data obtained from generalized correlations) and reasonable variations from the minimal case. A highly aliphatic mineral oil (Kaydol) was tested in the laboratory for equilibrium loading at $100 \mathrm{ppm} \mathrm{CS}_{2}$ and found to fit theoretical estimates of Henry's law coefficient. By using the theoretical approach, application of conventional gas absorption processes for $\mathrm{CS}_{2}$ removal was shown to be relatively expensive, mainly because of low equilibrium $\mathrm{CS}_{2}$ loadings in all possible absorbents, with attendant requirements for high liquid flow and relatively low superficial gas velocities to avoid flooding in absorption towers. For example, 13 conventional absorption towers ( $12 \mathrm{ft}$ in diameter) would be required at Teepak for $\mathrm{CS}_{2}$ removal only. Application of conventional desorption processing to Kaydol (or other possible $\mathrm{CS}_{2}$ absorption liquids) was evaluated and found to be infeasible. A very large amount of steam heat would be required. Also, because of low equilibrium $\mathrm{CS}_{2}$ loadings and relatively low $\mathrm{CS}_{2}$ vapor pressure at desorption temperatures, high vacuum and high temperature would be required. Recovery would be very expensive and highly inefficient, if not impossible.

Gas absorption with desorption $\mathrm{CS}_{2}$ recovery, therefore, was concluded to be infeasible at Teepak.

\subsubsection{Incineration}

Catalytic incineration was judged possible at Teepak. Incineration can destroy $\mathrm{CS}_{2}$ in air but would require a large capital investment and create a difficult $\mathrm{SO}_{2}$ /air separations problem. Because the main thrust of the project is to evaluate removal and recovery possibilities, incineration must remain a default option. However, catalytic incineration of $\mathrm{CS}_{2}$ to $\mathrm{SO}_{3}$ (allowing production of sulfuric acid $\left[\mathrm{H}_{2} \mathrm{SO}_{4}\right]$, a neutralizer used in the Teepak plant) may be possible given a catalyst development effort. Unfortunately, sulfuric acid is worth 3.7 cents per pound, while $\mathrm{CS}_{2}$ is worth 18.5 cents per pound. Thus, there is little incentive to adopt the catalytic or noncatalytic incineration approach, if recovery of $\mathrm{CS}_{2}$ remains possible.

\subsubsection{Membrane Separation}

It was determined that no existing ceramic membrane can remove $\mathrm{CS}_{2}$ from air effectively, even at high $\mathrm{CS}_{2}$ concentrations. Rubbery polymer membranes are a possibility, but none is available specifically for the $\mathrm{CS}_{2} /$ air system, and no data have been developed that would allow even a preliminary process design to be developed. However, simple calculations showed that the driving force in $\mathrm{CS}_{2}$ permeation through any membrane, ceramic or rubbery, is so low that a very large membrane surface would be required at high capital cost. One expert estimated a minimum of $\$ 25$ million for the membrane equipment alone. This approach was not ruled out on quantitative grounds; however, research would be 
required to develop the needed membrane and the permeation data for $\mathrm{CS}_{2}$. Pursuing the membrane option is not recommended at this time.

\subsubsection{Noncarbon Adsorption}

In the Teepak application, the $\mathrm{CS}_{2}$-contaminated air flow is normally very wet ( 80 to $100 \%$ relative humidity). Thercfore, any adsorbent would carry some advantage if it could be used without first drying the air; hydrophobic adsorbents would be preferred. In addition, $\mathrm{CS}_{2}$ has a very low autoignition temperature in air $\left(-100^{\circ} \mathrm{C}\right)$, so fire is always a concern for flammable adsorbents, such as activated carbon. Common noncartun adsorbents, such as common zeolite or silica gel, are hydrophilic and would be totally poisoned by water. However, many nonflammable, hydrophobic adsorbents exist or can be developed, and it was believed that these may have advantages. Of course, common noncarbon adsorbents could be used with air drying if they loaded well with $\mathrm{CS}_{2}$, since the cost of air drying has beer shown (Section 5) to be a relatively low fraction of total carbon adsorption plant costs. Therefore, adsorption data were compiled for a variety of noncarbon hyàrophubic and hydrophilic adsorbents. Unfortunately, it was found that none loaded with $\mathrm{CS}_{2}$ as well as carbon, almost wiihin an order of magnitude. Because the adsorbents tested range over all classes of commercial adsorption materials, the possibility of finding one with favorable properties does not seem promising.

\subsubsection{Activated Carbon Adsorption}

As mentioned above, a variety oî adsorbents were tested in the laboratory for both adsorption and desorption of $\mathrm{CS}_{2}$. The results show that all adisorbents other than activated carbon have relatively low loading capacity for $\mathrm{CS}_{2}$, but that carbon adsorption of $\mathrm{CS}_{2}$ is very efficient. In one case, a carbon supplied by Kureha Ltd. was found to contain, at equilibrium, $8 \%$ by weight of $\mathrm{CS}_{2}$ at only $1: 00 \mathrm{ppm} \mathrm{CS}_{2}$ in dry air. It was also desorbed relatively easily at only $100^{\circ} \mathrm{C}$. Other carbons loaded even higher, but desorption was more difficult. Tests also showed that use of wet air can reduce the average loading of $\mathrm{CS}_{2}$ on carbon by as much as $62 \%$, depending on the relative humidity ( $\mathrm{RH})$. Use of activated carbon adsorption isotherms estimated from laboratory data allowed a general process and cost analysis of preliminary process designs to be conducted for a hypothetical temperature-swing, activatedcarbon, gas-adsorption (TSA) plant at Teepak. Provided the problems (discussed below) associated with carbon adsorption can be overcome, the results indicate that gas adsorption is an expensive but possible means of $\mathrm{CS}_{2}$ recovery. For example, if $5 \% \mathrm{CS}_{2}$ loading of carbon is assumed, a grass-roots gas-adsorption plant at Teepak would require 20 operating adsorption towers with beds $7.5 \mathrm{ft}$ deep, for a total plant cost of $\$ 24.08$ million. If the air were totally dried before adsorption, the $\mathrm{CS}_{2}$ could be removed by 16 towers with 5.4 - $\mathrm{ft}$ beds at a cost of $\$ 23.42$ million. If the air were only partially dried to $50 \% \mathrm{RH}, 16$ operating towers with 5.5 - $\mathrm{ft}$ beds at a cost of $\$ 22.82$ million would be required. If the air were both pressurized to 50 pounds per square inch gauge (psig) and totally dried, the recovery could be accomplished by ten 6.1 - ft operating towers at a cost of $\$ 23.64$ million. Other TSA options are given in Section 5. Comparable costs for other forms of carbon adsorption plants, such 
as the moving bed concept pioneered by Kureha, remain to be evaluated. However, TSA is the most basic and simplest of the carbon adsorption configurations and is therefore likely to be also the lowest-cost configuration.

Unfortunately, activated carbon adsorption involves other problems. For example, because of the low autoignition temperature of $\mathrm{CS}_{2}$, a carbon/air/ $\mathrm{CS}_{2}$ system would constitute a severe fire hazard when heated only slightly. Means to alleviate this danger must be developed and tested. Fires likely have occurred at historical commerical carbon-based 'S $_{2}$ recovery installations because of insufficient desorption; if so, the danger might be lessened by careful attention to bed temperature during desorption. This idea, together with other possibilities, must be verified in tests. Additional deterrents to carbon adsorbent use are the possibility of $\mathrm{H}_{2} \mathrm{~S}$ poisoning of the carbon (the Teepak air contains trace $\mathrm{H}_{2} \mathrm{~S}$ ), the large transpori zone (unused bed) requirements of some carbons, and the reduction in adsorptive capacity resulting from mristure in the Teepak gas. However, since these deterrents could yield to a determined pilot effort, the pilot option is recommended as the next phase of this program.

Calculations indicated that stearn desorption has significant advantages over nitrogen desorption, mainly vecause steam will condense at relatively high temperature and low pressure and because $\mathrm{CS}_{2}$ is immiscible in water. These results should be verified in a pilot study.

It is concluded that further development of carbon adsorption presents the best current nossibility for $\mathrm{CS}_{2}$ recovery at Teepak. 


\section{TECHNOLOGY SCREENING}

\subsection{ON-LINE LITERA $\Upsilon$ TURE SEARCH}

An extensive on-line survey of chemical abstract literature was conducted. The major keyword "carbon disulfide" produced 10,380 references. These were amended by a variety of minor keywords (emissions control, waste gas, removal, isolation, scrubbing, separation, adsorption, absorption, catalysis), and a subset of 855 articles and patents resulted. These were screened for applicability to the Teepak situation, and 235 references were selected for further study. The 235 references are given in Appendix C. Table 2.1 lists the topics covered by these selections.

\subsection{TELEPHONE SURVEY}

Experts in gas separations, adsorption, adsorbents, catalysts, catalytic incineration, membrane separation, vapor-liquid equilibrium, and carbon disulfide $\left(\mathrm{CS}_{2}\right)$ were contacted by telephone. In many cases, they were very willing to share their knowledge and provided pertinent suggestions and references. This effort was helpful in obtaining general knowledge of the state of technology in these fields. However, data leading to specific technologies of promise were not obtained.

\subsection{SUMMARIES OF SEARCH TOPICS}

Pertinent topics are discussed in more detail in this section. The information was taken from both the on-line literature search and the telephone survey.

TABLE 2.1 Topics from On-Line Search

\begin{tabular}{lc}
\hline \multicolumn{1}{c}{ Topic } & $\begin{array}{c}\text { Number of } \\
\text { Selections }\end{array}$ \\
\hline Noncarbon adsorbents for $\mathrm{CS}_{2}$ & 49 \\
Removal of sulfur from gas & 40 \\
Removal of $\mathrm{CS}_{2}$ from air & 35 \\
Catalysts for sulfur removal & 26 \\
Activated carbon adsorption & 25 \\
Absorption of $\mathrm{CS}_{2}$ & 22 \\
Rayon plants & 20 \\
Vapor-liquid equilibrium of $\mathrm{CS}_{2}$ & 8 \\
Microbiological conversion of $\mathrm{CS}_{2}$ & 4 \\
Amine-based sorbents & 4 \\
Membrane separations of $\mathrm{CS}_{2}$ & 2 \\
& \\
Total & 235 \\
\hline
\end{tabular}




\subsubsection{Noncarbon Adsorbent; for $\mathrm{CS}_{2}$}

\subsubsection{Zeolites}

In one study, a $5 \mathrm{~A}$ zeolite molecular sieve was tested for $\mathrm{CS}_{2}$ adsorption and found to follow a Langmuir-type isotherm. ${ }^{1}$ Sodium-, calcium-, and iron-substituted zeolites were studied as well. The iron zeolites appeared to have an advantage when used for $\mathrm{CS}_{2}$ adsorption. Both erionite and niordenite also wore tested, but no comparable results were found.

In general, zeolites cannut adsorb $\mathrm{CS}_{2}$ with as high an initial isotherm slope as activated carbon. Since the presint case involves a very dilute vapor phase, the initial slope is critical; therefore, zeolites do not appear promising candidates for $\mathrm{CS}_{2}$ removal. However, actual isotherm data that would allow estimation of breakthrough curves for both adsorption and desorption on zeolites were hot found.

Because common zeolit is highly hydrophilic, it cannot be used in the Teepak application unless the contaminated air is first dried.

\subsubsection{Polymers}

A few ion-exchange resins have been studied superficially in connection with $\mathrm{CS}_{2}$ adsorption, but data useful to process design were not found. ${ }^{2}$ In many cases, ion-exchange resins did not work well for $\mathrm{CS}_{2}$, although $\mathrm{H}_{2} \mathrm{~S}$ was adsorbed efficiently. However, because $\mathrm{H}_{2} \mathrm{~S}$ can be classified as a "hard acid" and $\mathrm{CS}_{2}$ as a "soft base," could not be expected to adsorb $\mathrm{CS}_{2}$ efficiently. Because the available work on $\mathrm{CS}_{2}$ adsorption by ion-exchange resins is very limited, the negative results do not necessarily indicate that more compatible polymers are not possible.

Styrene-divinylbenzene copolymer was patented in 1976 as an adsorbent for $\mathrm{CS}_{2}$ recovery, ${ }^{4}$ but adequate data to gauge the usefulness of this adsorbent are not available. Resins with amine functionalities have been used to remove $\mathrm{CS}_{2}$ and other impurities from technical carbon monoxide.

In general, polymeric adsorbents including resins have teen well-used for aqueous systems, but their use in gas-phase separations has received very little attention. One reason for this lack is that it is difficult to prepare these materials in sufficiently large particle size to allow fixed-bed adsorption columns to operate at reasonably low pressure drop. At least one large chemical company (Dow) currently is addressing this problem. The problem is not as critical for fluidized-bed adsorption, and some fluidized-bed polymeric adsorbents have appeared, but none that can handle $\mathrm{CS}_{2}$ efficiently have been found. Testing, to be discussed in Section 4.3 of this report, verified this conclusion. 


\subsubsection{Silane Made-Up Composites}

One major class of composite adsorbents of possible value for $\mathrm{CS}_{2}$ recovery has been used in chromatography. Organic silanes can react with the hydrated surfaces of silica gel to produce a silane-bonded organic surface:

$$
\mathrm{R}\left(\mathrm{CH}_{3}\right)_{3} \mathrm{Si}(\mathrm{OH})_{3}+\mathrm{HO}-1-->\mathrm{R}\left(\mathrm{CH}_{3}\right) \mathrm{Si}(\mathrm{OH})_{2}-1+\mathrm{H}_{2} \mathrm{O}
$$

In Equation 1, $\mathrm{R}$ can be any organic radical. Many modified silica gels with different Rs can be purchased. Furthermore, organic silanes of many varieties can be purchased and used with silica gel to prepare different surfaces according to Equation 1. Alumina also has surface hydroxyl groups that can be used to modify its surface. At the present time, no studies on $\mathrm{CS}_{2}$ adsorption and silane made-up composites have been found. However, studies of amine functionalities for $\mathrm{SO}_{2}$ and $\mathrm{CO}_{2}$ have been performed, ${ }^{5}$ and others appear to be under consideration for a variety of adsorbates. ${ }^{6}$ Section 4.3 contains further discussion of silane made-up adsorbents.

\subsubsection{Impregnated Made-Up Composices}

In some cases, a composite adsorbent is made simply by mixing a solid adsorbent with a fluid that impregnates the pores. In this case, a chemical bond between the impregnated fluid and the pore surface of the adsorbent is unlikely. The lack of a bond would be an extreme disadvantage in an industrial process for $\mathrm{CS}_{2}$ recovery, because the fluid may not stay in the pores during a reasonable number of adsorption/desorption cycles. In one case, a calcium zeolite was impregnated with ammonia and used to adsorb acid gases. ${ }^{7}$ The performance increased the breakthrough time from $52 \mathrm{~min}$ to $78 \mathrm{~min}$. In another case, activated carbon was impregnated with $\mathrm{NaOH}$ solution and used to adsorb $\mathrm{CS}_{2}$ and other sulfur gases. ${ }^{8}$ The adsorption capacity of activated carbon for $\mathrm{H}_{2} \mathrm{~S}$ has been increased by impregnating the carbon with heavy metal compounds. ${ }^{9}$ Data allowing evaluation of particular impregnated adsorbents were not found. Surface modification of carbon by $\mathrm{SO}_{2}$ causes polar functionalities to form on the surfaces, thus changing the surface affinity for methanol and benzene. ${ }^{10}$ Because of the low polarity of $\mathrm{CS}_{2}$, this technique is not likely to be of value in $\mathrm{CS}_{2}$ recovery.

\subsubsection{Molecular-Engineered Layers}

Catalytica (Palo Alto, California) has developed another class of made-up adsorbent. Layers of inorganic complexes held together by columns of organic backbone can form structures for adsorption. Catalytica has made many of these structures, with differing functionalities. However, the firm declined to provide samples for testing with $\mathrm{CS}_{2}$. 


\subsubsection{Carbon-Based Adsorbents}

Activated carbon is prepared by heating various source materials (such as coal, wood, and coconut shell) in the absence of air to produce a char. The char is then "activated" by heating, in the presence of oxidizing agents such as steam, air, or $\mathrm{CO}_{2}$, to remove the more reactive portions of the char and to produce an extensive internal porous structure. Many variables are important in this process, and the final ability of the activated carbon to adsorb and hold a given substance such as $\mathrm{CS}_{2}$ is very dependent on how the carbons are prepared. This dependence relates to the internal surface structure and the type of functional groups on the internal surface that contain oxygen and hydrogen. To maximize $\mathrm{CS}_{2}$ adsorption, surface area should be maximized and oxygen functional groups minimized. The ability to meet this goal has been developed, and an "H-carbon," which contains no surface oxygen groups, can be prepared by activating char in $\mathrm{H}_{2}$ at $400^{\circ} \mathrm{C}$. Unfortunately, when exposed to air the H-carbon slowly gains oxygen.

Carbon has been used in many different development efforts to adsorb $\mathrm{CS}_{2}$ from air. ${ }^{11,12}$ It has several important advantages. First, most activated carbons are at least partially hydrophobic, so the wet Teepak air will not prevent $\mathrm{CS}_{2}$ adsorption totally, though it may be diminished. Also, because carbon has large internal surface area and excellent apparent affinity for $\mathrm{CS}_{2}$, carbon loading of $\mathrm{CS}_{2}$ can be high at low partial pressure of $\mathrm{CS}_{2}$. This loading has been verified in the current study, and tests on various carbons are discussed in detail in Section 4. Countering these advantages are the danger of fire for a carbon/air/CS 2 system desorbed by steam, the possibility that a large transport zone will limit the amount of useful bed, and the poisoning effect of $\mathrm{H}_{2} \mathrm{~S}$ contamination (a small concentration of $\mathrm{H}_{2} \mathrm{~S}$ is present [5 to $30 \mathrm{ppm}$ ] in the Teepak air).

Kureha Ltd. has developed a hard activated carbon for moving-bed adsorption. On the basis of tests described in Section 4, this or a similar material may have potential for fixed-bed temperature-swing adsorption and recovery of $\mathrm{CS}_{2}$. If an $\mathrm{H}$-carbon has a muchimproved $\mathrm{CS}_{2}$ adsorptive capacity relative to other carbons, it is possible to speculate that $\mathrm{H}_{2}$ could be used occasionally as a desorbing gas at $300^{\circ} \mathrm{F}$ or higher for $\mathrm{CS}_{2}$-loaded $\mathrm{H}$-carbon and simultaneously could regenerate the H-carbon. This possibility was not explored in the current project but could be studied in the pilot phase.

\subsubsection{Removal of $\mathrm{CS}_{2}$ from Air}

The common methods used to remove $\mathrm{CS}_{2}$ from air are mineral oil absorption and carbon adsorption. These methods are discussed in more detail in later sections.

A few less common methods of low efficiency and high cost were found. For example,

$\mathrm{CS}_{2}$ oxidation in air can be activated with ultraviolet light. ${ }^{13,14}$ In one case, a $\mathrm{CS}_{2}$ concentration of $26 \mathrm{ppm}$ was dropped to zero. However, the treated air flow was very small $(0.04 \mathrm{cfm})$. There appear to be two drawbacks to this method: it has been demonstrated only at a rate many orders of magnitude lower than needed for industrial application, and it destroys $\mathrm{CS}_{2}$ and therefore is not a recovery process. 
A cryogenic approach has been tried in which the viscose gases were cuoled in stages to $-133^{\circ} \mathrm{C}$, thus removing $\mathrm{CS}_{2}$ by condensation. ${ }^{15}$ The melting point of $\mathrm{CS}_{2}$ is $-110^{\circ} \mathrm{C}$, so the removed $\mathrm{CS}_{2}$ could have been solid. For the Teepak application, the vapor pressure of the solid or liquid $\mathrm{CS}_{2}$ must be less than that inherent in the 100-ppm Teepak air $\left(100 / 10^{6}=\right.$ $10^{-4} \mathrm{~atm}$ ) to remove most of the $\mathrm{CS}_{2}$ from the Teepak air. At $-133^{\circ} \mathrm{C}, \mathrm{CS}_{2}$ vapor pressure is about $0.017 \times 10^{-4} \mathrm{~atm}$, so about $98 \%$ of the $\mathrm{CS}_{2}$ could be recovered in this way. In any case, cooling $400,000 \mathrm{cfm}$ of air to $-133^{\circ} \mathrm{C}$ would be difficult at any reasonable cost, even if a heat pump were used as discussed. ${ }^{15}$

\subsubsection{Catalysts for Sulfur Removal}

Most processes for catalytic $\mathrm{CS}_{2}$ removal are related to the Claus Process for catalytic reduction of $\mathrm{H}_{2} \mathrm{~S}$ to elemental sulfur. In this process, which generally treats industrial gases that have a high $\mathrm{H}_{2} \mathrm{~S}$ concentration, some of the $\mathrm{CS}_{2}$ is oxidized to elemental sulfur and $\mathrm{CO}_{2}$. Residual gases, including $\mathrm{CS}_{2}$, often are passed to downstream reactors that hydrolyze $\mathrm{CS}_{2}$ to $\mathrm{H}_{2} \mathrm{~S}$ for further treatment. Many catalysts for $\mathrm{CS}_{2}$ hydrolysis have been studied, including transition metal oxides, alumina, and sulfides. Application of hydrolysis catalysts to the Teepak problem would involve catalytic hydrolysis of $\mathrm{CS}_{2}$ in the Teepak air flow and subsequent $\mathrm{H}_{2} \mathrm{~S}$ removal by caustic scrub. The catalytic treatment of $\mathrm{CS}_{2}$ in concentrations as low as $100 \mathrm{ppm}$ has no precedent. The rate of removal likely would be controlled by diffusion and would suffer from the low driving force. A large, expensive reactor and an expensive process and catalyst development project certainly would be required. Because the main interest of this report is $\mathrm{CS}_{2}$ recovery and because $\mathrm{CS}_{2}$ would be destroyed in a catalytic hydrolysis process, no further hydrolysis investigations are planned. However, this approach may have advantages over incineration and can be viewed as an alternative to incineration that requires further study.

Catalytic incineration of $\mathrm{CS}_{2}$ to $\mathrm{CO}_{2}$ and $\mathrm{SO}_{2}$ is a technology that could be applied without a development project; however, because such a large volume of air must be treated at Teepak, the reactors and heat exchangers will be large and the cost will be high. Other significant drawbacks are that $\mathrm{CO}_{2}$ and $\mathrm{SO}_{2}$ are also pollutants and that $\mathrm{CS}_{2}$ is destroyed. One positive incentive is that the $\mathrm{SO}_{2}$ produced could be used to produce sulfuric acid, a viscose feed material. However, $\mathrm{CS}_{2}$ is worth 18.5 cents per pound and $\mathrm{H}_{2} \mathrm{SO}_{4}$ is worth 3.7 cents per pound. Because one pound of $\mathrm{CS}_{2}$ will produce 2.58 pounds of $\mathrm{H}_{2} \mathrm{SO}_{4}$, the acid produced will be worth about half the value of the incinerated $\mathrm{CS}_{2}$. Because a catalytic reactor to convert $\mathrm{SO}_{2}$ to $\mathrm{SO}_{3}$ and a sulfuric acid plant also would be required, there is little economic incentive for this approach as long as $\mathrm{CS}_{2}$ recovery remains possible.

\subsubsection{Absorption of $\mathrm{CS}_{2}$}

A common way to remove $\mathrm{H}_{2} \mathrm{~S}$ from gases is absorption in an aqueous alkaline solution. $\mathrm{CS}_{2}$ also can be removed simultaneously by this procedure, provided that $\mathrm{CS}_{2}$ absorption products can be removed rapidly and efficiently from solution by oxidation or another method. In one case, it was found that $100 \mathrm{ppm} \mathrm{CS}_{2}$ in ventilation air could be 
reduced to $30 \mathrm{ppm}$ by alkaline scrubbing $(9.7 \mathrm{pH})$ when the absorption product was oxidized to sulfur, sulfates, and sulfites with air. ${ }^{16}$ An earlier, similar result was reported when $\mathrm{NaOH} / \mathrm{Na}_{2} \mathrm{CO}_{3}$ solution was used and $\mathrm{CS}_{2}$ absorption products were oxidated by dissulved quinone. $^{17}$ In a German patent filed in $1976,{ }^{18}$ inorganic oxidants such as free chlorine, chemisorbents such as polyalkyline glycols, oxidation promoters such as hydroquinone, and oxidation catalysts such as vanadium salts were mentioned as means of removal of absorption products. The patent contained sufficient details of this process to allow an estimate of the number of standard ( 5 -ft diameter) absorption towers required to reduce $\mathrm{CS}_{2}$ from $100 \mathrm{ppm}$ to about $20 \mathrm{ppm}$ for the Teepak case of $400,000 \mathrm{cfm}$. About 105 absorption towers would be needed. Data allowing an estimate of the necessary regeneration equipment were not given. Because $\mathrm{CS}_{2}$ is destroyed in this process and because both the installation cost and the plant size would be extremely large, it was judged that the alkaline absorption process should not be studied further at this time.

Other aqueous salt solutions have been tested, such as $\mathrm{NaClO}$ and chelated iron, with results similar to those for alkaline solution.

Physical absorption of $\mathrm{CS}_{2}$ from air by various liquids has been reported frequently in the literature. Hydrocarbon oil, ${ }^{19}$ mineral oil, ${ }^{20}$ solar oil, ${ }^{21}$ and other liquids including liquid $\mathrm{CS}_{2}$ have been used. ${ }^{22}$ Physical absorption of $\mathrm{CS}_{2}$ from air was analyzed and evaluated in the current study. The results are discussed in Section 3 of this report. Because $\mathrm{CS}_{2}$ recovery and absorbent regeneration are so difficult, gas absorption was judged infeasible.

\subsubsection{Rayon Plants}

Various studies have analyzed the viscose process in terms of factors that affect the concentration of $\mathrm{CS}_{2}$ emissions, such as heat balance, suction sites, ${ }^{23}$ and spinning area configuration. ${ }^{24}$ One study showed that the cost-benefit of recovering $\mathrm{CS}_{2}$ is $10 \%$ of the total factory output value. ${ }^{25}$ Several foreign reviews of $\mathrm{H}_{2} \mathrm{~S}$ and $\mathrm{CS}_{2}$ removal and recovery methods have been published, ${ }^{26,27}$ and a study showing the effects of certain oxides on the activated-carbon fire hazard in adsorption recovery has appeared in Russian literature. ${ }^{28}$

\subsubsection{Vapor-Liquid Equilibrium of $\mathrm{CS}_{2}$}

The design of a separations column that uses any particular solvent to absorb $\mathrm{CS}_{2}$ from gas requires vapor-liquid equilibrium data for the $\mathrm{CS}_{2} /$ solvent system. Very little specific information for solvents of higher molecular weight has been found. Some data on cyclohexane and other hydrocarbons have been reported, ${ }^{29}$ but these solvents are probably too volatile for practical use. A Russian study has provided limited data on mineral oil..$^{30}$

More general work that allows rough estimates for a limited number of solvents is available. For example, solubility parameters, ${ }^{31}$ coupled with the Scatchard Hildebrand regular solution theory, ${ }^{32}$ can be used to estimate binary activity coefficients, provided the 
two components are nonpolar. Because $\mathrm{CS}_{2}$ is highly nonpolar, this method can produce rough estimates for nonpolar solvents such as benzene or paraffins. This upproach is taken in Section 3. That section also describes bench-scale absorption tests that were used to develop data for process analysis of $\mathrm{CS}_{2}$ recovery by liquid solvent absorption.

\subsubsection{Microbiological Conversion of $\mathrm{CS}_{2}$}

The thiobasillus bacteria can destroy $\mathrm{CS}_{2}$ - if an appropriate mode of combining the gas and bacteria and an efficient means of controlling $\mathrm{pH}$ and providing the proper addition of nutrients are found. ${ }^{33}$ One study reported a degradation rate of $70 \mathrm{~g} / \mathrm{m}^{3} \cdot \mathrm{hr}^{34}$. In the Teepak case, about $213,000 \mathrm{~g}$ of $\mathrm{CS}_{2}$ must be destroyed per hour; therefore, approximately 220 reaction towers ( $5 \mathrm{ft}$ by $25 \mathrm{ft}$ ) would be required for microbiological conversion. This amount is clearly beyond any reasonable economic justification, even if additional unfavorable aspects, such as the fact that $\mathrm{CS}_{2}$ would be destroyed and that little experience with such systems has accumulated, are overlooked.

\subsubsection{Amine-Based Solvents}

Carbon disulfide and carbon dioxide will form chemical complexes with amine:

$$
\mathrm{R}-\mathrm{NH}_{2}+\mathrm{CX}_{2}=\underset{\mathrm{H}}{\mathrm{R}}-\frac{\mathrm{N}}{\mathrm{X}}-\mathrm{C}-\mathrm{XH}
$$

where $\mathrm{X}$ is either sulfur or oxygen. This reaction can be reversed wi ih mild heating. Aminebased absorbents, as well as adsorbents, have been tested for removal and recovery of both $\mathrm{CO}_{2}$ and $\mathrm{CS}_{2}$. A variety of aqueous amine solutions, including ethylene diamine, ${ }^{35}$ have been used to remove $\mathrm{CS}_{2}$ from air and other gases. The solution has been regenerated by vacuum distillation at $170^{\circ} \mathrm{C} .^{35}$ It is not likely that much $\mathrm{CS}_{2}$ was recovared in this way because $\mathrm{CS}_{2}$ readily reacts in an aqueous alkaline medium. No data that would allow a quantitative estimate of removal or recovery rate of $\mathrm{CS}_{2}$ from amine solutions were found.

It is possible to produce amine-functionalized silica gel $^{36}$ by reacting organic silanes with surface hydroxyl groups. This type of made-up adsorbent was discussed in Section 2.3.1. No rate or equilibrium information for this type of adsorbent has been found.

This general approach is discussed in more detail in Section 4.

\subsubsection{Membrane Separation of $\mathrm{CS}_{2}$}

Tw, types of membranes commonly are used for gaseous separation: a ceramic or inorganic type and a rubbery or organic type. On the basis of extensive telephone communication, it was determined that no data or experience exists for $\mathrm{CS}_{2}$ permeation and separation through ceramic-type membranes. A very small amount of experience (but no data) was found for $\mathrm{CS}_{2}$ permeation through a polydimethylsiloxane membrane, ${ }^{37}$ which is 
more rubbery than ceramic. On the basis of rough calculations by one jxpert contacted, the large Teepak air flow and low $\mathrm{CS}_{2}$ concentration would require a capital investment of more than $\$ 25$ million for a membrane separator to separate the plant's $\mathrm{CS}_{2}$. Because no permeation data are available for $\mathrm{CS}_{2}$, laboratory data development and a pilot study also would be required. This process is expected to be more costly than gas sorption development, and no further study of membrane separation was made. 


\section{GAS ABSORPTION}

\subsection{INTRODUCTION}

In the packed-tower or fixed-bed type of gas absorption, a nonvolatile absorption liquid with minimum dissolved absorbate is sprayed into the top of the tower and flows downward through the packing, as shown in Figure 3.1. Gas containing an absorbate or substance to be removed (such as $\mathrm{CS}_{2}$ ) enters the bottom of the tower and flows upward through openings around the liquid-drenched packing. In a properly operating tower, the liquid is progressively enriched in $\mathrm{CS}_{2}$ as it flows downward, and at the bottom of the tower the $\mathrm{CS}_{2}$ concentration in the exiting liquid is maximum. This enriched liquid then must be desorbed in a stripping or distillation column and sent back to the top of the tower. Thus, the $\mathrm{CS}_{2}$ is recovered in this process.

\subsection{ABSORPTION LIQUID}

\subsubsection{Ideal Solutions}

To estimate the required number and dimensions (and thereby the cost) of absorption towers, one must first know how $\mathrm{CS}_{2}$ will distribute itself at equilibrium between the gas and liquid phases. If, for example, $\mathrm{CS}_{2}$ has the same affinity for the absorbing liquid as it has for liquid $\mathrm{CS}_{2}$, the liquid/CS $\mathrm{CS}_{2}$ solution is said to be "ideal". and Raoult's law applies. A simplified approximate form of Raoult's law, which applies at atmospheric pressure and $25^{\circ} \mathrm{C}$, can be written as follows:

$$
y=x\left(\rho^{\circ} / P\right)=x(366 / 760)=0.48 x
$$

where $\mathrm{p}^{\circ}$ is the vapor pressure of $\mathrm{CS}_{2}$ at $25^{\circ} \mathrm{C}$, and $\mathrm{y}$ and $\mathrm{x}$ are mole fractions of $\mathrm{CS}_{2}$ in the gas and liquid, respectively.

In the present case, $\mathrm{CS}_{2}$ is in very low concentrations in the gas, and it is more useful to use Henry's law: ${ }^{38} p=k x$, but if $K$ is defined as the ratio of Henry's law constant, $k$, to total pressure (i.e., $\mathrm{K}=\mathrm{k} / \mathrm{P}$ ) it is a constant independent of $\mathrm{x}$ or $\mathrm{y}$, at least in the range of very low $x$ and $y$. Here, $p$ is the partial pressure of $\mathrm{CS}_{2}$. To be brief, we refer to $\mathrm{K}$ als "Henry's law constant" in the following discussion, and we may write:

$$
\mathrm{y}=\mathrm{Kx}
$$

In the special case of an ideal solution, which is ideal over the total range $\mathrm{x}=0$ to $\mathrm{x}=1.0$, Raoult's law and Henry's law are ideritical, so the value of $K$ for such an ideal solution is known; it is 0.48 . For such a hypottetical solution, for example, if $\mathrm{K}$ is larger than 0.48 , the 


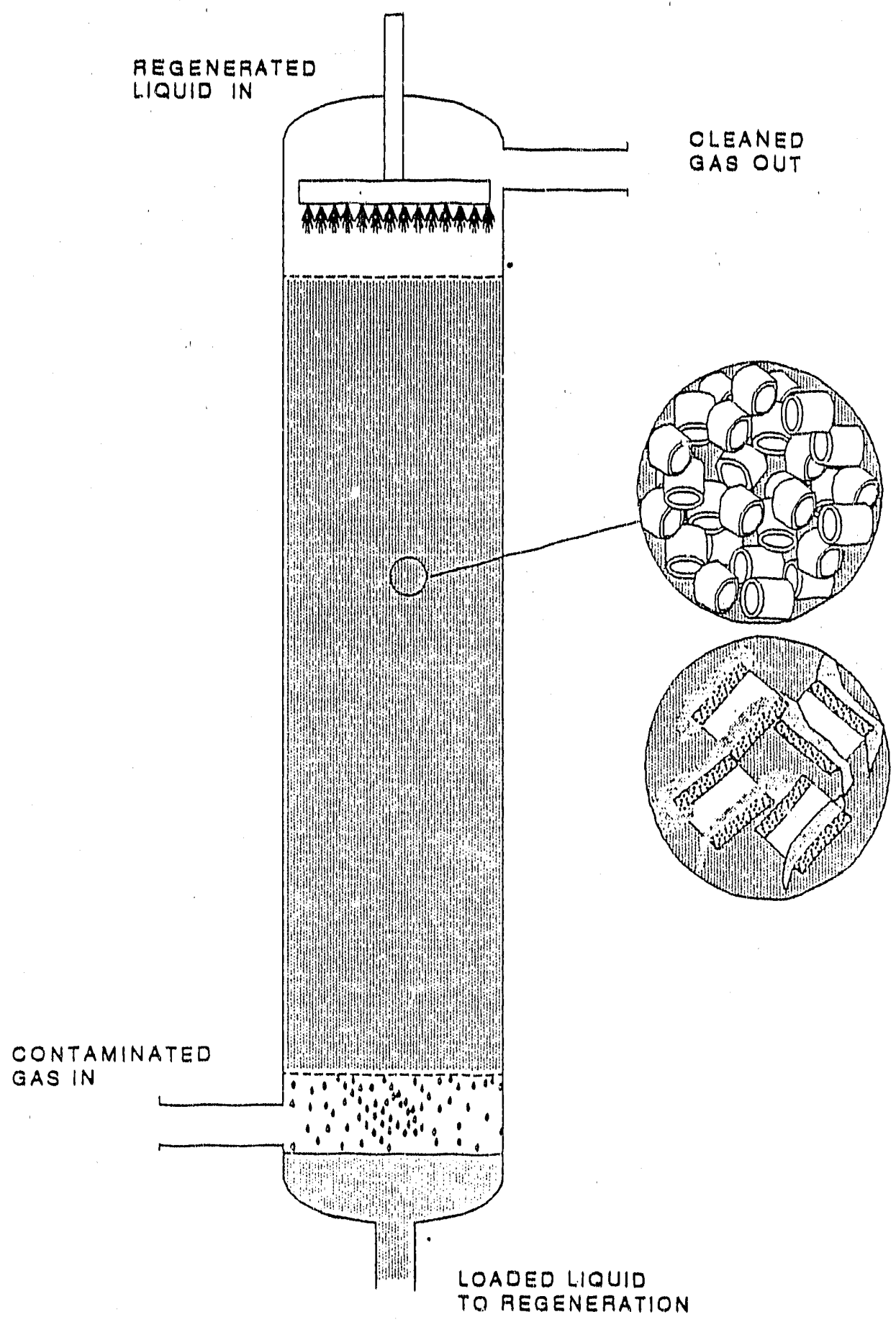

FIGURE 3.1 Schematic of Gas Absorption Tower 
gas phase concentration is higher at equilibrium and $\mathrm{CS}_{2}$ has proportionally less affinity for the absorbing liquid than for liquid $\mathrm{CS}_{2}$. If $\mathrm{K}$ is smaller than $0.48, \mathrm{CS}_{2}$ has proportionally more affinity for the absorbing liquid than for liquid $\mathrm{CS}_{2}$. If $\mathrm{K}$ is very low, the absorbing liquid may form a chemical bond with $\mathrm{CS}_{2}$, so the process may not be strictly physical absorption.

Values of $\mathrm{K}$ for nonideal physical absorbents (such as oils or other organic or inorganic liquids) are about the same order of magnitude as 0.48 , roughly between 0.1 and 1.5. In general, few liquids can produce a $\mathrm{K}$ for $\mathrm{CS}_{2}$ lower than 0.48 , and such liquids often are unsuitable as absorbents for other reasons, as will be seen in Section 3.7.

\subsubsection{Solubility Parameter as a Criterion for Absorbent Selection}

$\mathrm{CS}_{2}$ has no permanent polarity and no tendency for hydrogen bonding but very high polarizability. As can be seen in charts of solubility parameters, ${ }^{39,40}$ some organic compounds come more or less close to having these same properties, and this similarity would make them good candidates for a $\mathrm{CS}_{2}$ absorption liquid. Benzene is one of these. Unfortunately, benzene is a relatively volatile liquid and has an appreciable vapor pressure at ambient temperature. Therefore, it could not be used economically as a $\mathrm{CS}_{2}$ absorbent, because the air exiting the absorption column would be highly contaminated with benzene, a known carcinogen.

From study of the $\mathrm{CS}_{2}$ absorption literature, it appears likely that the best absorbent candidates are aliphatic hydrocarbon oils with high molecular weight. In general, vaporliquid equilibrium data for $\mathrm{CS}_{3}$ solutions are not available in the literature except for a few solvents of no value to $\mathrm{CS}_{2}$ gas absorption. Some oils were tested in the current project and will be discussed later. However, to present a general orientation to the problem we first discuss how $\mathrm{K}$ can be estimated for such liquids from regular solution theory and solubility parameter data.

For example, Table 3.1 was compiled by referring to a table of solubility parameters. $^{31}$ As mentioned above, solubility parameters have three components: hydrogen bonding, permanent polarity, and polarizability. Because $\mathrm{CS}_{2}$ has no hydrogen bonding or permanent polarity components but is highly polarizable, the solvents chosen for Table 3.1 have extremely low hydrogen bonding and zero permanent polarity component. If the three vector components of solubility parameters are considered to be hydrogen bonding, polarity, and polarizability, $\delta$ represents the scalar value of a solubility parameter in the table.

By using Regular Solution Theory, ${ }^{40,41}$ it is easy to show that the activity coefficient $(\gamma)$ for a binary liquid solution can be written as:

$$
\mathrm{RT} \ln \gamma=v_{1} \Phi_{2}^{2}\left(\delta_{1}-\delta_{2}\right)^{2} \equiv \mathrm{N}
$$


TABLE 3.1 Solubility Parameters and Henry's Law Constants for Various Solvents

\begin{tabular}{lccc}
\hline \multicolumn{1}{c}{ Solvent } & $\begin{array}{c}\text { Solubility } \\
\text { Parameter, } \delta \\
\left(\mathrm{cal}^{3} \mathrm{~cm}^{3}\right)^{0.5}\end{array}$ & $\begin{array}{c}\text { Molar Volume, } v \\
\left(\mathrm{~cm}^{3} / \mathrm{mole}\right)\end{array}$ & $\begin{array}{c}\text { Henry's Law } \\
\text { Constant, } \\
\mathrm{K}\end{array}$ \\
\hline Butane & 6.89 & 100.3 & 1.27 \\
Decane & 7.67 & 194.5 & 0.83 \\
Decalin & 9.18 & 154.4 & 0.51 \\
Heptane & 7.48 & 146.5 & 0.91 \\
Hexadecane & 7.97 & 183.8 & 0.73 \\
Isopentane & 6.85 & 116.3 & 1.31 \\
Nonane & 7.67 & 178.6 & 0.83 \\
Octane & 7.57 & 162.5 & 0.87 \\
Pentane & 7.09 & 115.1 & 1.13 \\
Triethylpentane & 6.89 & 165.0 & 1.28 \\
Carbon disulfide & 10.00 & 61.0 & 0.48 \\
\hline
\end{tabular}

where $\delta_{1}$ and $\delta_{2}$ are the scalar solubility parameters of the two compounds, $v_{1}$ is the molar volume of component 1 , and $\Phi_{2}$ is a ratio dependent on molar volumes and mole fractions:

$$
\Phi_{2}=v_{2} x_{2} /\left(v_{2} x_{2}+v_{1} x_{1}\right)
$$

By using Equation 5, a rough estimate of Henry's Law constant can be obtained:

$$
\mathrm{K}=0.48 \exp (\mathrm{N} / \mathrm{RT})
$$

Equation 7 was used to estimate Henry's law constants for solutions of $\mathrm{CS}_{2}$ in the solvents of Table 3.1; the results are in the last column. In this case, $\mathrm{N}$ was calculated at $\mathrm{x}_{1}=0.01$ because Henry's law is applicable at low solute concentrations.

Several of the solvents in Table 3.1 would be possibilities for absorbing $\mathrm{CS}_{2}$, but unfortunately they are too volatile for actual use in an absorption column. This statement is demonstrated more clearly in Table 3.2 , in which the Clausius-Clapyron equation ${ }^{38}$ has been used to estimate the vapor pressure of the best five solvents from Table 3.1.

As shown in the eighth column of Table 3.2, in most cases the solvent in air leaving a hypothetical gas absorption column would be higher in estimated concentration than the entering $\mathrm{CS}_{2}$. Even the least volatile solvent, Hexadecane (50 ppm leaving), is unacceptable, both environmentally and economically. The next step would be to seek solvenis with the same chemical structure but higher molecular weight and lower ambient vapor pressure. Even then, few possibilities exist. F(i example, the chemical structure of benzene, one of the 
TABLE 3.2 Estimated Gas Absorption Losses for Various Absorbents ${ }^{a}$

\begin{tabular}{lcccccccc}
\hline Absorbent & $\mathrm{K}$ & $\mathrm{MW}$ & $\begin{array}{c}\mathrm{BP} \\
\left({ }^{\circ} \mathrm{C} /{ }^{\circ} \mathrm{F}\right)\end{array}$ & $\begin{array}{c}\mathrm{p} \\
\left(\mathrm{g} / \mathrm{cm}^{3}\right)\end{array}$ & $\begin{array}{c}\Delta \mathrm{H} \text { vap } \\
(\mathrm{Btw} / \mathrm{lb})\end{array}$ & $\begin{array}{c}\mathrm{p} \text { vap } \\
(\mathrm{atm})\end{array}$ & $\begin{array}{c}\text { Eutlet } \\
(\mathrm{ppm})\end{array}$ & $\begin{array}{c}\text { Losses } \\
(\mathrm{mole} / \mathrm{min})\end{array}$ \\
\hline Decalin & 0.51 & 138 & $193 / 379$ & 0.896 & 129 & $2.46 \times 10^{-3}$ & 2,460 & 2.51 \\
Hexadecane & 0.73 & 226 & $287 / 548$ & 0.775 & 100 & $5.02 \times 10^{-5}$ & 50 & 0.051 \\
Decane & 0.83 & 142 & $174 / 345$ & 0.730 & 119 & $5.12 \times 10^{-3}$ & 5,115 & 5.22 \\
Nonane & 0.83 & 128 & $151 / 303$ & 0.718 & 123 & $1.26 \times 10^{-2}$ & 12,603 & 12.86 \\
Octane & 0.87 & 114 & $126 / 258$ & 0.704 & 130 & $3.01 \times 10^{-2}$ & 30,097 & 30.71 \\
\hline
\end{tabular}

a $\mathrm{K}=$ Henry's law constant, $\mathrm{MW}=$ molecular weight, $\rho=$ liquid density, $\Delta H$ vap $=$ heat of vaporization, $p$ vap $=$ pressure of solvent vapor, Outlet $=$ concentration at absorber outlet.

better solvents for $\mathrm{CS}_{2}$, is a single aromatic ring, but, as discussed above, benzene has low molecular weight and appreciable vapor pressure at room temperature. The higher molecular weight analogs of benzene are naphthalene and anthracene. Unfortunately, the melting point of naphthalene is $80^{\circ} \mathrm{C}$ and that of anthracene $213^{\circ} \mathrm{C}$, totally precluding both as possibilities. In general, it will be difficult to find analogs of higher molecular weight that are liquid and not highly viscous at room temperature. Some forms of mineral oil have reasonably low volatility and viscosity at ambient temperature. One such oil was tested and produced a Henry's law constant of 0.24. This is discussed further in Section 3.7.

Rather than look for further data on aliphatic liquids, we used a generalized and variable Henry's law constant to assess the potential of gas absorption for $\mathrm{CS}_{2}$ recovery. If absorption seems viable in general, further searching for favorable liquids could proceed as outlined above.

\subsection{ABSORPTION TOWER ANALYSIS}

With these simple ideas concerning ideal solution and Henry's Law in mind, it is possible to evaluate $\mathrm{CS}_{2}$ absorption in general terms without the need to define the vaporliquid equilibrium of $\mathrm{CS}_{2}$ and various absorbents explicitly. We first set up an absorption tower analysis procedure from which we developed a family of absorption tower computer programs. Their use with variable inputs allowed general conclusions about $\mathrm{CS}_{2}$ removal and recovery to be reached.

The computer programs are based on common fundamental absorption tower calculations. ${ }^{42}$ First, an overall $\mathrm{CS}_{2}$ balance on the absorption column is performed to define an "operating line." The mass transfer coefficients for $\mathrm{CS}_{2}$ transport from gas to gas/liquid interface and from gas/liquid interface to liquid are estimated. The operating line, the mass transfer coefficients, and Equation 4 with an assumed $\mathrm{K}$ are used to estimate the required absorption tower height for a given condition of $\mathrm{CS}_{2}$ absorption. The details of these 
calculations, along with the main Fortran computer program that was developed, are presented in detail in Appendix A.

\subsubsection{Tower Diameter}

The programs were used first to determine the effect of tower diameter on the required number of towers. The towers were assumed to be packed with 1-in. Raschig rings. A hypothetical absorbing liquid with Henry's law constant $\mathrm{K}=0.5$ was assumed. The towers also were assumed to receive air contaminated with $100 \mathrm{ppm} \mathrm{CS}_{2}$ and to emit cleaned air at $10 \mathrm{ppm}$. The effect of moisture in the air was not addressed explicitly but was liimped with other effects that may slightly increase the Henry's law constant. The hypothetical absorption liquid was assumed to have zero vapor pressure and the molecular weight (102) and viscosity of propylene carbonate (a common absorption liquid). To show the effects of pressure, individual plots for various total operating pressures (minus the required pressure drop) are included in the graphical presentation to follow. The calculations are based on. optimizing the liquid rate required for the 400,000-cfm flow of the $\mathrm{CS}_{2}$-contaminated air and iterating to match bed depth to available pressure drop. A "flooding curve," taken from Perry and Chilton's Chemical Engineers' Handbook, ${ }^{43}$ was incorporated numerically into the code and is shown in Figure 3.2.

Thus, the total cross-sectional area is lixed by the liquid and gas rates and other settings mentioned above, the necessity to obtain optimum gas/liquid contact, and the $1 \mathrm{in}$. of $\mathrm{H}_{2} \mathrm{O}$ per foot of gas side assumed pressure drop in the tower. The parameters used in the calculations to follow are, in general, shown in Table 3.3. As shown in Figures 3.3a and 3.3c, absorption bed depth and gas superficial velocity are constant as tower diameter is varied. However, variation in tower diameter changes the number of towers required because the total cross-sectional area is fixed for a given pressure. Tower diameter is plotted against the required number of towers in Figure 3.3b. If only one tower is to be used and inlet pressure is 1 psig (plus the required pressure drop), the tower must be much larger than $30 \mathrm{ft}$ in diameter. However, if 30 towers are used they need be only approximately $7 \mathrm{ft}$ in diameter. Because towers $12 \mathrm{ft}$ in diameter, the largest that can be obtained from vendor stock, are less expensive than field-prefabricated towers, and are common for large gas flows, this diameter was chosen as the standard for further analyses. Figure 3.3b shows that approximately 12 towers $12 \mathrm{ft}$ in diameter would be required to handle the Teepak air at $1 \mathrm{psig}$. If the air were compressed to $100 \mathrm{psig}$, only five towers would be required.

\subsubsection{Superficial Velocity}

As shown in Figure 3.3c, the superficial gas velocity for the absorption tower is $274 \mathrm{ft} / \mathrm{min}$ for 1 psig. This figure is calculated by:

$$
V=\left(Q /\left(N_{T} A_{T}\right)\right)(P /(P+14.7))
$$




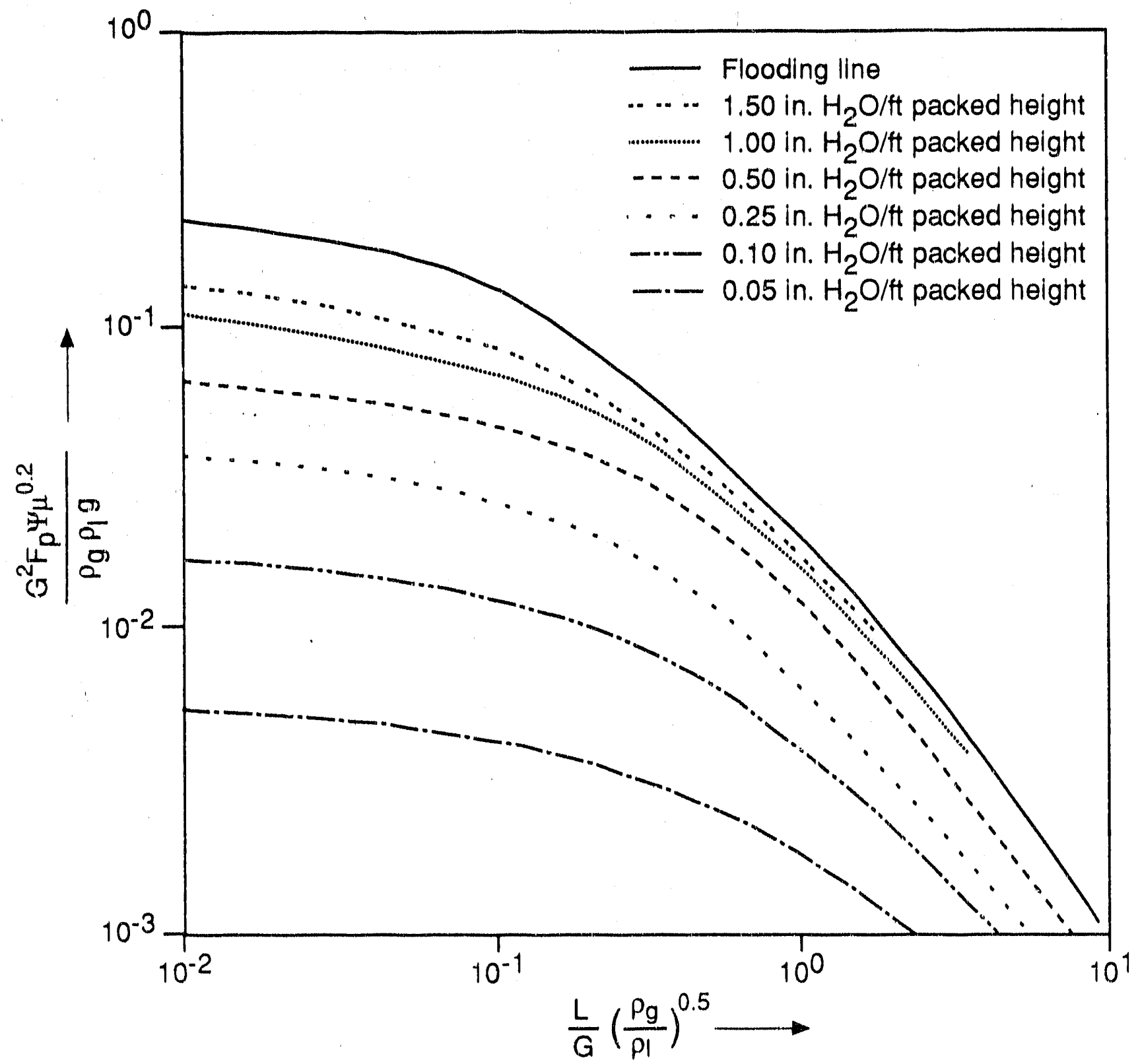

FIGURE 3.2 Generalized Flooding and Pressure Drop Correlations for Absorption Tower Packings (adapted from Ref. 43) 


\section{TABLE 3.3 Values Used in Gas Absorption Calculations}

\begin{tabular}{lc}
\multicolumn{1}{c}{ Parameter } & Value \\
\hline Liquid density $\left(\mathrm{lb} / \mathrm{ft}^{3}\right)$ & 74.5 \\
Liquid molecular weight & 102 \\
Liquid viscosity (cp) & 0.3 \\
$\mathrm{CS}_{2} /$ liquid diffusion & $5.0 \times 10^{-5}$ \\
coefficient (ft $\left.{ }^{2} / \mathrm{hr}\right)$ & \\
Tower diameter (ft) & 12 \\
$\begin{array}{l}\text { Outlet } \mathrm{CS}_{2} \text { concentration } \\
\text { (mole } \mathrm{CS}_{2} \div \text { mole air) }\end{array}$ & $10^{-5}$ \\
$\begin{array}{l}\text { Inlet } \mathrm{CS}_{2} \text { concentration } \\
\text { (mole } \mathrm{CS}_{2}+\text { mole air) }\end{array}$ & $10^{-4}$ \\
Inlet liquid loading & \\
Optimum liquid rate multiplier & 1.5 \\
Air viscosity (cp) & 0.018 \\
$\mathrm{CS}_{2} /$ air diffusion coefficient $\left(\mathrm{ft}^{2} / \mathrm{hr}\right)$ & 0.62 \\
Inlet pressure (psig) & 1.0361 \\
Outlet pressure (psig) & \\
\hline
\end{tabular}

a See Appendix A, Section A.2.

In this formula, $Q$ is volumetric rate, $\mathrm{N}_{\mathrm{T}}$ is number of towers, $\mathrm{P}$ is 1 psig plus pressure drop requirements, and $A_{T}$ is cross-sectional area. To determine if this velocity is of a proper order of magnitude that is compliant with comrnon absorption tower operating norms, an empirical factor called a "v-load" term ${ }^{44}$ is calculated:

$$
V_{\text {load }}=V\left(\rho_{\mathrm{V}} /\left(\rho_{\mathrm{L}}-\rho_{\mathrm{V}}\right)\right)^{1 / 2}
$$

where $\mathrm{V}$ is superficial velocity in $\mathrm{ft} / \mathrm{s}$ and the $\rho \mathrm{s}$ are vapor and liquid densities. For the 1-psig case, we obtain $V_{\text {luad }}=0.154 . V_{\text {load }}$ should vary between 0.05 and 0.3 ; therefore, 0.154 is acceptable, and the calculated gas velocity is appropriate for the 1-psig case. 


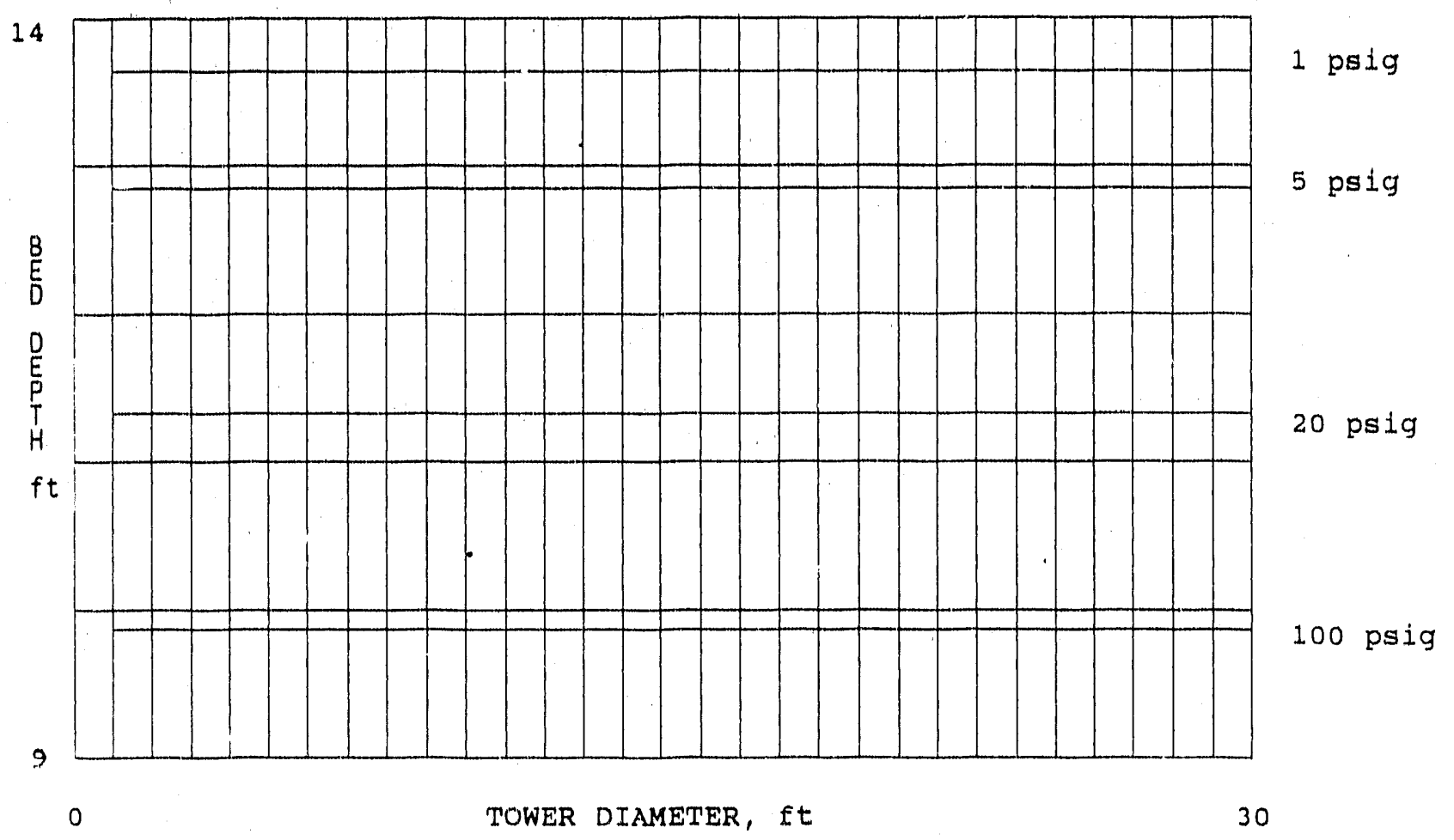

FIGURE 3.3a Absorption Bed Depth vs. Tower Diameter

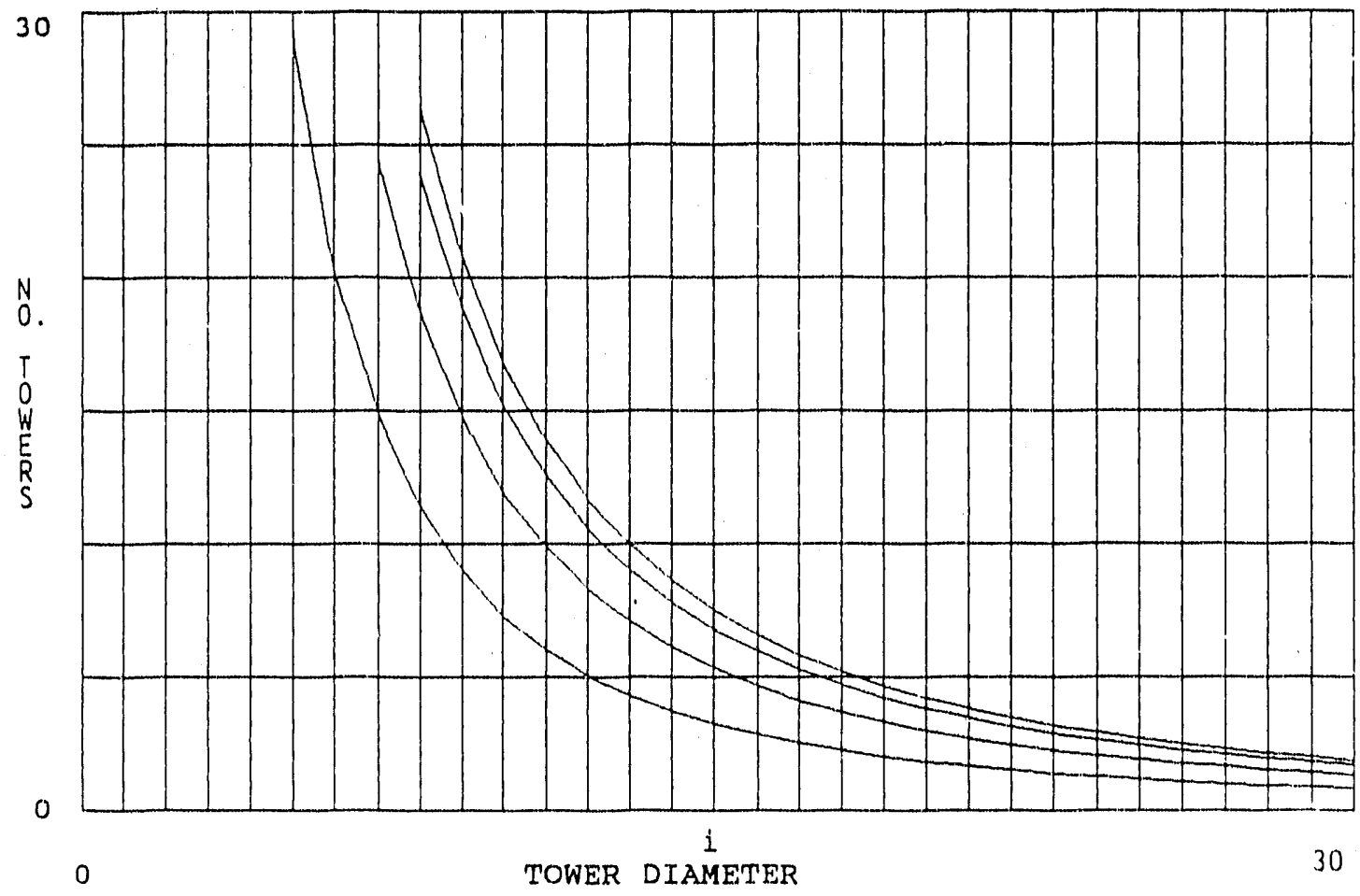

FIGURE 3.3b Number of Absorption Towers vs. Diameter for 1, 5, 20, and 100 psig 


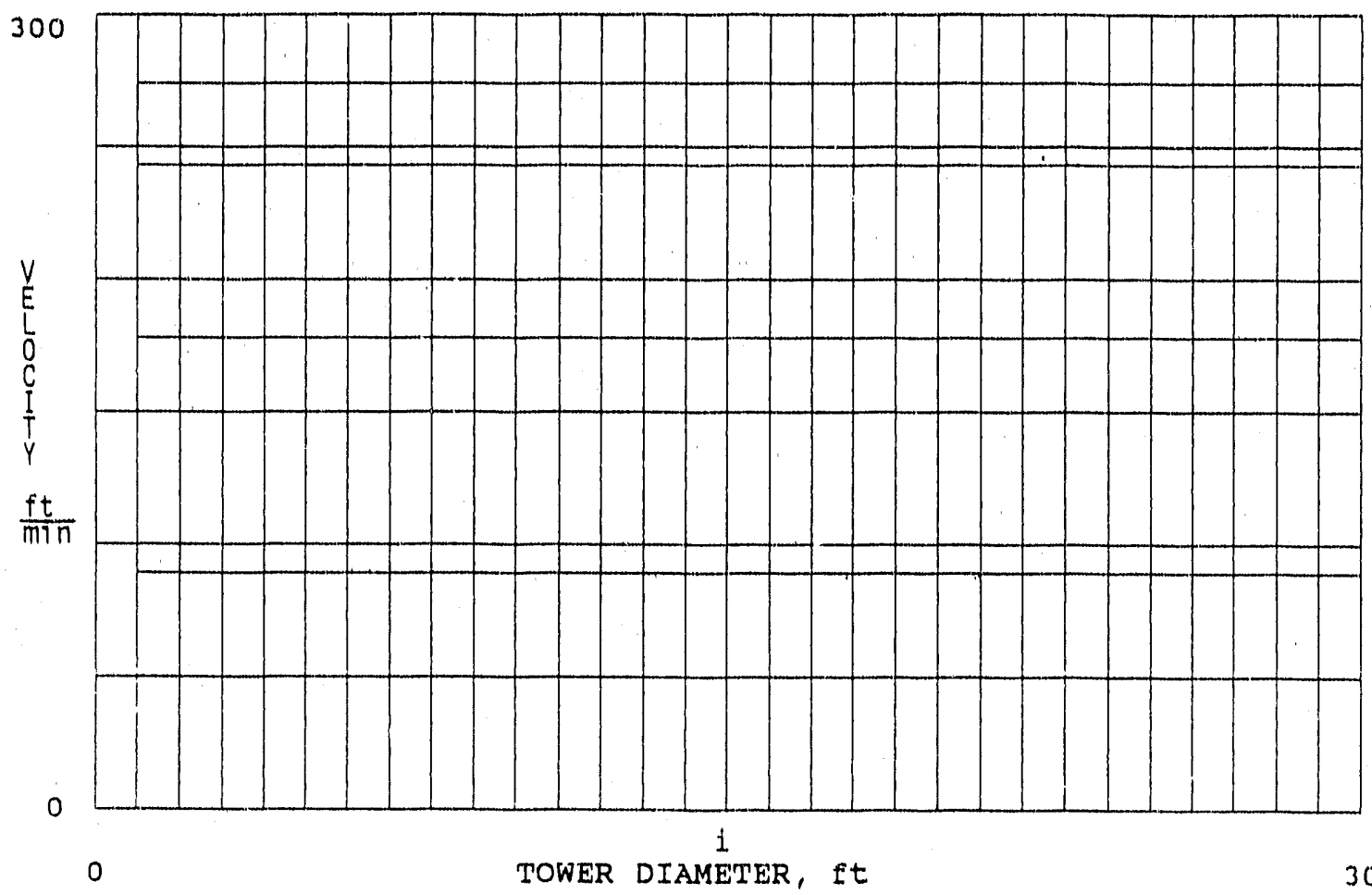

$1 \mathrm{psig}$

5 psig

$20 \mathrm{psig}$

$100 \mathrm{psi}$

FIGURE 3.3c Superficial Velocity vs. Diameter

\subsubsection{Operation at Elevated Pressure}

For higher pressures, $V_{\text {luad }}$ would drop to about 0.015 below the suggested low, if it is assumed that velocity drops according to the reduced volumetric flow and that pressure drop is constant. Thus, it may be concluded that at higher pressures, higher velocities should be used (providing additional pressure drop), further reducing the required number of towers.

However, compression of 400,000 cfm of air is very costly. Figure 3.4, prepared from data supplied by Ingersoll Rand, ${ }^{45}$ shows a plot of approximate capital costs for compressors versus pressure. Also plotted is brake horsepower, a number proportional to power consumption and thus to compressor operating costs. A trade-off between the compression costs and the savings in tower costs through compression could be possible (see Figures $3.3 \mathrm{~b}$ and 3.4), provided a reasonable estimate of tower costs is available. Tower height is analyzed further after the following brief discussion of the advantages to Teepak of concentrating $\mathrm{CS}_{2}$ emissions into less air.

\subsubsection{Reduction in Air Rate by Concentrating $\mathrm{CS}_{2}$}

If $\mathrm{CS}_{2}$ could be concentrated, the number of towers required would be reduced. The absorption computer programs again were used to demonstrate this effect. Figures 3.5 a and $3.5 \mathrm{~b}$ show the variation in required bed depth and number of 12 -ft-diameter towers as the 


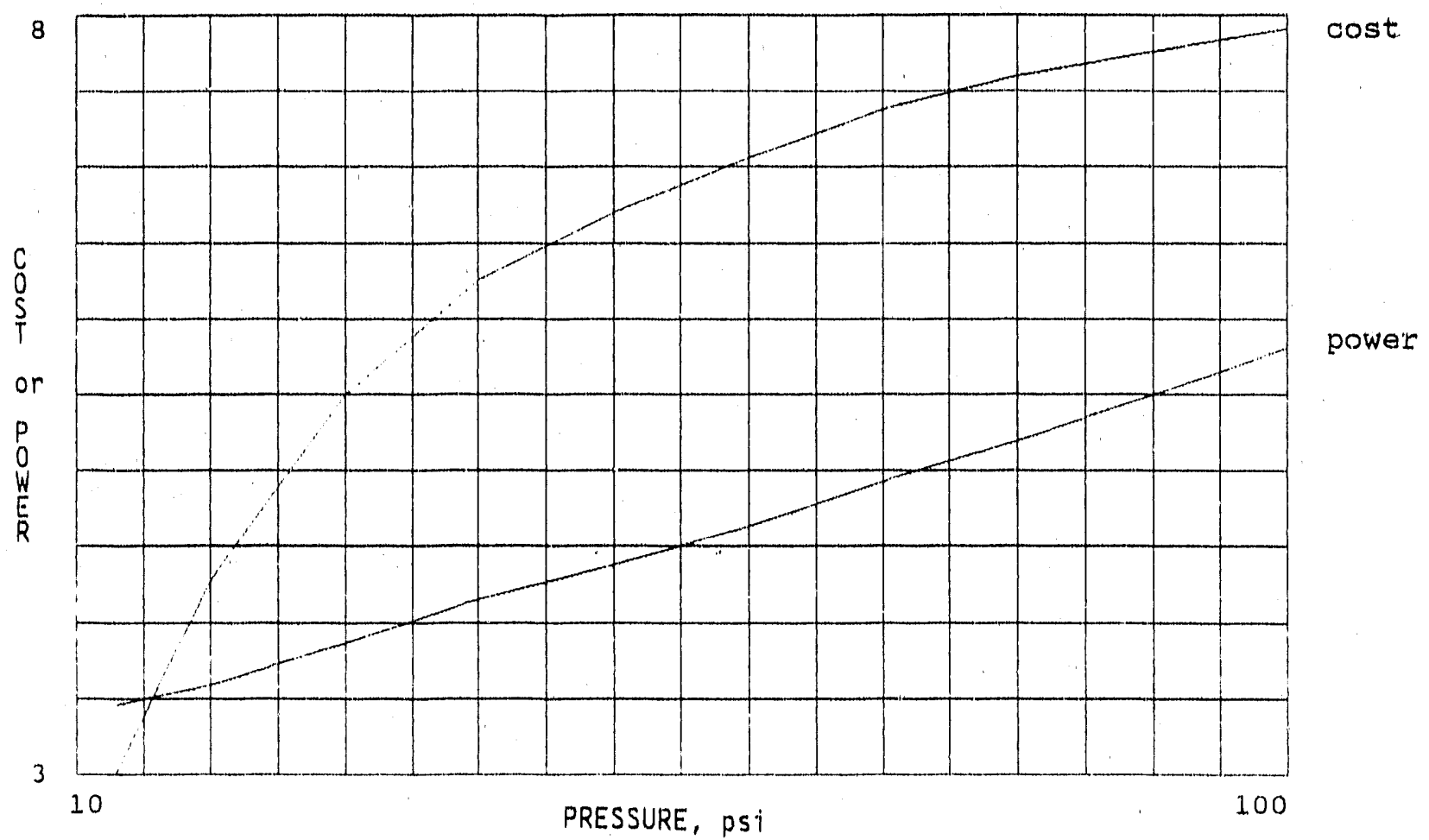

FIGURE 3.4 Cost of Compressors (millions of dollars) and Power Consumption $(1,000$ hp) vs. Pressure (psig)

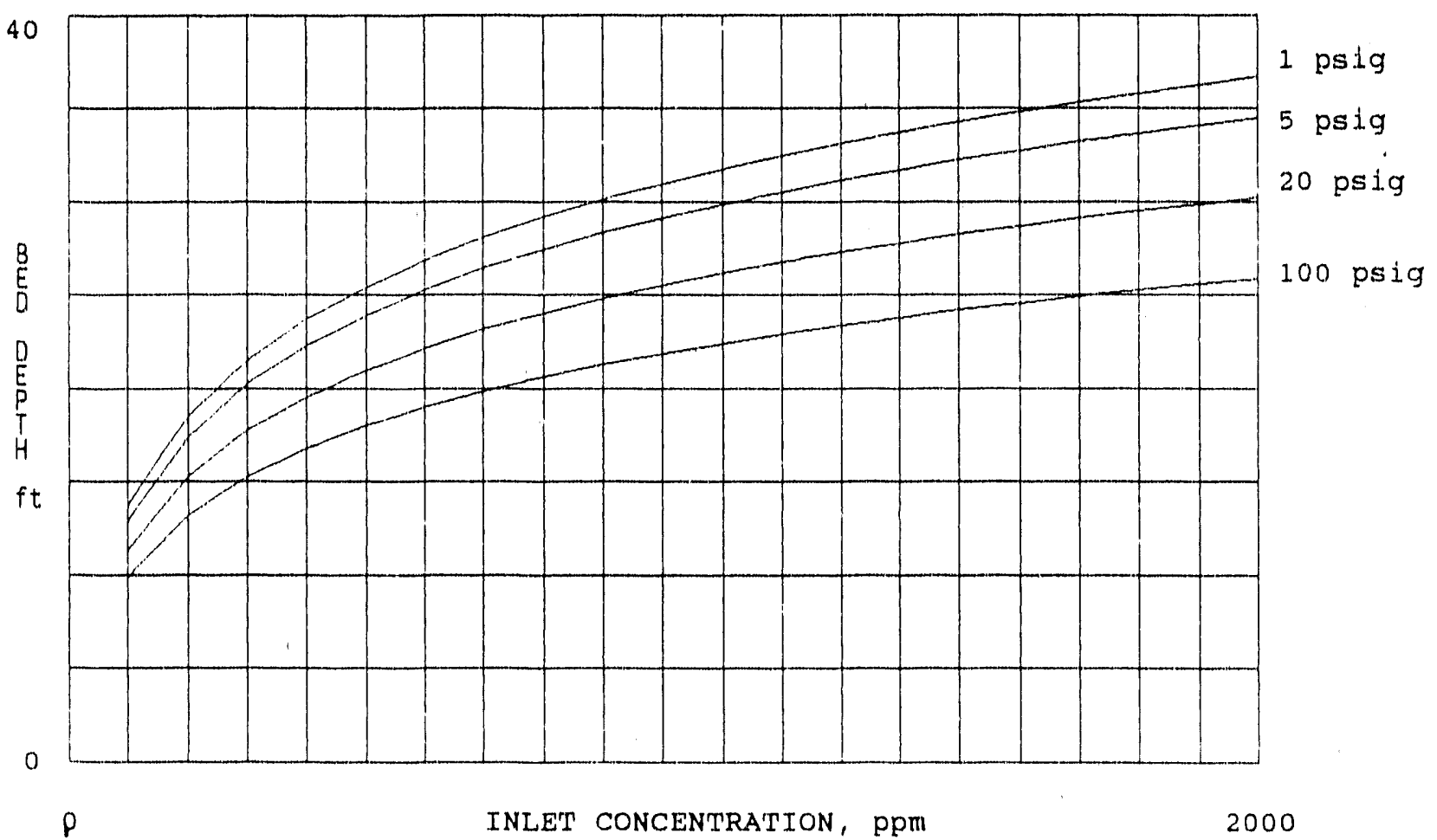

FIGURE 3.5a Absorption Bed Depth vs. Inlet Concentration 


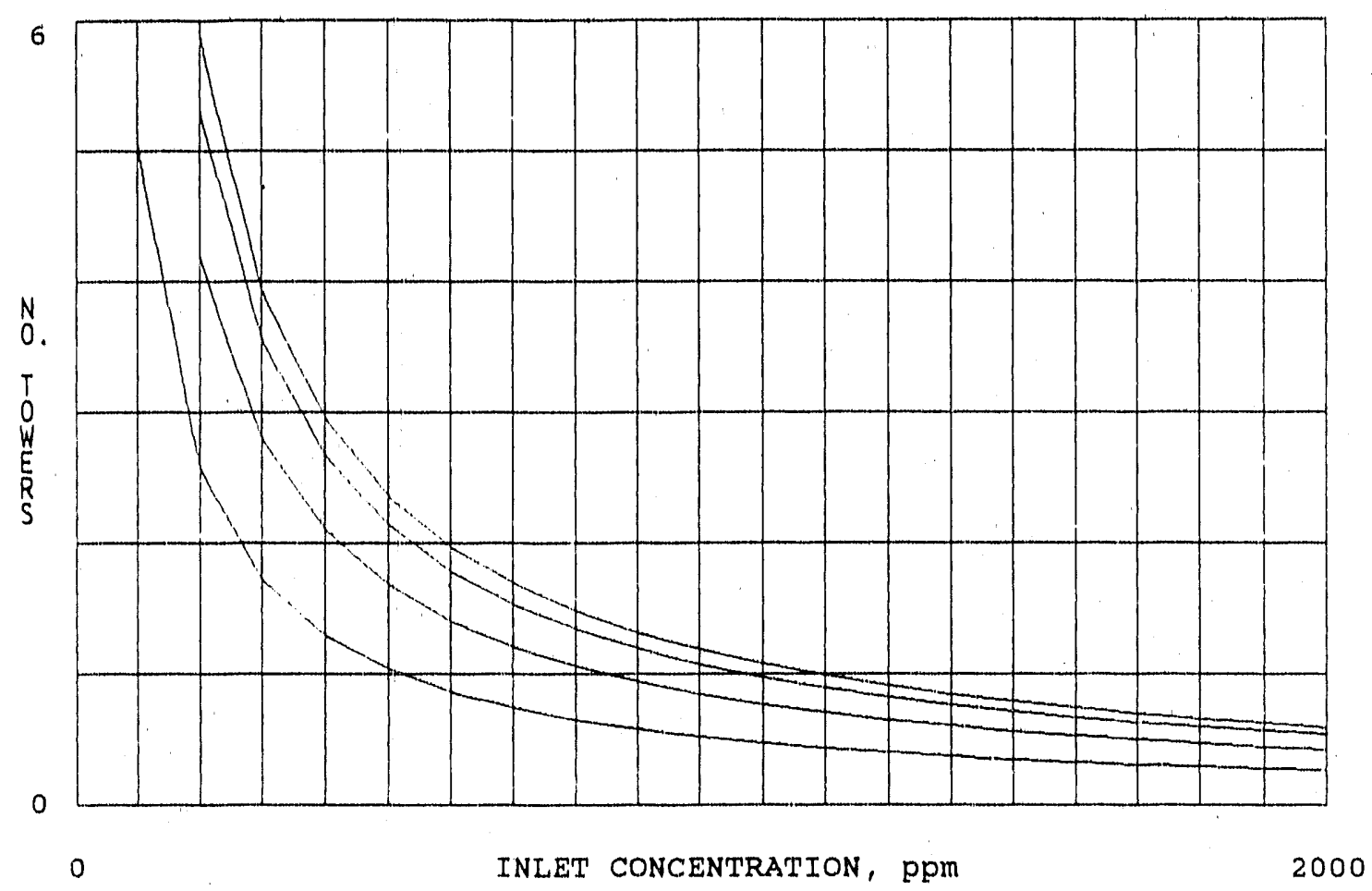

FIGURE 3.5b Number of Absorption Towers vs. Inlet Concentration for 1, 5, 20, and 100 psig

$\mathrm{CS}_{2}$ is concentrated into less air. Pressures of $1,5,20$, and 100 psig are shown. If, for the 1-psig case, the Teepak $\mathrm{CS}_{2}$ flow $(8.4 \mathrm{lb} / \mathrm{min})$ were dispersed into less air to increase the concentration to $200 \mathrm{ppm}$, approximately six towers would be required. However, if the $\mathrm{CS}_{2}$ were concentrated into the same amount of air and the air was compressed to $100 \mathrm{psig}$, only 2.6 towers would be required. Because the curve of Figure 3.5b is steepest at lower concentrations, most of the advantage of concentration occurs below $800 \mathrm{ppm}$. For example, for the 1-psig case, concentrations from $100 \mathrm{ppm}$ to $800 \mathrm{ppm}$ reduce the number of tower's from 6 to 1.5 , but concentrations from $800 \mathrm{ppm}$ to $2,000 \mathrm{ppm}$ only reduce the number of towers from 1.5 to 0.6 , an additional one-tower reduction.

\subsubsection{Tower Height Dependence}

The number of towers required, while important, is not the only dilemma in gas absorption of $\mathrm{CS}_{2}$. The ability of the liquid to absorb $\mathrm{CS}_{2}$ and the rate of mass transfer of $\mathrm{CS}_{2}$ from gas to liquid will determine the bed depth (tower height), a very important economic factor. Bed depth depends on many factors, but three are especially important:

- The Henry's law constant (K) will define the ability of the liquid to absorb and hold $\mathrm{CS}_{2}$. 
- The inlet concentration of $\mathrm{CS}_{2}$ in the air will affect the ability of the liquid to absorb $\mathrm{CS}_{2}$, and it also will affect the rate of mass transfer of $\mathrm{CS}_{2}$ from the gas into the liquid.

- The outlet concentration of $\mathrm{CS}_{2}$ defines the required efficiency of separation; therefore, bed depth depends directly on this factor.

The effect of inlet concentration was discussed in the previous section. Next, the effects of Henry's law constant and outlet concentration will be explored.

\subsubsection{Effect of Henry's Law Constant}

Figure 3.6a shows the variation of bed depth as $\mathrm{K}$ ranges from 0.1 to 1.0. Table 3.3 contains the other important inputs for this calculation. Figure 3.6b shows how the number of towers varies with Henry's law constant. This constant affects the number of towers because highly absorbing liquids (with low $\mathrm{K}$ ) require less liquid flow to remove the same amount of $\mathrm{CS}_{2}$. Additional gas can then be sent through each tower, thus reducing the required number of towers. This effect is also seen in Figure 3.6c; superficial gas velocity is higher at low $\mathrm{K}$. The slopes of the curves for all pressures are small, so $\mathrm{K}$ does not have a large effect.

In regard to the discussion of absorbing liquids presented previously, one possibility would be a Henry's law constant a few percent higher than the ideal solution case, say $\mathrm{K}=0.5$, which (as shown in Table 3.1) may be achieved by decalin. Figures $3.6 \mathrm{a}$ and $3.6 \mathrm{~b}$ predict, for the 1-psig case, that 12 towers $13.7 \mathrm{ft}$ high and $12 \mathrm{ft}$ in diameter would be required. Pressure at $100 \mathrm{psig}$, for the $\mathrm{K}=0.5$ case, would reduce the requirements to five towers $9.9 \mathrm{ft}$ high and $12 \mathrm{ft}$ in diameter. Reducing $\mathrm{K}$ to lower values does not help much, because the slopes of the curves are shallow. For example, if a liquid with $\mathrm{K}=0.1$ was found, 10 towers $12 \mathrm{ft}$ high would be required to clean the gas to $10 \mathrm{ppm}$ for the 1-psig case and four towers $7 \mathrm{ft}$ high for the 100-psig case.

\subsubsection{Effect of Outlet Concentration}

Figures $3.7 \mathrm{a}$ and $3.7 \mathrm{~b}$ depict the effect of changing the outlet concentration requirements. In these figures, tower height and number of towers are plotted against outlet concentration for four different pressures and the standard case (towers $12 \mathrm{ft}$ in diameter, $400,000 \mathrm{cfm}, \mathrm{K}=0.5$, and $100 \mathrm{ppm}$ inlet). As shown in Figure 3.7a and as expected, the outlet concentration has a large effect on bed depth. However, Figure 3.7b shows that the outlet concentration has only a relatively small effect on number of towers. If we take the most favorable hypothetical case, in which it is assumed Teepak is only required to clean the gas to $40 \mathrm{ppm}$ (a very unlikely situation given the current clean-air laws), and if an absorbing liquid of $\mathrm{K}=0.5$ were available, then Figures $3.7 \mathrm{a}$ and $3.7 \mathrm{~b}$ predict that about 11 towers $5 \mathrm{ft}$ 


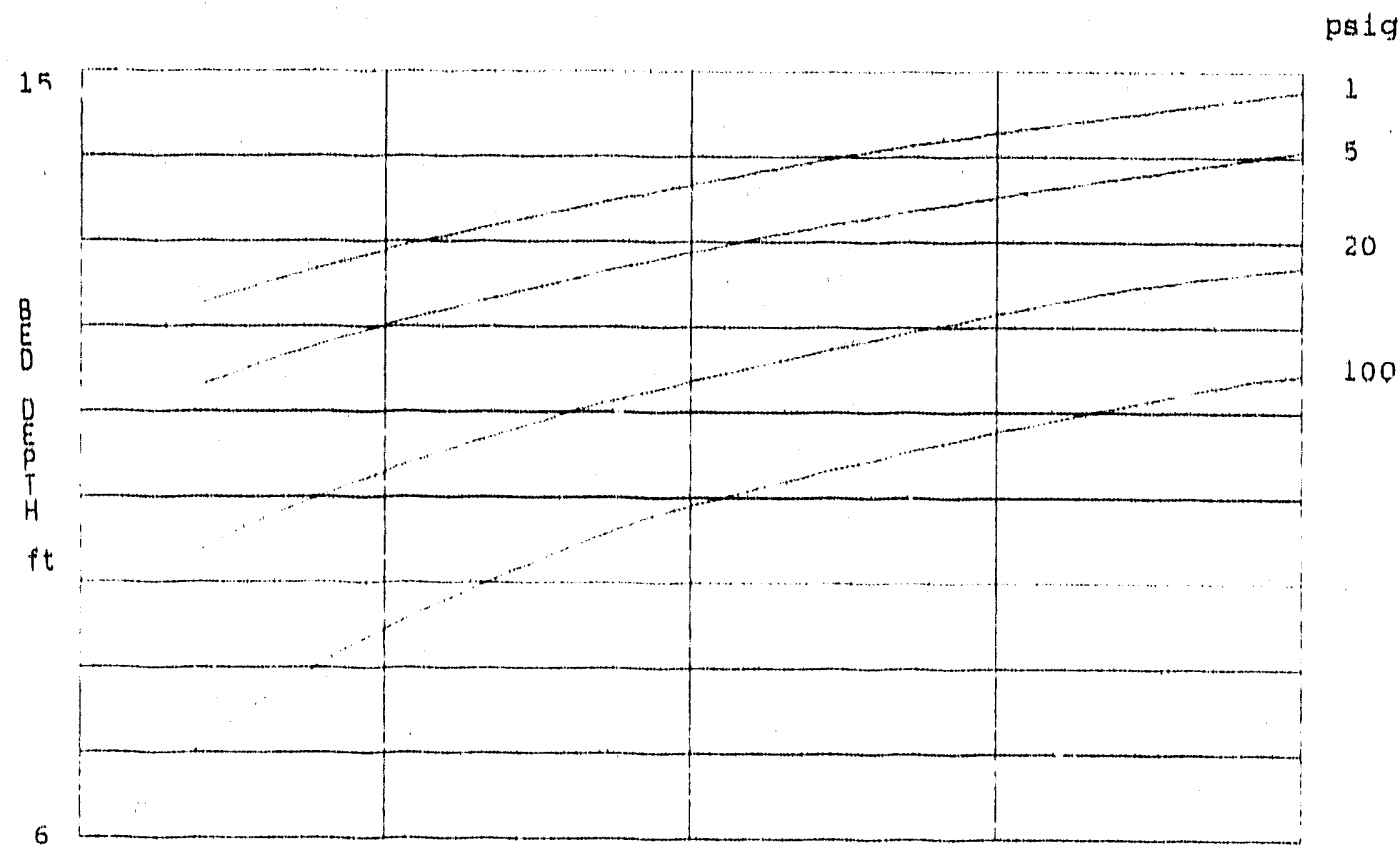

HENRY'S LAW CONSTANT

1.0

FIGURE 3.6a Absorption Bed Depth vs. Henry's Law Constant

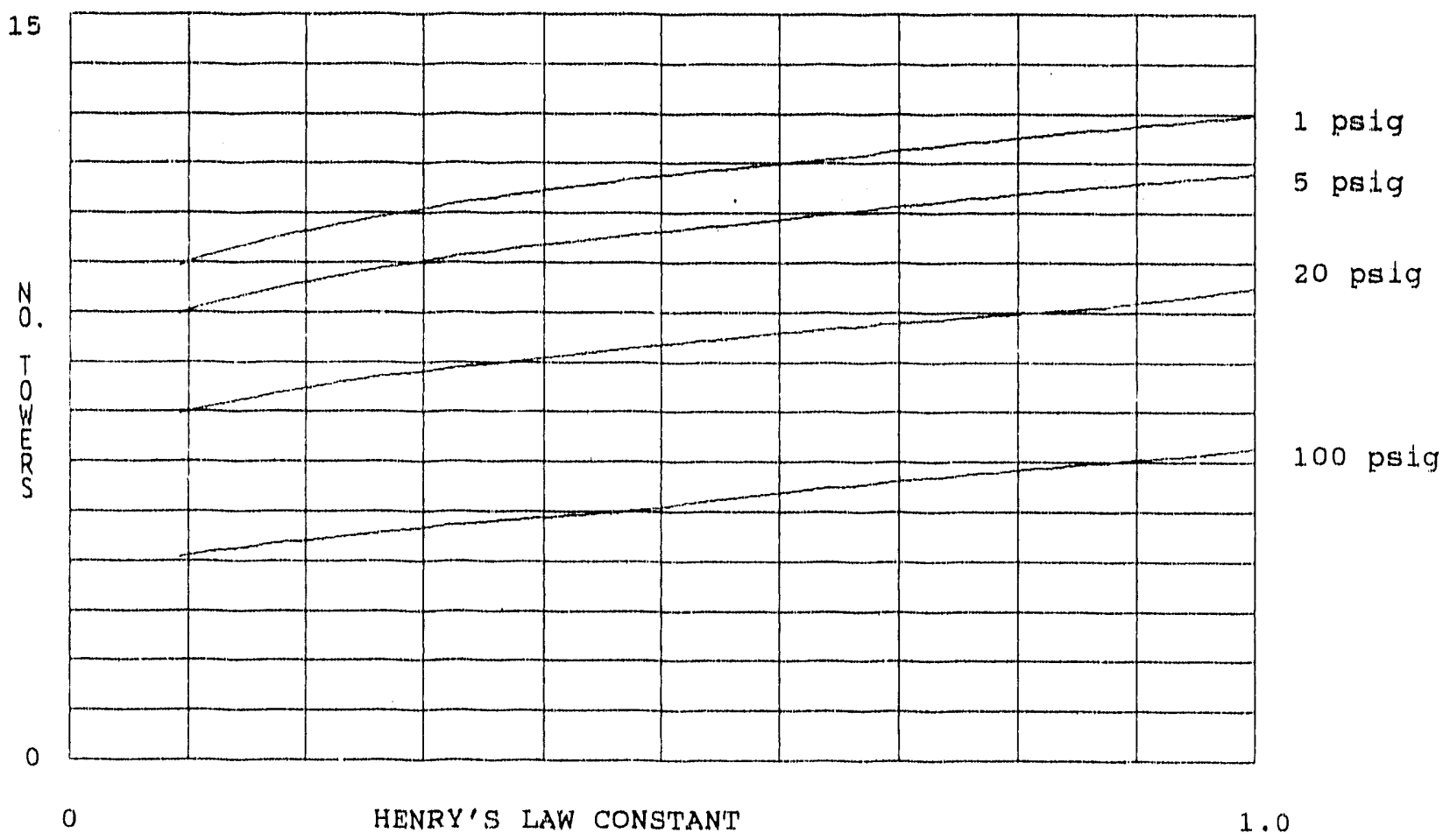

FIGURE 3.6h Number of Absorption Towers vs. Henry's Law Constant 


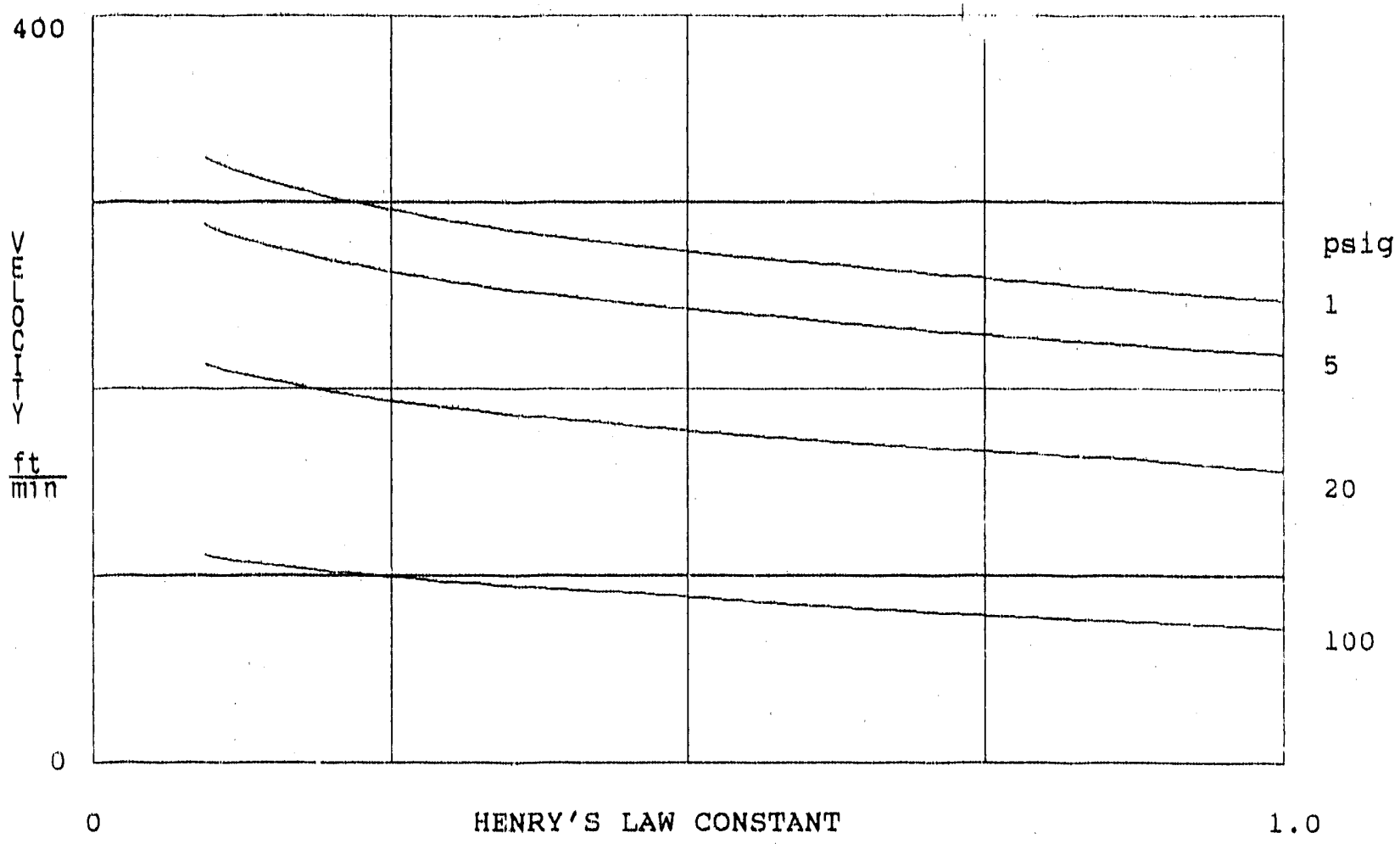

FIGURE 3.60 Superficial Velocity vs. Henry's Law Constant

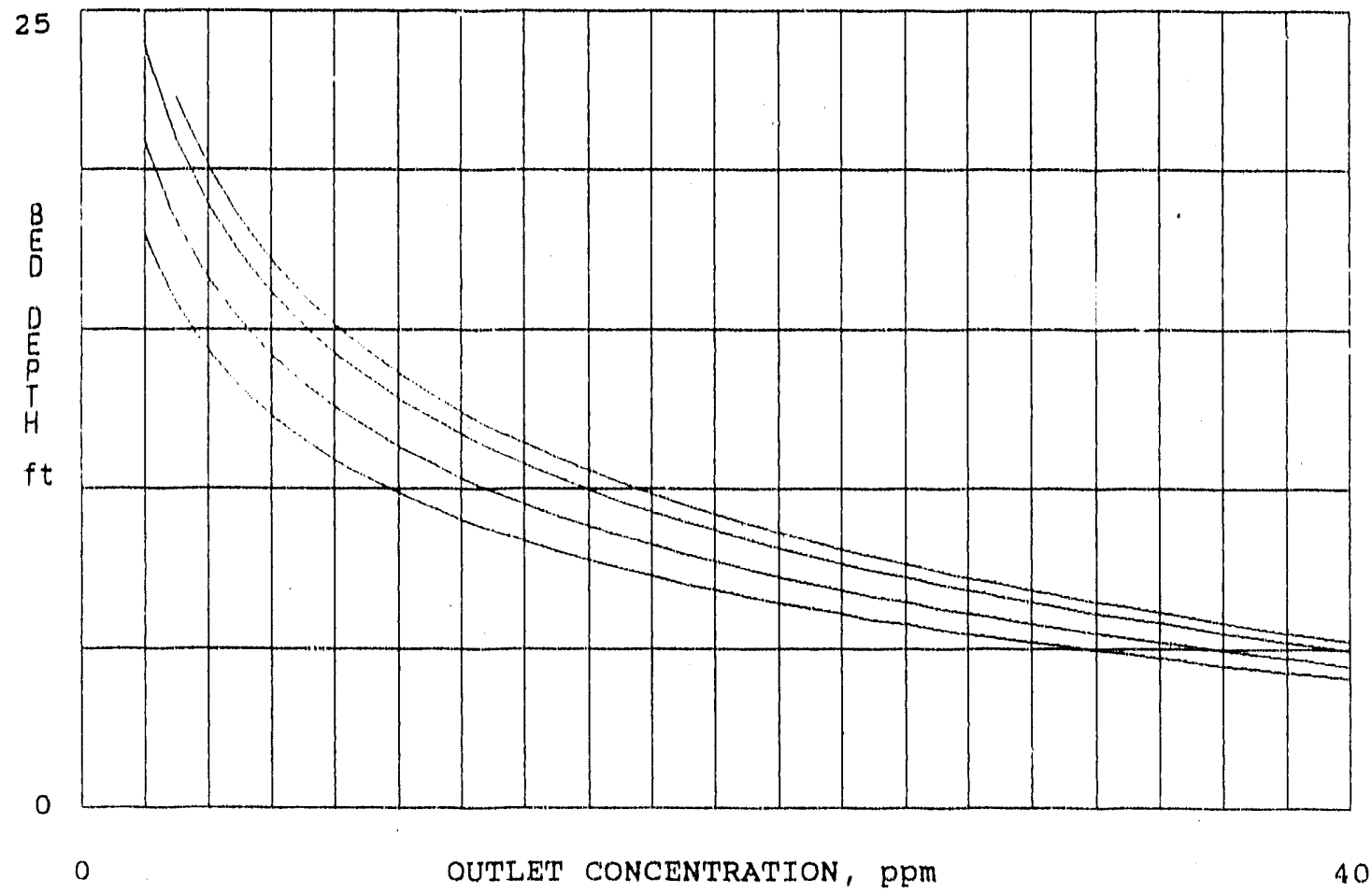

FIGURE 3.7a Absorption Bed Depth vs. Outlet Concentration at 1, 5, 20, and 100 psig 


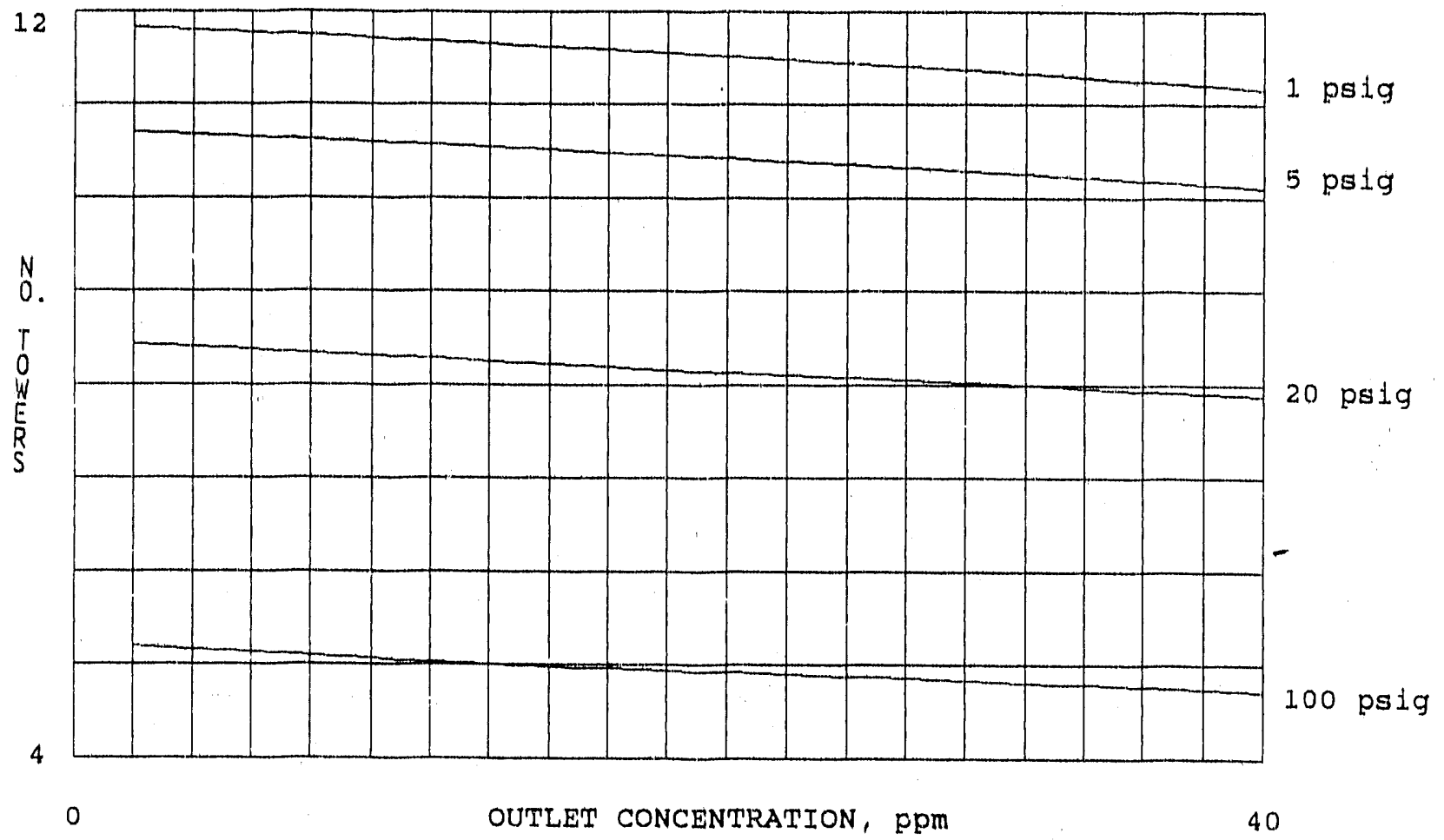

FIGURE 3.7b Number of Absorption Towers vs. Outlet Concentration

high would be required at 1 psig and five towers $4 \mathrm{ft}$ high at $100 \mathrm{psig}$. Conversely, if the gas must be cleaned to $2 \mathrm{ppm}$, then twelve 25 -ft-high towers would be required at 1 psig. It can be concluded that, given the Teepak case of $400,000 \mathrm{cfm}$ of $100 \mathrm{ppm} \mathrm{CS}_{2}$, the degree of cleanup required will have a large effect on the cost of a gas absorption recovery system.

\subsubsection{Effect of Pressure Drop}

The pressure drop usually associated with gas absorption is between 0.5 and $1.5 \mathrm{in}$. $\mathrm{II}_{2} \mathrm{O}$ per foot of bed. If additional pressure drop is used, the velocity of gas flow will increase and more gas can be forced through a given absorption tower. Therefore, the required number of towers will decrease, as shown in Figure 3.8b. But the figure also shows that the curves flatten out with increasing pressure drop. In addition, bed depth increases with pressure drop, as shown in Figure 3.8a. We thus may conclude that there is no advantage to increasing pressure drop above approximately $1.0 \mathrm{in}, \mathrm{H}_{2} \mathrm{O}$ per foot.

\subsection{MASS-TRANSFER COEFFICIENT}

The least accurate part of the bed depth calculation is the estimation of masstransfer coefficients in the tower. The gas film transfer coefficient $\left(\mathrm{k}_{\mathrm{h}}\right)$ controls the rate of transport of $\mathrm{CS}_{2}$ to the liquid surfaces. The liquid film transfer coefficient $\left(\mathrm{k}_{1}\right)$ controls the 


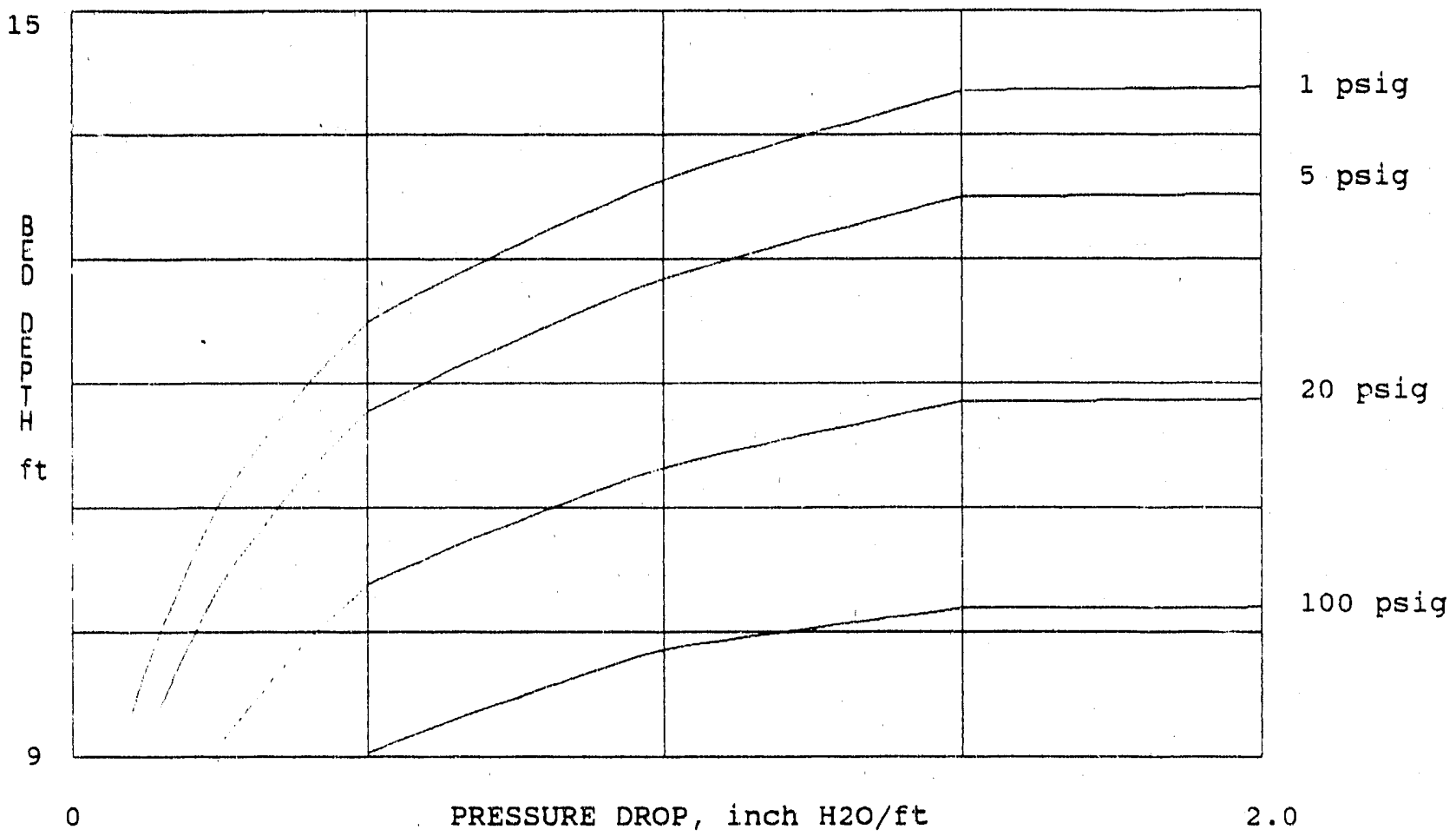

FIGURE 3.8a Absorption Bed Depth vs. Available Pressure Drop

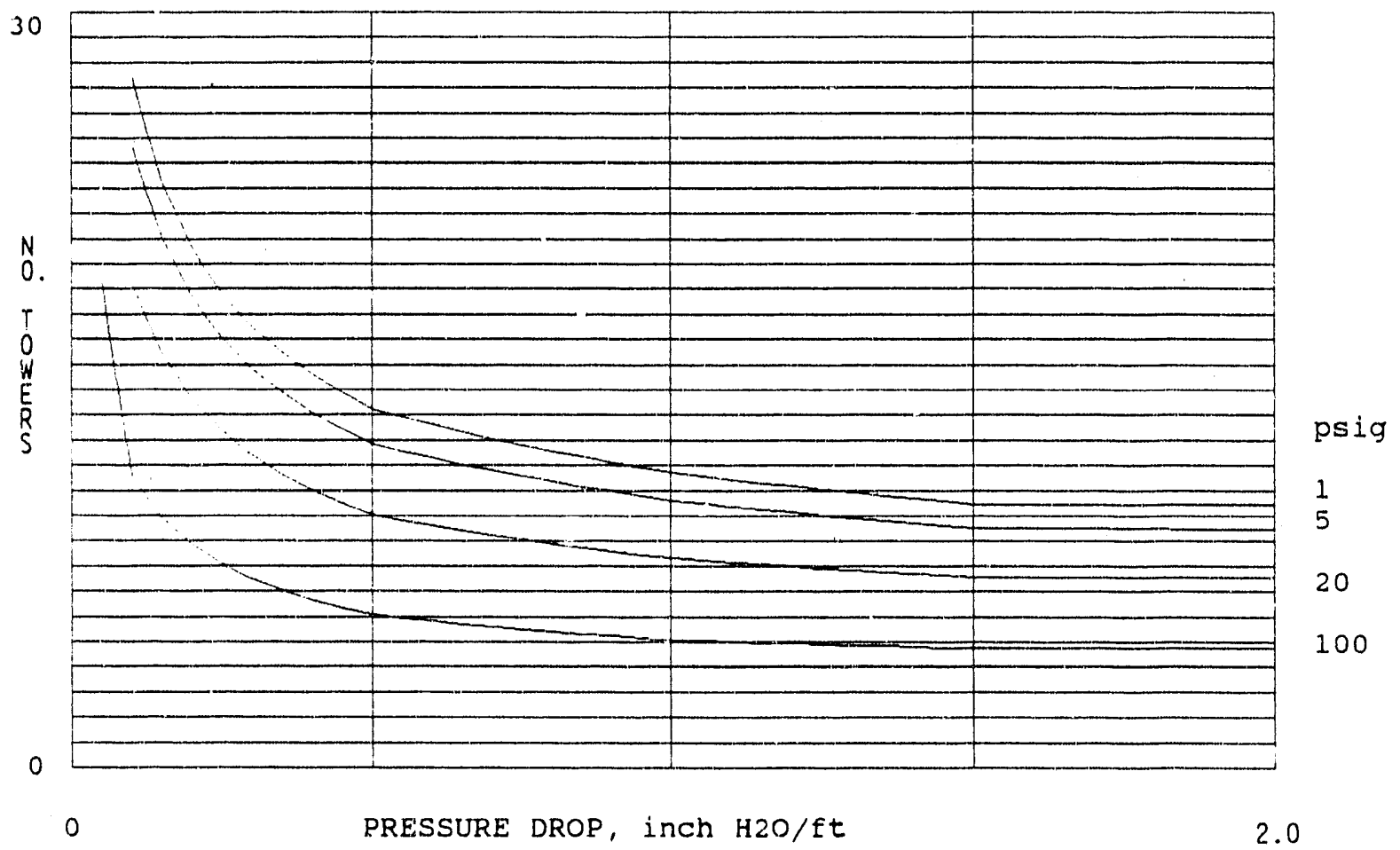

FIGURE 3.8b Number of Absorption Towers vs. Available Pressure Drop 


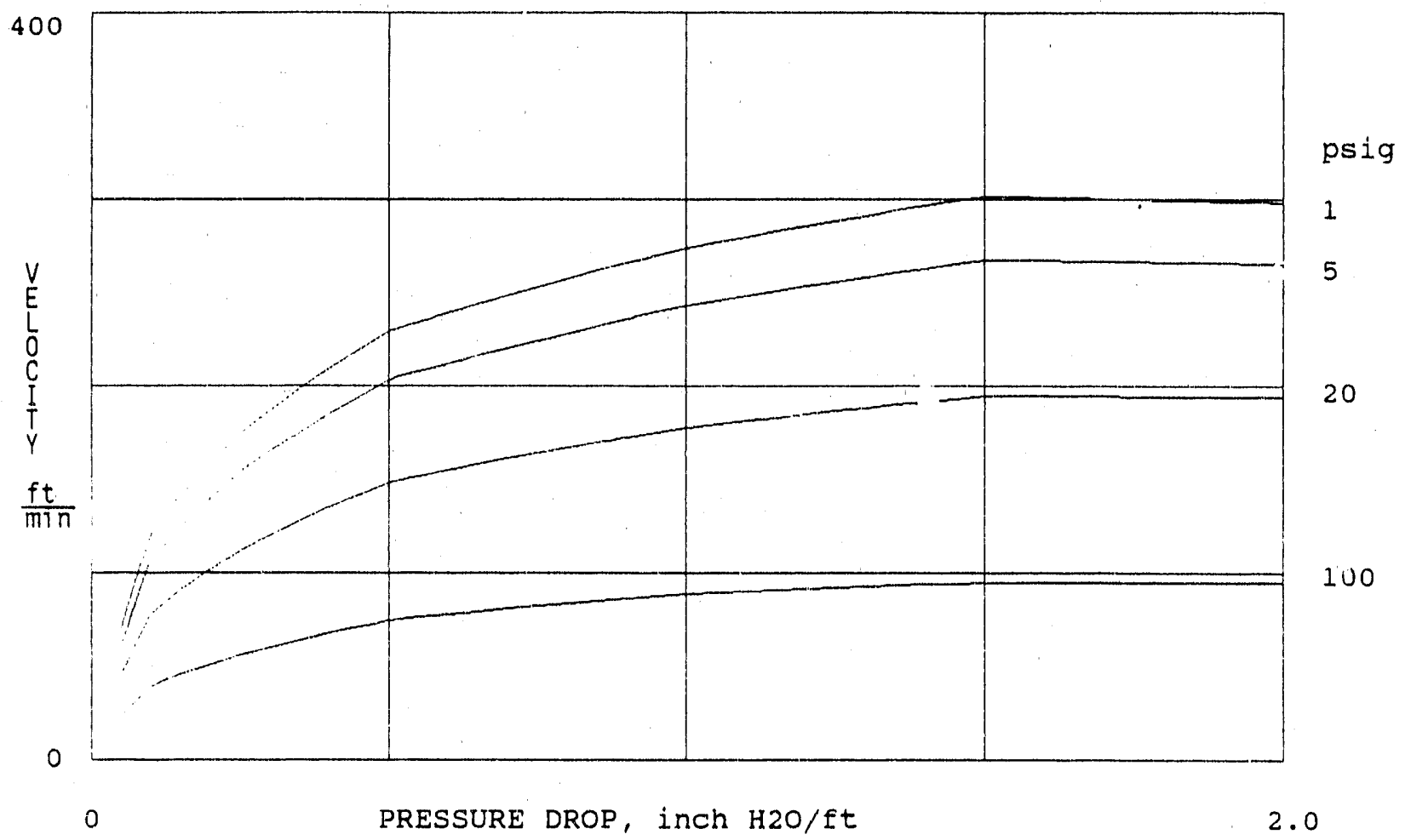

FIGURE 3.8c Superficial Velocity vs. Available Pressure Drop

rate of transport of $\mathrm{CS}_{2}$ into the bulk liquid. In the absorption tower model used to prepare Figures 3.3a through 3.8c, these coefficients were obtained by using well-known correlations, which are the best available but are probably less accurate than most correlations used for other, simpler, heat- and mass-transfer applications. For the gas side coefficient, the correlation of Taecker and Hougen ${ }^{46}$ was used. For Raschig rings, this correlation is:

$$
\mathrm{k}_{\mathrm{g}}=1.7\left(\mathrm{G} / \rho_{\mathrm{g}} \mathrm{M}\right)\left(\mathrm{GA} \mathrm{p}^{0.5} / \mu\right)^{-0.41}\left(\mu / \rho_{\mathrm{g}} \mathrm{D}_{\mathrm{g}}\right)^{-213}
$$

where $A_{p}$ is a factor for Rashig rings, $G$ is the mass velocity of the gas stream in $l b / h r \cdot f t^{2}, D_{g}$ is the gas phase diffusion corfficient, and $M$ is the average gas molecular weight (about $29 \mathrm{lb} / \mathrm{mole})$.

For the liquid side coefficient, the correlation of Shulman ${ }^{47}$ was used:

$$
\mathrm{k}_{1}=25.1 \mathrm{D}_{1}\left(\mathrm{D}_{\mathrm{p}} \mathrm{L} / \mu_{1}\right)^{0.45}\left(\mu_{1} / \rho_{1} \mathrm{D}_{1}\right)^{0.5} / \mathrm{D}_{\mathrm{p}}
$$

where $D_{1}$ is liquid-phase diffusion coefficient $\left(\mathrm{ft}^{2} / \mathrm{hr}\right), \mathrm{D}_{\mathrm{p}}$ is the diameter of a sphere that has the same surface area as an element of packing, $L$ is liquid rate $\left(\mathrm{lb} / \mathrm{hr} \cdot \mathrm{ft}^{2}\right)$, and $\rho_{1}$ is liquid 
density. Similar correlations have been shown to reproduce data from a large variety of packed tower systems to accuracies of $\pm 30 \%$ for gas side coefficients. ${ }^{43}$

Therefore, varying these coefficients over a range larger than the possible error bands is valuable in assessing the effeci on bed depth and determining if an inaccurate mass transfer coefficient could change the current assessment of gas absorption for $\mathrm{CS}_{2}$ recovery significantly. In the case where Henry's law constant $(K)$ is 0.5 , pressure is $1 \mathrm{psig}$, and $\mathrm{CS}_{2}$ concentration is $100 \mathrm{ppm}$ in and $10 \mathrm{ppm}$ out, tower height changes as both the gas and liquid coefficients $\left(\mathrm{k}_{\mathrm{g}}\right.$ and $\mathrm{k}_{\mathrm{l}}$ ) are varied (see Figure 3.9). The values of $\mathrm{k}_{\mathrm{g}}$ and $\mathrm{k}_{\mathrm{l}}$ (calculated from Equations. 10 and 11) were multiplied by factors ranging from 0.1 to 2.0 , so that the variation was from $10 \%$ to $200 \%$ of the estimated value. The adjusted $\mathrm{k}_{\mathrm{g}}$ is plotted on the horizontal axis in Figure 3.9, and each curve represents a different multiplication factor for $\mathrm{k}_{\mathrm{g}}$ as shown. When the $\mathrm{k}_{\mathrm{l}}$ multiplication factor is 1.0 and the gas-side mass-transfer coefficient $\left(\mathrm{k}_{\mathrm{g}}\right)$ is varied from 0.7 to $1.3, \mathrm{a} \pm 30 \%$ range, tower height will change from $18 \mathrm{ft}$ to about $11 \mathrm{ft}$. The variation in tower height for this $\pm 30 \%$ variation in $\mathrm{k}_{\mathrm{g}}$ is $+38 \%$ but only $-15 \%$. Therefore, around the 13 -ft mean the gas phase coefficient has a much larger effect if it is in error on the minus side. For example, a $-75 \%$ error will increase tower height by 21 to $34 \mathrm{ft}$, while a $+75 \%$ error will reduce tower height by only 4 to $9 \mathrm{ft}$. This effect also occurs for liquid phase coefficients. As seen in the figure, if $\mathrm{k}_{\mathrm{g}}$ were underestimated by an order of magnitude, the estimated tower height would rise from $13 \mathrm{ft}$ to $49 \mathrm{ft}$, while if it were overestimated by an order of magnitude, height would drop from $13 \mathrm{ft}$ to $11 \mathrm{ft}$.

From these results, we may conclude that, within the usual $\pm 30 \%$ error band for mass-transfer correlations, tower height may be estimated too high but is not likely to be estimated significantly too low as a result of using the correlations (Equations. 10 and 11). In any case, the error is not likely to exceed $40 \%$.

\subsection{LIQUID PROPERTIES}

In Section 3.2, it was shown that an aliphatic liquid potentially could produce a Henry's law coefficient for $\mathrm{CS}_{2}$ solubility of 0.5 or lower. This liquid could be some type of paraffinic oil of unknown density, viscosity, and molecular weight. Rather than estimate these properties for an unknown fluid, we used the properties of a common gas absorption liquid, propylene carbonate, in the calculations. ${ }^{48}$ Because these liquid properties, along with the liquid diffusion coefficient, are used to calculate the mass-transfer coefficient, it is necessary to evaluate the sensitivity of tower height estimation to inaccuracies in these properties. The computer model was run with each property varying between $-50 \%$ and $+50 \%$ of the values in Table 3.3. The results are given in Figures 3.10a and 3.10b. For example, the liquid density used in these calculations was $74.5 \mathrm{lb} / \mathrm{ft}^{3}$, so in the figures the variation in tower height and number of towers is given as a function of liquid density as it varies from $37.25 \mathrm{lb} / \mathrm{ft}^{3}$ to $111.75 \mathrm{lb} / \mathrm{ft}^{3}$. Similarly, the liquid molecular weights varied between 51 and 153, liquid viscosity between $0.15 \mathrm{cp}$ and $0.45 \mathrm{cp}$, and diffusion coefficient between $2.5 \times 10^{-5} \mathrm{ft}^{2} / \mathrm{hr}$ and $7.5 \times 10^{-5} \mathrm{ft}^{2} / \mathrm{hr}$. All these properties attain the values used in previous

calculations and meet at a common point in the center of the figures. Results for larger variations are given in Section 3.7. 
liquid

phase

coefficient

50

0

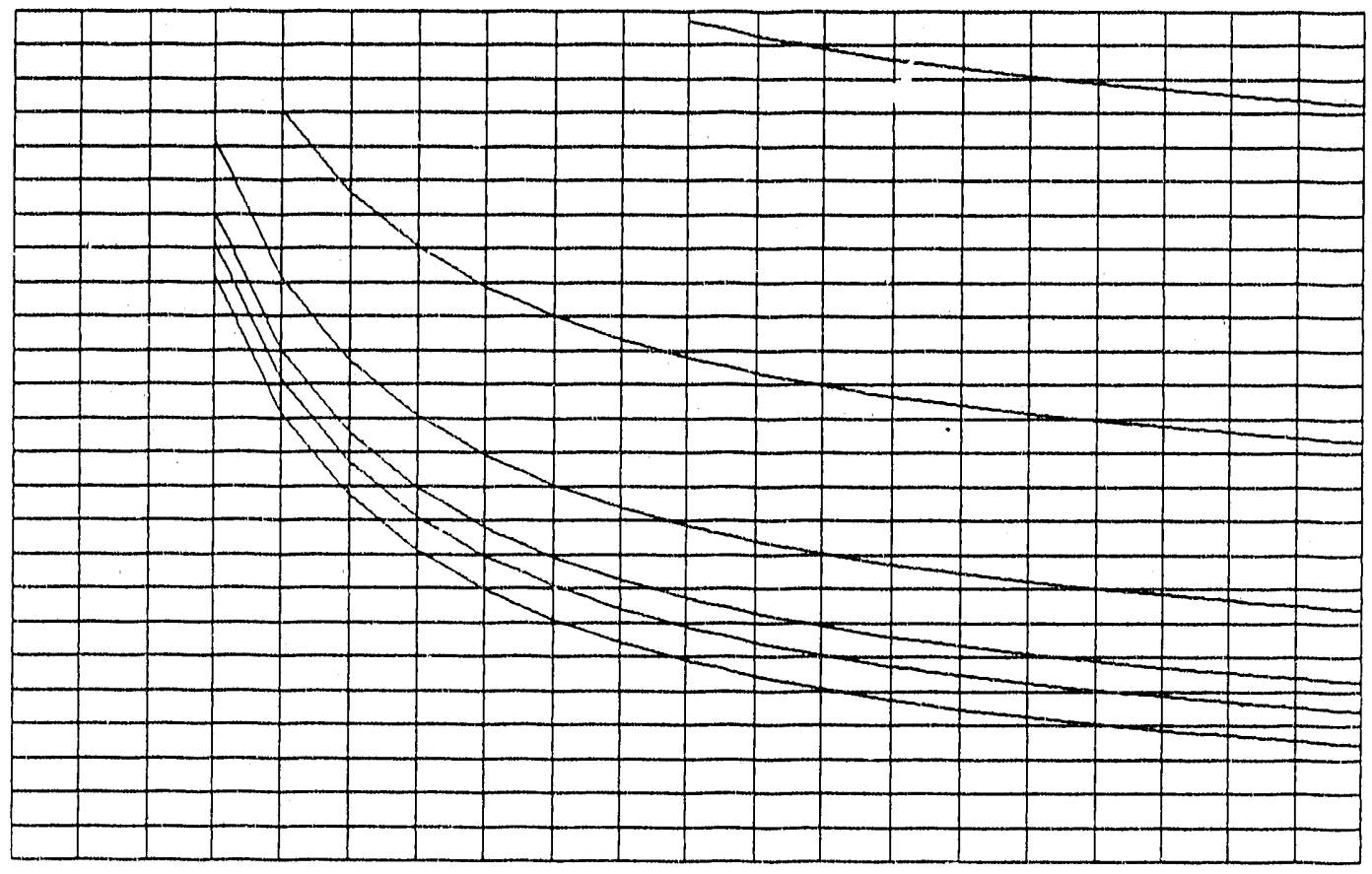

0.1

0.2

0.4

0.7

1.0

2.0

0.0

GAS PHASE MASS TRANSFER COEFFICIENT MULTIPLIER

2.0

FIGURE 3.9 Variation of Tower Height with Mass-Transfer Coefficients $k_{g}$ and $\mathrm{k}_{1}\left(\mathrm{~mole} / \mathrm{hr} \cdot \mathrm{ft}^{2}\right)$

Figure 3.10 a shows that the variation in tower height for $\pm 50 \%$ variation of the liquid properties is as follows: density $\pm 18 \%$, viscosity $\pm 3 \%$, molecular weight $\pm 5 \%$, and diffusion coefficient: $\pm 9 \%$. From Figure $3.10 \mathrm{~b}$, we see that varying molecular weight, viscosity, and diffusion coefficient has a negligible effect on number of towers but that varying liquid density has a noticeable effect. From this result, we may conclude that, for limited variation of liquid properties other than density, the effect on tower height and number of towers is well within the band created by uncertainties in mass-transfer coefficient. Therefore, the estimates in Section 3.3 will apply to other possible liquid solvents of similar density. However, solvents with different densities could produce different results and should be accounted for. For example, most hydrocarbon densities are about $56 \mathrm{lb} / \mathrm{ft}^{3}$. Figures $3.10 \mathrm{a}$ and $3.10 \mathrm{~b}$ show that, at this density, such a solvent requires a correction of 1.6-ft tower height reduction; also, five additional towers aire required for such a solvent. 


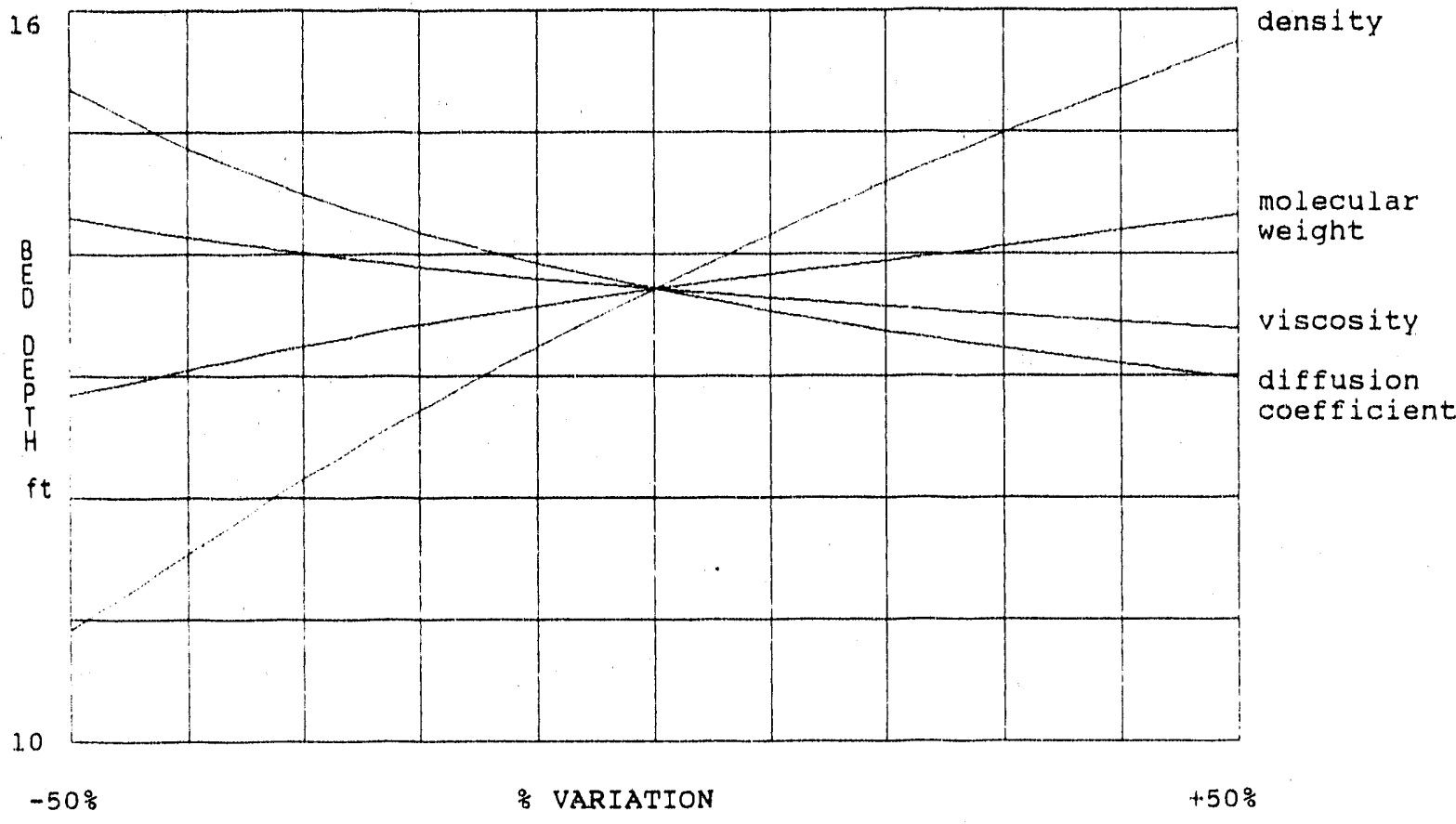

FIGURE 3.10a Variation of Tower Height with Liquid Properties (K=0.5, $\mathrm{P}=1 \mathrm{psig}$, $\mathrm{CS}_{2}$ concentration $=100 \mathrm{ppm}$ in and $10 \mathrm{ppm}$ out, horizontal axis is percent variation of property from values used in previous calculations)

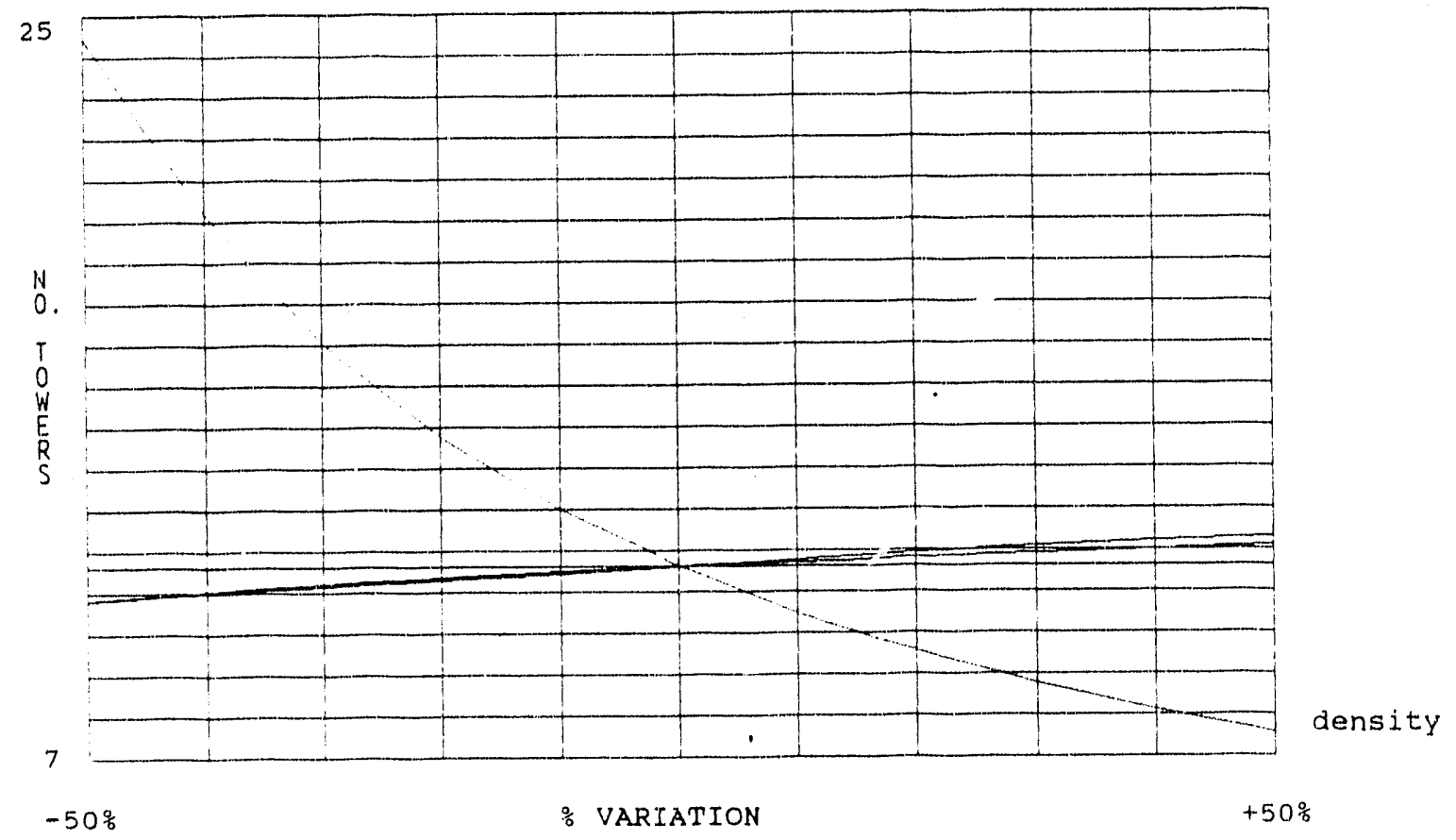

FIGURE 3.10b Variation of Number of Towers with Liquid Properties $(K=0.5$, $P=1 \mathrm{psig}, \mathrm{CS}_{2}$ concentration $=100 \mathrm{ppm}$ in and $10 \mathrm{ppm}$ out, horizontal axis is percent variation of property from values used in previous calculations) 


\subsection{ABSORPTION TESTS}

The results of Section 3.5 clearly show that the physical properties of the absorbing liquid are important, even within the likely error band of $\pm 30 \%$. As mentioned in Section 3.2.2, Henry's law constant can be expected to be 0.5 or less for aliphatic oils. Such oils can have much larger variation in physical properties than those investigated in Section 3.5. For example, Kaydol, a mineral oil distilled from petroleum by Witco Corporation, is $100 \%$ saturated hydrocarbon and should be a good absorbent for $\mathrm{CS}_{2}$. A comparison of the physical properties of Kaydol and propylene carbonate is given in Table 3.4.

The ability of Kaydol to absorb $\mathrm{CS}_{2}$ at 100 ppm was measured by modifying the ANL dynamic adsorption test rig (see Section 4.1.2 for a discussion of the adsorption test rig). Figure 3.11a shows a schematic of the modified test rig. Metered air is mixed with metered $\mathrm{CS}_{2} /$ air to produce a flow of air with $100 \mathrm{ppm} \mathrm{CS}_{2}$. The mixture is preheated by an oil bath and flows into a sparger that bubbles the gas through Kaydol. Absorption is detected by semicontinuous measurement of $\mathrm{CS}_{2}$ concentration in the off-gas with the flan:e photometric. detector of a gas chromatograph. The results of one such test are shown in Figure 3.11b. The loading is calculated by integrating the difference between inflow and outflow over time. As shown in the figure, the loading of $4.03 \times 10^{-4}$ mole $\mathrm{CS}_{2}$ per mole Kaydol translates into a Henry's law constant of 0.248 . This value indicates that $\mathrm{CS}_{2}$ has a high affinity for Kaydol. Therefore, Kaydol is, relatively, a very good absorbent for $\mathrm{CS}_{2}$. However, at $100 \mathrm{ppm}$, the partial pressure of $\mathrm{CS}_{2}$ relative to its vapor pressure at the same temperature is very small; therefore, the magnitude of loading of $\mathrm{CS}_{2}$ in Kaydol is very small.

\subsection{KAYDOL ABSORPTION CALCULATIONS}

Figures $3.12 \mathrm{a}$ and $3.12 \mathrm{~b}$ were prepared with the absorption tower model in Appendix A and with the pressures, diffusion coefficients, inlet-outlet concentrations, and other nonliquid property constants of Table 3.3 (similar to the calculations in Section 3.3). The physical property constants were those of Kaydol. These figures depict the model's prediction of variation in absorption bed depth and in number of towers when Henry's Law

TABLE 3.4 Properties of Absorption Liquids

\begin{tabular}{lcc}
\multicolumn{1}{c}{ Property } & $\begin{array}{c}\text { Propylene } \\
\text { Carbonate }\end{array}$ & Kaydol \\
\hline Density $\left(\mathrm{lb} / \mathrm{ft}^{3}\right)$ & 74.5 & 54.7 \\
Molecular weight & 102 & 424 \\
Viscosity $(\mathrm{Cp})$ & 0.3 & 58.82 \\
$\mathrm{CS}_{2}$ diffusivity $\left(\mathrm{ft}^{2} / \mathrm{hr}\right)$ & $5 \times 10^{-5}$ & $2.5 \times 10^{-6}$ \\
\hline
\end{tabular}




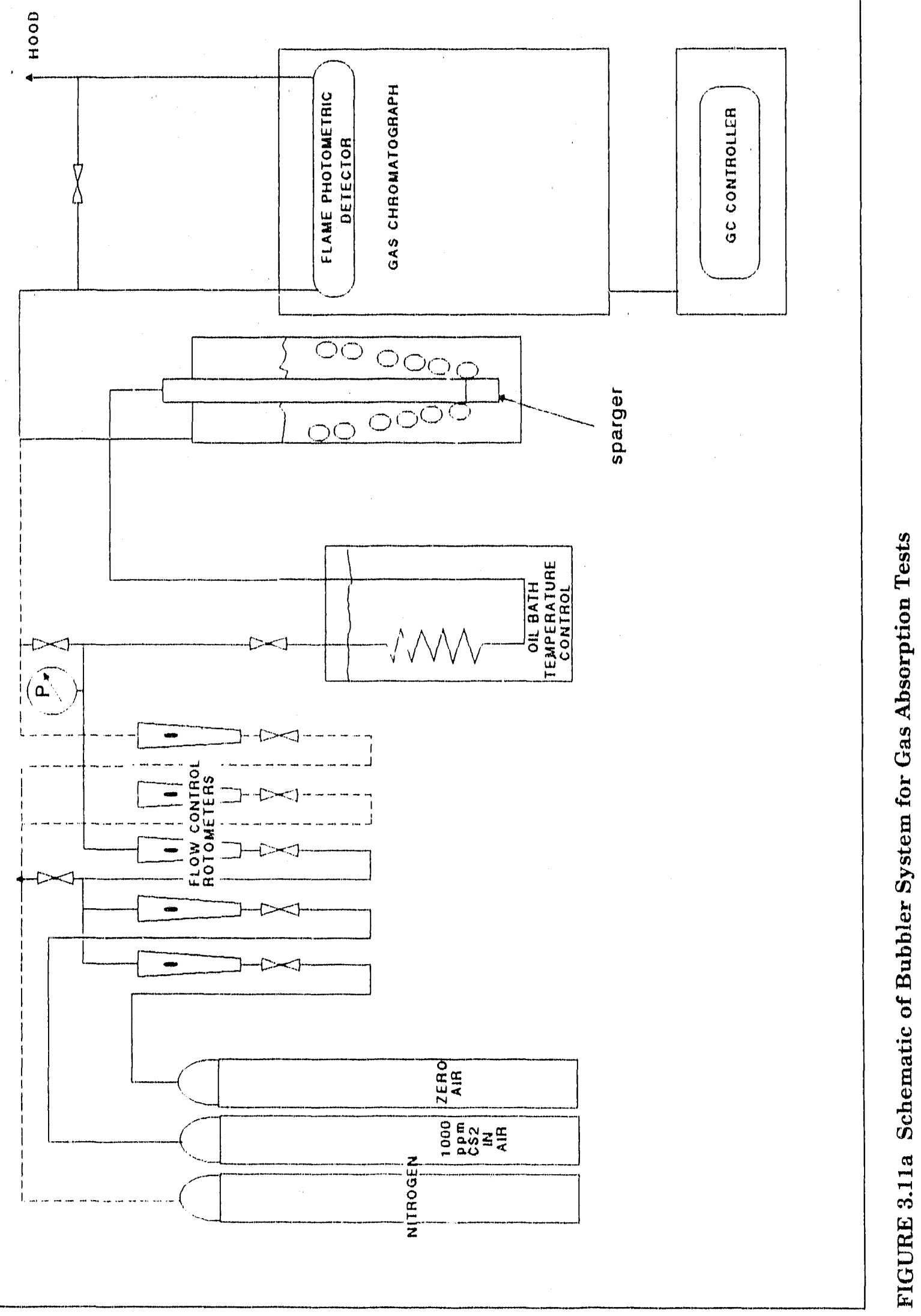




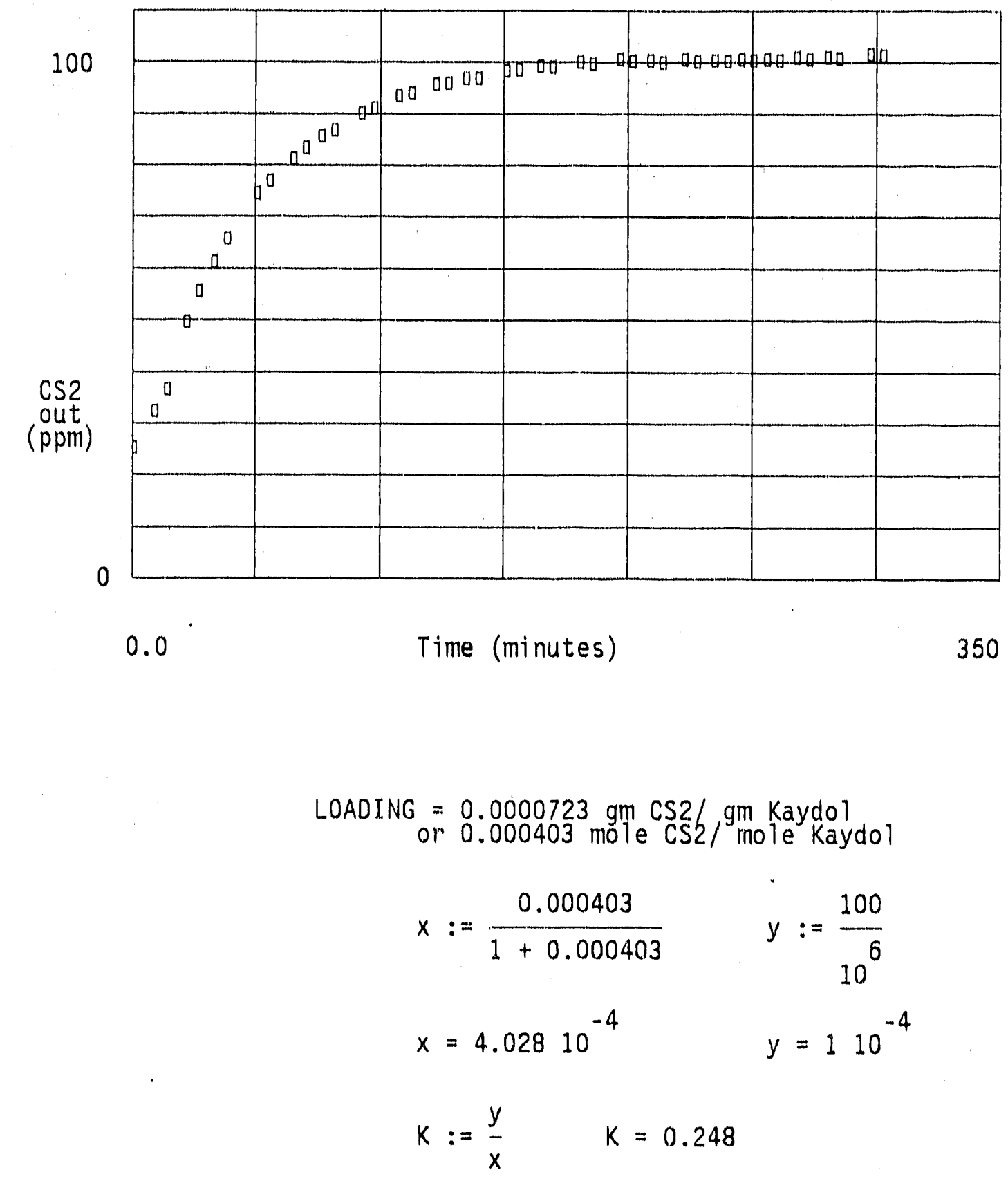

FIGURE 3.11b Rate Curve for Absorption of $\mathrm{CS}_{2}$ by Kaydol 


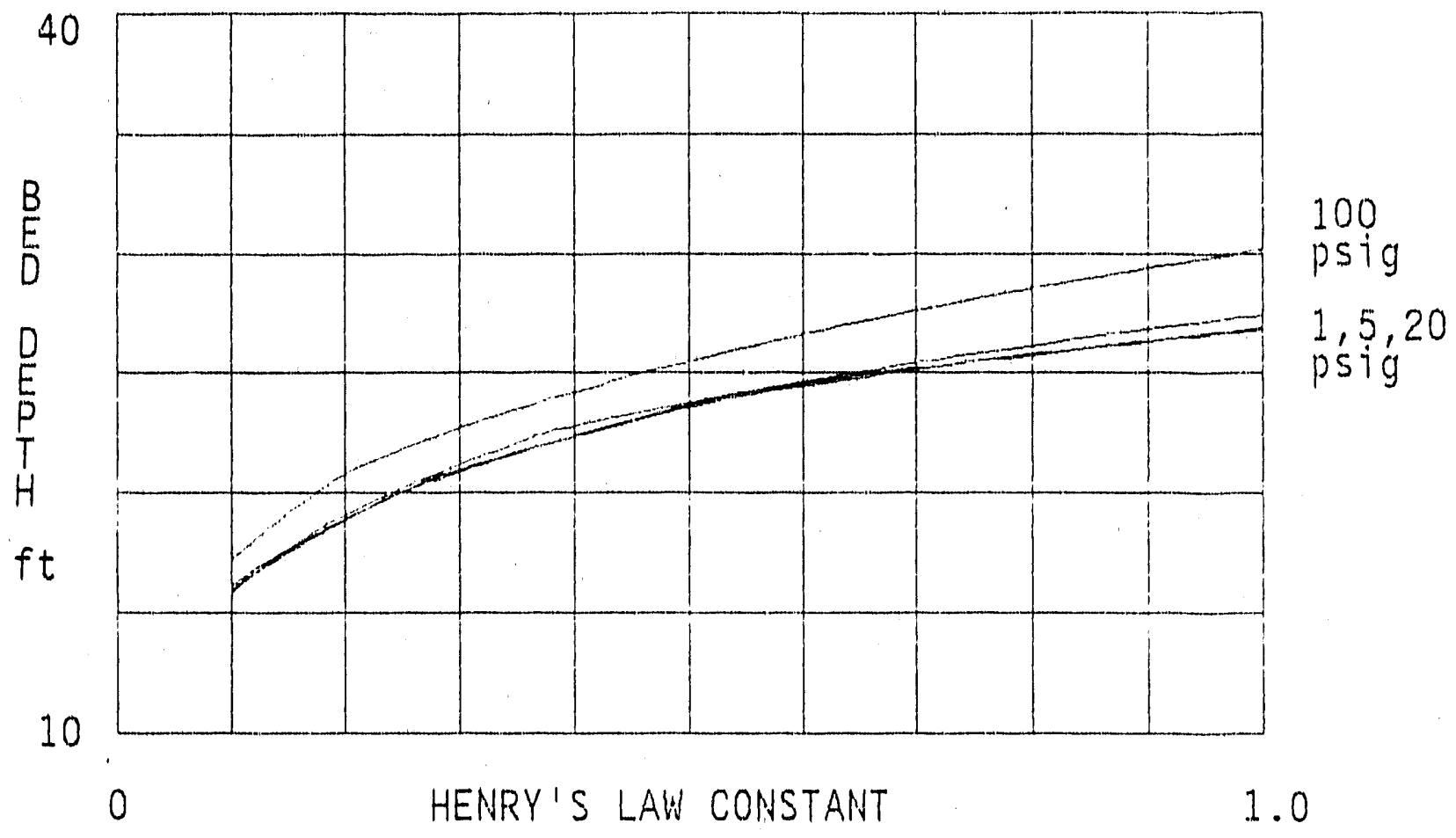

FIGURE 3.12a Absorption Bed Depth vs. Henry's Law Constant, Based on Kaydol Properties

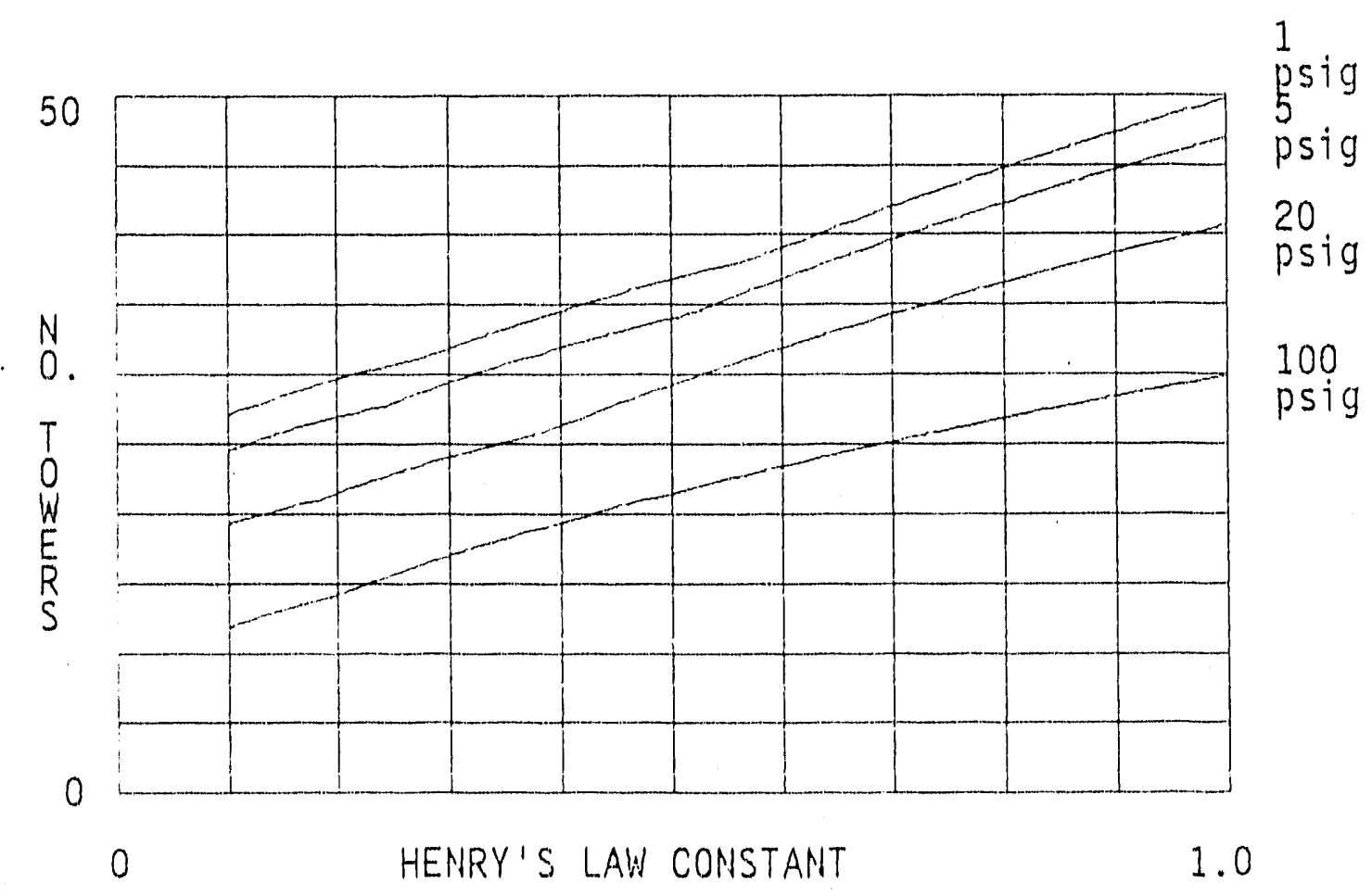

FIGURE 3.12b Number of Absorption Towers vs. Henry's Law Constant, Based on Kaydol Properties 
constant is varied and when an absorbing liquid with the physical properties of Kaydol is used (see Table 3.4). Figures 3.13 a and 3.13 b show the results when propylene carbonate properties are used for the absorbing liquid. The effects of very different physical propertios are evident from a comparison of the two sets of curves. For example, it is clear that an absorption system that uses a liquid with Kaydol properties requires significantly more absorption bed depth and more towers than a system that uses a liquid with propylene carbonate properties. The additional requirements depend on the magnitude of the liquids' Henry's law constants, but in general, as seen in the figures, additional requirements exist for all values of Henry's Law constant,

To discern the effect of Henry's law constant more easily, additional plots were made as liquid viscosity was varied for two different values of Henry's law constant. The plots are shown in Figures 3.14a, 3.14b, 3.15a, and 3.15b. From this comparison, it can be seen that at 1 psig, a reduction in Henry's law constant from 0.5 to 0.25 reduces bed depth by an average of less than $1 \mathrm{ft}$ and reduces tower requirements by two. We conclude that reduction of Henry's law constant is not a highly effective means of reducing the cost of $\mathrm{CS}_{2}$ gas absorption (see also Figures $3.6 \mathrm{a}$ and $3.6 \mathrm{~b}$ ). Therefore, in this case the effects of physical properties of the absorbent exceed those of other factors.

Figures 3.16a, 3.16b, 3.17a, and 3.17b depict the effect of $\mathrm{CS}_{2}$ diffusivity in the liquid. The first two figures were obtained from computer runs that used the diffusivity of propylene carbonate $\left(5 \times 10^{-5} \mathrm{ft}^{2} / \mathrm{hr}\right)$, and the others were obtained by using the Kaydol value $\left(2.5 \times 10^{-6} \mathrm{ft}^{2} / \mathrm{hr}\right)$. From this comparison, it can be seen that diffusivity has a large effect on required bed depth, which more than doubles as diffusivity droys from that of propylene carbonate to that of Kaydol.

Figures $3.18 \mathrm{a}$ and $3.18 \mathrm{~b}$, as compared with $3.19 \mathrm{a}$ and $3.19 \mathrm{~b}$, show the effect of liquid density. Under the conditions described in these figures, the $36 \%$ increase in density from propylene carbonate to Kaydol is seen to have a relatively small effect.

Figures 3.14 a through $3.19 \mathrm{~b}$ demonstrate that an increase in molecular weight tends to increase the number of towers significantly but reduce the bed depth.

In summary, Figures 3.12 a through $3.19 \mathrm{~b}$ make it clear that reducing the molecular weight and viscosity of the absorbent will tend to reduce the number of towers, while increasing the molecular weight, viscosity, and diffusivity will reduce bed depth. Reduced density also tends to reduce bed depth. Because diffusivity has a relatively large effect on bed depth, the best compromise probably would be to look for a liquid with high diffusivity (to reduce bed depth) but also with low viscosity and molecular weight ( to reduce the number of towers), 


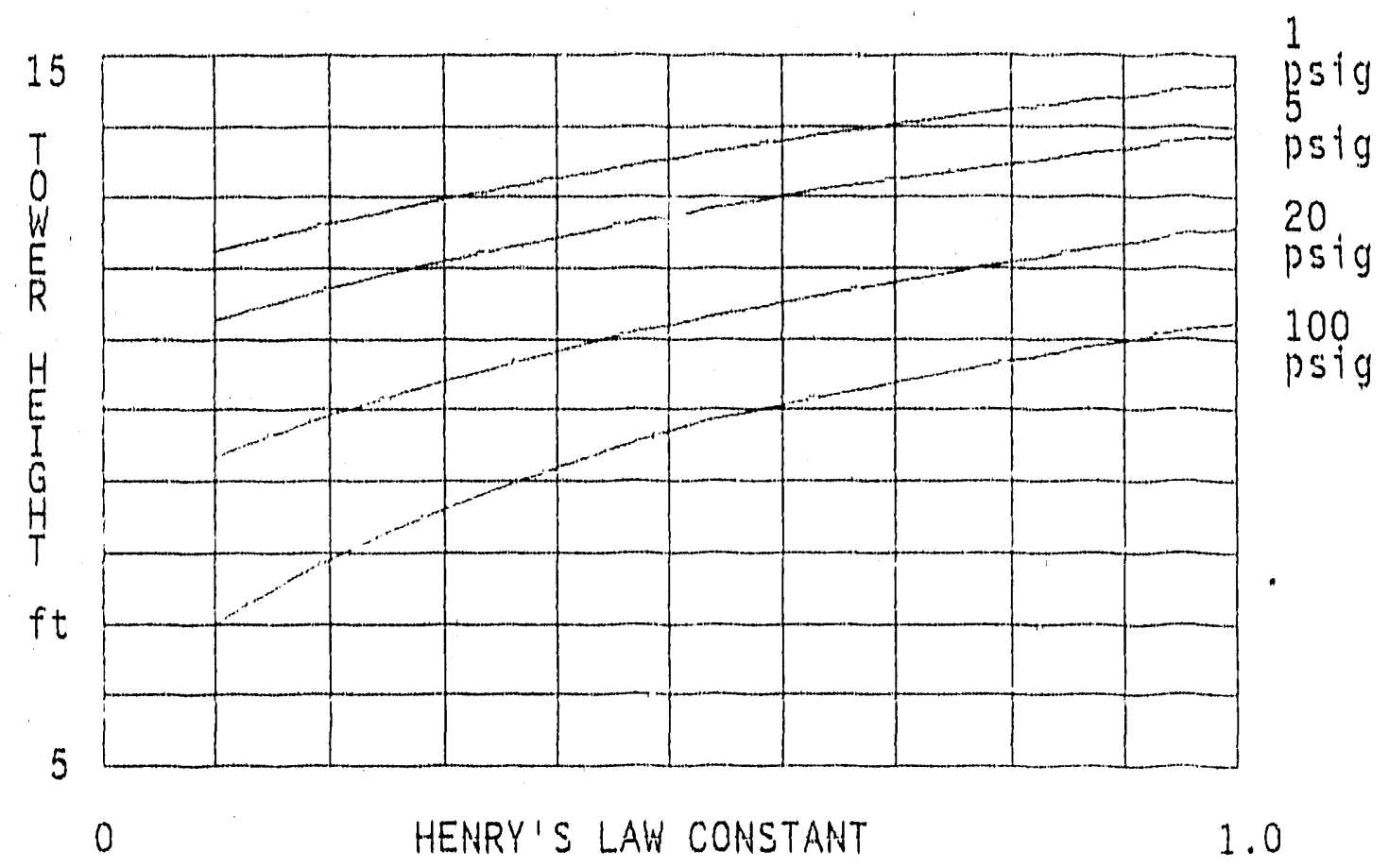

FIGURE 3.13a Absorption Bed Depth vs. Henry's Law Constant, Based on Propylene Carbonate Properties

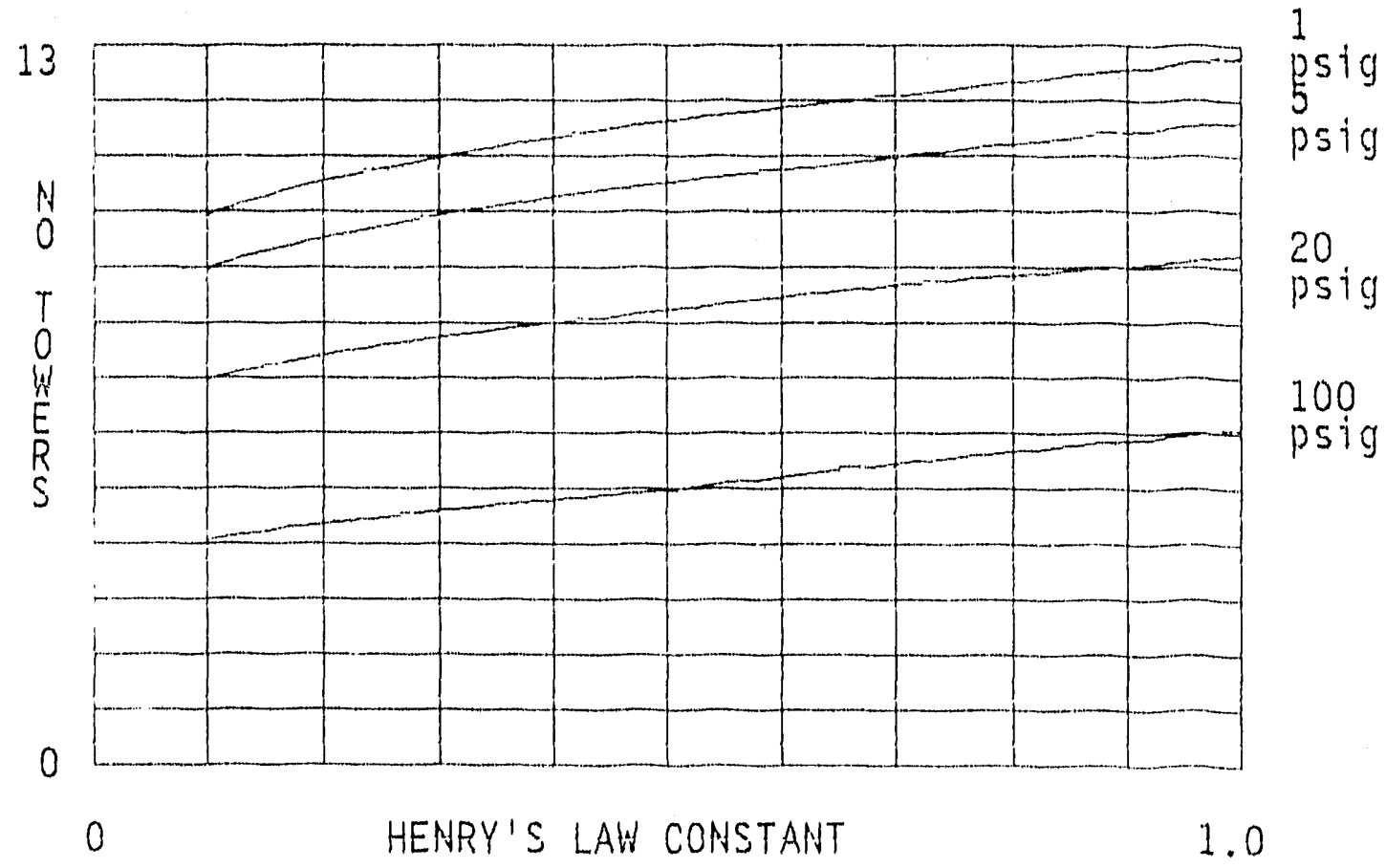

FIGURE 3.13b Number of Absorption Towers vs. Henry's Law Constant, Based on Propylene Carbonate Properties 


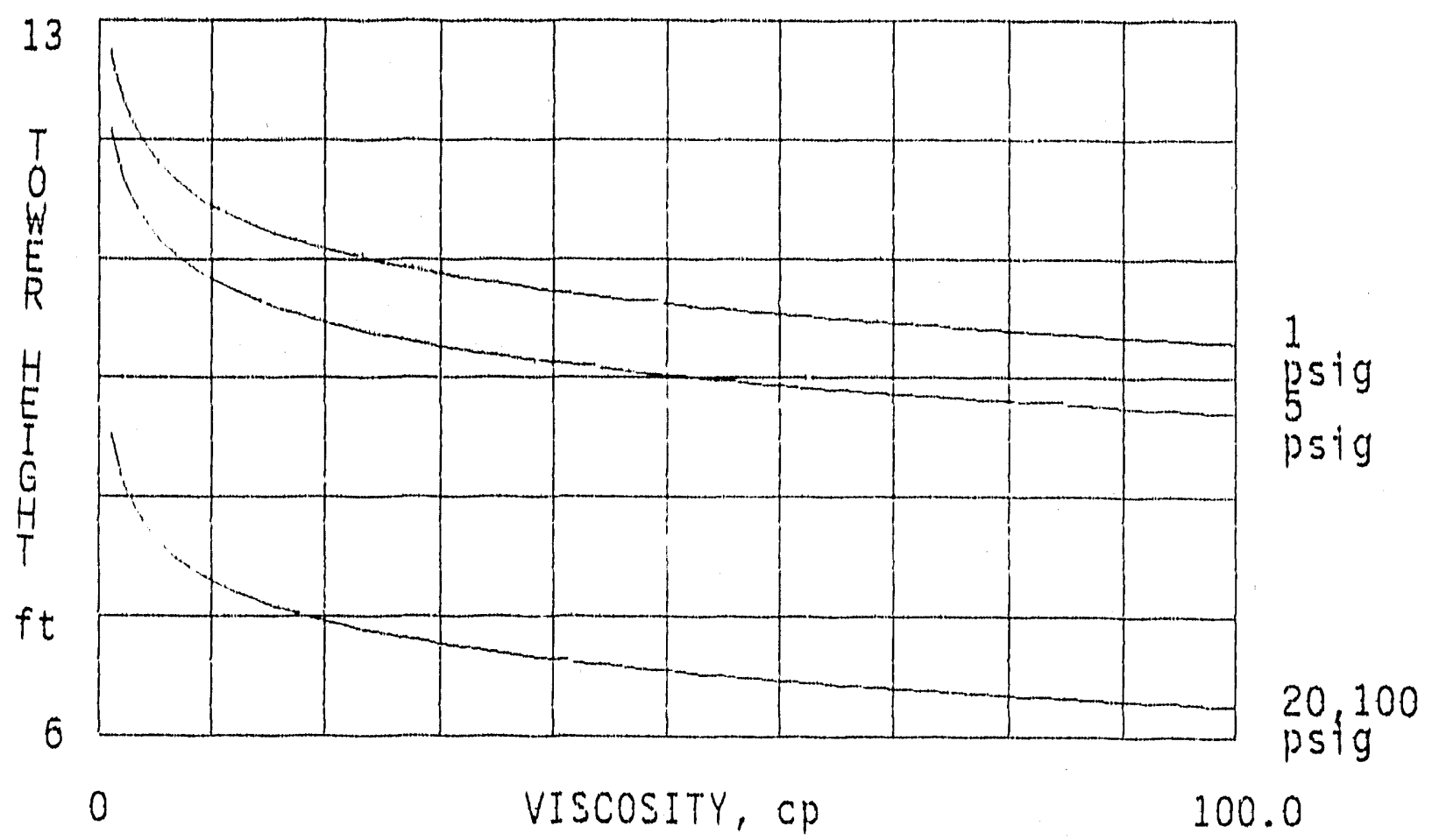

FIGURE 3.14a Absorption Bed Depth vs. Liquid Viscosity (Henry's law constant $=0.5$ )

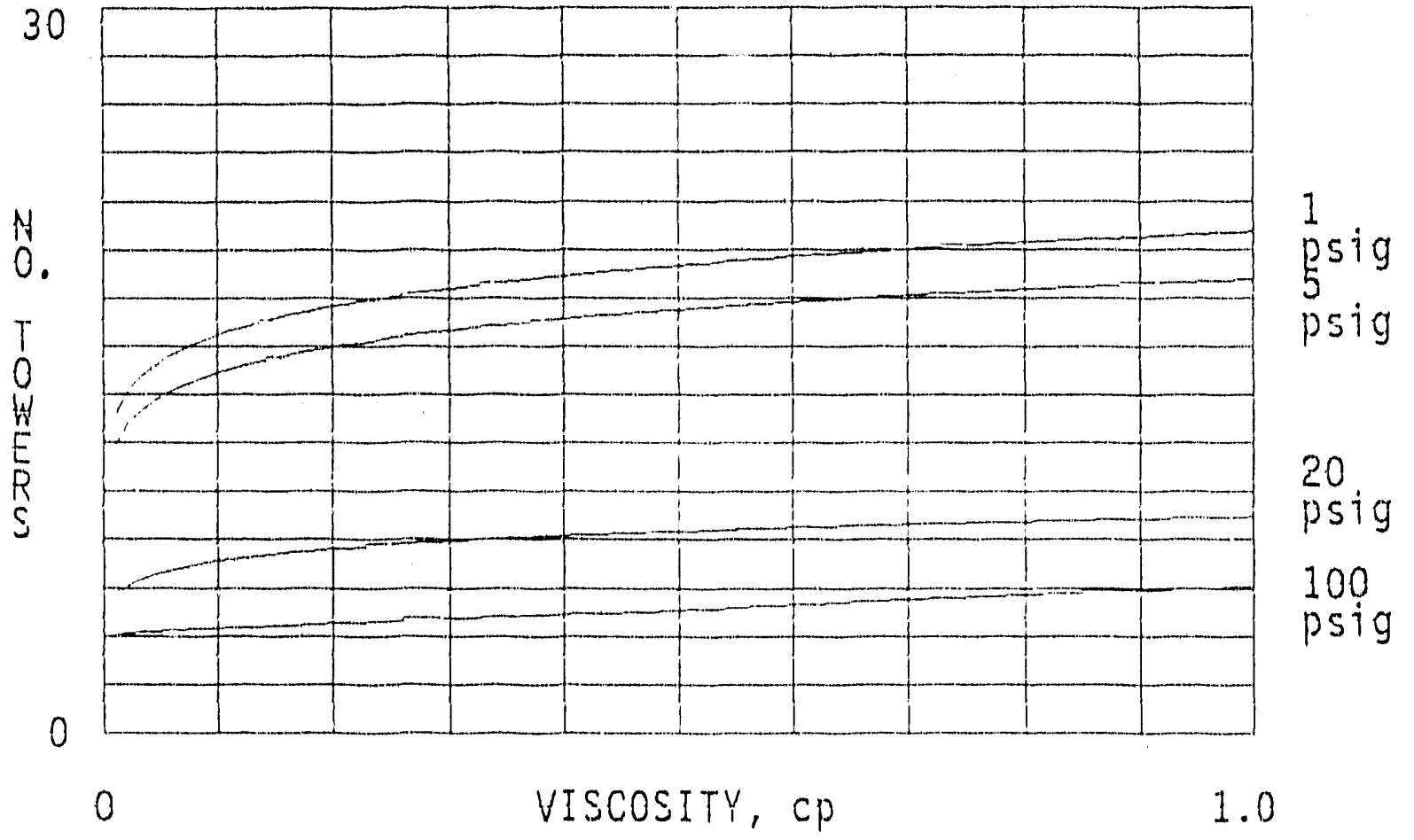

FIGURE 3.14b Number of Absorption Towers vs. Liquid Viscosity (Henry's law constant $\mathbf{= 0 . 5 )}$ 


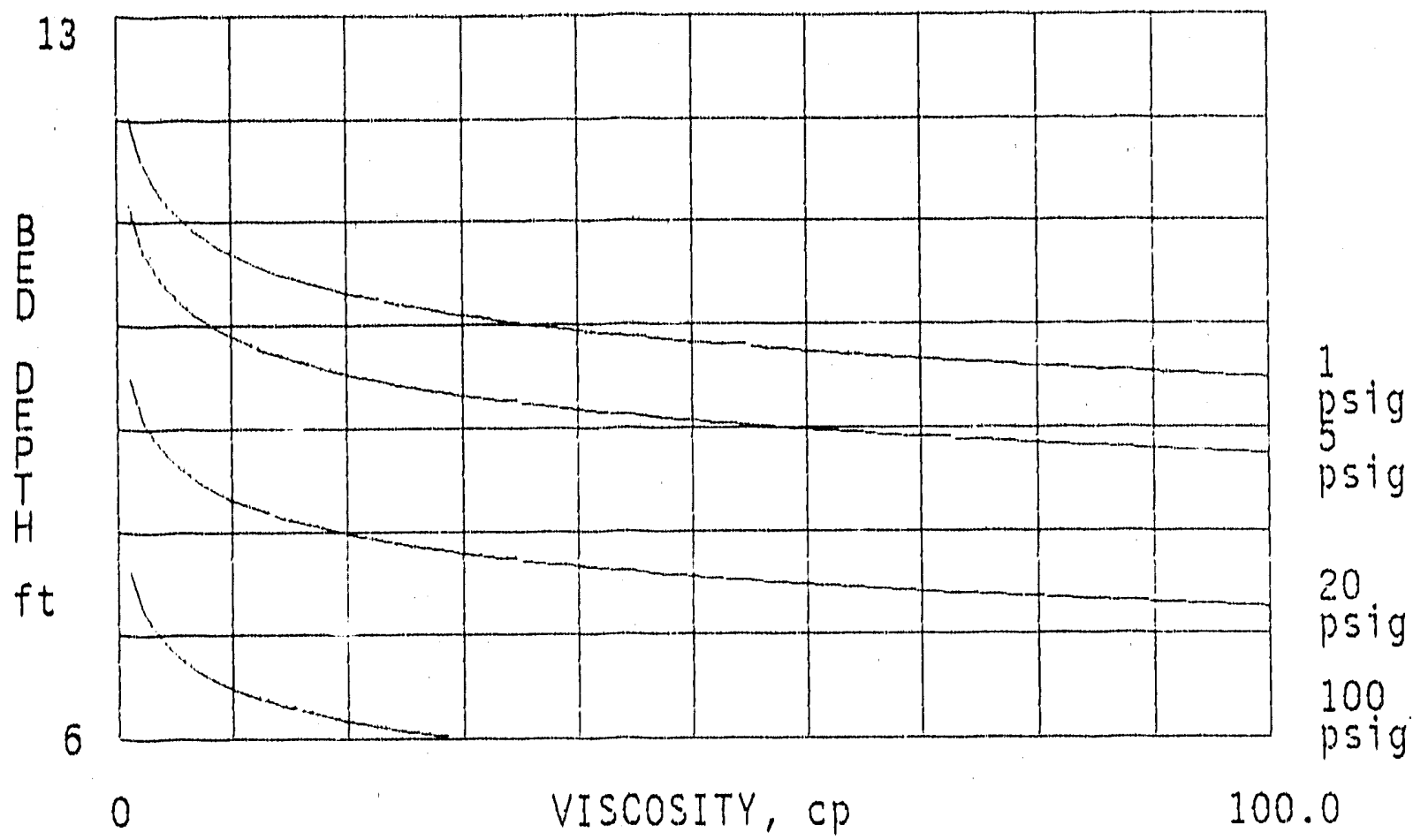

FIGURE 3.15a Absorption Bed Depth vs. Liquid Viscosity (Henry's law constant $=0.25$ )

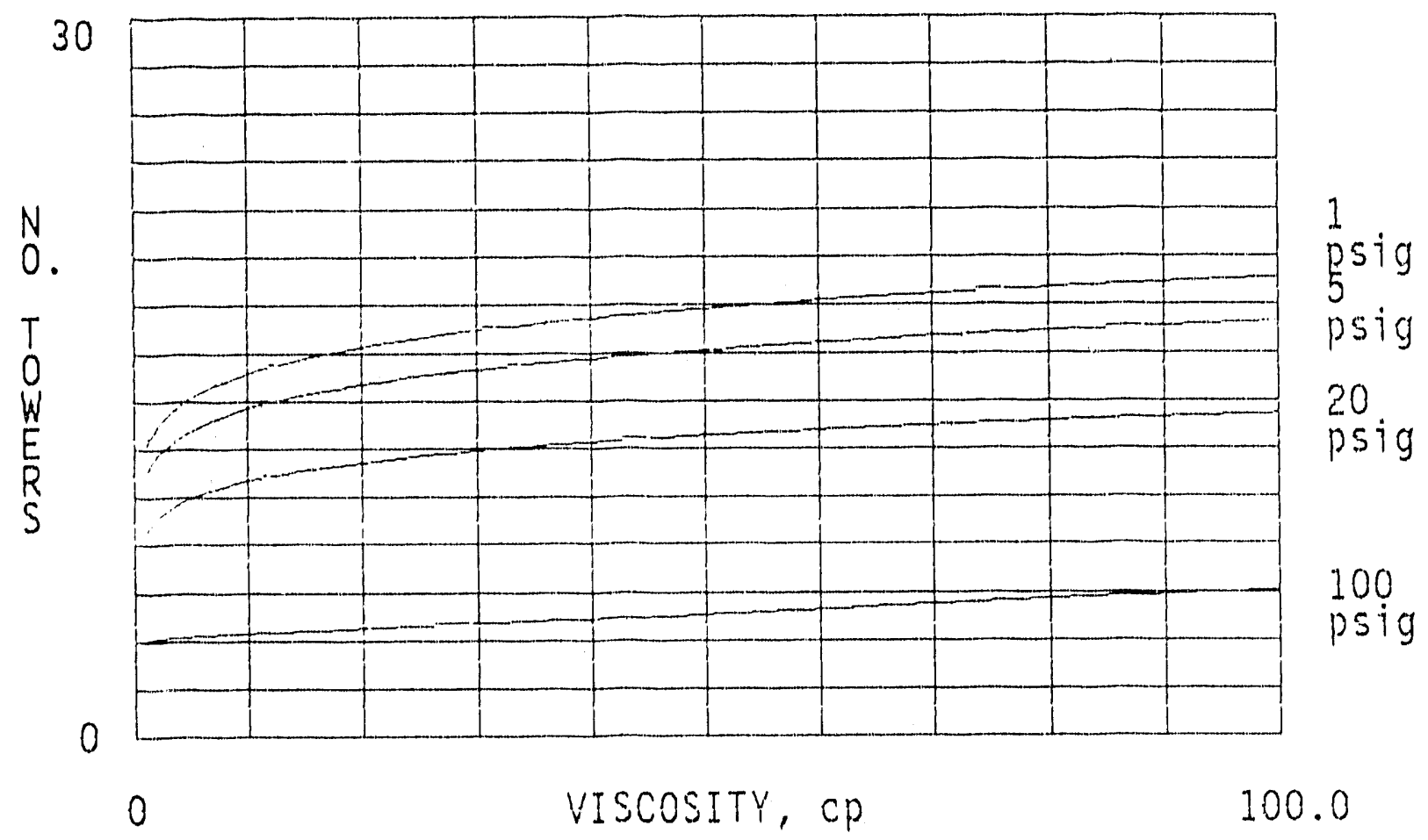

FIGURE 3.15b Number of Absorption Towers vs. Liquid Viscosity (Henry's law constant $=0.25$ ) 


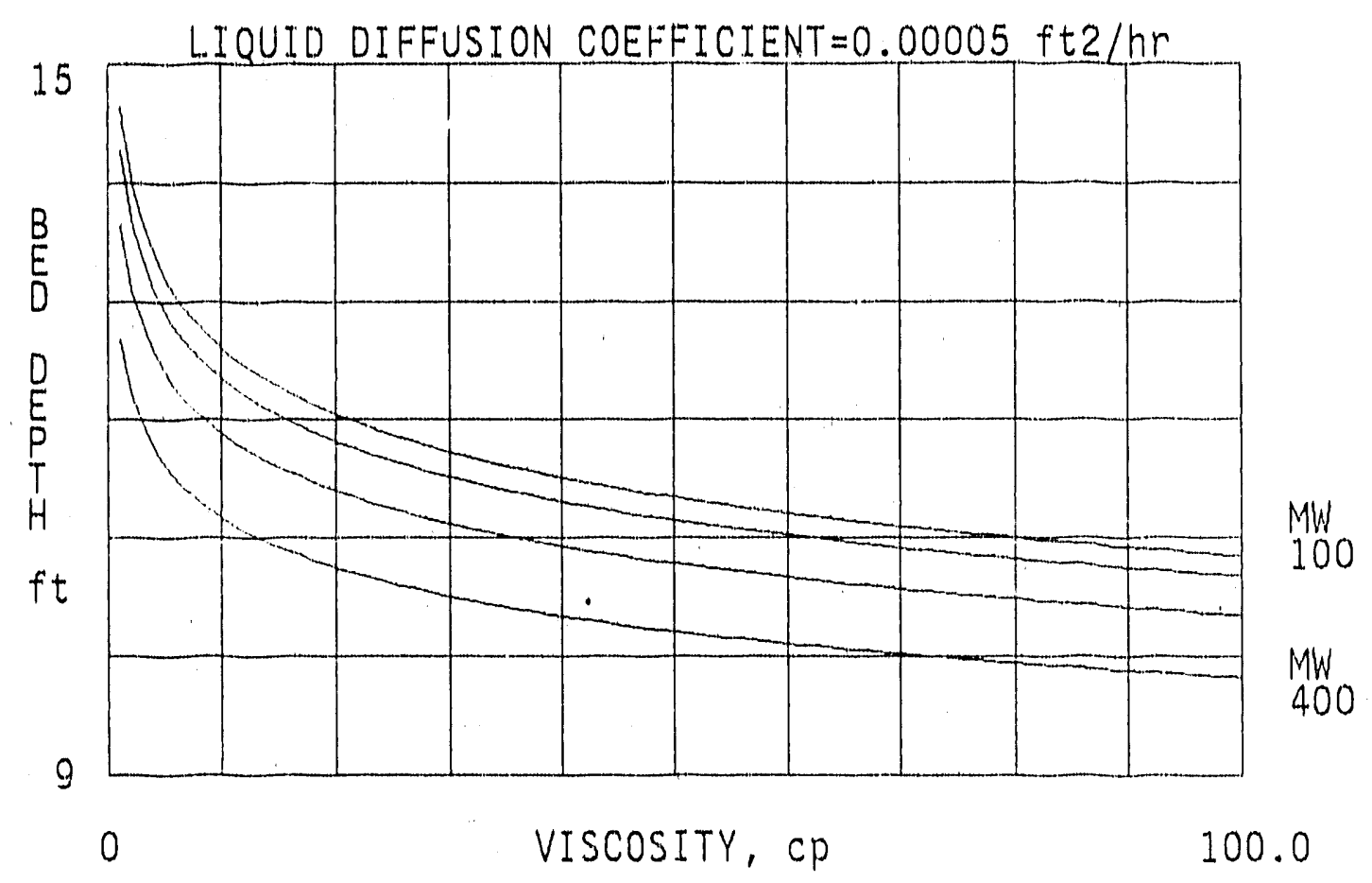

FIGURE 3.16a Absorption Bed Depth vs. Liquid Viscosity and Molecular Weight

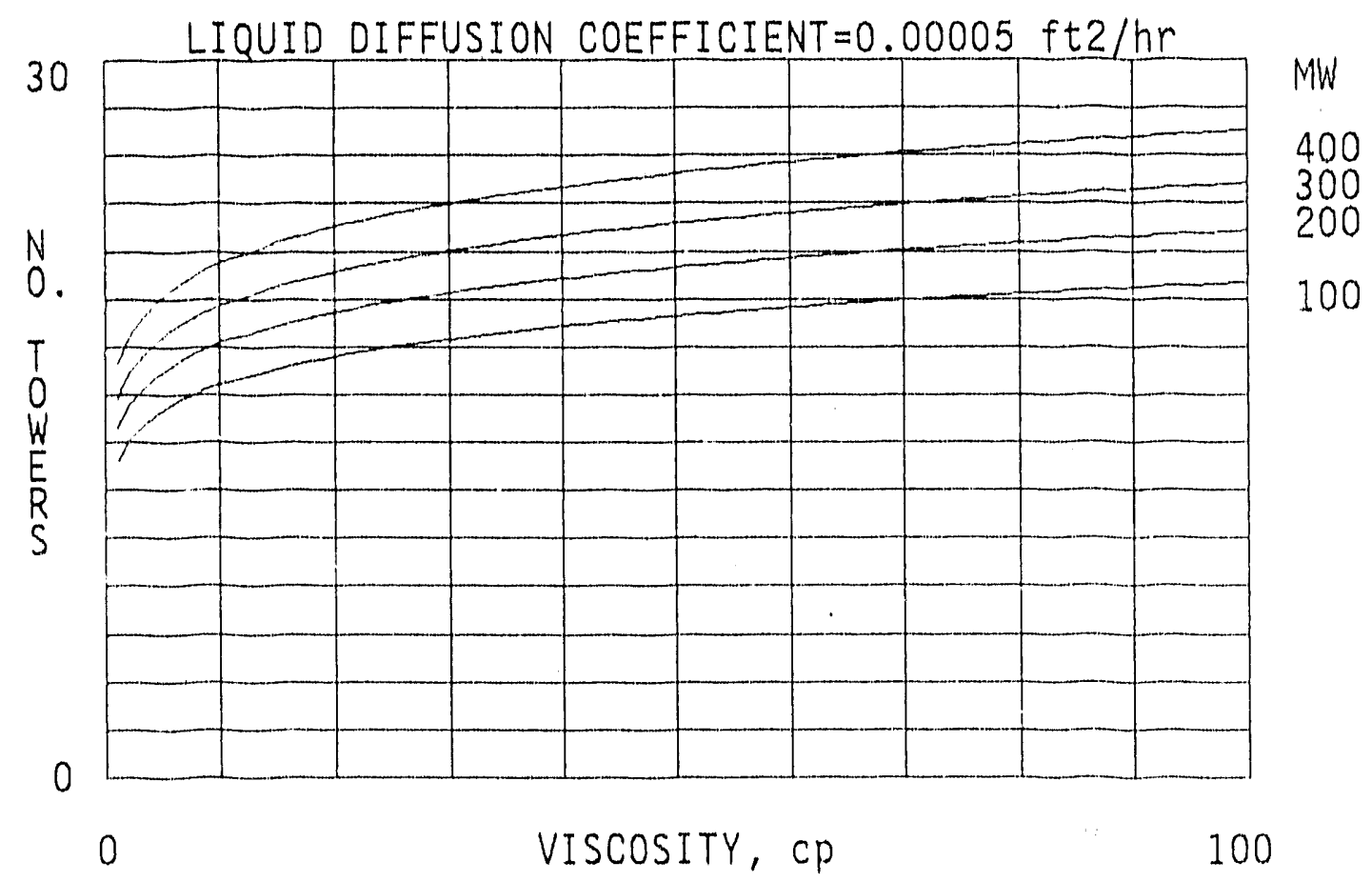

FIGURE 3.16b Number of Absorption Towers vs. Liquid Viscosity and Molecular Weight 


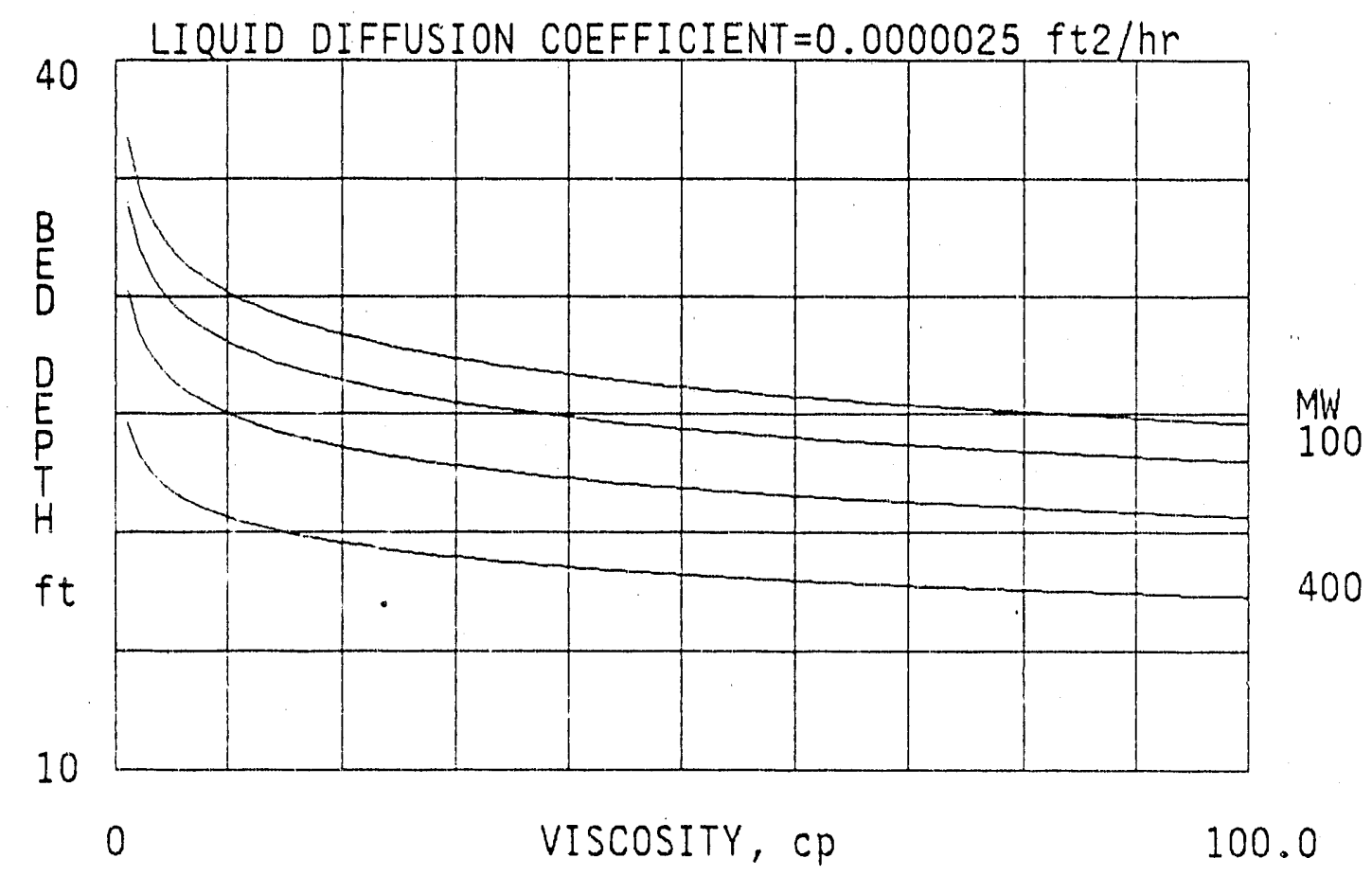

FIGURE 3.17a Absorption Bed Depth vs. Liquid Viscosity and Molecular Weight

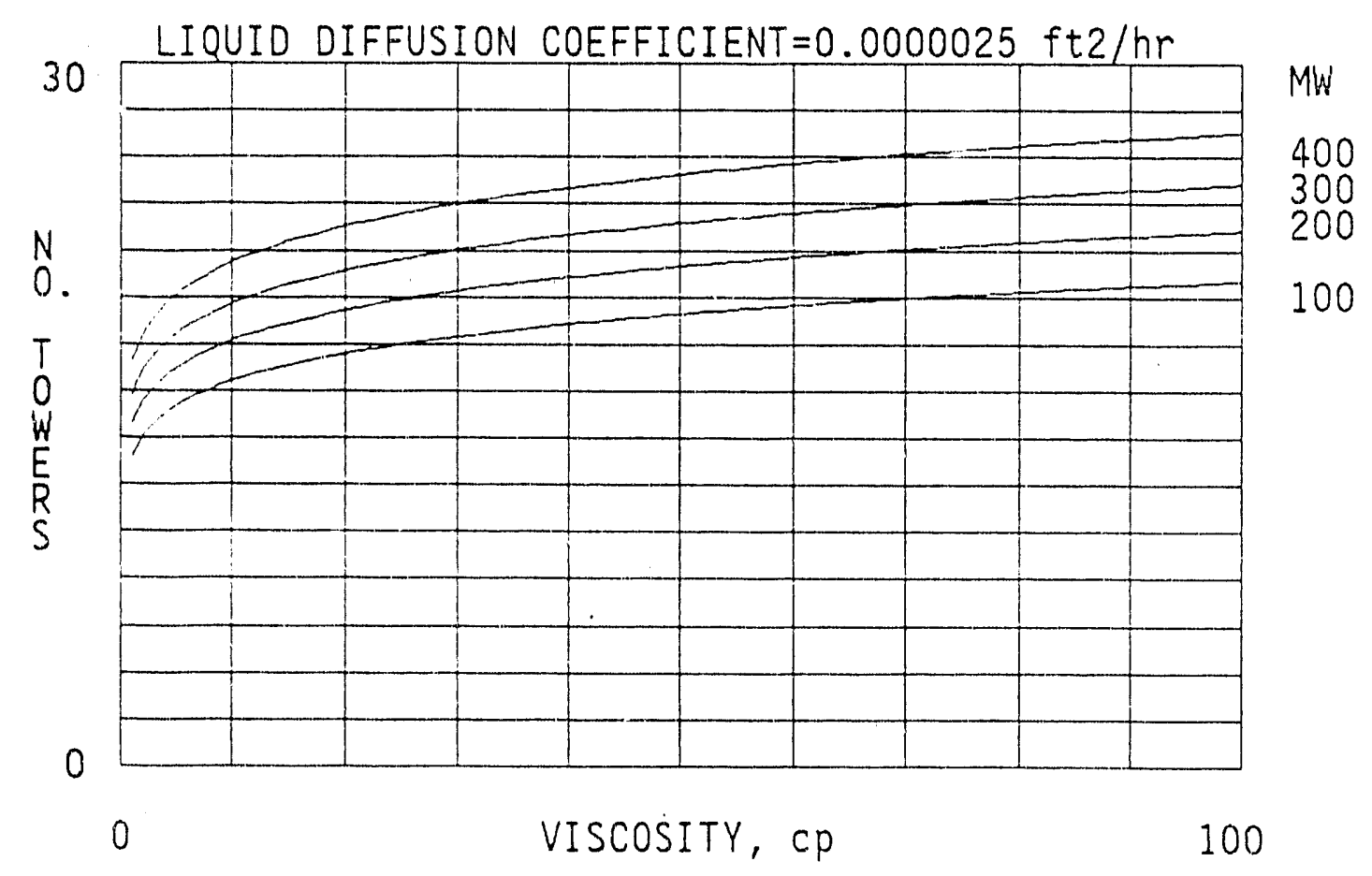

FIGURE 3.17b Number of Absorption Towers vs. Liquid Viscosity and Molecular Weight 


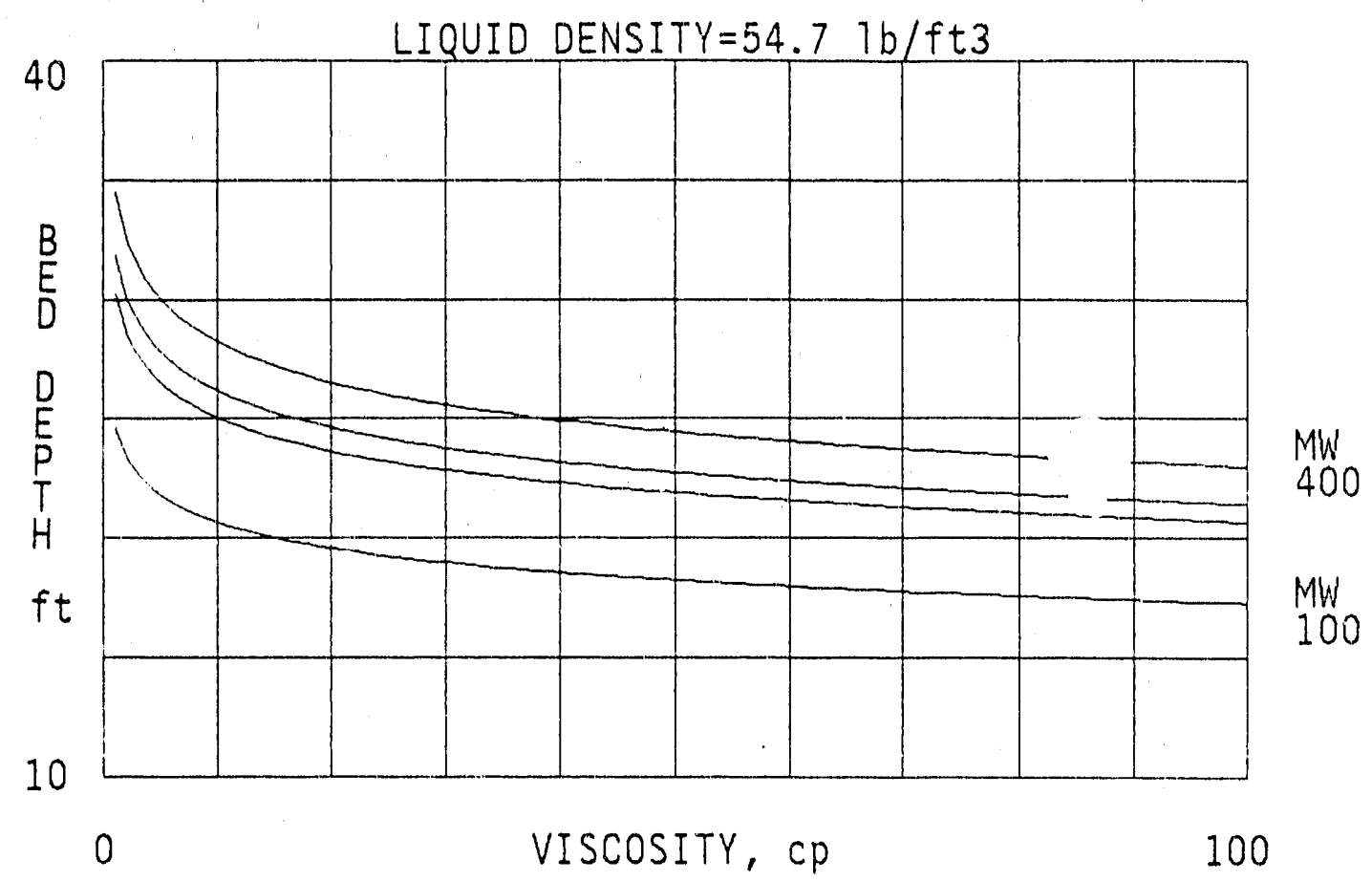

FIGURE 3.18a Absorption Bed Depth vs. Liquid Viscosity and Molecular Weight

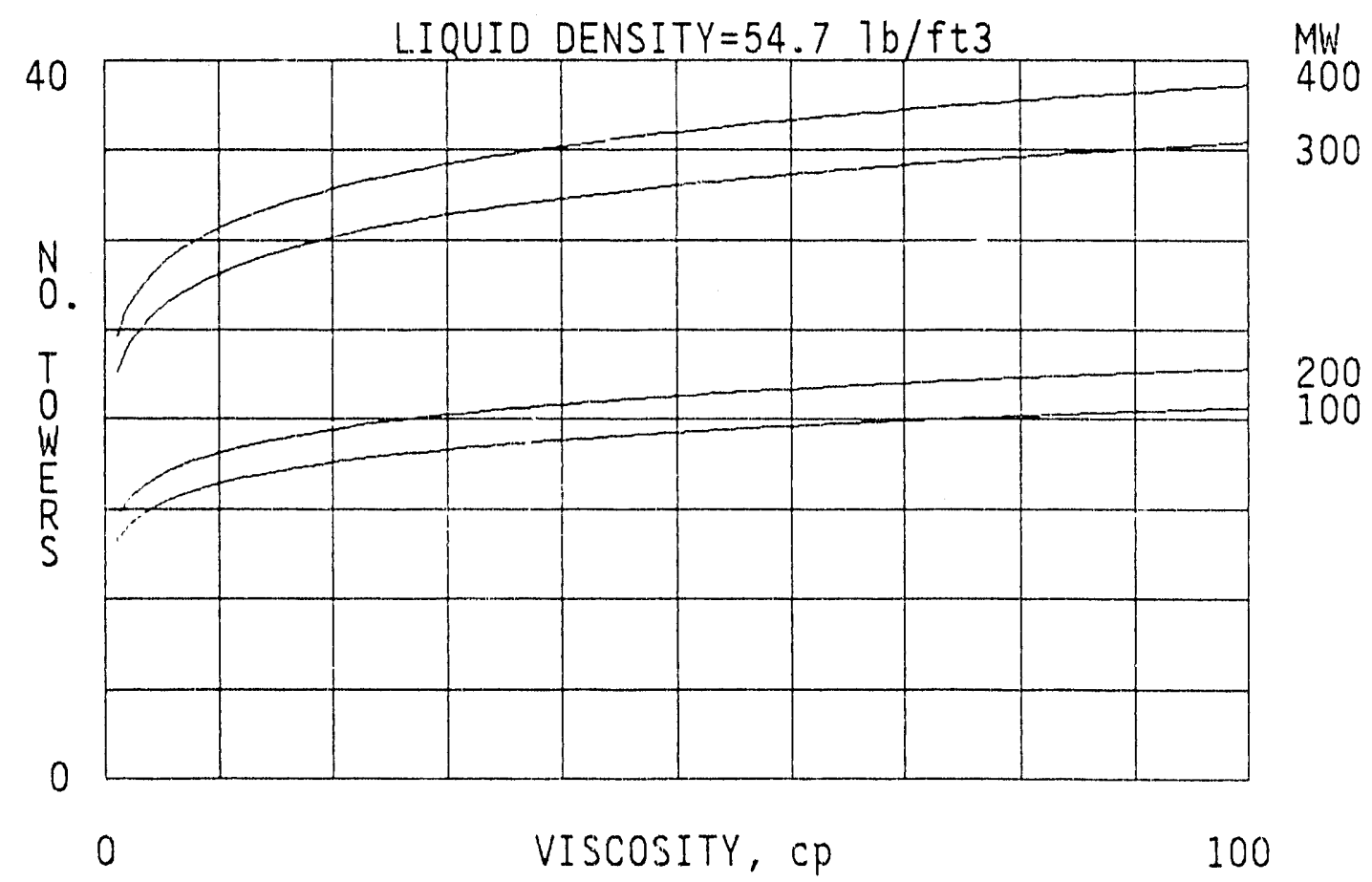

FIGURE 3.18b Number of Absorption Towers vs. Liquid Viscosity and Molecular Weight 


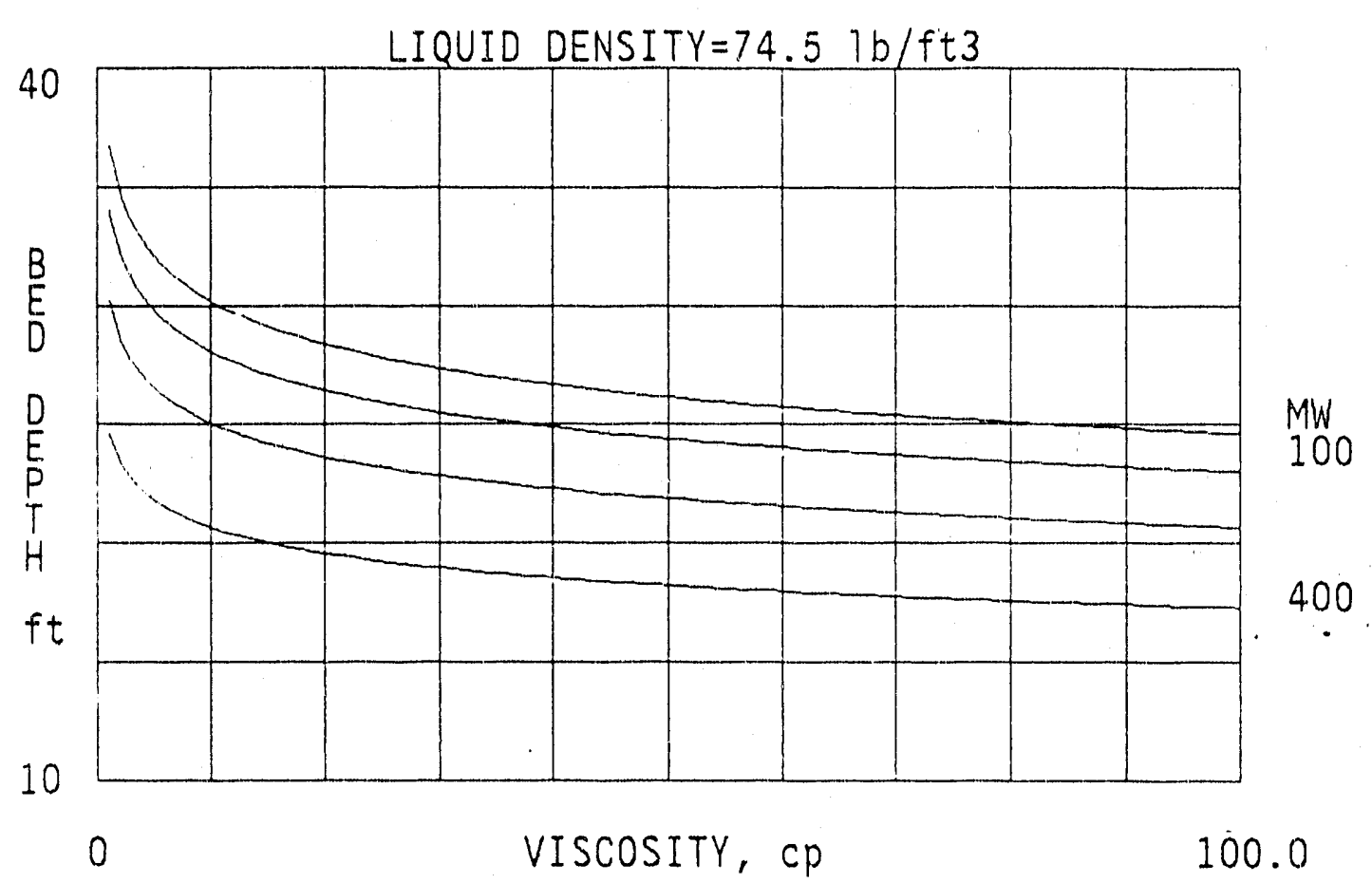

FIGURE 3.19a Absorption Bed Depth vs. Liquid Viscosity and Molecular Weight

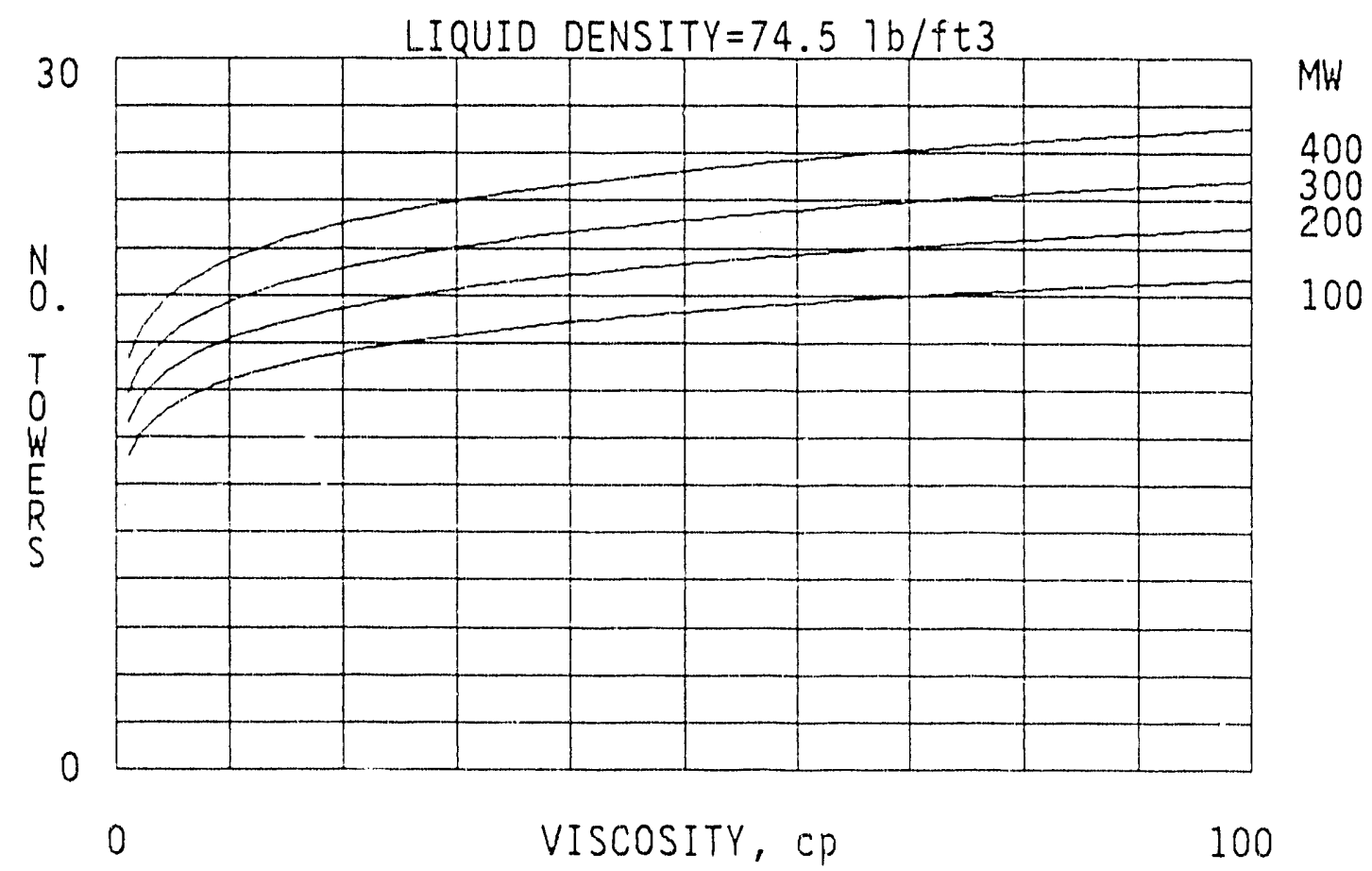

FIGURE 3.19b Numbe of Absorption Towers vs. Liquid Viscosity and Molecular Weight 


\subsection{SYSTEM REQUIREMENTS FOR GAS ABSORPTION}

\subsubsection{Liquid Pumping}

Because $\mathrm{CS}_{2}$ loading is very low for any absorption liquid in contact with $100 \mathrm{ppm}$ $\mathrm{CS}_{2}$ in air, a large flow of liquid would be required. Calculations outlined in Appendix A show that about 7,000 gallons per minute (gpm) of total absorbent flow would be required at about a 30 -ft head. Pumping tables ${ }^{43}$ show that this flow would utilize about seven 1,000 -gpm centrifugal pumps. The cost of the pumps would be roughly $\$ 30,000$.

\subsubsection{Desorption Heating Requirements}

To recover the small concentration of $\mathrm{CS}_{2}$ in the absorption liquid, all the liquid must be heated to at least $300^{\circ} \mathrm{F}\left(150^{\circ} \mathrm{C}\right)$. The flow rate of liquid, as shown in Appendix A, will be about $40,000 \mathrm{~mole} / \mathrm{hr}$. For paraffin-based oils, specific heat is approximated with the formula: ${ }^{43}$

$$
C_{p}=0.425 / d^{1 / 2}+0.0009(t-15)
$$

where $\mathrm{C}_{\mathrm{p}}$ is in cal $/ \mathrm{g} \cdot{ }^{\circ} \mathrm{C}$ ( or Btu/b $\cdot{ }^{\circ} \mathrm{F}$ ), $\mathrm{d}$ is density $\left(\mathrm{g} / \mathrm{cm}^{3}\right.$ ), and $\mathrm{t}$ is temperature $\left({ }^{\circ} \mathrm{C}\right.$ ). The total heating requirement for desorption, therefore, can be estimated as a function of heating temperature for absorbing liquids of various densities and molecular weights. For example, to heat $4 \times 10^{4} \mathrm{~mole} / \mathrm{hr}$ Kaydol $(\mathrm{d}=54.7 / 62.4=0.877$, molecular weight $=424)$ from $77^{\circ} \mathrm{F}$ to $300^{\circ} \mathrm{F}$ requires $2 \times 10^{9} \mathrm{Btu} / \mathrm{hr}$. Steam tables show that the heat of vaporization of saturated water at $300^{\circ} \mathrm{F}$ and $69 \mathrm{psi}$ is $907.4 \mathrm{Btu} / \mathrm{lb}$. Heating the Kaydol thus would require about $2.2 \times 10^{6} \mathrm{lb} / \mathrm{hr}$ of saturated steam at $300^{\circ} \mathrm{F}$ and $69 \mathrm{psi}$.

Figure 25-3 in Perry's harıdbook ${ }^{43}$ indicates that the installed cost in 1969 of a steam generation package providing $3 \times 10^{5} \mathrm{lb} / \mathrm{hr}$ of low-pressure steam is $\$ 1.2$ million. Assuming $6 \%$ yearly inflation from 1969 to 1992, the installed cost of a dedicated steam plant for the Teepak absorption system would be about $\$ 1.2 \times 10^{6}(1.06)^{23}\left(2.2 \times 10^{6}\right) /\left(3 \times 10^{5}\right)=\$ 33$ million. This very large cost is the result of the low $\mathrm{CS}_{2}$ concentration in the Teepak air emissions.

\subsubsection{Desorption Processing}

As mentioned in the previous section, desorption requires vacuum heating to reduce the ability of the liquid to hold $\mathrm{CS}_{2}$. To approximate the vapor-liquid equilibrium $\mathrm{CS}_{2}$ concentration under the evacuated and heated conditions, we assume Raoult's law applies:

$$
\mathrm{Py}=\mathrm{p}^{\circ} \mathrm{x}
$$


where $\mathrm{P}$ is total pressure, $\mathrm{y}$ is the mole fraction of $\mathrm{CS}_{2}$ in the vapor, $\mathrm{p}^{0}$ is vapor pressure of pure $\mathrm{CS}_{2}$ at the system temperature, and $\mathrm{x}$ is the mole fraction of $\mathrm{CS}_{2}$ in the liquid.

To use Equation 13, $\mathrm{CS}_{2}$ vapor pressure data are required. Perry's handbook ${ }^{43}$ provides such data for $0^{\circ} \mathrm{F}$ to $120^{\circ} \mathrm{F}$. Because higher temperatures are required, the data plotted in Figure 3.20 have been extrapolated. Thus, on the basis of classical thermodynamics, vapor pressure will have an exponential relationship to temperature (i.e.; the Clausius-Clapyron equation applies):

$$
\ln \mathrm{p}^{\circ}=-\Delta \mathrm{H} / \mathrm{R}(1 / \mathrm{TR})+\mathrm{C}
$$

From the figure, $\Delta \mathrm{H} / \mathrm{R}=5966.5$ and $\mathrm{C}=13.066$. Eqquation 14 can now be used to obtain the pure $\mathrm{CS}_{2}$ vapor pressure, given any value of $\mathrm{TR}$.

If desorption is assumed to occur at subatmospheric pressure in a heated vessel, Equations 1.3 and 14 (along with the original $\mathrm{CS}_{2}$ loading of the desorption liquid, $\mathrm{x}_{\mathrm{j}}$ ) can be used to estimate the percent recovery. For this calculation, it is assumed that thermodynamic equilibrium is attained in the desorption vessel. Let $F_{c}^{i}$ equal moles of $\mathrm{CS}_{2}$ per second carried with the inlet solution into the vacuum stripper and $\mathrm{F}_{\mathrm{S}}=$ moles of solvent carried in per second. The inlet mole fraction of $\mathrm{CS}_{2}$ is thus:

$$
\mathbf{x}_{\mathrm{i}}=\mathrm{F}_{\mathrm{c}}^{\mathrm{i}} /\left(\mathrm{F}_{\mathrm{c}}^{i}+\mathrm{F}_{\mathrm{S}}\right)
$$

This equation can be rearranged to give the molar rate of $\mathrm{CS}_{2}$ into the stripper:

$$
\mathrm{F}_{\mathrm{c}}^{\mathrm{i}}=\left(\mathrm{F}_{\mathrm{s}} \mathrm{x}_{\mathrm{i}}\right) /\left(1-\mathrm{x}_{\mathrm{i}}\right)
$$

Let $\quad \mathrm{F}_{\mathrm{c}}^{0}=$ moles $\mathrm{CS}_{2}$ per second out of the vacuurn stripper as carried with the solvent:

$$
\mathrm{F}_{\mathrm{c}}^{\mathrm{n}}=\left(\mathrm{F}_{\mathrm{s}} \mathrm{x}_{0}\right) /\left(1-\mathrm{x}_{0}\right)
$$




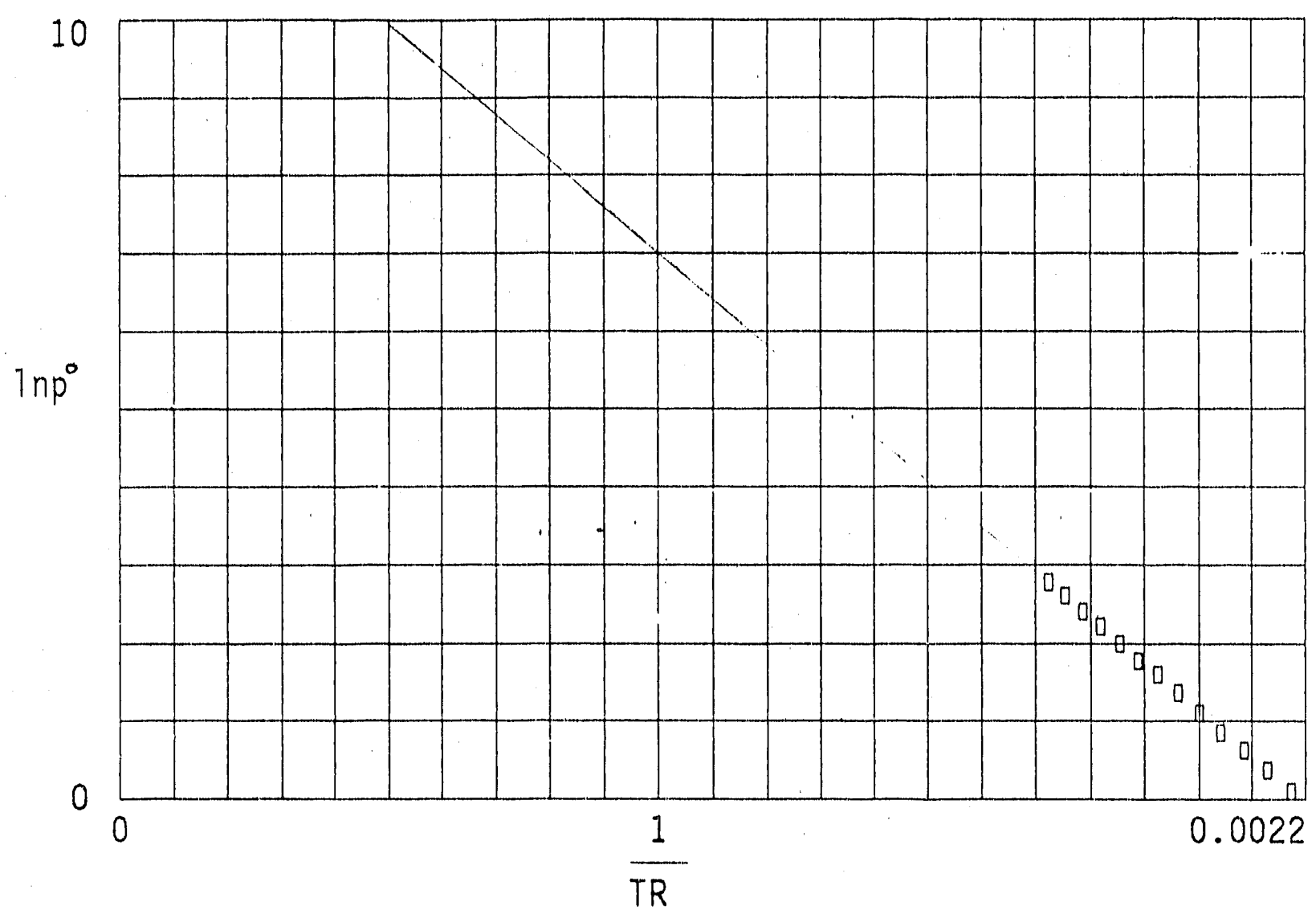

FIGURE 3.20 Clausius-Clapyron Extrapolation of $\mathrm{CS}_{2}$ Vapor Pressure Data ( $p=\mathrm{CS}_{2}$ vapor pressure in psi; $T R=$ system temperature in degrees $R$ )

where $\mathrm{x}_{0}$ is the mole fraction of $\mathrm{CS}_{2}$ in the solution leaving the stripper. Let $\mathrm{Q}$ be the percentage of $\mathrm{CS}_{2}$ recovered by vacuum stripping of the inlet solution:

$$
\mathrm{Q}=100\left(\mathrm{~F}_{\mathrm{c}}^{\mathrm{i}}-\mathrm{F}_{\mathrm{c}}^{0}\right) / \mathrm{F}_{\mathrm{c}}^{\mathrm{i}}
$$

Substituting Equations 16 and 17 into Equation 18 and rearranging the order, we obtain an expression for $\mathrm{Q}$ in terms of inlet and outlet $\mathrm{CS}_{2}$ mole fractions:

$$
\mathrm{Q}=100\left\lfloor 1-\left(\mathbf{x}_{0}\left(1-\mathbf{x}_{\mathrm{i}}\right)\right) /\left(\mathrm{x}_{\mathrm{j}}\left(1-\mathbf{x}_{0}\right)\right)\right\rfloor
$$

Let us assume Raoult's law applies to the solution leaving the vacuum stripper. From Equation 13, we have 


$$
\mathrm{x}_{0}=\mathrm{y}_{0} \mathrm{P} / \mathrm{p}^{\circ}
$$

We further assume that at the temperature and pressure of the vacuum stripper, the solvent has negligible vapor pressure compared with dissolved $\mathrm{CS}_{2}$. Therefore, $y_{0}=1$ and Equation 20 becornes:

$$
\mathbf{x}_{0}=P / p_{0}
$$

Outlet mole fraction $\left(\mathrm{x}_{0}\right)$, can be written in terms of $\mathrm{T}$ (temperature in ${ }^{\circ} \mathrm{F}$ ) and $\mathrm{P}$ (pressure in psi of the vacuum stripper) by combining Equations 21 and 14.

$$
\mathbf{x}_{0}=\mathrm{P} / 472597.8 \exp (-5966.5 /(\mathrm{T}+460))
$$

Combining Equations 22 and 19 allows the percentage recovered $(\mathrm{Q})$ to be calculated in terms of inlet mole fraction $\left(x_{1}\right)$, temperature of the desorber $(T)$, and desorption absolute pressure (P). Figures 3.21a through 3.21e were prepared by using Equation 19 to show the requirements for vacuum stripping recovery, assuming the solution is ideal in the sense of Raoult's law. As seen in previous sections, solvents with good ability to hold $\mathrm{CS}_{2}$ would be near-ideal. Solvents that could load up higher in $\mathrm{CS}_{2}$ than near-ideal solutions would not be ideal, but they would be very difficult to desorb. Thus, the ideal assumption is reasonable for estimates of desorbability of $\mathrm{CS}_{2}$.

For perspective, we first recall from Appendix A that the maximum loading of absorption liquid with a Henry's law constant of 0.48 is $x_{j}=1.39 \times 10^{-4}$. Also, the measured maximum loading of Kaydol was $x_{i}=4.028 \times 10^{-4}$, as shown in Figure 3.11b.

We first assume $x_{j}=1 \times 10^{-4}$ and ask what vacuum stripper temperatures and pressures are required to obtain at least $80 \%$ recovery of $\mathrm{CS}_{2}$. From Figure 3.21 a, it is clear that recovery of $\mathrm{CS}_{2}$ from a solution for which $\mathrm{x}_{1}=1 \times 10^{-4}$ is not feasible. Recovery of $80 \%$ at $300^{\circ} \mathrm{F}$ would require a pressure of about 0.01 psia, an expensive process vacuum to maintain. To desorb at $0.5 \mathrm{psi}$ would require a temperature of $1,600^{\circ} \mathrm{F}$. Again, this level is clearly infeasible, because most solvents would be destroyed at such a temperature.

Figure $3.21 \mathrm{~b}$ shows that, if $\mathrm{x}_{1}=5 \times 10^{-4}, 500^{\circ} \mathrm{F}$ and 0.1 psia are required for $80 \%$ recovery. Temperatures above $900^{\circ} \mathrm{F}$ are needed if a 0.5 -psia vacuum is used. This requirement clearly would be very expensive.

Figure $3.21 \mathrm{c}$ shows that, at $\mathrm{x}_{\mathrm{j}}=50 \times 10^{-4}$, a potentially feasible temperature of $300^{\circ} \mathrm{F}$ would require a 0.2 -psia vacuum. A 1.0 -psia vacuum still would require $500^{\circ} \mathrm{F}$, a temperature close to the threshold of decomposition for many organic solvents. 


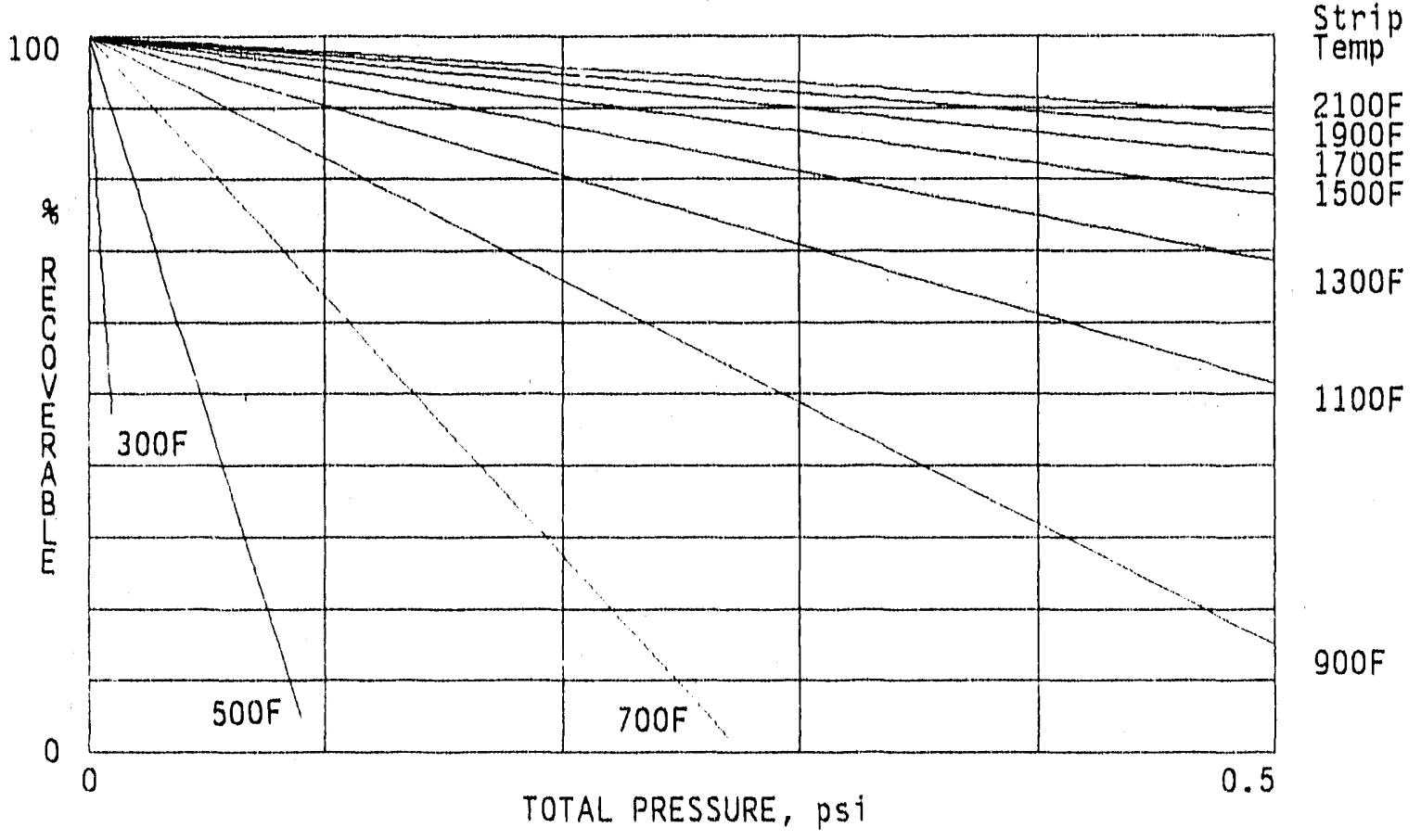

FIGURE 3.21a Variation of Percentage of $\mathrm{CS}_{2}$ Recovered with Temperature and Pressure of Vacuum Stripper (mole fraction of $\mathrm{CS}_{2}$ in liquid $=0.0001$ )

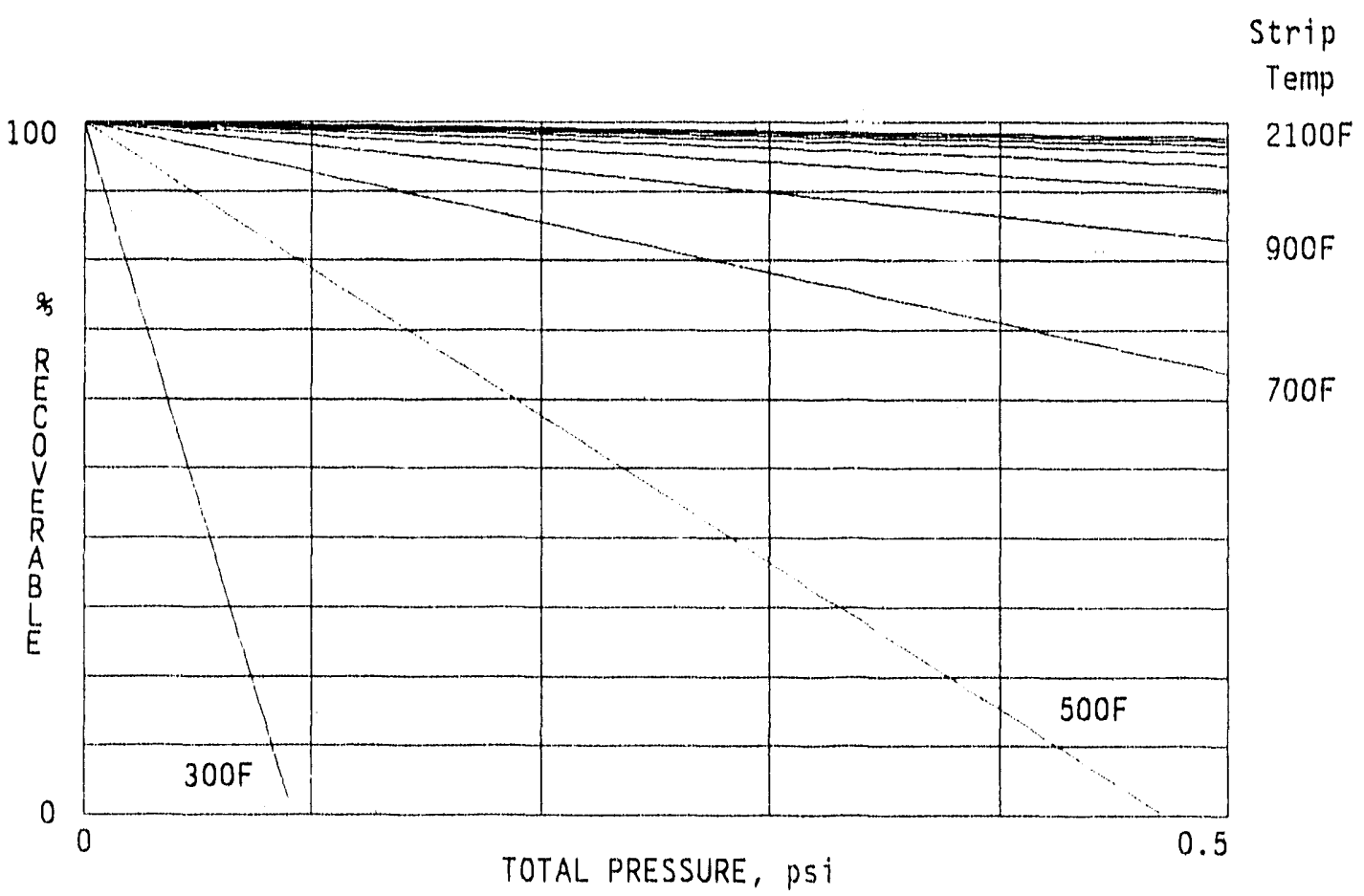

FIGURE 3.21b Variation of Percentage of $\mathrm{CS}_{2}$ Recovered with 'Temperature and Pressure of Vacuum Stripper (mole fraction of $\mathrm{CS}_{2}$ in liquid $=0.0005$ ) 


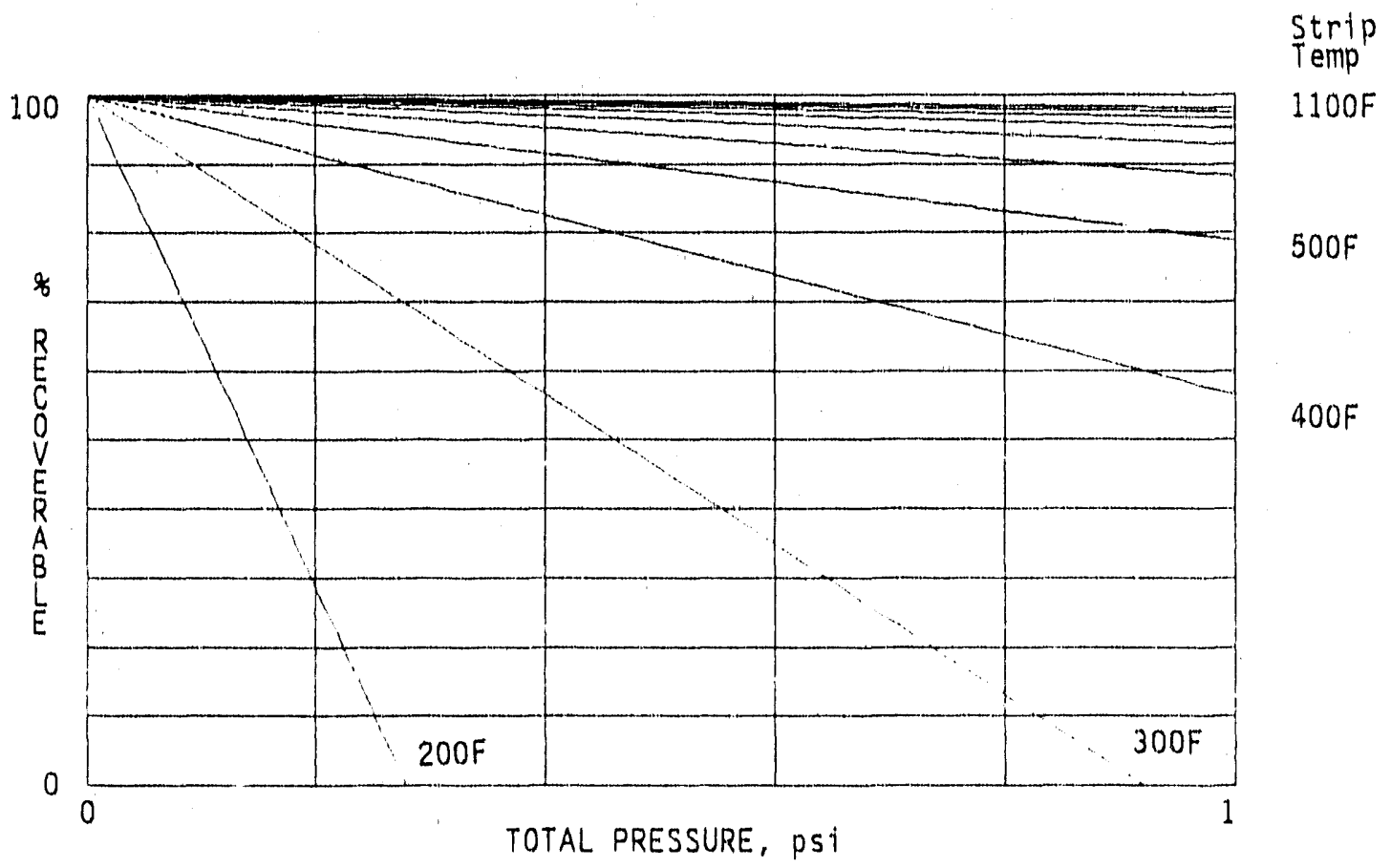

FIGURE 3.21c Variation of Percentage of $\mathrm{CS}_{2}$ Recovered with Temperature and Pressure of Vacuum Stripper (mole fraction of $\mathrm{CS}_{2}$ in liquid $=0.005$ )

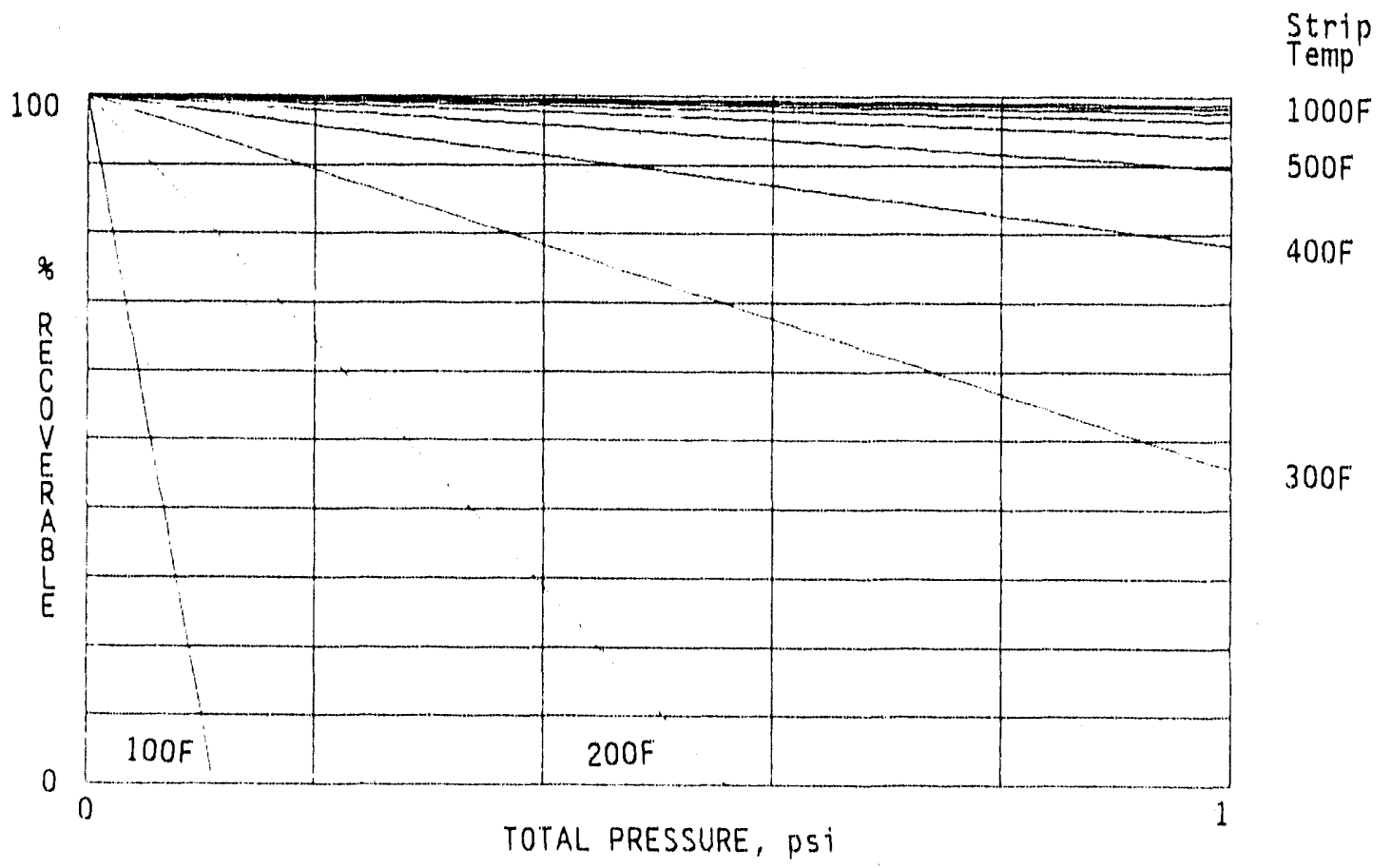

FIGURE 3.21d Variation of Percentage of $\mathrm{CS}_{2}$ Recovered with Temperature and Pressure of Vacuum Stripper (mole fraction of $\mathrm{CS}_{2}$ in liquid $=0.01$ ) 


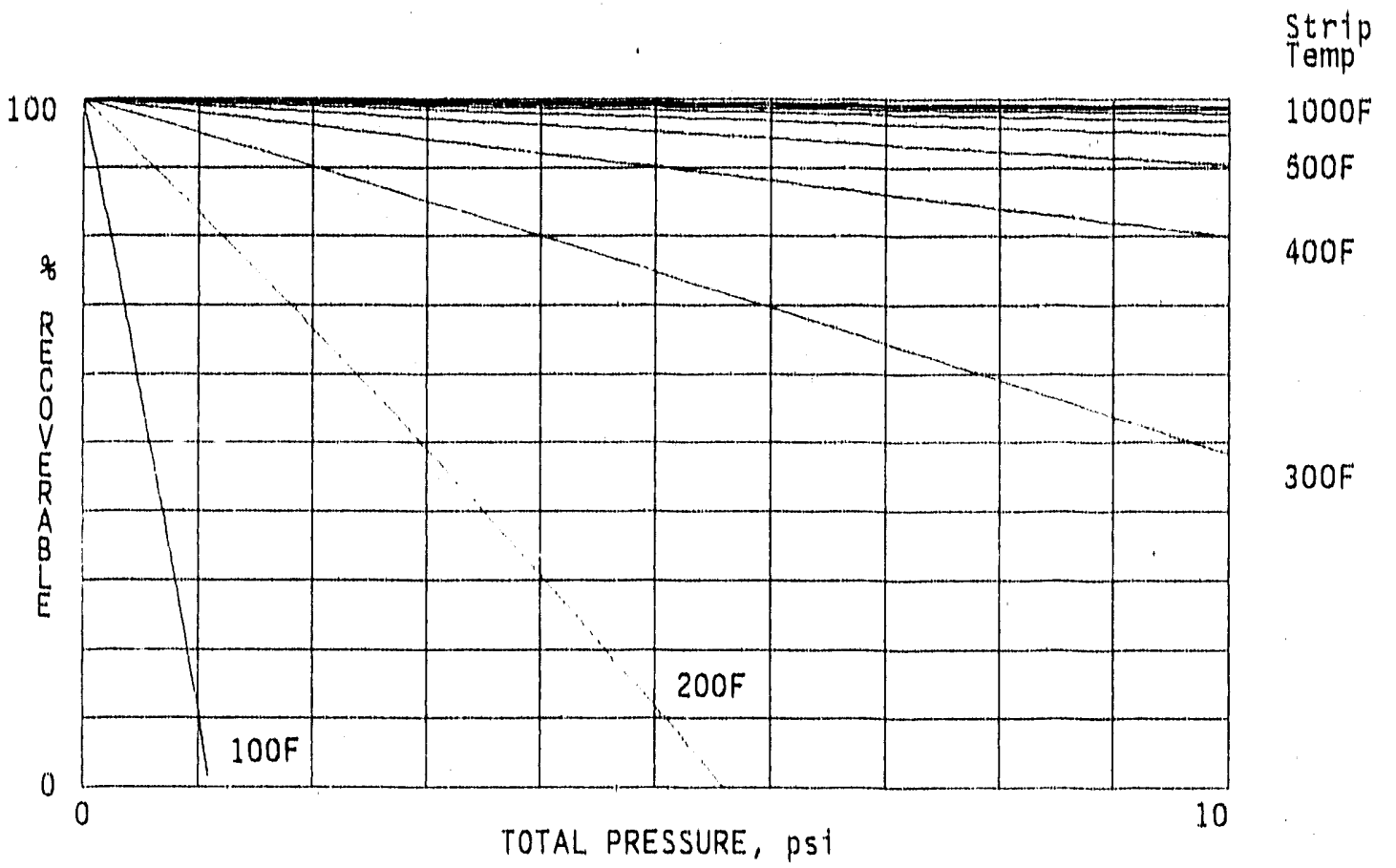

FIGURE 3.21e Variation of Percentage of $\mathrm{CS}_{2}$ Recovered with Temperature and Pressure of Vacuum Stripper (mole fraction of $\mathrm{CS}_{2}$ in liquid $=0.1$ )

Figure 3.21d shows that, at $\mathrm{x}_{1}=0.01$, a $300^{\circ} \mathrm{F}$ recovery is possible at 0.4 psia. Figure $3.21 \mathrm{e}$ shows that, if the liquid could be concentrated to 0.1 mole fraction of $\mathrm{CS}_{2}$, vacuum stripping would work well, resulting in $80 \%$ recovery either at 10 psia and $400^{\circ} \mathrm{F}$ or at 4 psia and $300^{\circ} \mathrm{F}$.

On the basis of the results given above and in Sections 3.8 .2 and 3.8.3, we must conclude that, although gas absorption could be used to remove $\mathrm{CS}_{2}$ from the Teepak emissions at a high but possible plant cost, the recovery of $\mathrm{CS}_{2}$ from the necessarily large absorption liquid flow is economically infeasible. Furthermore, because the absorption liquid could not be regenerated, the possibility of using gas absorption as a removal method only would be precluded. 


\section{GAS ADSORPTION}

\subsection{PRELIMINARY AINALYSES}

\subsubsection{Adsorbents}

An extensive literature study was conducted to identify the adsorbents best for CS, recovery. The following items are the main conclusions from that effort:

- $\mathrm{CS}_{2}$ has the following properties: no permanent polarity, no hydrogen bonding, and very high polarizability. Because these characteristics are roughly those of aliphatic hydrocarbons and also are close to those of benzene and certain other special aromatics, it was supposed that polymeric adsorbents that were styrene-based and had aliphatic linkages would be good candidates.

- Activated carbons can be manufactured in a nonoxidizing environment, thus nearly eliminating oxygen functionalities on the internal surface. Such materials are termed "H.carbons." The internal surfaces of oxygen-free carbon resemble graphite. Because graphite has no polarity and is highly polarizable, it was believed that H-carbons should be studied extensively. A variety of different H-carbons are available commercially, and it was decided that a range of these could offer good possibilities.

- It is well known that $\mathrm{CS}_{2}$ can react with amine groups to form a weakly bonded chemical compound. Furthermore, this reaction can be reversed with mild heating. It was suggested that, if preparation of the internal surface of an adsorbent to carry amine groups was possible, this surface would make $\mathrm{CS}_{2}$ adsorption possible. On the basis of the literature (mostly electrochemical studies), it was found that amine functionalities can be bonded to surfaces containing hydroxyl groups. Because both silica gel and alumina contain hydroxyl groups on their internal surfaces, it was decided to learn the techniques of preparing aminefunctionalized silica gel and alumina adsorbents.

- Zeolites are well-known adsorbents for many separation problems. However, zeolites generally adsorb water more strongly than most other substances. Therefore, if water is present in the mixture to be separated, it will adsorb strongly and poison the surface for other adsorbents. This effect is especially relevant for $\mathrm{CS}_{2}$, which has physical adsorption characteristics very different from those of water. Unfortunately, the Teepak emissions that carry $\mathrm{CS}_{2}$ are usually 
saturated with water vapor. Therefore, common zeolites are not beliuved to be good candidates for an adsurption process at Teepal.

In recent years, howover, several hydrophobic adsorbents have been developed, mostly by Union Carbide Corporation at its research facility near Tarrytown, New York. One of these, called Silicalite, is made of silica and has a zeolite structure but does not contain the metals that tend to make common zeolites hydrophilic. Another hydrophobic zeolite material now boing tested at Tarrytown is called Purasiv. It may be that these materials, because of their alleged hydrophobic characteristics, could load well with $\mathrm{CS}_{2}$ in the presence of water.

- Activated alumina, common zeolite, and silica gel are used extensively as adsorbents in process industries for many types of separations. In spite of the hydrophilic nature of these materials, it was believed they should be tested for $\mathrm{CS}_{2}$ adsorption.

- A large number of prepared adsorbents are used in laboratory and industrial processes such as chromatographic separations and ion exchange. Although these adsorbents are only available in small quantities and are very expensive, it was decided that several of these should be tested for $\mathrm{CS}_{2}$ adsorption.

\subsubsection{Adsorbent Test Rig Design}

A gas adsorption dynamic test rig with the following features was designed:

- Variable flow rate of adsorbent gases;

- Precise control of flow by using accurately calibrated gas rotometers;

- Ability to adjust mixing to allow any concentration of mlxed gases to be sent to the adsorption column;

- Variable length of adsorption column to adjust for materials of widely varying mass transfer zones;

- Ability to detect effluent from the adsorption column at concentrations as low as $1 \mathrm{ppm} \mathrm{CS}_{2}$ (molar basis) by using a flame photometric detector that is part of the Shimadzu gas chromatograph purchased for the project;

- Continuous, automatic, and unattended sampling with automatic readout and programmable time-delay between samplings; 
- Accurate temperature control of the column at settings between $0^{\circ} \mathrm{C}$ and $170^{\circ} \mathrm{C}$; and

- Desorption testing of variable desorption gases, adjustable temperature, and a large range of flow dilution (to allow the flame photometric method to detect high absorbate concentration).

\subsubsection{Modeling}

The literature was searched extensively for available models that would allow the ariticipated experimental data to be correlated and would estimate the practicality of a given adsorbent for the Teepak situation. A.large amount of arcane information was found. Generally, adsorption modeling methods are based on noristeady solution of partial differential equations, and the results are not easy to use in a practical way. We wanted to find a simple method that could be used to estimate the length of the mass transfer zone in adsorption (early tests at 'Teepak indicated large mass transfer zones for many adsorbents). In particular, the effect of particle size is important, as both mass transfer zone length and pressure drop requirements depend, at least in part, on particle size.

As a result of this search, we developed a set of computer programs that will produce a preliminary process design (number of towers, tower height, tower diameter, pressure drop requirements, etc.) given the characteristics of the adsorption isotherm for an adsorbent. These programs are based on the work of Basmadjian. ${ }^{49}$ Details are given in Appendix B.

\subsection{I.ABORATORY ADSORPTION TEST RIG}

\subsubsection{Procurement}

In general, construction of the test rig followed prior planning, but some delays affected the schedule.

It was originally planned to purchase a Hewlett-Packard Gas Chromatograph with a custom flame photornetric detector, an automatic sampling valve, and a programmable controller. However, the low bid was for a comparable model from Schimadzu Scientific Instruments, Inc. Because we were unfamiliar with this equipment, it was necessary to study the system before it was used. From this study it was determined that an automatic sampling valve was necessary. 'The valve was developed with the help of Schimadzu technicians. The Shimadzu equipment performed adequately.

It was originally planned to use an automatic machine to obtain adsorption isotherms for each of the adsorbents. Accordingly, Porous Materials, Inc. (Ithaca, New York), was asked if it could supply a BET machine that could be used with $\mathrm{CS}_{2}$ at very low pressures. (The concentration of $\mathrm{CS}_{2}$ in the Teepak air is only $100 \mathrm{ppm}$, the mole fraction is only $10^{-4}$, and the partial pressure is less than 0.00015 psi.) Porous Materials assured us 
that it could provide an adequate machine, won the bid, and promised delivery before March 31, 1991. When the BE'T machine still hadn't been delivered by May 15, the latest date it could be of use to the project, the purchase contract with Porous Materials, Inc., was canceled. Fortunately, the dynamic test rig, coupled with the Basmadjian model, was adequate for adsorpition evaluations.

\subsubsection{Fabrication}

Construction of the adsorption test rig began in April 1991. An angle-iron frame was built to hold the five flow controllers and tubing. A constant-temperature oil bath was purchased and tested for temperature controllability. It was found to be adequate at $\pm 0,5^{\circ} \mathrm{C}$ control for both adsorption temperature $\left(25^{\circ} \mathrm{C}\right)$ and desorption temperature (about $150^{\circ} \mathrm{C}$ ), Delivery of the Schimadzu gas chromatograph with flame photometric detection was somewhat delayed; when it arrived, it was necessary to construct an electronic timing and trigger device that would automatically activate the air-driven sampling switch and allow adjustment by the programmable gas chromatograph controller.

Figure 4.1 shows the layout of the test rig. The first rotometer controls the flow of dilution air, which mixes with the flow of $\mathrm{CS}_{2} /$ air from the 1,000-ppm CSS 2 air tank. The relative settings of these flow meters can produce an adsorption column feed stream with any $\mathrm{CS}_{2}$ concentration between $0 \mathrm{ppm}$ and $1,000 \mathrm{ppm}$.

This mixing feature is especially important because it allows the adsorbent to be equilibrated with any concentration of $\mathrm{CS}_{2}$, effectively producing an isotherm point for the given material in the adsorption column. Because the flame photometric detector can detect and record very low $\mathrm{CS}_{2}$ concentrations, it is possible to determine sorbent loading without weighing the column - simply by integrating the difference between inflow and outflow of CS $_{2}$ continuously.

The other rotometers control the flow of nitrogen to the column and to the flame photometric detector. Since $\mathrm{CS}_{2}$ is highly ignitable (autoignition temperature of about $100^{\circ} \mathrm{C}$ ) and carbon is very combustible, the column cannot be desorbed safely with air. Nitrogen must be used, and the consequent features are incorporated into the rig design. One rotometer is used in desorption. Nitrogen dilution of the flow to the flame photometric detector is also necessary. During desorption tests, depending on the loading and retention characteristics of the column materials, larger $\mathrm{CS}_{2}$ concentrations must be measured. Concentrations of several thousand ppm $\mathrm{CS}_{2}$ can take up all the available detection band, and the reading will "peg out" at the high end. With the nitrogen dilution feature, the $\mathrm{CS}_{2}$ concentration can be diluted until accurate continuous measurement is possible.

The oil bath temperature controller has two important functions. First, it provides

oil with an accurately and precisely controlled temperature for external use. In this case, the hath's built-in pump is used to send the oil to an outer jacket around the adsorption column. 


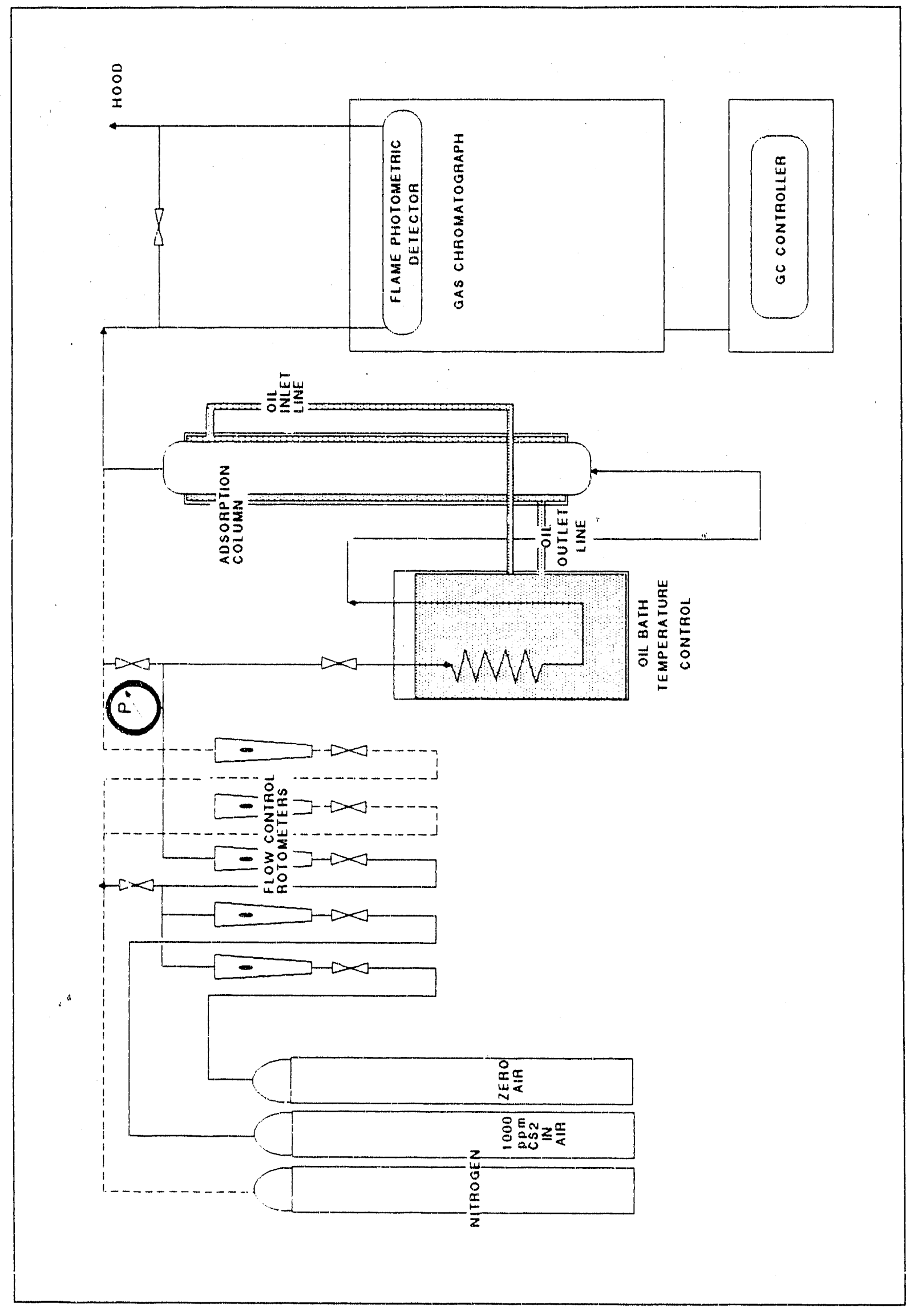

 
With a large column/jacket heat transfer area, the bath oil can control adsorption column temperature accurately. This control is especially important in desorption tests, which may require a temperature near $300^{\circ} \mathrm{F}$.

The second function is to provide temperature conditioning of the inlet air. In addition to the jacketing effect, the inlet gas to the column must be controlled or it is possible a cooler lower section of the adsorption column could tend to exaggerate the $\mathrm{CS}_{2}$ retention of a portion of the column and possibly skew the data. To prevent this, the inlet gas is passed through coils submerged in the bath fluid, as shown in Figure 4.1, and the preconditioned gas is sent directly into the column bottom.

The adsorption column is made of glass and is fitted with gas input and output sections of porous ceramic that allow an even distribution of flow into and out of the column with minimal possibility of channeling. The column length is variable; the maximum height is about $20 \mathrm{~cm}$. The dianieter is fixed. As mentioned above, the column is jacketed to allow accurate temperature contivi. The jacket also is made of ylass and allows a cylindrical column of heat transfer fluic! (in this case, oil) to flow upward. This fluid completely surrounds the adsorption column and is separated only by the glass wall of the column. Temperature equilibrium is attained quickly and is maintained as long as the temperaturecontrolled fluid continues to flow.

\subsubsection{Testing}

Testing of the adsorption rig components followed construction. The most critical feature of the system was the flame photometric detector. During the shake-down tests, it was found that, as mentioned previously, the detector zould be overwhelmed at high $\mathrm{CS}_{2}$ concentrations and that, as a result, the desorption tests would be partly ineffective, especially during early desorption. This finding required a slight redesign and refabrication of the test rig to incorporate the nitrogen dilution system shown in Figure 4.1.

Calibration of the flame photometric response was a large part of the shake-down testing program. A very accurately prepared mixture of air and $\mathrm{CS}_{2}$ was purchased and, by using known dilution factors and rotometers 1 and 2 , a calibration curve for $\mathrm{CS}_{2}$ over all possible ievels was prepared. This step was considered especially important because the accuracy of any equilibrium measurement (as when the rig is used to estimate adsorption isotherms) depends on the cumulative accuracy of outlet gas detection.

Tests on actual adsorbents in the column demonstrated the importance of minimizing flow resistance. Some of the tubing used in the system was one-sixteenth of an inch in diameter. When large flows were required, excessive pressure drop occurred and prevented testing at adsorption pressures near 1 psig. Accordingly, tubing of this size was replaced or made as short as possible. This correction reduced flow resistance and allowed adsorption to proceed at pressures near 0 psig. 
Additional adsorption tests on activated carbon confirmed the assumption, made during experimental design, that final equilibrium column loading could be estimated with reasonable accuracy by continuously recording the $\mathrm{CS}_{2}$ concentration exiting the column and, at saturation (i.e., when outlet concentration equals inlet concentration), by subtracting the cumulative exiting $\mathrm{CS}_{2}$ mass from the cumulative entering $\mathrm{CS}_{2}$ mass.

\subsubsection{Adsorbent Preparation}

As discussed in Section 4.1, the adsorbents planned for testing were all commercially available except the amine-functionalized material. Because no literature was found on preparing this material for adsorbent testing (although much experience exists in general silane functionalization), ${ }^{50}$ a large amount of exploratory work was necessary to develop a method that provided reasonable assurance that the surfaces actually were covered with amine. Because this work constituted a significant fraction of the effort expended in this project, a summary of the work follows.

\subsubsection{Organusilane Surface-Covering Procedure}

Liquid aminosilanes were obtained from Union Carbide (trade number A1100). They were dried by molecular sieve dehydration for several hours. Silica gel or activated alumina was prepared by drying overnight in an oven heated to $110^{\circ} \mathrm{C}$. The silica gel was removed from the oven, allowed to cool for five minutes in a humidity-controlled vessel $(59 \%$ relative humidity). This procedure introduced a consistent amount of water vapor onto the internal surfaces of the absorbent. The dry A1100 was removed from the desiccator. The silica gel was dumped quickly into a beaker containing dry toluene, and the organosilane was added; then the mixture was stirred for two hours. The reaction that occurred was as follows.

Excess water on the surface hydrolyzed the aminosilane (A1100):

$$
\mathrm{NH}_{2}\left(\mathrm{CH}_{3}\right)_{3} \mathrm{Si}\left(\mathrm{OC}_{2} \mathrm{H}_{5}\right)_{3}+\mathrm{H}_{2} \mathrm{O}-->\mathrm{NH}_{2}\left(\mathrm{CH}_{3}\right)_{3} \mathrm{Si}(\mathrm{OH})_{3}
$$

The hydrated silane then reacted with chemically attached $\mathrm{OH}$ groups that are always present on the silica surface:

$$
\mathrm{NH}_{2}\left(\mathrm{CH}_{3}\right)_{3} \mathrm{Si}(\mathrm{OH})_{3}+\mathrm{HO}-1-->\mathrm{NH}_{2}\left(\mathrm{CH}_{3}\right)_{3} \mathrm{Si}(\mathrm{OH})_{2}-1+\mathrm{H}_{2} \mathrm{O}
$$

Sufficient $\mathrm{OH}$ groups are estimated to exist on silica and alumina so that a monolayer of amino groups formed on the silica gel. 


\subsubsection{Estimation of Surface Reaction Effectiveness}

Silica gel with $300 \mathrm{~m}^{2} / \mathrm{g}$ should be able to attach 0.9 millimoles of aminosilane per gram of silica gel. To estimate the extent of this reaction, the solid was dried, treated with a known amount of $0.1 \mathrm{NHCl}(0.1 \mathrm{~N} \mathrm{NaOH})$, and then titrated with base. This procedure resulted in an average value of 0.62 millimoles $/ g$, so the process was not $100 \%$ efficient. However, it was adequate and arı adsorbent with attached amine was produced. Aminefunctionalized alumina was prepared by the same procedure, and the treated material carried an average of 0.56 millimoles of amine per gram.

If it were assumed that each amine functionality could adsorb one $\mathrm{CS}_{2}$ molecule, then the maximum loading of the adsorbent would be about: $((0.56+0.62) / 2)\left(76 \times 10^{-3}\right)=$ $0.045 \mathrm{~g} \mathrm{CS}_{2}$ per gram adsorbent or, at equilibrium, the adsorbent would carry about $4.5 \%$ by weight of $\mathrm{CS}_{2}$. Because this loading is comparable to activated carbon's capacity for $\mathrm{CS}_{2}$, we were encouraged to continue the effort to prepare amine-functionalized adsorbents.

\subsubsection{Infrared Spectra of Amine-Functionalized Adsorbents}

To ensure further that the adsorbents were receiving the aminosilane on the surface, an extensive Fourier Transform Infrared (FTIR) analysis was conducted. Pellets of KBr were prepared by mixing modified and unmodified adsorbents with a reagent grade of $\mathrm{KBr}$ (200 $\mathrm{mg}$ ) and pressing the mixture into disks. The amount of adsorbent used varied from $0.5 \mathrm{mg}$ to $50 \mathrm{mg}$. However, the best results were obtained when the adsorbent weight was about $4 \mathrm{mg}$.

The covalent bond (Al-O-Si) between the adsorbent and A1100 could not be observed from FTIR spectral observations because of the obscuring effect of the water region. However, the $\mathrm{CH}$ band (about 2,900 $\mathrm{cm}^{-1}$ ) could be observed. Also, the area of the $\mathrm{OH}$ band (about $3,500 \mathrm{~cm}^{-1}$ ) was shown to decrease. By observing the $\mathrm{CH}$ peak and the $\mathrm{OH}$ peak, we may conclude that the alumina and A1100 are covalently linked. These results are shown in Figures 4.2 and 4.3 , which are representative of the results for the other adsorbents.

\subsection{DATA COLLECTION}

Data from this study are from two sources. While the contract was being negotiated, while funds were not yet available, and later while ANL was waiting for delivery of items with long lead times (e.g., the Shimadzu gas chromatograph), Teepak agreed to undertake adsorption testing at the facility in Danville, Illinois. Accordingly, one of their on-line chromatographs, which already was calibrated for $\mathrm{CS}_{2} /$ air detection, was modified to serve as a detector and constant temperature oven for a small adsorpticn column. With this equipment, Teepak tested the full range of adsorbents before the construction of the adsorption test rig at Argonne was complete. These data are presented below, along with data obtained using the Argonne test rig. The results are shown in Figures 4.4 through 4.9. 


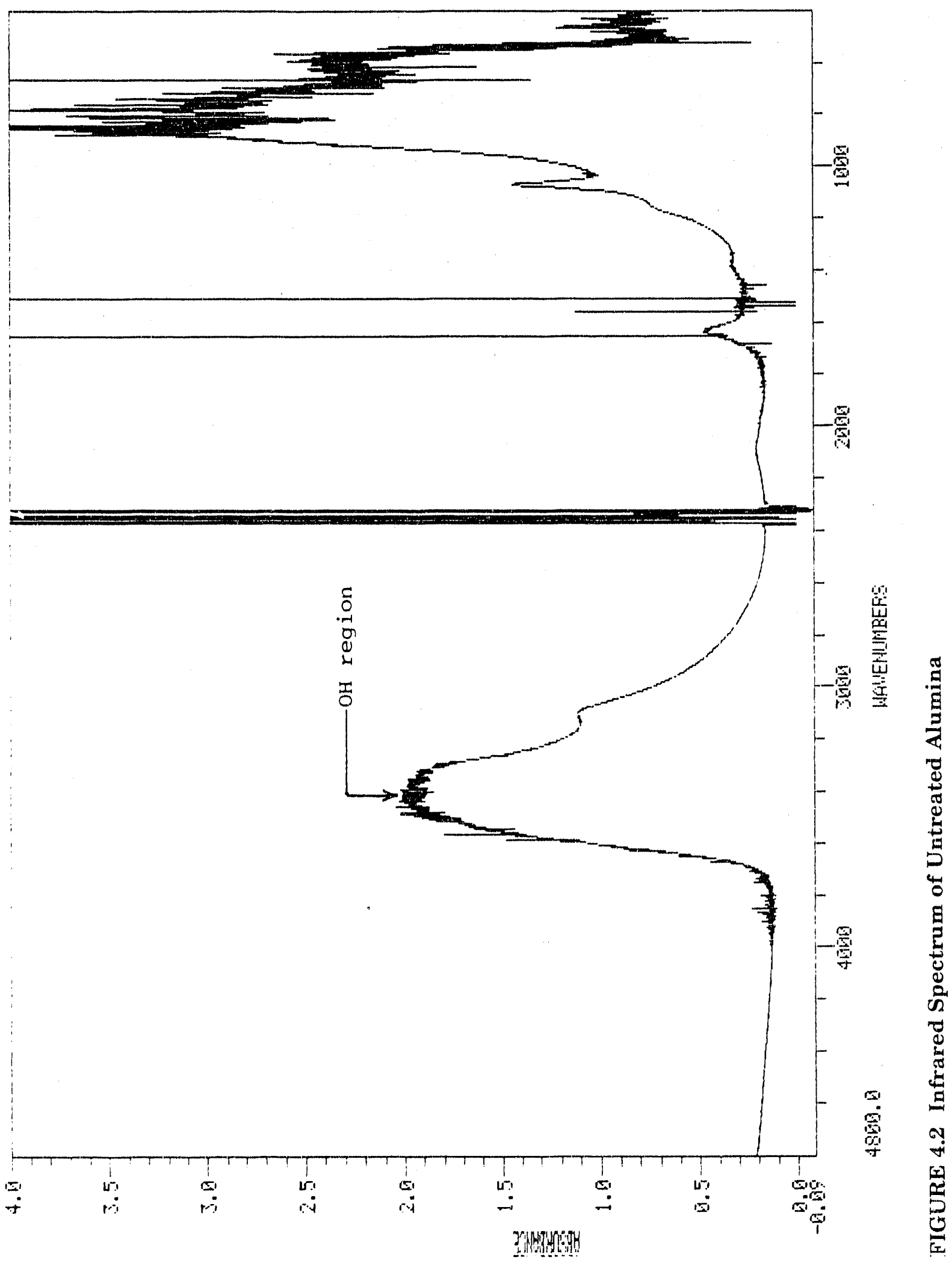




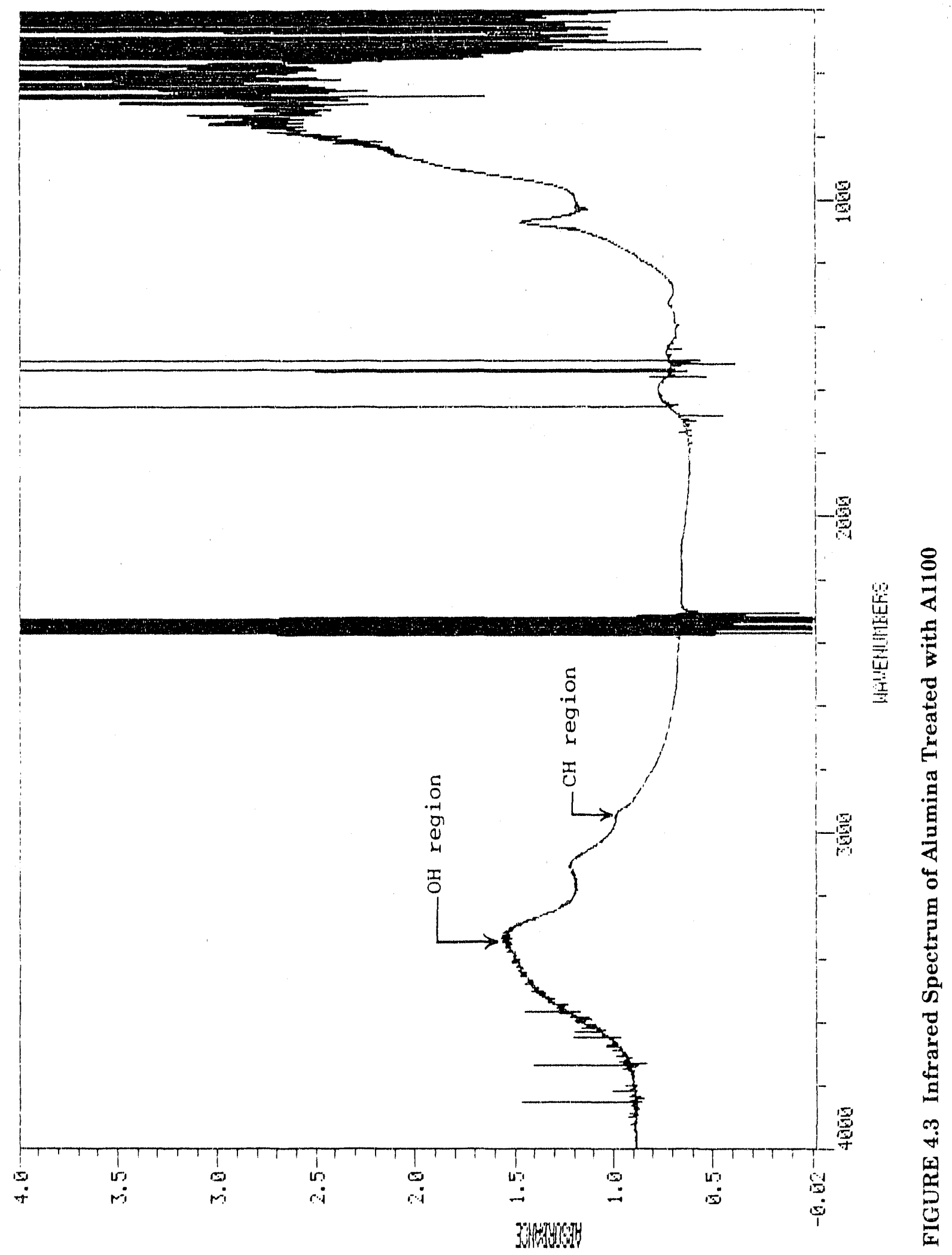



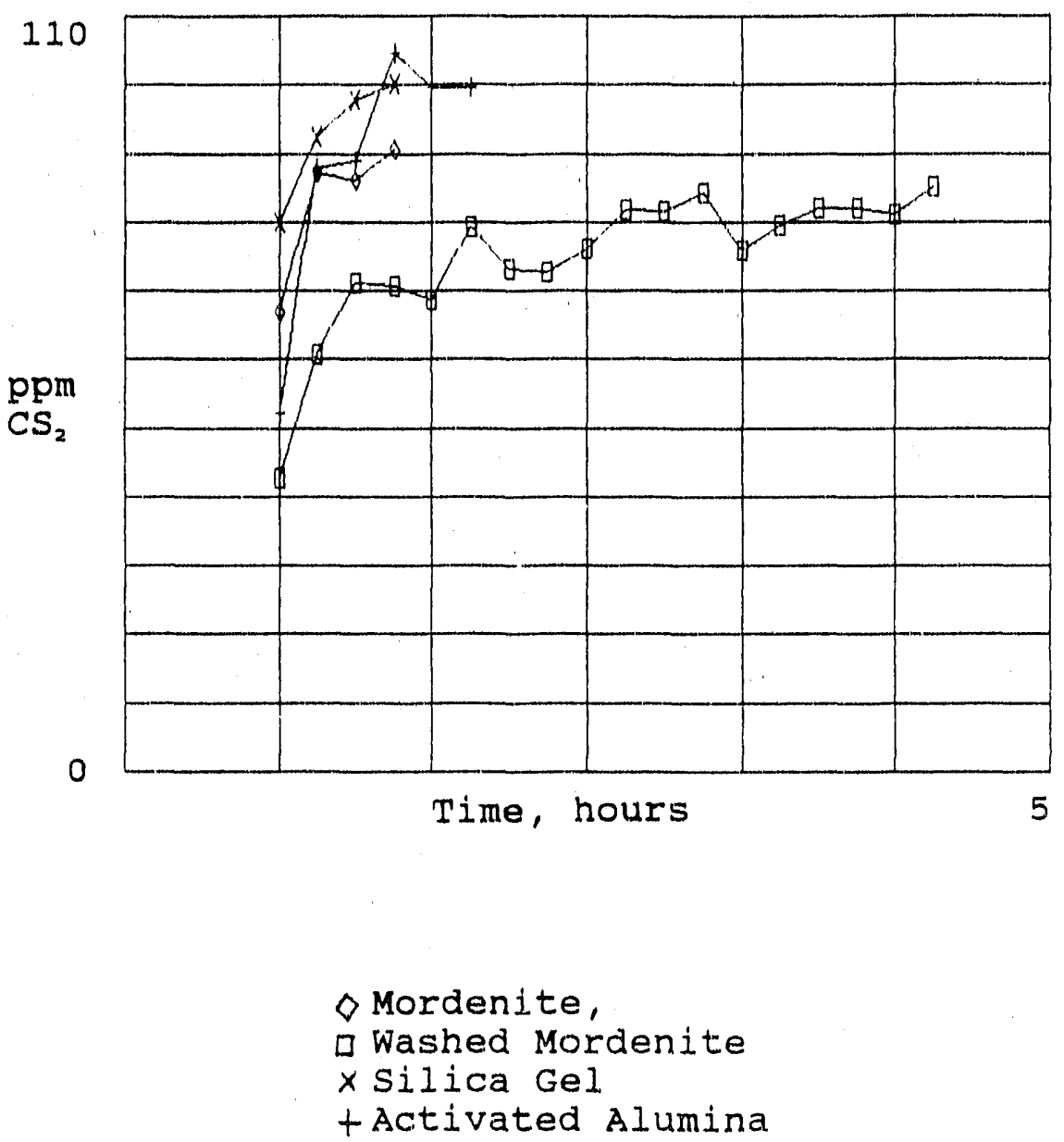

FIGURE 4.4 Breakthrough Plots for $\mathrm{CS}_{2}$ with Common Adsorbents

\subsubsection{Common Adsorbents}

Silica gel, activated alumina, and the clay mineral mordenite (a material commonly used in nonprocess adsorption) were studied in the adsorption tests. As seen in Figure 4.4, silica gel, activated alumina, and unwashed mordenite have very little ability to clean $\mathrm{CS}_{2}$ from air. In each case, $\mathrm{CS}_{2}$ was never reduced below $50 \mathrm{ppm}$, and breakthrough of the inlet concentration, $100 \mathrm{ppm}$, occurred in less than an hour. Water-washed mordenite had the most ability to hold $\mathrm{CS}_{2}$, but even in this case the 100 "ppm flow was never reduced below $40 \mathrm{ppm}$. Table 4.1 shows the loading attained for all adsorbents tested. Because the common adsorbents can hold little $\mathrm{CS}_{2}$, they are clearly unsuitable for use at Teepak.

\subsubsection{Prepared Adsorbents}

Several different substrates were reacted with aminosilanes to produce an adsorbent containing amino groups. Figures 4.5 and 4.6 show the ability of these materials to hold up 

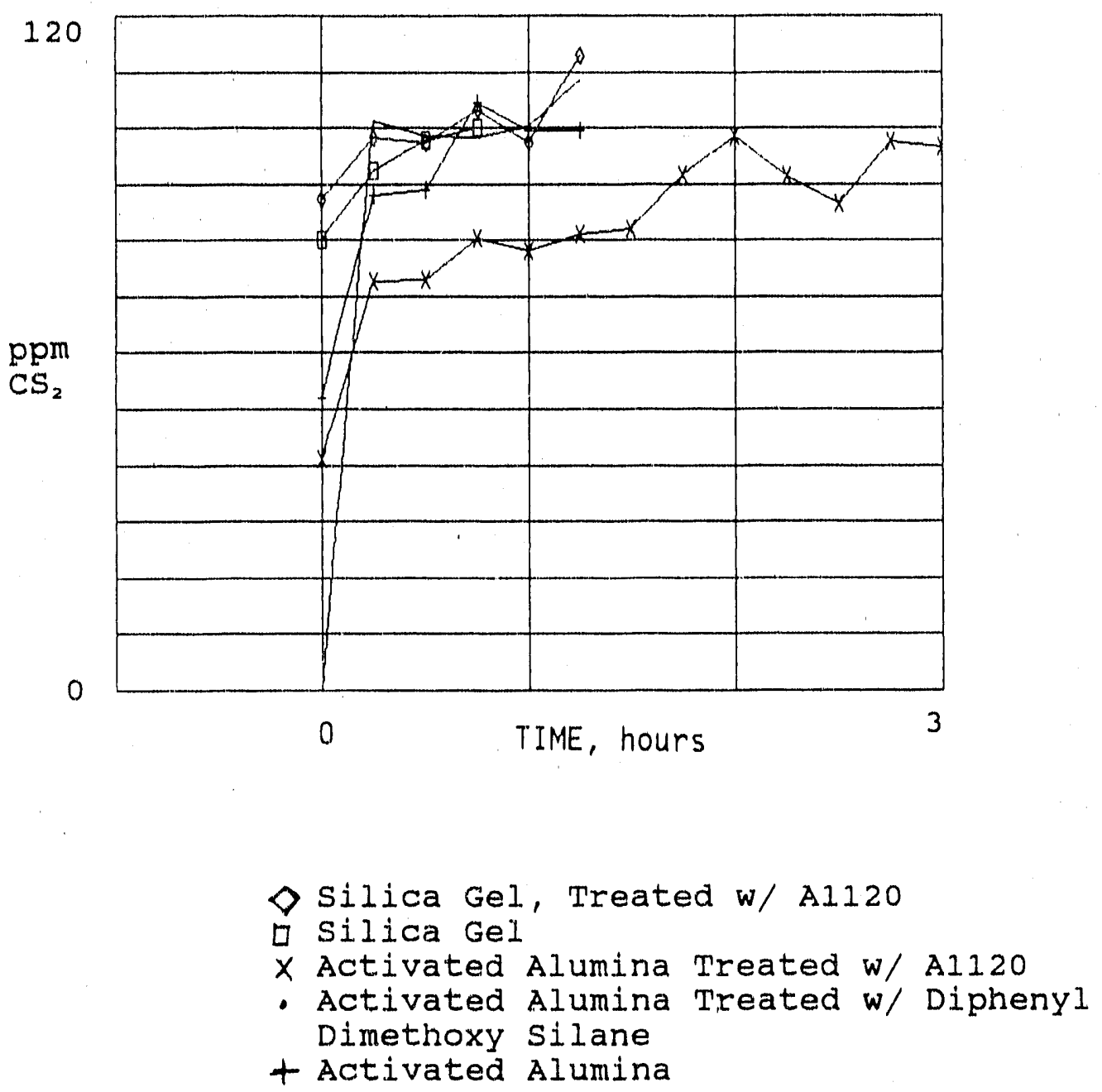

\section{FIGURE 4.5 Breakthrough Plots for $\mathrm{CS}_{2}$ with Prepared Adsorbents}

$\mathrm{CS}_{2}$. In each case, the aminosilane treatment resulted in no significant advantage for $\mathrm{CS}_{2}$ removal. Some results were interesting, however; in particular, the amino treatment seemed to improve the ability of activated alumina to hold up $\mathrm{CS}_{2}$, but no such difference was noted for silica gel.

One diphenyl silane treatment was tried; results indicated that the resulting adsorbent was very ineffective in holding up $\mathrm{CS}_{2}$. It had $100 \%$ holdup for a few minutes, but within $15 \mathrm{~min}$ the $100 \mathrm{ppm}$ had nearly broken through. The results in Figure 4.5 were obtained by using materials treated with aminosilanes in ANL laboratories. A commercially prepared aminosilane/silica gel was obtained so that parallel tests could be run to eliminate any possibility that the ANL material was not properly prepared (and therefore did not hold up $\mathrm{CS}_{2}$ properly). These materials, obtained from Waters, Inc., were tested in the ANL adsorption rig. The results are shown in Figure 4.6. The figures clearly show that the commercially prepared aminosilane/silica gel is not a better absorbent for $\mathrm{CS}_{2}$ than the ANLprepared materials. These treated adsorbents, therefore, have no practical value for $\mathrm{CS}_{2}$ recovery at Teepak. 

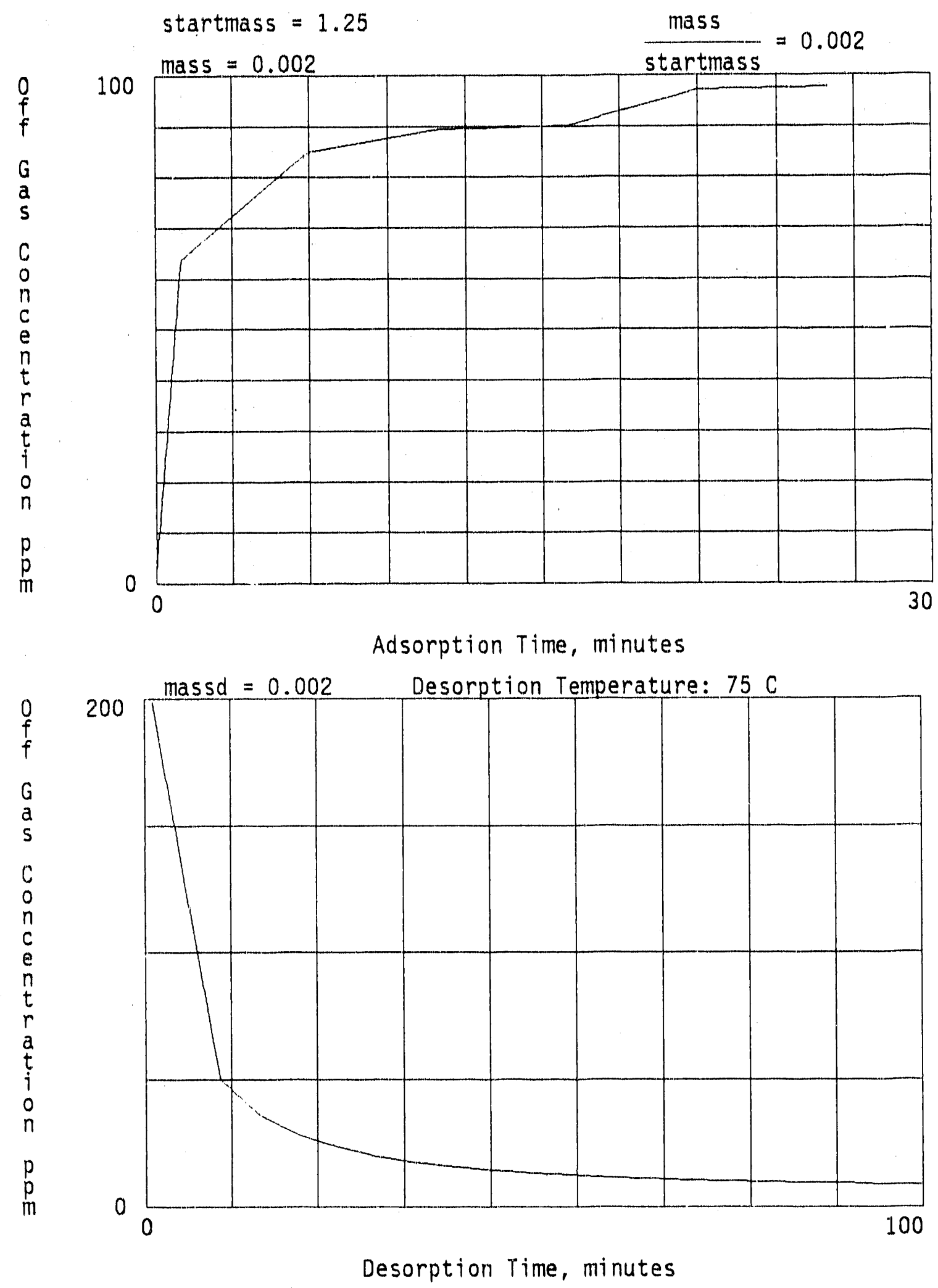

FIGURE 4.6 Adsorption and Desorption of Aminosilane/Silica: Off-Gas Concentration in ppm vs. Time in Minutes 

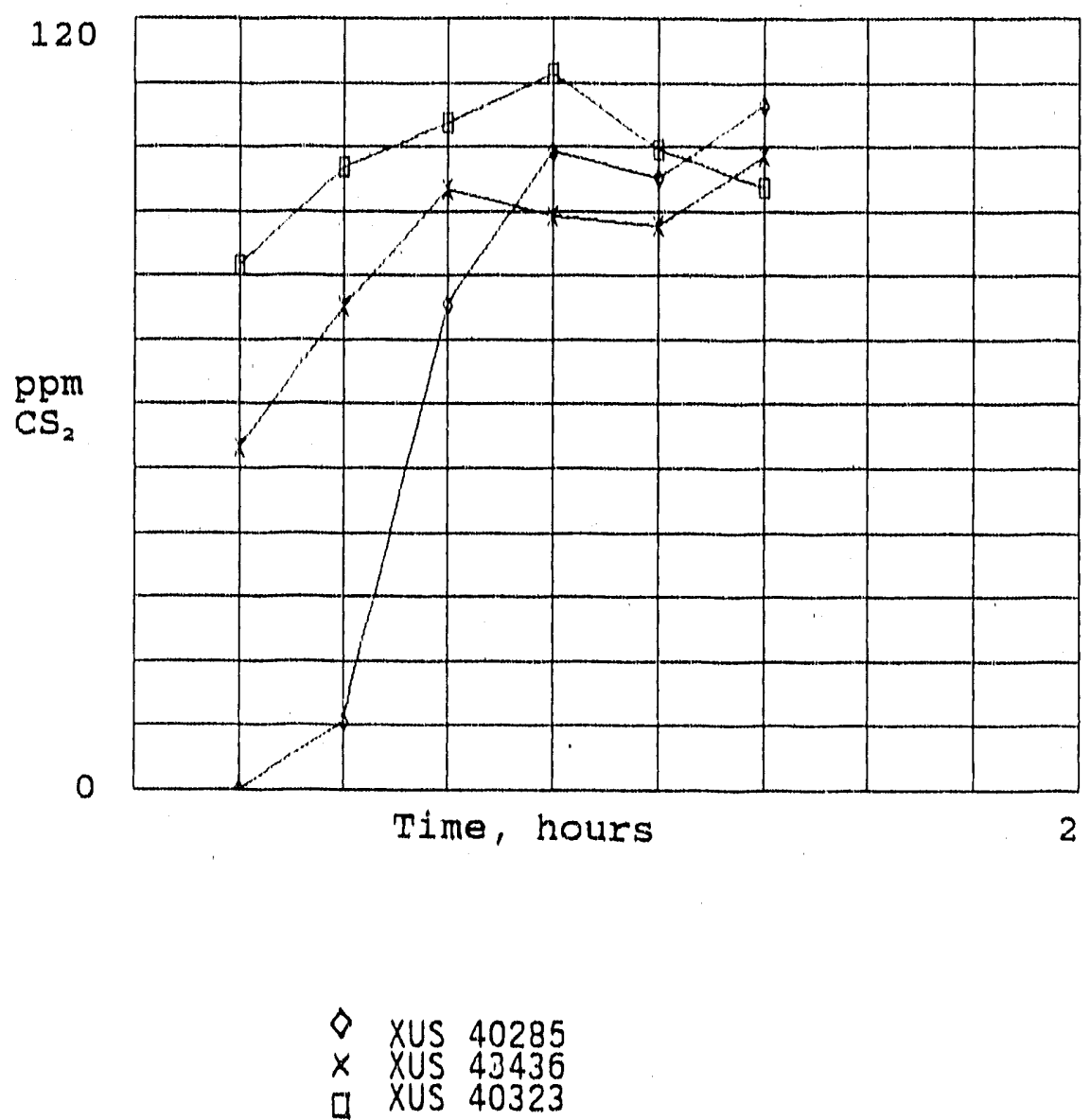

FIGURE 4.7 Breakthrough Plots for $\mathrm{CS}_{2}$ with Polymeric Absorbents

\subsubsection{Polymeric Adsorbents}

The polymeric adsorbents tested were obtained from Dow Chemical Company. They were styrene-based and, according to solubility theory, should have had at least some ability to remove $\mathrm{CS}_{2}$. Figures 4.7, 4.8, and 4.9 show that, except for XUS-40285, which has some small holdup ability, these adsorbents are little better than the common adsorbents. As shown in Table 4.1, their loadings are better than those of the common adsorbents but are still relatively small. It must be concluded that the polymers have little potential for $\mathrm{CS}_{2}$ recovery.

Figures 4.10 and 4.11 show the holdup characteristics of amberlite, a commonly used chromatographic packing. Again, both the breakthrough plot and the loading (see Table 4.1) are not encouraging. 


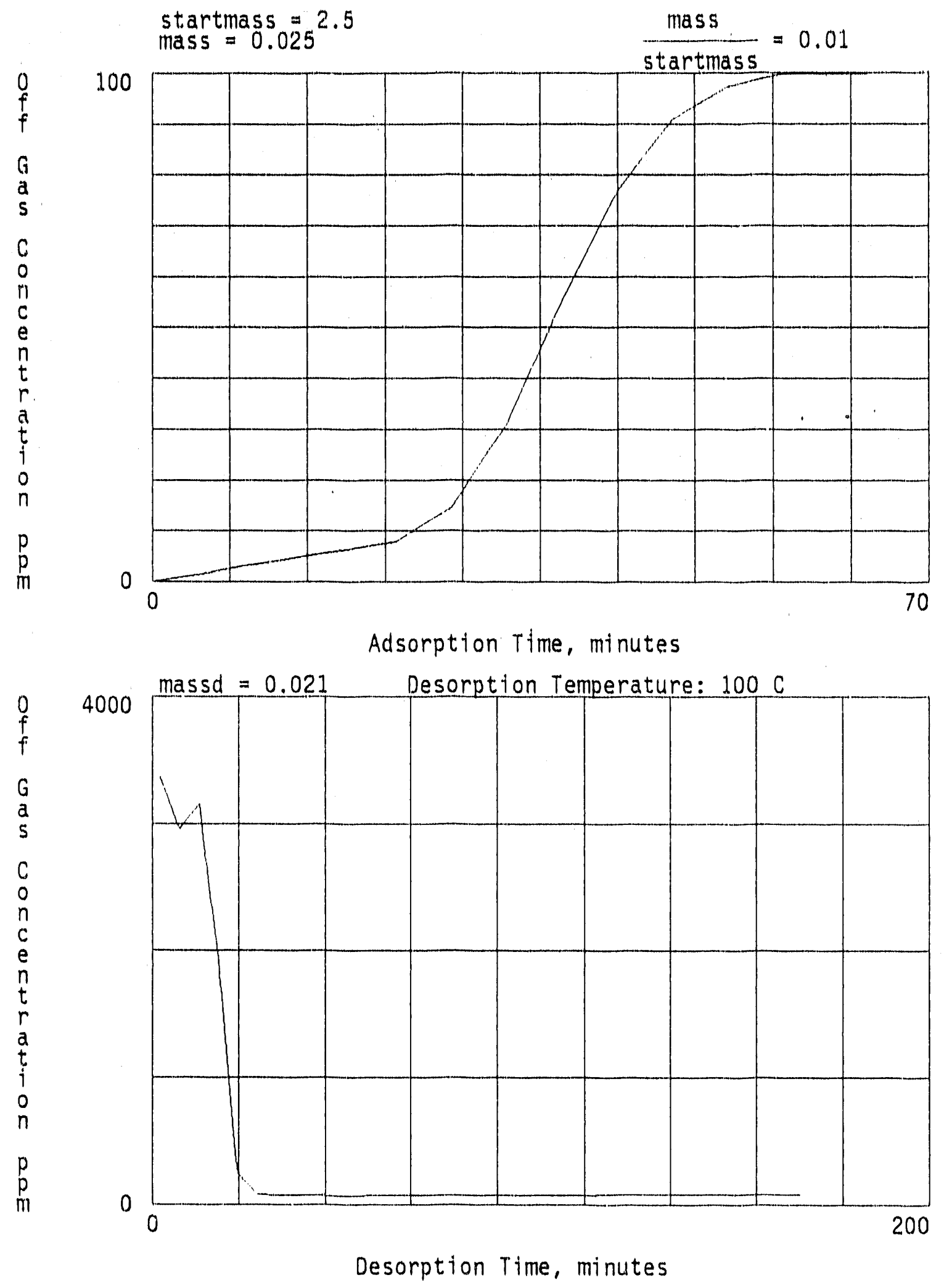

FIGURE 4.8 Adsorption and Desorption of XUS-40285 Polymer: Off-Gas Concentration in ppm vs. Time in Minutes 


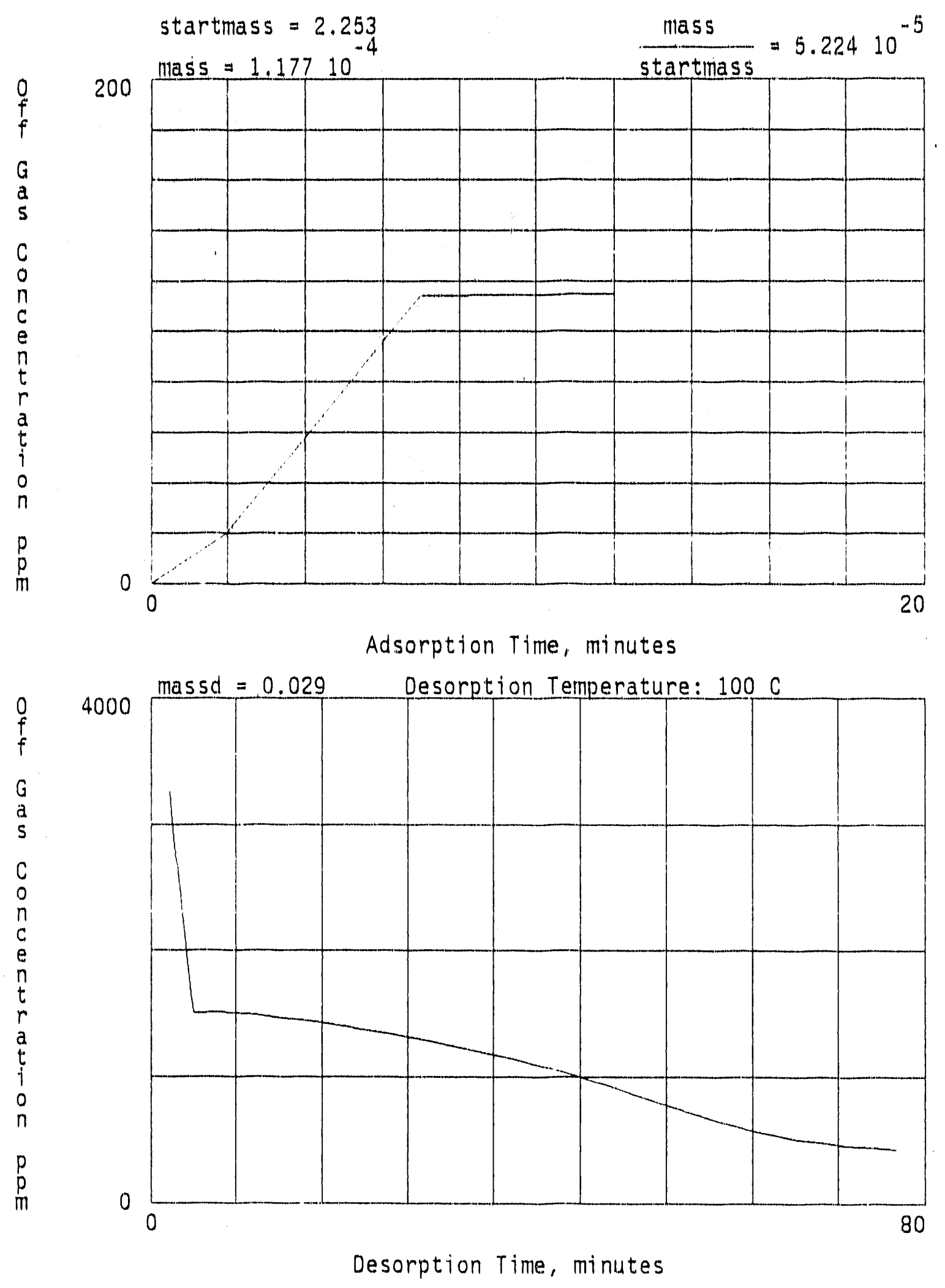

FIGURE 4.9 Adsorption and Desorption of XUS-40323 Polymer: Off-Gas Concentration in ppm vs. Time in Minutes 
TABLE 4.1 Adsorbent Loadings

\begin{tabular}{lcc}
\hline & $\begin{array}{c}\text { Maximum Loading, } q_{a} \\
\text { (grams CS } \\
\text { adsorbent) }\end{array}$ \\
\cline { 2 - 3 } Adsurbent & \multicolumn{2}{c}{ Teepak } \\
\hline Mordenite (washed) & 0.0041 \\
Silica gel & 0.001 & \\
Activated alumina & 0.0015 & \\
Silica gel (treated with aminosilane) & 0.0019 & 0.002 \\
Alumina (treated with aminosilane) & $<0.0001$ & \\
Adsorbent polymer XUS-40285 & 0.0074 & 0.010 \\
Adsorbent polymer XUS-43436 & 0.0037 & \\
Adsorbent polymer XUS-40323 & 0.0010 & 0.0005 \\
Amberlite & 0.0021 & 0.0020 \\
Silicalite & 0.0134 & 0.0120 \\
Activated carbon (xtrusorb) & 0.042 & 0.063 \\
Kureha carbon & 0.062 & 0.088 \\
BPL carbon & 0.056 & 0.064 \\
PCB carbon & 0.085 & 0.114 \\
\hline
\end{tabular}

\subsubsection{Hydrophobic Adsorbents}

Figures 4.12 and 4.13 show the breakthrough curves for Silicalite, a silica-based molecular sieve. This material clearly has some holdup potential, and in Table 4.1 we also see that it has a higher loading than the polymers and common adsorbents. Figure 4.13 shows that under desorption at $150^{\circ} \mathrm{C}\left(300^{\circ} \mathrm{F}\right)$ Silicalite releases $\mathrm{CS}_{2}$ rapidly, desorbing in about 20 min. However, further testing with moist air showed Silicalite to be poisoned by moisture; in practice, it does not measure up to its alleged hydrophobicity. Therefore, Silicalite is not promising for the Teepak application.

\subsubsection{Activated Carbon Adsorbents}

Four different activated carbons are characterized in Figures 4.14 through 4.18. Each has very favorable br akthrough properties, especially the Kureha bead carbon (GBAC carbon), which will hold up any $\mathrm{CS}_{2}$ breakthrough for $7 \mathrm{hr}$ after the inlet flow begins. Furthermore, the plot for GBAC carbon rises very sharply with time after breakthrough, indicating a very short mass-transfer zone. This zone would translate in 6 (1) an efficient fixedbed adsorption process, provided pressure drop was not excessive. The zone effect may be related to particle size (small for the bead carbon), so further evaluation will be necessary, Figure 4.17 also shows that desorption of $\mathrm{GBAC}$ carbon at $100^{\circ} \mathrm{C}$ requires more than $10 \mathrm{hr}$. $\mathrm{CSS}_{2}$ thus is held tightly in the GBAC carbon and requires considerable activation for 


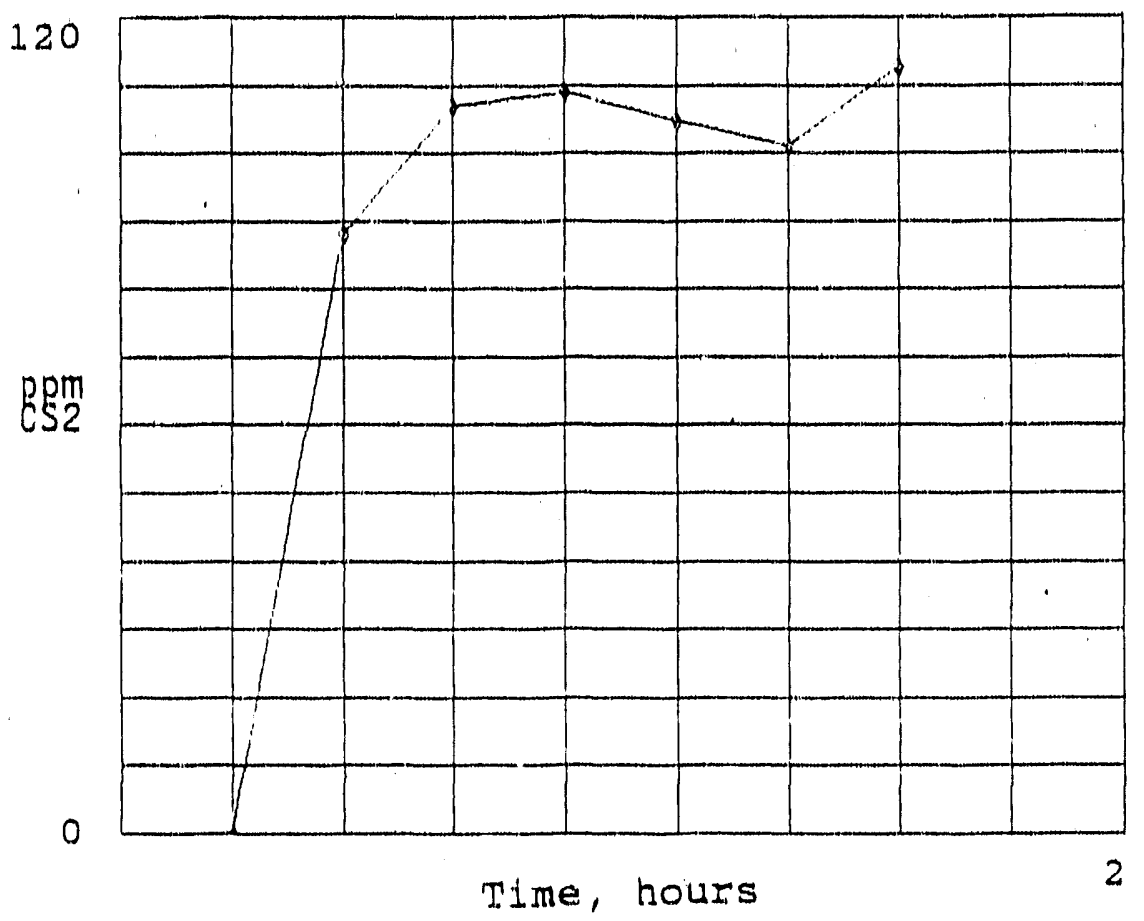

FIGURE 4.10 Breakthrough Plot for $\mathrm{CS}_{2}$ with Amberlite

moderate desorption rates. This characteristic may or may not lessen the appeal of the GBAC carbon and indicates firther desorption study is needed.

In general, the carbons loaded up very well with $\mathrm{CS}_{2}$. The concentration in the gas phase is only $1.00 \mathrm{ppm} \mathrm{CS}_{2}$, about 0.027 weight percent or 0.01 mole percent, and at equilibrium this concentration produces a loading range from 5 to 11 weight percent in carbon adsorbent. Carbon has a great affinity for $\mathrm{CS}_{2}$, and at present this phenomenon represents the best hope for removal and recovery from the Teepak air.

Table 4.1. shows that carbons generally load about an order of magnitude higher than the other adsorbents studied. Activated carbon is clearly superior to any of the materials tested so far and may make efficient adsorption and recovery possible at Teepak if the other known problems $\left(\mathrm{H}_{2} \mathrm{~S}\right.$ and $\mathrm{H}_{2} \mathrm{O}$ poisoning, water loading, fire hazard) can be overcome. Evaluation of the desorption capability of carbon will require further study.

Table 4.1 shows PCB to be the highest loading carbon. Since loading will have a pronounced effect on adsorption efficiency, the effect of loading $\left(a_{0}{ }^{\circ}\right)$ is evaluated in Section 4.4.4. 

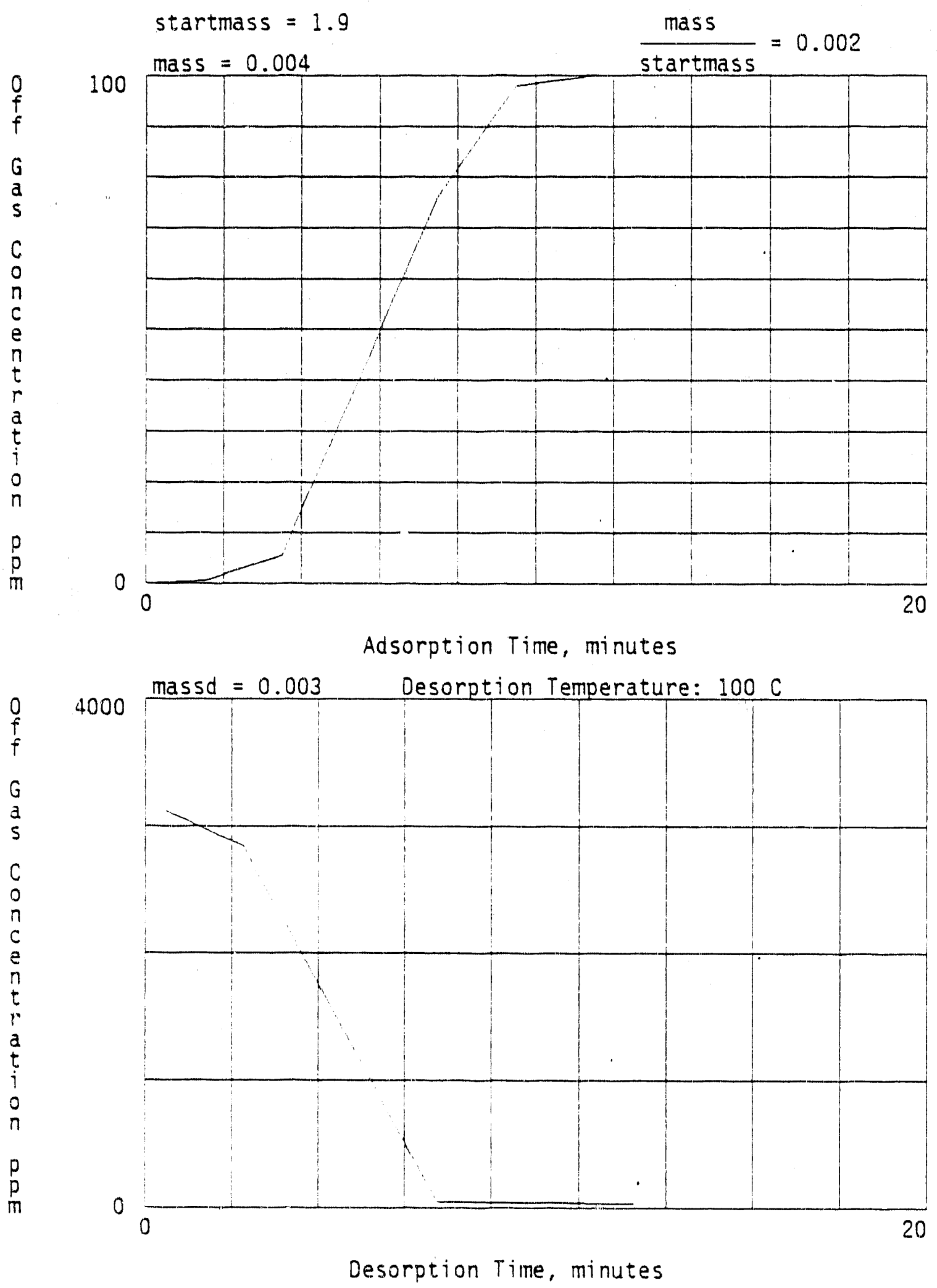

FIGURE 4.11 Adsorption and Desorption of Amberlite: Off-Gas Concentration in nnm vs. Time in Minetes 


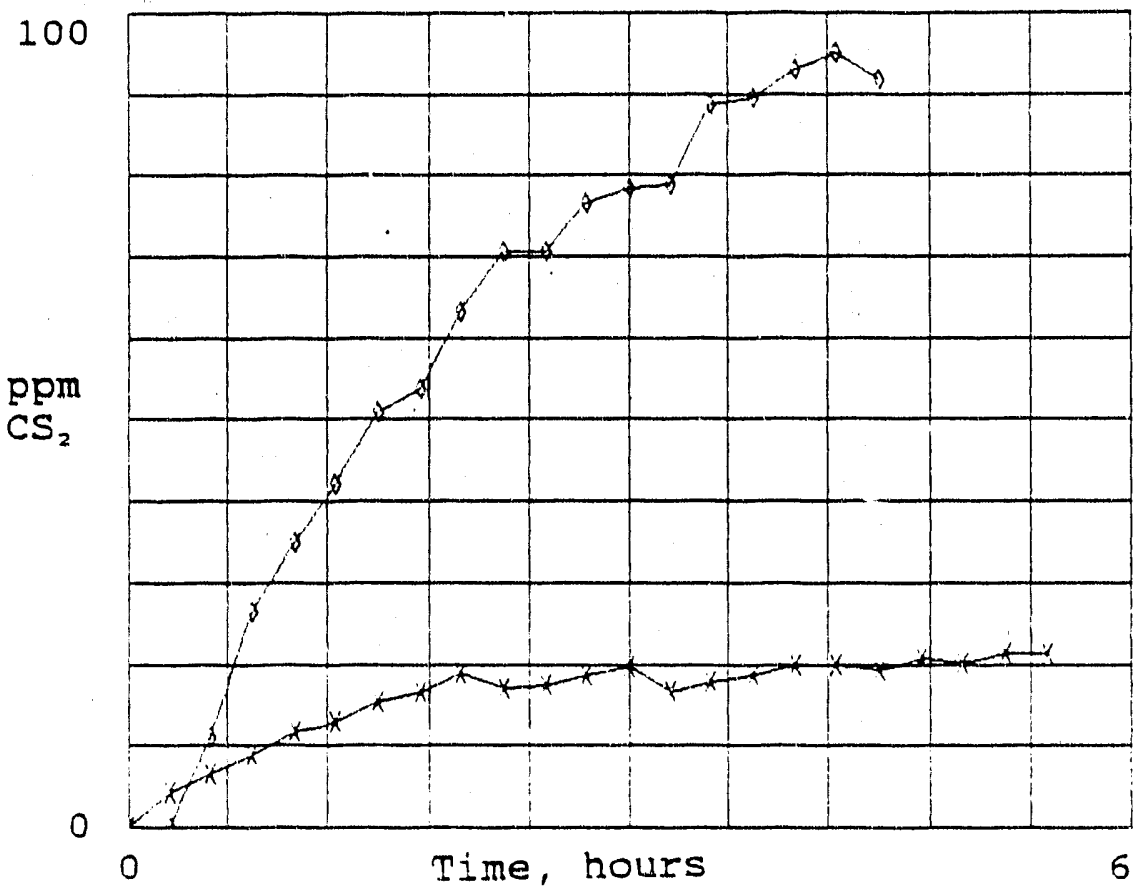

$\begin{array}{llll}\diamond 100 & \text { ppm } & \text { CS2 } & \text { Feed } \\ \times 24 & \text { ppm } & \text { CS2 } & \text { Feed }\end{array}$

FIGURE 4.12 Breakthrough Plot for $\mathrm{CS}_{2}$ with Silicalite

\subsection{DATA CORRELATION}

The adsorption data presented in Section 4.3 are interesting from a scientific viewpoint; the extreme difference in $\mathrm{CS}_{2}$ loading between activated carbon and all other adsorbents tested has not been reported previously. However, the primary goal of the current project was not to develop scientific data but rather to develop information that will lead to a viable $\mathrm{CS}_{2}$ recovery process at Teepak. Therefore, the data must be translated into processinformation, and this information in turn must allow estimation of feasibility and cost for installation at Teepak. Data correlation thus is in terms of adsorption process design. In the present context, this effort concentrates on fixed-bed, thermal swing adsorption (TSA). Parametric studies are used to determine how the important process design parameters (those that affect feasibility and cost) change as independent variables change.

Other carbon adsorption processes are also possible, such as moving bed and pressure swing adsorption. These are not addressed in this report because (1) TSA is the most fundamental and simplest process and represents a good basis for the comparisons and parametric studys that follow in this report, and (2) insufficient resources are available for analyses of other processes. This, along with desorption analyses, must come at a later phase of the Teepak project. 

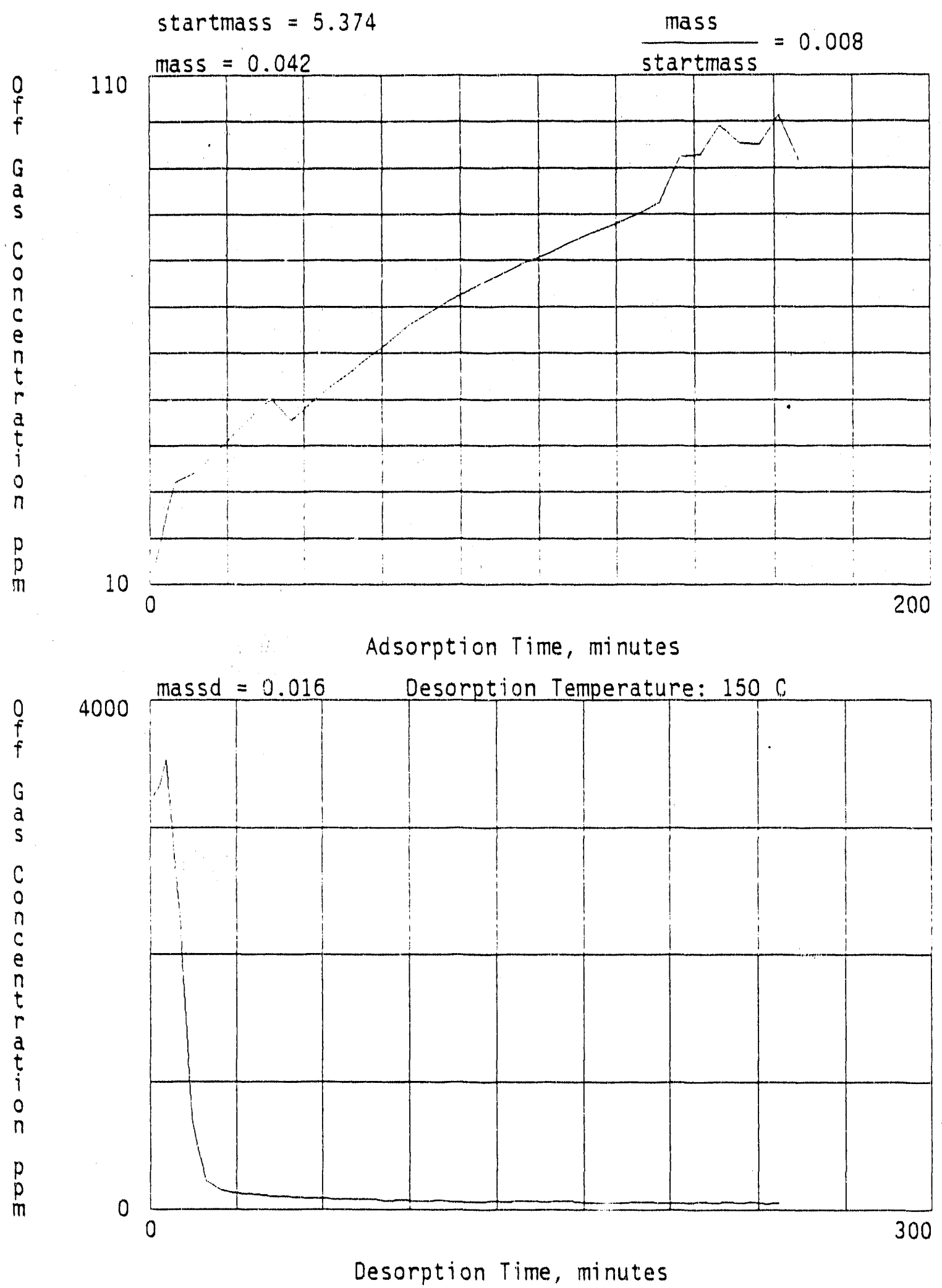

FIGURE 4.13 Adsorption and Desorption of Silicalite: Off-Gas Concentration in ppm vs. Time in Minutes 


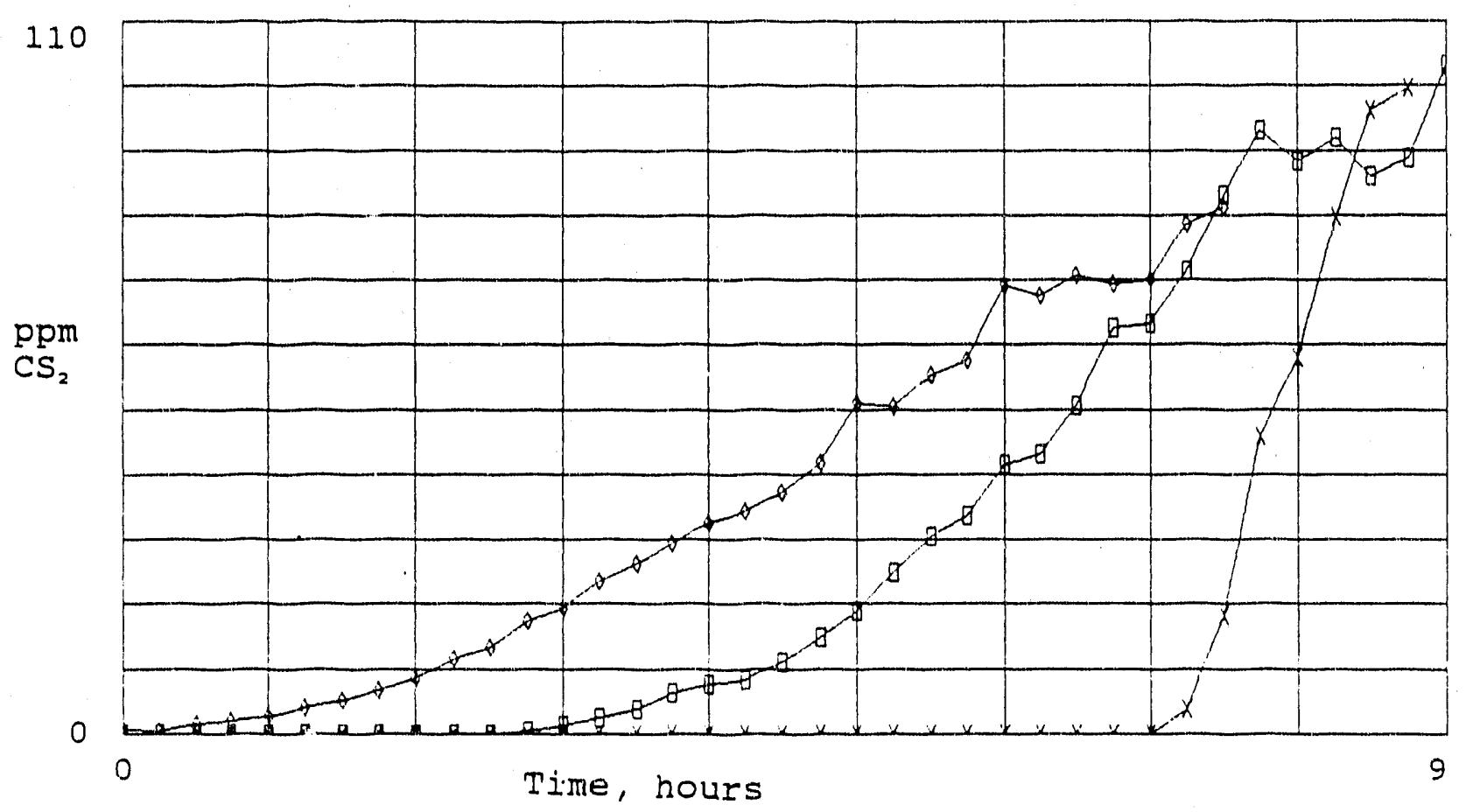

$\triangle$ PCB Carbon
Xtrusorb
$\times$ Kureha Bead Carbon

FIGURE 4.14 Breakthrough Plot for $\mathrm{CS}_{2}$ with Activated Carbon

\subsubsection{Gas Adsorption Process Description}

\subsubsection{Adsorption}

In fixed-bed, thermal swing gas adsorption, adsorption towers are packed with adsorbent particles such as activated carbon. All adsorbents have extensive pore structure with very large internal surface area. Particle size usually varies between 0.25 and $0.1 \mathrm{in}$. but can be another specified size if required. Gas containing a substance to be removed (such as $\mathrm{CS}_{2}$ ) enters either the top or the bottom of the tower and flows upward or downward through openings between particles. The adsorbate diffuses into the pores of the adsorbent and is physically adsorbed onto the internal surfaces. If the carrying gas (in the Teepak case, air) does not have much affinity for the adsorbent surface and hence has a much smaller equilibrium adsorption concentration, the carrying gas will pass through the column and leave the adsorbate behind. The concentration of adsorbed $\mathrm{CS}_{2}$ gradually will build up until it attains equilibrium with the $\mathrm{CS}_{2}$ in the feed gas, after which no more $\mathrm{CS}_{2}$ can be removed from the gas. The adsorbent is then said to be "loaded." It is important to realize that, 

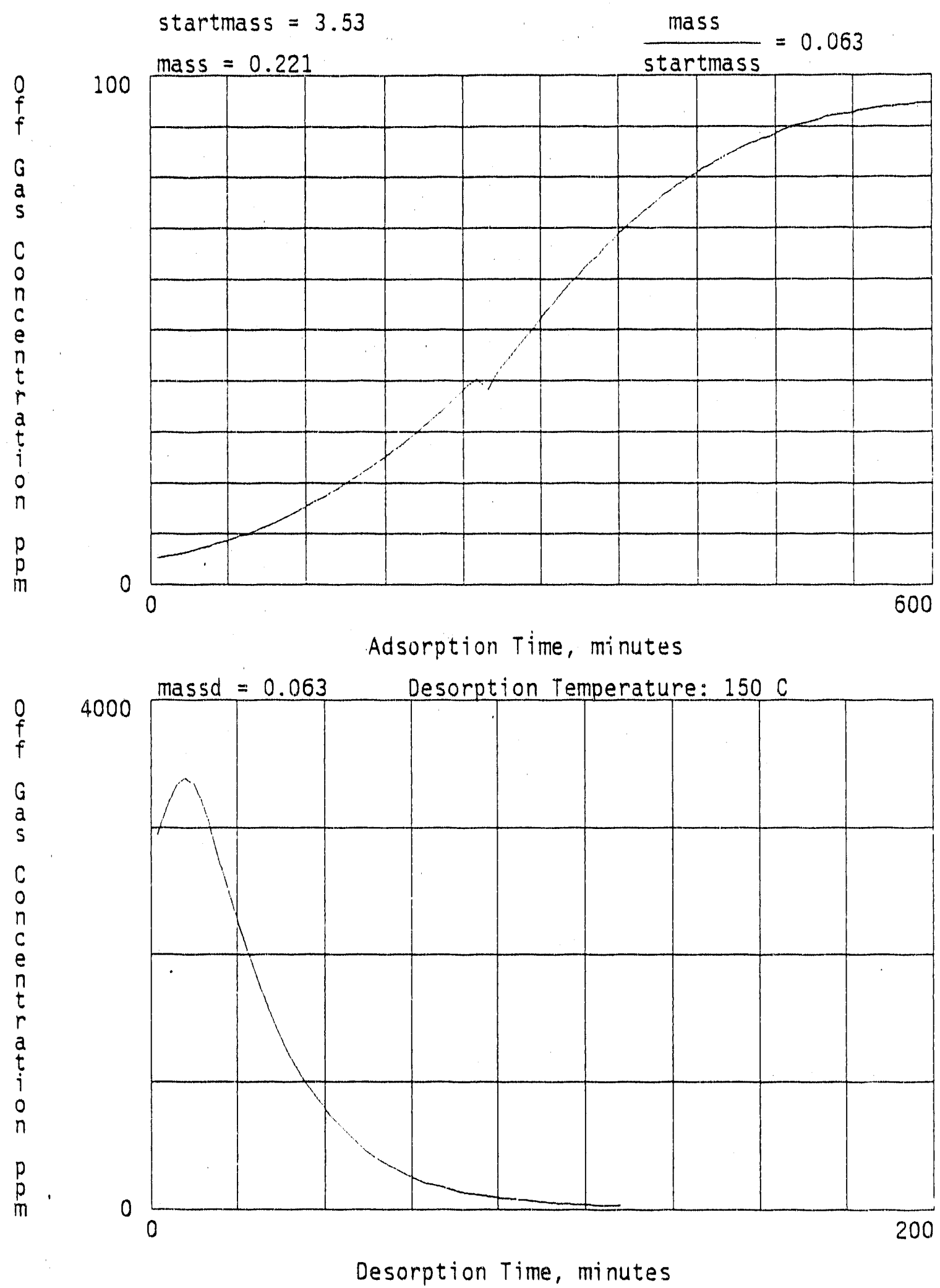

FIGURE 4.15 Adsorption and Desorption of Xtrusorb-700 Carbon: Off-Gas Concentration in ppm vs. Time in Minutes 


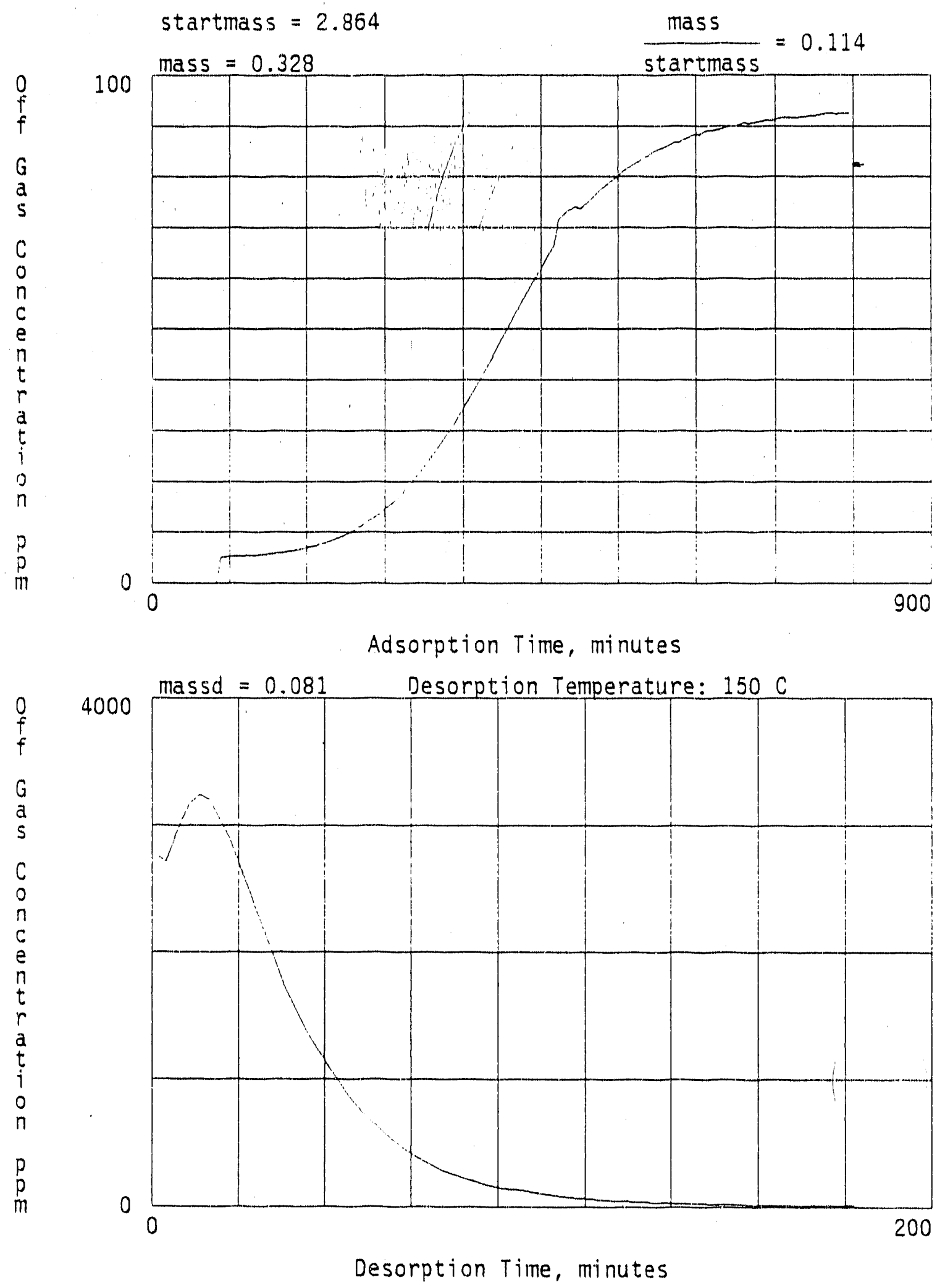

FIGURE 4.16 Adsorption and Desorption of PCB Carbon: Off-Gas Concentration in ppm vs. Time in Minutes 

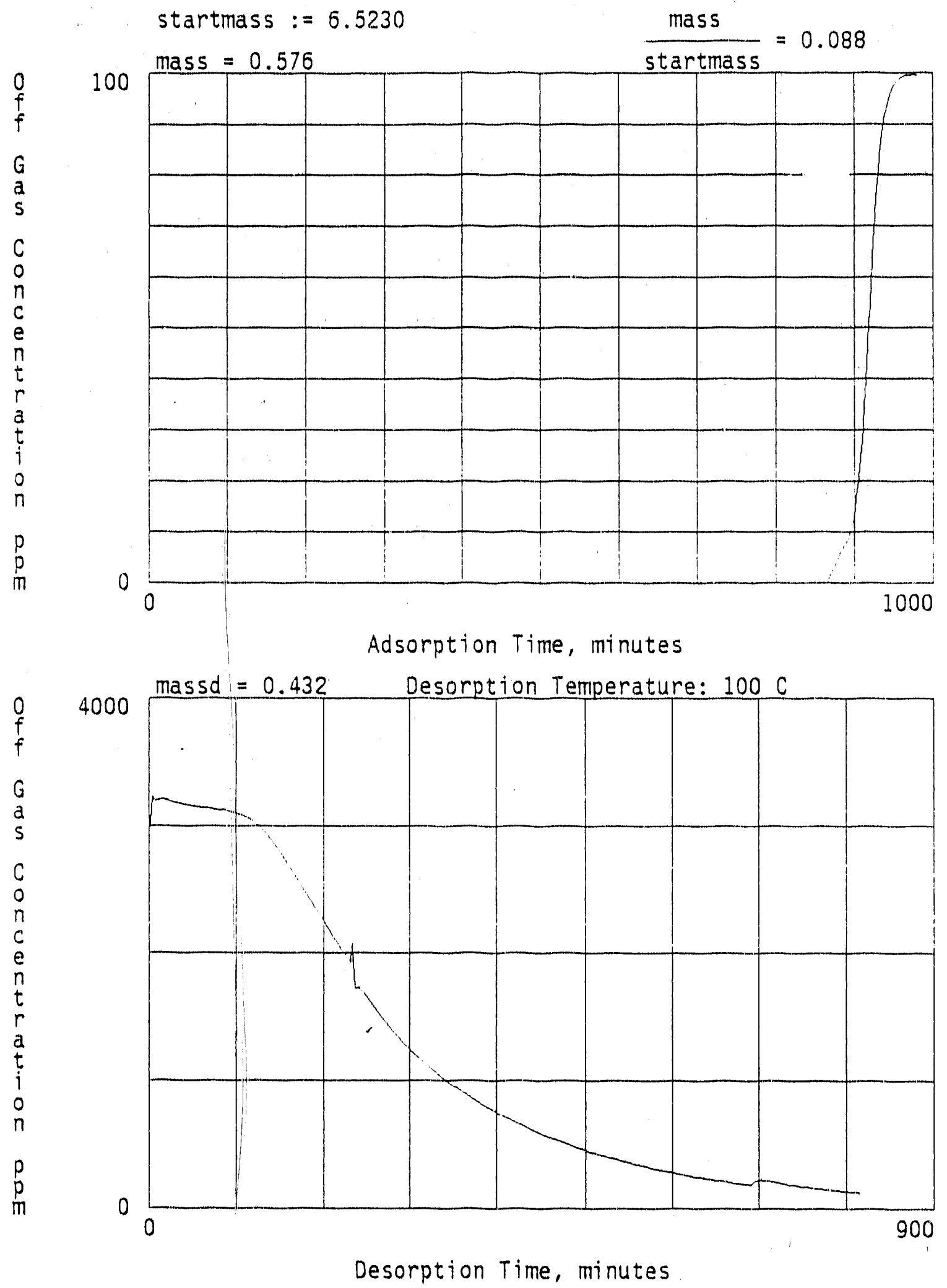

FIGURE 4.17 Adsorption and Desorption of GBAC Carbon: Off-Gas Concentration in ppm vs. Time in Minutes 


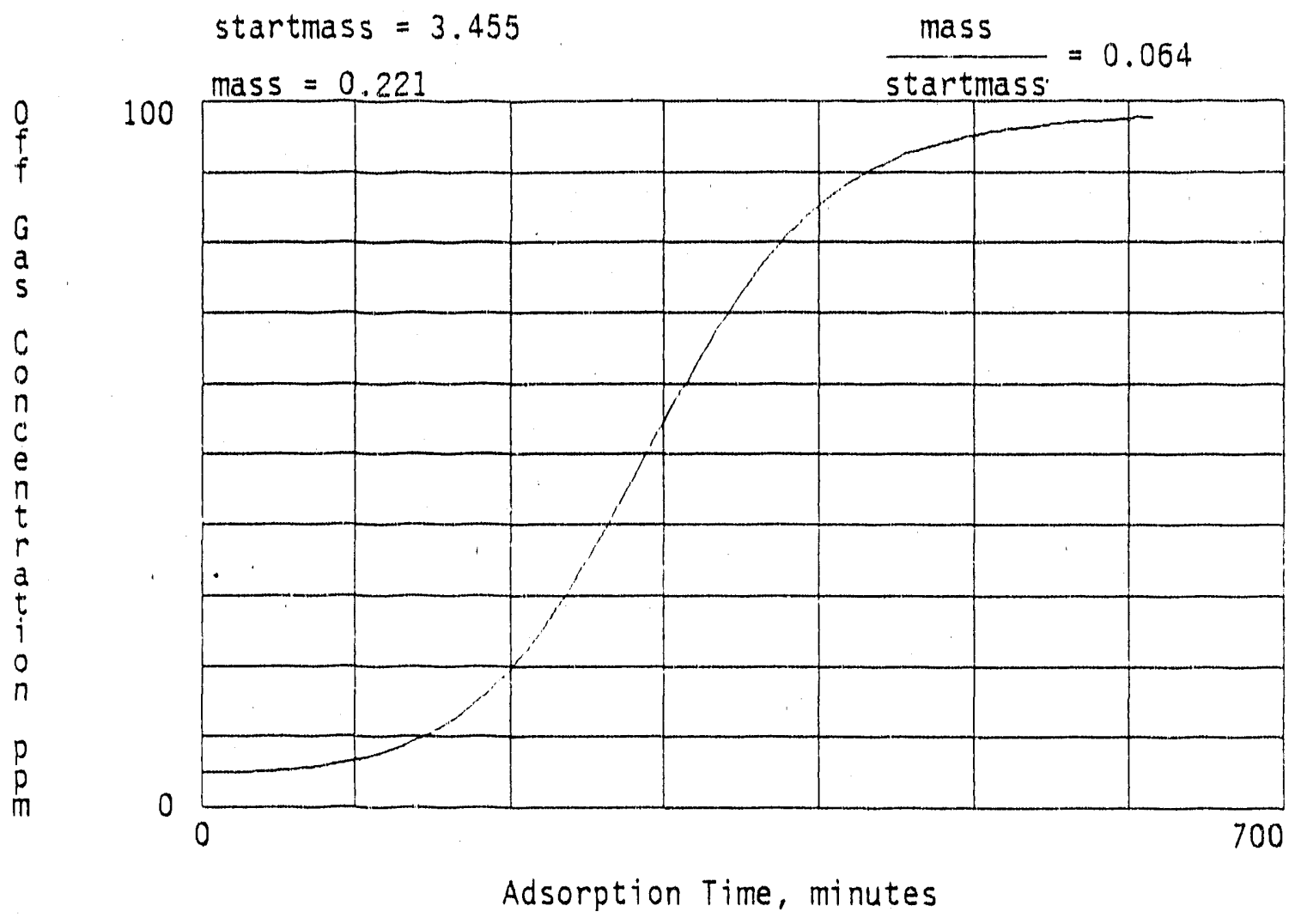

FIGURE 4.18 Adsorption of BPL Carbon: Off-Gas Concentration in ppm vs. Time in Minutes

because loading is an equilibrium phenomenon, the loading for a given adsorbent depends directly on the inlet concentration of the gas.

Attainment of loading begins at the gas inlet end of the column and gradually moves toward the outlet end. This process is shown, for a downward-flow tower, in Figure 4.19. Between the fully loaded particles and the particles that have been exposed only to clean air is a zone called the "mass transfer zone" or "adsorption zone" where the particles are in the process of being loaded. In some cases this zone can be very wide, especially if resistance to diffusion of $\mathrm{CS}_{2}$ is high and if $\mathrm{CS}_{2}$ has less affinity for the adsorbent at lower $\mathrm{CS}_{2}$ concentrations (the "unfavorable isotherm" case). When the front of the mass-transfer zone reaches the outlet and $\mathrm{CS}_{2}$ begins to exit the column, "breakthrough" has occurred. At this point, the gas flow usually is redirected to another tower of fresh adsorbent. This "breakpoint" is defined by stipulating some small value for y (i.e., defining the minimum $\mathrm{CS}_{2}$ concentration that can be tolerated). However, if the flow continues the outlet concentration will increase until the back side of the mass-tiansfer zone reaches the outlet. At that point, all the adsorbent in the column is loaded and no furiher separation is possible. The length of the mass-transfer zone has important economic significance because a large mass-transfer zone will leave much of the adsorbent in the column less than fully loaded at breakthrough. 


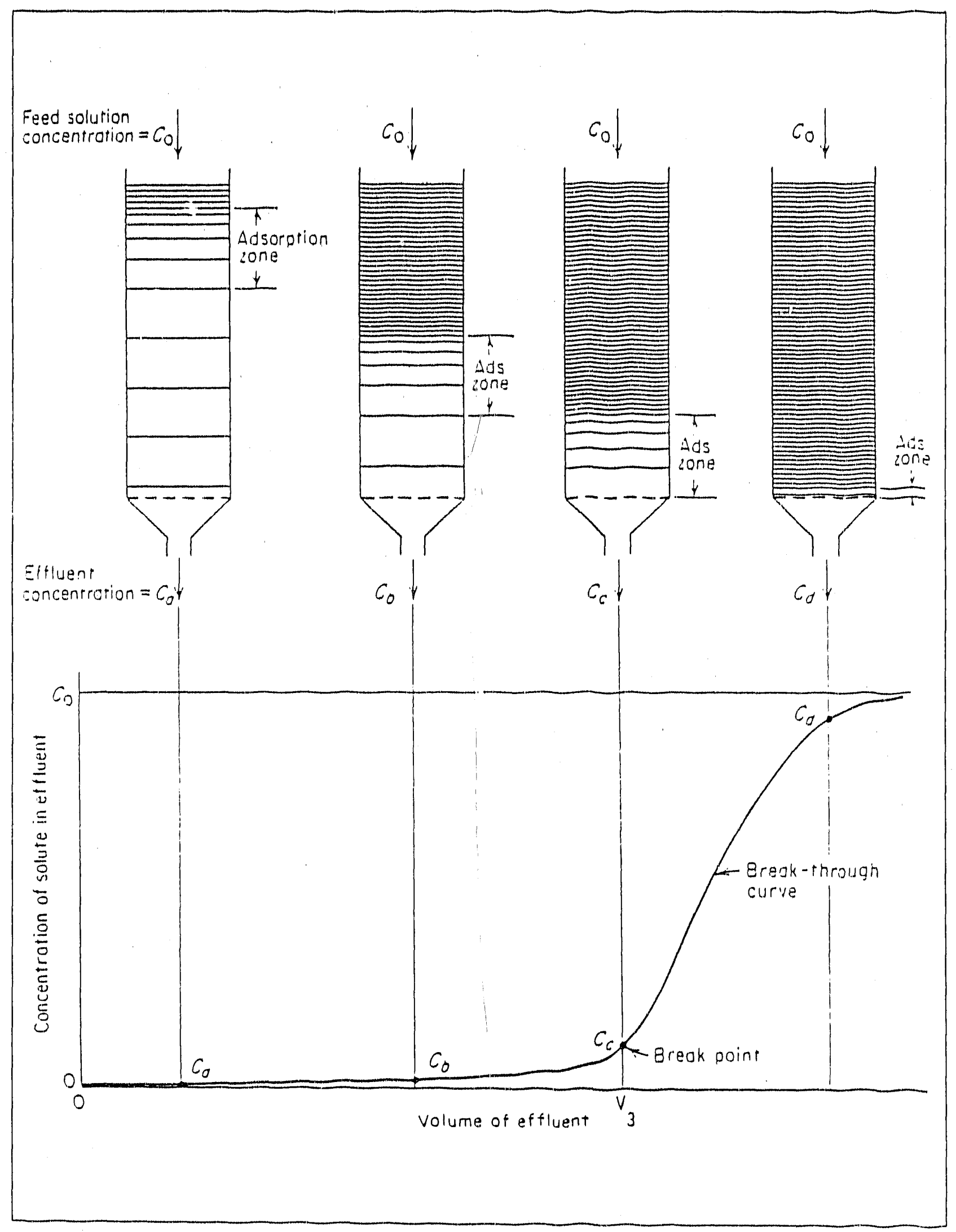

FIGURE 4.19 Breakthrough Curve for Adsorption 


\subsubsection{Desorption}

When flow is switched to a fresh tower, the loaded tower then must be desorbed to recover the $\mathrm{CS}_{2}$ and to prepare the tower for reuse. Desorption results from elevating the temperature and purging the adsorbent with a $\mathrm{CS}_{\mathrm{g}}$-free gas (such as steam or nitrogen) so that the adsorption equilibrium is shifted to low $\mathrm{CS}_{2}$ affinity for the adsorbent. The $\mathrm{CS}_{2}$ so released is then swept out of the column with the purge, which should be as small as possible. $\mathrm{CS}_{2}$ thereby becomes concentrated in tho purge gas and can be recovered by rondensation or distillation.

There are several conditions under which $\mathrm{CS}_{2}$ can be recovered from desorption gras by cooling and pressurization. We first discuss the $\mathrm{N}_{2}$ desorption case. The vapor pressure of $\mathrm{CS}_{2}, \mathrm{p}_{\mathrm{CS}}$, at various temperatures can be expressed in terms of the Clausius-Clapyron equation. ${ }^{38}$ The constants for this equation have been obtained from vapor pressure and temperature data for $\mathrm{CS}_{2}$ in Section 3. The result is:

$$
p_{\mathrm{CS} 2}=472550.55 \exp [-5966.5 /(T+460)]
$$

where $\mathrm{p}_{\mathrm{CS} 2}$ is the vapor pressure in psia of $\mathrm{CS}_{2}$ at temperature $\mathrm{T}$ in ${ }^{\circ} \mathrm{F}$.

A formula for the moles of $\mathrm{CS}_{2}$ condensable per mole of desorption gas ( $Q$ ) can be given in terms of $\mathrm{p}_{\mathrm{CS} 2}$ and the concentration of $\mathrm{CS}_{2}$ in the desorption gas:

$$
\mathrm{Q}=\mathrm{x} /\left(10^{6}-\mathrm{x}\right)-\mathrm{p}_{\mathrm{CS} 2} /\left(\mathrm{P}-\mathrm{p}_{\mathrm{CS} 2}\right)
$$

The first term on the right side of Equation 26 represents the moles of $\mathrm{CS}_{2}$ per mole of $\mathrm{N}_{2}$ idesorption gas) when $\mathrm{x}$ moles of $\mathrm{CS}_{2}$ are contained in 1 million moles of total gas (i.e., the concentration of $\mathrm{CS}_{2}$ in the desorbing gas is $\mathrm{x} \mathrm{ppm}$ ). The second term represents the moles of $\mathrm{CS}_{2}$ per mole of $\mathrm{N}_{2}$ when the desorbed total vapor is in equilibrium with pure $\mathrm{CS}_{2}$ liquid at the given temperature and total pressure (P). Therefore, $\mathrm{Q}$ represents the difference between the desorption vapor loading at the desorption temperature and the loading at the condensation temperature. If $\mathrm{Q}$ is zero or below, liquid $\mathrm{CS}_{2}$ cannot be obtained by condensation. As $Q$ increases, improved recovery becomes possible. $Q$ can be converted into molar percent of $\mathrm{CS}_{2}$ recoverable $(R)$ by dividing Equation 26 by $\mathrm{x} /\left(10^{6}-\mathrm{x}\right) 100$ :

$$
R=100-\left(p_{C S 2} /\left(P-p_{C S 2}\right)\right)\left(\left(10^{6}-x\right) / x\right) 100
$$

Combining Equations 25 and 27, assuming $P$ is 1 atm, and plotting $R$ versus $x$ for various condensation temperatures produces Figure $4.20 \mathrm{a}$. This figure shows the important interactive effects of condenser temperature (TC) and $\mathrm{CS}_{2}$ desorption gas concentration 


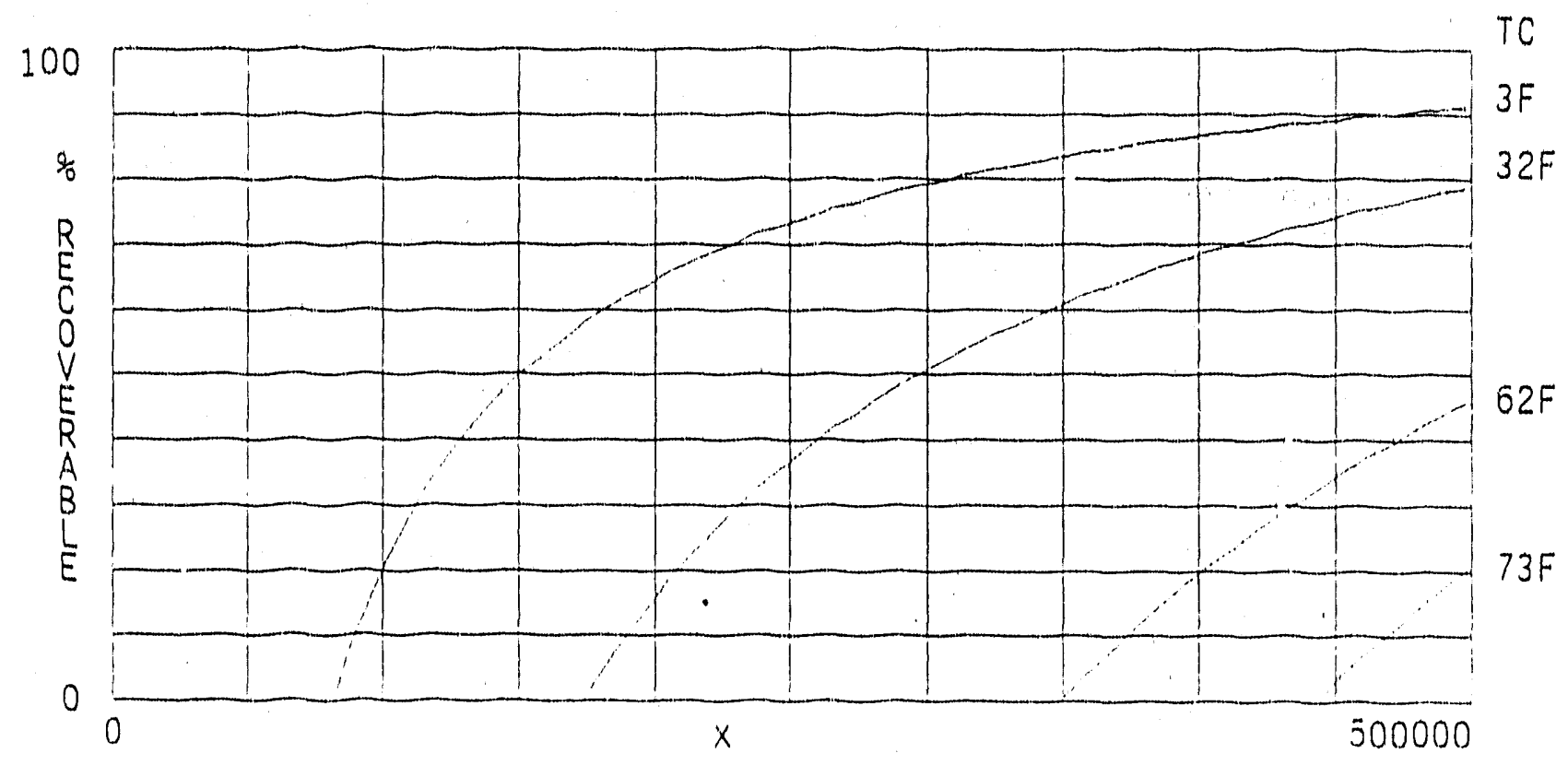

FIGURE 4.20a Mole Percont $\mathrm{CS}_{2}$ Recoverable vs. $\mathrm{CS}_{2}$ Concentration in $\mathrm{N}_{2}$ Desorption Gas ( $x$ in ppm) for Yarious Condensation Temperatures (TC) (absolute pressure $=1 \mathrm{~atm}$ )

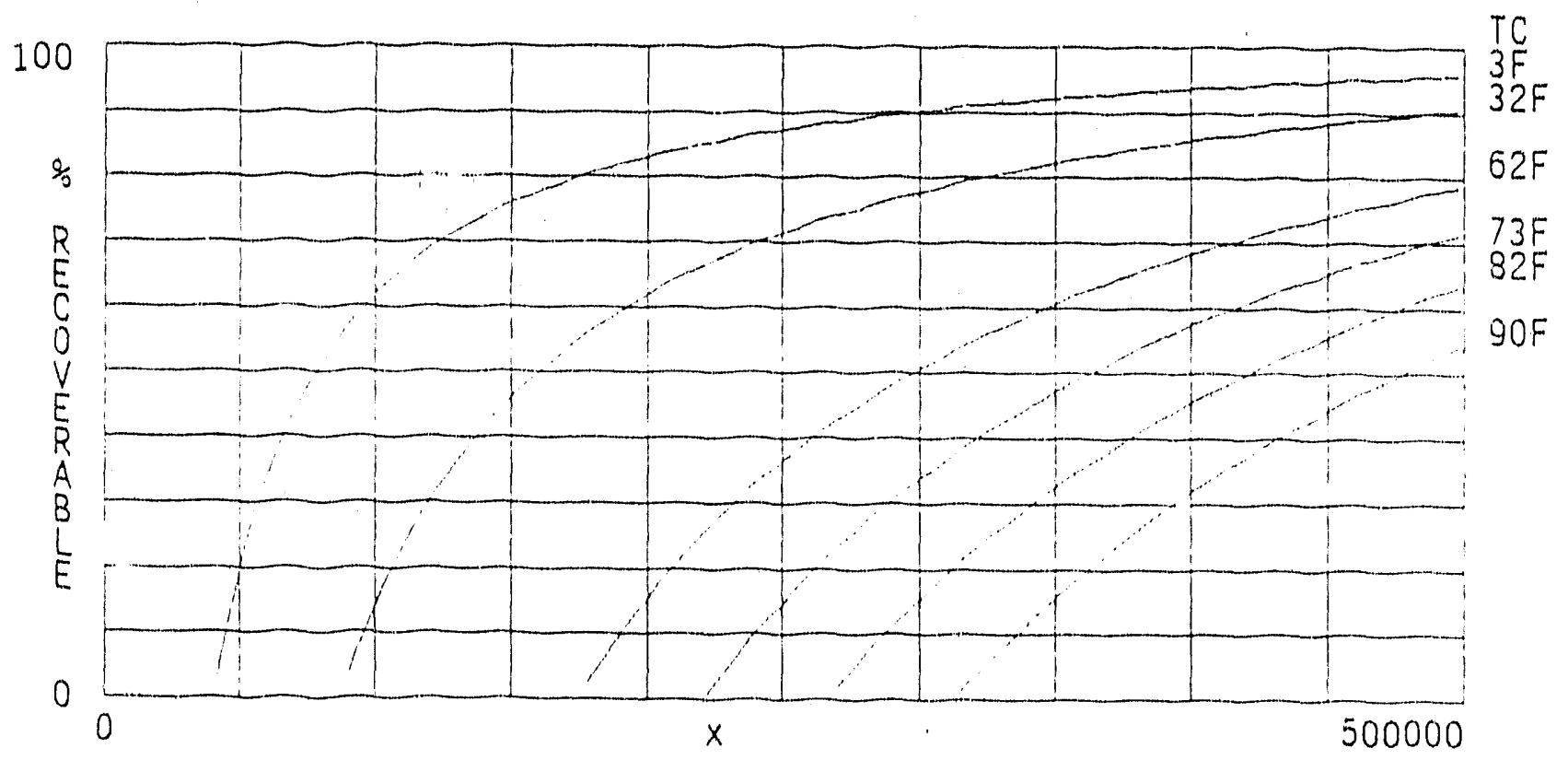

FIGURE 4.20b Mole Percent $\mathrm{CS}_{2}$ Recoverable vs. $\mathrm{CS}_{2}$ Concentration in $\mathrm{N}_{2}$ Desorption (ias ( $x$ in ppm) for Various Condensation Temperatures (TC) (absolute pressure $=2 \mathrm{~atm}$ ) 
$(\mathrm{x} p \mathrm{pm})$. Condensation temperatures near the freezing temperature of water ( $\left.32^{\circ} \mathrm{F}\right)$ and concentrations near $500,000 \mathrm{ppm}$ are required for at least $80 \%$ recovery after inert gas desorption. Even if a condenser operates at $32^{\circ} \mathrm{F}$, recovery is not possible if concentration is less than $175,000 \mathrm{ppm}$. To make $50 \%$ recovery possible, conoentration must be $300,000 \mathrm{ppm}$; $80 \%$ recovery is possible at $500,000 \mathrm{ppm}$. For gas at $500,000 \mathrm{ppm}$, about $35 \%$ recovery is possible with a condenser at $62^{\circ} \mathrm{F}$, and $20 \%$ recovery is possible at $73^{\circ} \mathrm{F}$.

The $82^{\circ} \mathrm{F}$ curve is below zero $\mathrm{R}$ at all concentrations below $500,000 \mathrm{ppm}$; therefore, if condensation is to be avoided in ducts that transport the loaded desorption gas to the condenser, the temperature in these ducts must be $82^{\circ} \mathrm{F}$ or above.

The preceding discussion assumes atmospheric pressure. If the loaded desorbing gas is compressed, condensation and recovery at lower concentrations and higher temperatures becomes possible. For example, F'igure 4.20 b shows that $80 \%$ recovery is possible at 2 atm total pressure, $320,000 \mathrm{ppm}$, and $32^{\circ} \mathrm{F}$. More than $50 \%$ recovery is possible at $500,000 \mathrm{ppm}$ at $90^{\circ} \mathrm{F}$. The decision on condenser pressurization must be based on economic concerns and is beyond the scope of this study. It will require more specific and detailed analyses of condenser systems.

Steam as a desorption medium also was briefly analyzed. Such usage would eliminate an $\mathrm{N}_{2}$ /steam heat exchange step. Because steam is condensable and liquid $\mathrm{CS}_{2}$ and water are immiscible, a phase rule ${ }^{38}$ analysis is required. Before the phase analysis, preparation of concentration/temperature plots for $\mathrm{CS}_{2}$ and $\mathrm{H}_{2} \mathrm{O}$ is necessary.

From published data, ${ }^{43}$ the Clausius-Clapyron equation that relates temperature $\left(\mathrm{T}_{\mathrm{w}}\right.$ in $\left.{ }^{\circ} \mathrm{F}\right)$ to $\mathrm{H}_{2} \mathrm{O}$ vapor pressure $\left(\mathrm{p}_{\mathrm{w}}\right.$ in psia) has been developed as follows:

$$
\begin{aligned}
\mathrm{C}_{\mathrm{w}} & =8.835 \times 10^{3} \\
\mathrm{~K}_{\mathrm{w}} & =7.531 \times 10^{6} \\
\mathrm{p}_{\mathrm{w}} & =\mathrm{K}_{\mathrm{w}} \exp \left(\mathrm{C} /\left(\mathrm{T}_{\mathrm{w}}+460\right)\right)
\end{aligned}
$$

The corresponding equation for $\mathrm{CS}_{2}$ is:

$$
\begin{aligned}
\mathrm{C}_{\mathrm{c}} & =-5.966 \times 10^{3} \\
\mathrm{~K}_{\mathrm{c}} & =4.7255 \times 10^{5} \\
\mathrm{p}_{\mathrm{c}} & \left.=\mathrm{K}_{\mathrm{c}} \exp \left(\mathrm{C}_{\mathrm{C}} / \mathrm{T}_{\mathrm{c}}+460\right)\right)
\end{aligned}
$$


In an $\mathrm{H}_{2} \mathrm{O} / \mathrm{CS}_{2}$ system, the total pressure ( $\mathrm{P}$ in psia) is given by:

$$
P=p_{w}+p_{c}
$$

In terms of $\mathrm{CS}_{2}$ concentration ( $\mathrm{x}$ in ppm), $\mathrm{p}_{\mathrm{c}}$ is given by:

$$
p_{0}=x P 10^{-6}
$$

Equations 28 and 29 can be inverted as follows:

$$
\begin{gathered}
T_{\mathrm{c}}=\left(\mathrm{C}_{\mathrm{c}} / \ln \left(\mathrm{p}_{\mathrm{c}} / \mathrm{K}_{\mathrm{c}}\right)\right)-460 \\
\mathrm{~T}_{\mathrm{N}}=\left(\mathrm{C}_{\mathrm{W}} / \ln \left(\mathrm{p}_{\mathrm{W}} / \mathrm{K}_{\mathrm{W}}\right)\right)-460
\end{gathered}
$$

After incorporating Equations 30 and 31, both Equations 32 and 33 can be plotted on the same diagram. The result, Figure $4.21 \mathrm{a}$, gives the temperatures, as a function of $\mathrm{x}$, at which both $\mathrm{CS}_{2}$ and $\mathrm{H}_{2} \mathrm{O}$ liquid vapor pressures become equal to their partial pressures in the desorbing steam when the total pressure is $1 \mathrm{~atm}$. Assuming desorption with superheated steam, a vapor consisting of steam plus $\mathrm{x}$ ppm of $\mathrm{CS}_{2}$ vapor will exit the desorption tower. If the $\mathrm{CS}_{2}$ concentration is $400,000 \mathrm{ppm}$ and the desorption temperature is $300^{\circ} \mathrm{F}\left(150^{\circ} \mathrm{C}\right)$, the desorption gas before it enters the condenser can be represented as point A on Figure 4.21. The phase rule for point A gives:

$$
\begin{aligned}
& \text { no, of components - no, of phases }+2=\text { degrees of freedom } \\
& 2-1+2=3
\end{aligned}
$$

With pressure and composition fixed, the system has one more degree of freedom, so temperature can be reduced further in the condenser, and no condensation will occur until point $\mathrm{B}$ is reached. Then the $\mathrm{H}_{2} \mathrm{O}$ partial pressure is equal to $\mathrm{H}_{2} \mathrm{O}$ vapor pressure, and water will begin to condense; thus another phase appears: liquid $\mathrm{H}_{2} \mathrm{O}$. The phase rule for point $\mathrm{B}$ gives: degrees of freedom $=2-2+2=2$.

With only two degrees of freedom and pressure fixed, vapor composition must vary when $\mathrm{T}$ is reduced further, and $\mathrm{H}_{2} \mathrm{O}$ will continue to condense. When point $\mathrm{C}$ is reached, $\mathrm{CS}_{2}$ partial pressure is equal to $\mathrm{CS}_{2}$ vapor pressure, and liquid $\mathrm{CS}_{2}$ will begin to condense. But 
liquid $\mathrm{CS}_{2}$ and water are immiscible, so three phases will be present; degrees of freedom $=2-3+2=1$.

With only one degree of treedom, taken up by fixed pressure, further cooling will not change temperature or vapor composition but will result in condensation of the vapor at constant composition and tenperature until all vapor is condensed. Thus, in principle at least, it is always possible to obtain $100 \% \mathrm{CS}_{2}$ recovery at any concentration. In practice, however, limitations of heat transfer rate may result in condensation of less than $100 \%$. Figure 4.21a shows that the desorption effluent (steam and $\mathrm{CS}_{2}$ mixture), if at 500,000 ppm and 1 atm total pressure, can yield $100 \% \mathrm{CS}_{2}$ recovery if cooled to $76^{\circ} \mathrm{F}$. At 1 atm and only $100,000 \mathrm{ppm}$, the desorption effluent must be cooled to $12^{\circ} \mathrm{F}$ to allow $100 \%$ recovery,

If the desorption eftluent is compressed to 2 atm, complete recovery is possible at higher temperatures. For example, Figure 4.21b shows that cooling to only $115^{2} \mathrm{~F}$ is needed at 500,000 ppm and $2 \mathrm{~atm}$; at 100,000 ppm and $2 \mathrm{~atm}$, cooling to only $38^{\circ} \mathrm{F}$ is required for possible $100 \%$ recovery.

We conclude that, because of steam condensation, Cis recovery through steam desorption can be acheved at higher yields and with less cooling than (CS $\mathrm{S}_{\mathrm{g}}$ recovery through nitrogen desorption. This conclusion is based only on thermodynamics. A complete analysis that uses practical rate estimates to detine heat exchange surface is required to verify the advantage. Only temperature swing adsorption has been analyzed in this report. However, the moving bed technology uses continuous withdrawal of carbon for desorption, so further advantages of pressurized steam desorption may occur in a moving bed system. This evaluation will occur early in the next phase of this project.

\subsubsection{Solid Adsorbents and Isotherms}

Many adsorbents are used in gas adsorption separation processes. All have extensive porous structure and hundreds of square meters of internal' surface area per gram. As mentioned in Section 4.1.1, the commonly used adsorbents are activated carbon, zeolite, silica gel, and alumina. A few others are available, such as polymeric materials (usually styrene based) and various ion-exchange resins, which can have different chemical functionalities on their internal surfaces. These materials usually have significantly less surface area than activated carbon and other commonly used adsorbents. Testing of all of these adsorbent types for $\mathrm{CS}_{2}$ was discussed in Section 4.1.1.

As in the case of gas absorption into a liquid sorbent, it is necessary to understand how $\mathrm{CS}_{2}$ will distribute itself at equilibrium between the gas and sorbent phases for solid sorbents. This information then can be used to estimate the required number and dimensions of adsorption towers and the required flow rates in an adsorption system for Teepak. 


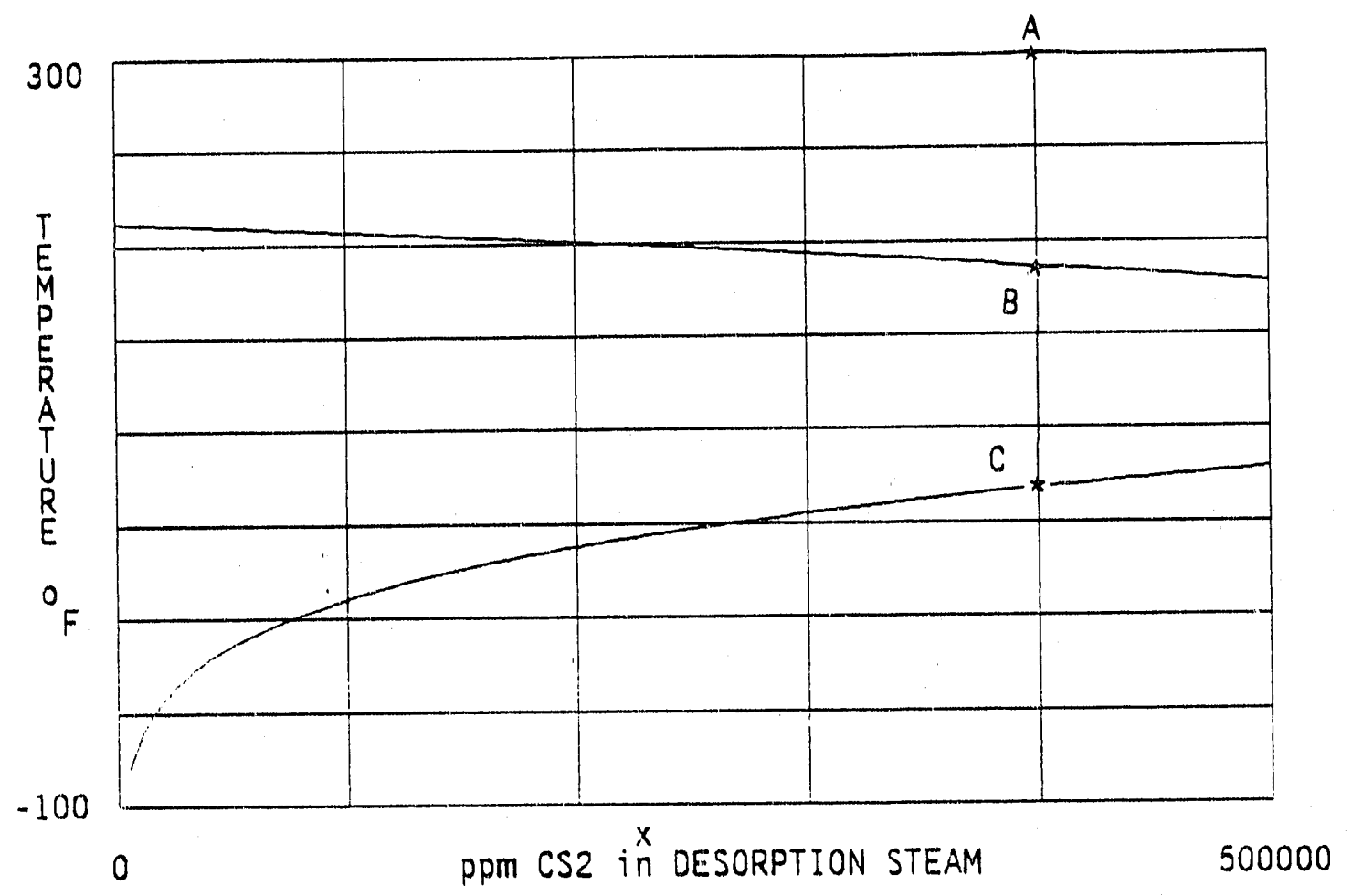

FIGURE 4.21a Phase Diagram for $\mathrm{CS}_{2} / \mathrm{H}_{2} \mathrm{O}$ System at 1 atm

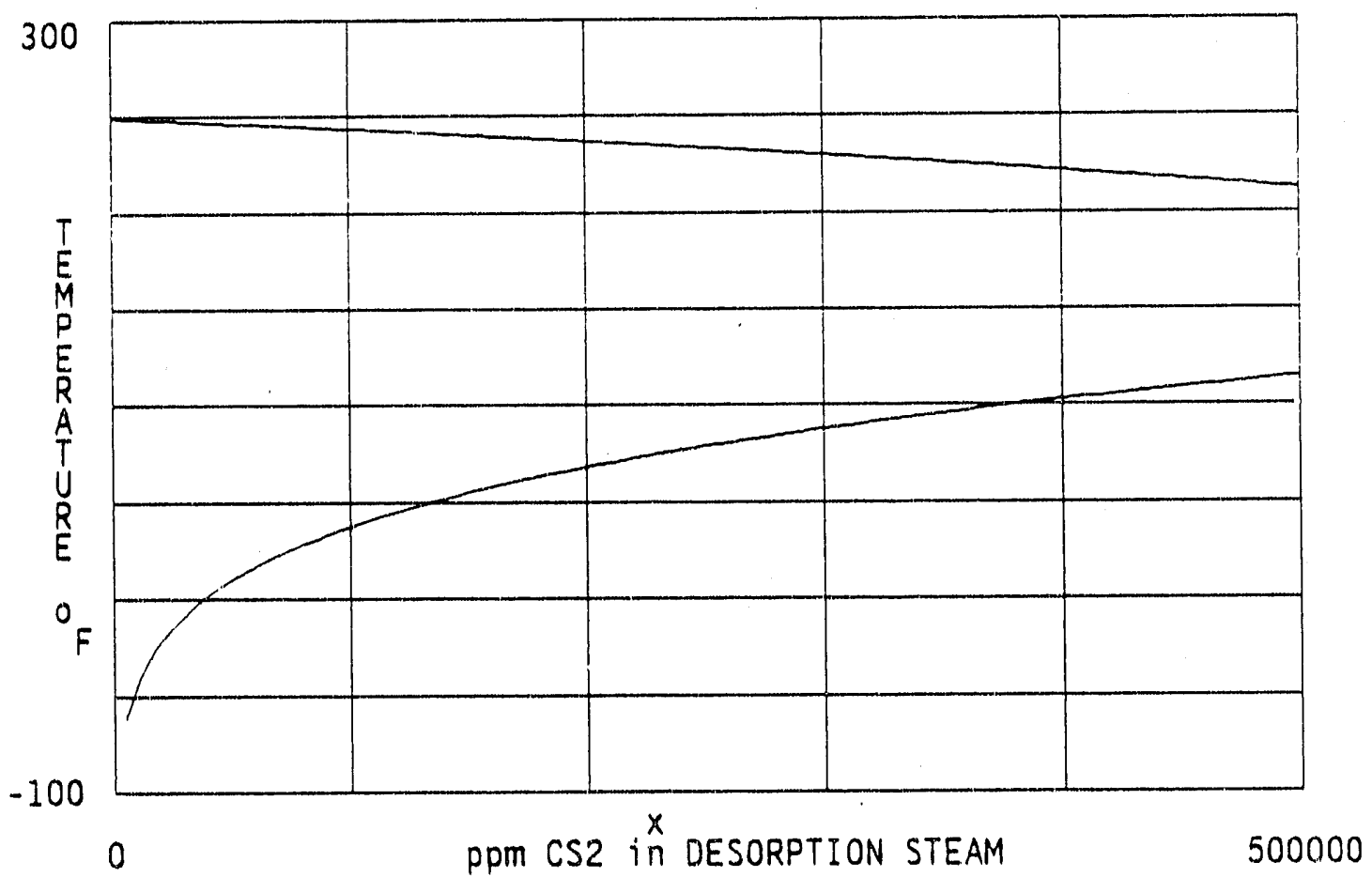

FIGURE 4.21b Phase Diagram for $\mathrm{CS}_{2} / \mathrm{H}_{2} \mathrm{O}$ System at 2 atm 
An inverse measure of an adsorbate's affinity for an adsorbent is the "separation factor" $R$. It is defined as follows:

$$
R=\left(y / y_{0}\right)\left(1-q / q_{0}\right) /\left(\left(q / q_{0}\right)\left(1-y / y_{0}\right)\right)
$$

where $\mathrm{y}$ is $\mathrm{CS}_{2}$ concentration in the gas phase and $\mathrm{q}$ is $\mathrm{CS}_{2}$ concentration in the solid phase in equilibrium with $y$. The term $y_{0}$ is a reference gas concentration (in this case, the highest available concentration, or the inlet gas concentration) and $q_{0}$ is the corresponding solidphase $\mathrm{CS}_{2}$ concentration at equilibrium with inlet gas. The units of $y$ and $q$ are arbitrary and, in this case, we take the units of $y$ as ppm and of $q$ as grams of $\mathrm{CS}_{2}$ per gram of adsorbent. If $\mathrm{y}$ is low and $\mathrm{q}$ high, then $\mathrm{CS}_{2}$ has high affinity for the adsorbent and $\mathrm{R}$ will be low. Conversely, if $\mathrm{CS}_{2}$ has low affinity for the adsorbent, $R$ will be high. Separation factor is an important input in process calculations for a $\mathrm{CS}_{2}$ adsorption separations plant.

To use separation factor for design, experimental data relating $\mathrm{y}$ and $\mathrm{q}$ over a given range at a given temperature are needed. Such data usually are plotted with $q$ on the vertical axis, and the result is called an "isotherm." Figure 4.22 shows two isotherms for $\mathrm{CS}_{2}$ adsorption on activated carbon, one at $77^{\circ} \mathrm{F}$ and the other at $300^{\circ} \mathrm{F} .{ }^{51}$ This plot represents the only high-quality measured set of isotherm data that we have found in the literature for $\mathrm{CS}_{2}$ adsorption on any adsorbent. In the Teepak case, $\mathrm{CS}_{2}$ partial pressure is 0.00147 psia $(100 \mathrm{ppm}$ ), which is not discernible on Figure 4.22. Figure 4.23 shows an expanded view of an isotherm representative of $\mathrm{CS}_{2}$ on carbon. (This figure is an enlargement of the left side of the $77^{\circ} \mathrm{F}$ curve in Figure 4.22.) At $100 \mathrm{ppm} \mathrm{CS}_{2}$, carbon can adsorb more than $5 \%$ of its weight in $\mathrm{CS}_{2}$. As mentioned in Section 4.3 , this loading is much larger than that for any other adsorbent, making carbon the adsorbent of choice for $\mathrm{CS}_{2}$ recovery. In Section 4.3, data from $\mathrm{CS}_{2}$ adsorption measurements for a variety of different adsorbents were presentec' in the form of breakthrough plots similar to that shown in Figure 4.19. Each breakthrough plot represents one point on the adsorption isotherm, the point at which $\mathrm{CS}_{2}$ concentration is $100 \mathrm{ppm}$ in air. The corresponding vertical distance to the isotherm we call the maximum loading and give the symbol $\mathrm{q}_{0}$. The maximum loading represents the grams $\mathrm{CS}_{2}$ per gram adsorbent in equilibrium with a vapor containing $100 \mathrm{ppm} \mathrm{CS}_{2}$.

Because more than one point on the $\mathrm{CS}_{2}$ isotherms for the adsorbents tested was not obtained, it is necessary to generalize the isotherm concept so that . nroper characterization of the adsorption isotherm can he defined and systematically varied in later calculations. In other wolds, because of finding limitations it was impossible to produce, in this project, enough breakthrough plots at different $\mathrm{CS}_{2}$ concentrations to create adequate isotherms for each adsorbent. Therefore, we developed a method of estimating separation factor from the single measured $q_{0}$. Because $q_{0}$ represents the essential $C_{2}$ maximum-loading measurement, it is believed that this method will give consistent relative estimates of loading that can be used to estimate the range of effectiveness of gas adsorption for $\mathrm{CS}_{2}$ recovery. 


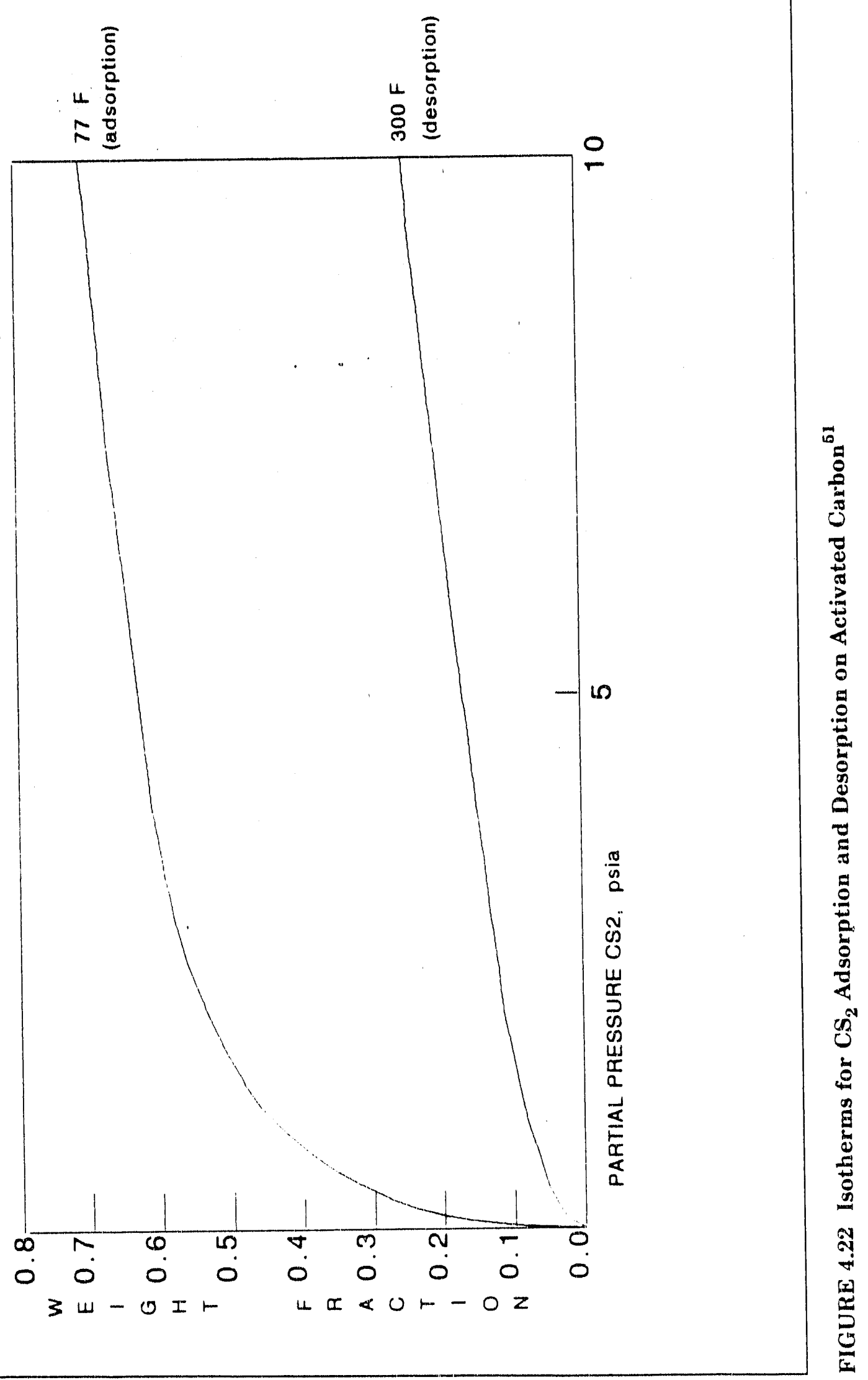




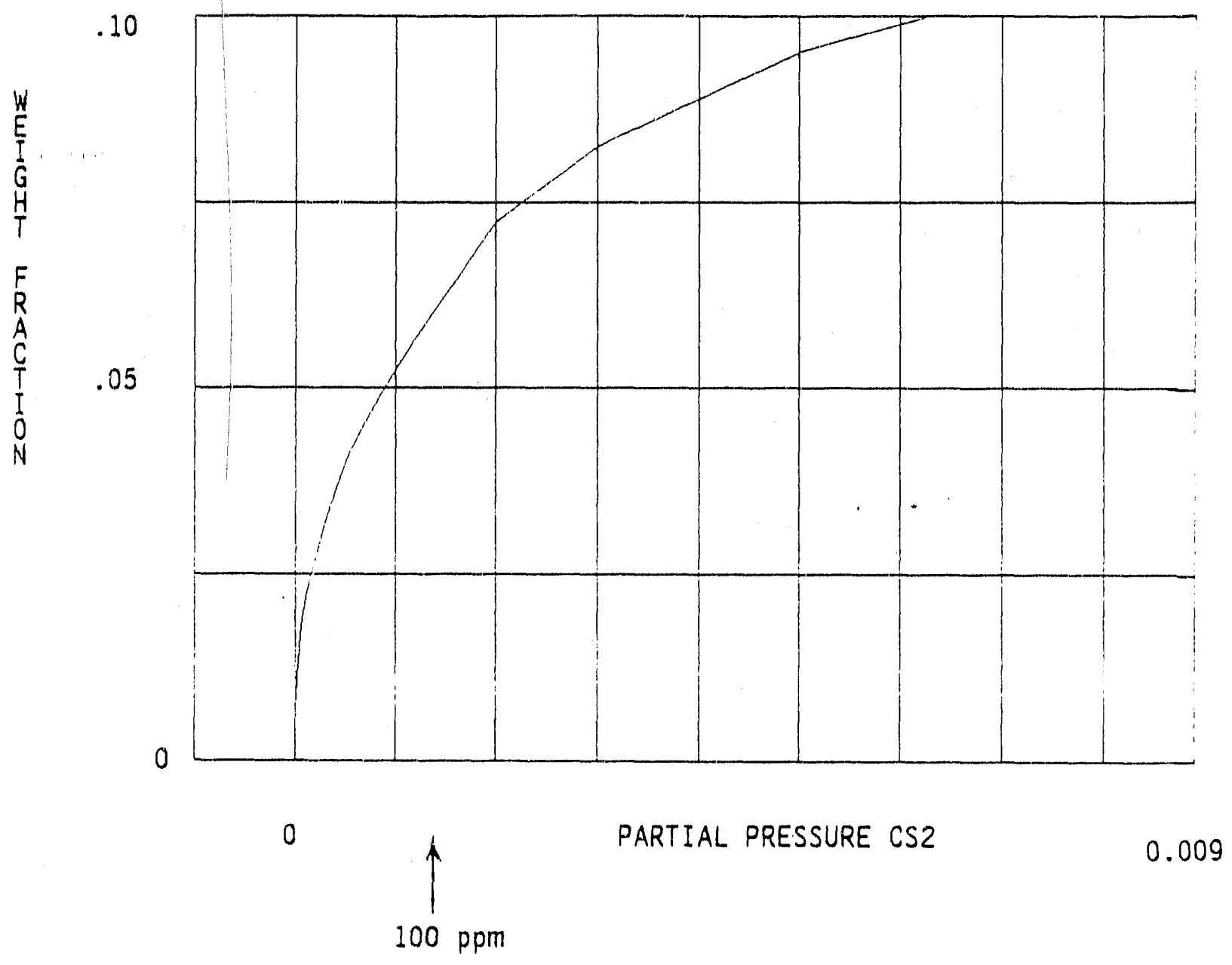

\section{FIGURE 4.23 Expanded View of a Representative Carbon Isotherm}

First, the time adsorption is to cease (the breakpoint) must be stipulated. Referring to Figure 4.19 , we see that when the volume of effluent reaches $V_{3}$, the concentration of $\operatorname{CS}_{2}$ is $y=C_{c}$, which is $10 \%$ of $y_{0}=C_{0}$, the feed concentration. This level is a reasonable definition of breakpoint for the Teepak case, as it represents a $\mathrm{CS}_{2}$ removal efficiency of considerably more than $90 \%$. If we make this assumption, we have $y / y_{0}=0.10$ and Equation 35 can be rearranged:

$$
R=\left(q_{10} / q-1\right) / 9
$$

In the Basmadjian method, which will be used for process calculations, if both the maximum loading $\left(\mathrm{q}_{0}\right)$ and the equilibrium loading $(\mathrm{q})$ at the breakpoint $\left(\mathrm{y}=0.1 \mathrm{y}_{0}\right)$ are known, $R$ can be estimated and adsorption column height calculated with reasonable accuracy. However, because only $\mathrm{q}_{\mathrm{f}}$ was measured for each adsorbent, a method of relating $\mathrm{q}$ to the measured $\mathrm{q}_{0}$ must be defined. Figure 4.24 has been used for this purpose; it defines 


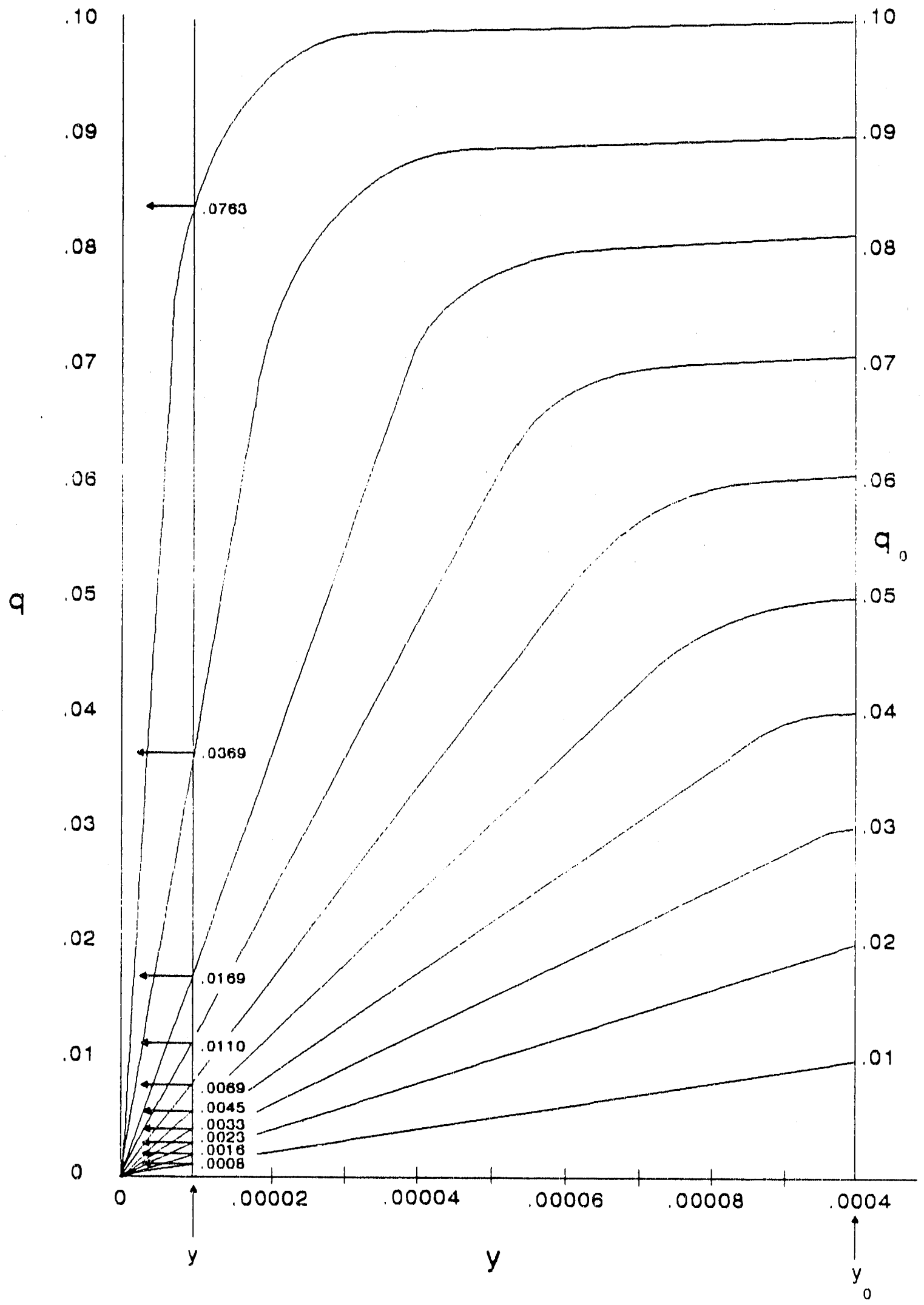

FIGURE 4.24 Variable Isotherm Definition 
the shape of isotherms from $\mathrm{q}_{0}=0.01$ to $\mathrm{q}_{0}=0.10$. The isotherm shape characteristic of carbon has been retained, and the initial slope, defined by $q_{0}$, is used to define $q$. Figure 4.25 shows a curve fit from $\mathrm{q}_{0} / \mathrm{q}$ data extracted from Figure 4.24. A regression equation was fitted from the data and used to give a numeric relationship between $q$ and $q_{0}$. This relationship, combined with Equation 29, was used to obtain $R$ in the computer program (to be discussed later) that was developed to relate $q_{0}$ to adsorption plant requirements.

\subsubsection{Adsorption Tower Design}

The means of varying the adsorption isotherm described above make it possible to evaluate $\mathrm{CS}_{2}$ adsorption in general terms and to estimate design of an adsorption plant for $\mathrm{CS}_{2}$ removal and recovery.

Because gas adsorption is a nonsteady process, the required calculations include time as an additional variable. Therefore, gas adsorption analysis methods can be quite complex. Many methods and techniques have been developed for such calculations. Of these, many are complicated, arcane, and only valid for certain conditions (e.g., constant separation factor, diffusion controlling, etc.). In an effort to provide a simple method with proven accuracy, Basmadjian ${ }^{49}$ has published graphs from which gas adsorption tower design can proceed. This method allows the bed depth (i.e., tower height) to be estimated given values for the input items shown in Table 4.2.

To calculate the required number of adsorption towers, the superficial gas velocity in the adsorption bed is needed. This velocity depends on bed depth, pressure, and flow resistance of the packed bed. Published pressure drop and velocity curves were used to develop a method of iterating between a velocity calculation that assumes bed depth and a Basmadjian calculation that yields a revised bed depth. Algorithms were developed to interpolate in both the Basmadjian graphs and the pressure-drop graphs. The complete calculation was programmed for computer solution. Appendix B contains the details of this calculation and also lists the main computer program, which is coded in Microsoft Fortran 77. The program shown, ADSORB.FOlR, gives bed depth, tower requirement, and superficial gas velocity as functions of loading of the adsorbent $\left(\mathrm{q}_{10}\right)$. Other programs (not given) were developed from ADSORB.FOR to estimate the effect of other important factors such as breakthrough time, tower diameter, and pressure drop.

By using ADSORB.FOR and the numeric inputs from Table 4.2, the following results were obtained:

- Number of towers required $=18$

- Bed depth $=5 \mathrm{ft}$ 


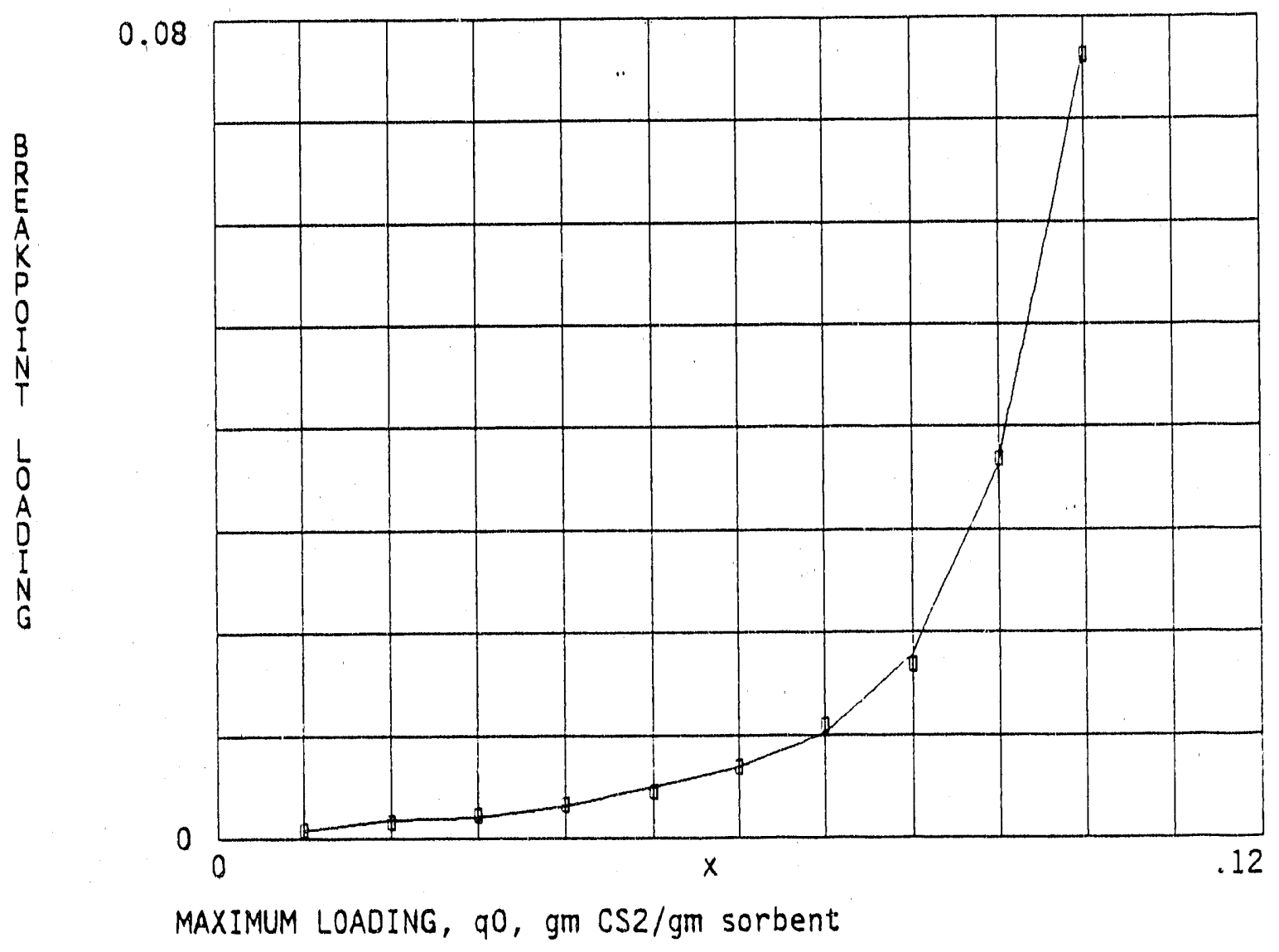

FIGURE 4.25 Curve Fit of Breakpoint Loading with Maximum Loading for the Isotherms of Figure 4.24

TABLE 4.2 Input for Adsorption System Calculation, Nominal Case

\begin{tabular}{lc}
\hline \multicolumn{1}{c}{ Factor } & Value \\
\hline Separation factor & Eq. 35 \\
Breakthrough time & $16 \mathrm{hr}$ \\
Gas flow rate & $400,000 \mathrm{cfm}$ \\
Inlet gas concentration & $\mathrm{y}_{\mathrm{o}}=100 \mathrm{ppm}$ \\
Bed density & $30 \mathrm{lb} / \mathrm{ft}^{3}$ \\
Particle size & $4 \times 6 \mathrm{mesh}^{-3}$ \\
Particle diffusivity & $1.01 \times 10^{-3} \mathrm{ft}^{2} / \mathrm{min}$ \\
Tower diameter & $12 \mathrm{ft}$ \\
Breakpoint concentration & $10 \mathrm{ppm}$ \\
Maximum loading (q $\left.\mathrm{q}_{\mathrm{n}}\right)$ & $0.05 \mathrm{~g} / \mathrm{g}$ \\
Total available pressure drop & $2 \mathrm{psi}$ \\
Total pressure & $15.7 \mathrm{psi}(1 \mathrm{psig})$ \\
\hline
\end{tabular}


Thus, for the case defined in Table 4.2, the 400,000-cfm Teepak air flow, after drying, can be reduced from $100 \mathrm{ppm} \mathrm{CS}_{2}$ to $10 \mathrm{ppm}$ by splitting the flow into 18 adsorption towers, each with activated carbon packing $5 \mathrm{ft}$ deep. As each tower becomes filled in $16 \mathrm{hr}$, it must be taken off-stream and steam-desorbed. Thus, more than 18 towers must be available to provide spares during desorption. As in Section 3 for gas absorption, we now proceed to analyze the gas adsorption case further, varying some of the more significant input parameters.

\subsubsection{Effect of Maximum Loading}

The model was run with all numeric inputs giveri in Table 4.1, except that the maximum loading $\left(\mathrm{q}_{10}\right)$ varied from 0.01 to 0.10 . The results are shown as the 1-psig case in Figures 4.26a, 4.26b, and 4.26c. As expected, the capacity of an adsorbent to load with $\mathrm{CS}_{2}$ at 100 ppm, as defined by $q_{n}$, has a large effect on the depth of adsorbent bed required. As seen in Figure 4.26a, if the adsorbent will load with only $1 \% \mathrm{CS}_{2}$, then the required bed depth is more than $10 \mathrm{tt}$, but if the adsorbent will load with $10 \% \mathrm{CS}_{2}, 2.5 \mathrm{ft}$ is sufficient bed depth. The nominal case is $5 \%$ loading, which results in the nominal bed depth of $5 \mathrm{ft}$ as mentioned in the previous section.

If the effect of $q_{0}$ is limited strictly to bed depth, then the difference between $10 \mathrm{ft}$ and $2.5 \mathrm{ft}$ may not have overriding economic significance. However, as bed depth increases, resistance to flow through the bed also increases, and, at constant pressure drop, the gas throughput diminishes and the number of towers required to handle the Teepak flow increases. This effect is seen in Figure 4.26b. Thus, 30 towers with 10 -ft bed depth are required for the $1 \% \mathrm{CS}_{2}$ loading case, while only 13 towers with 2.5 -ft bed depth are required for the $10 \%$ case. Eighteen towers with 5 -ft bed depth are needed for the nominal $5 \%$ case. This effect can be seen in another way by plotting the superficial gas velocity through the tower as a function of maximum loading, as shown in Figure 4.26c. Thus, the gas velocity through the $1 \%$ loading adsorbent is only $100 \mathrm{ft} / \mathrm{min}$, while the velocity for the shorter $10 \%$ loading bed is $230 \mathrm{tt} / \mathrm{min}$. This effect is caused by the imposition of constant pressure drop. In Section 4.4.8, the advantages of allowing larger pressure drops are considered. .

The calculations shown are for dry gas. However, laboratory testing has shown that one of the main effects of using a humidified gas in carbon adsorption, as at Teepak, is that the maximum loading of the carbon is reduced. Comprehensive data on hindrance of $\mathrm{CS}_{2}$ adsorption by $\mathrm{H}_{2} \mathrm{O}$ was not obtained. However, measurement of $\mathrm{CS}_{2}$ loading at $100 \mathrm{ppm}$ for both the dry air case $(0 \%$ relative humidity $[\mathrm{RH}])$ and the wet air case $(100 \% \mathrm{RH})$ have been obtained for GBAC carbon by Teepak. The results are $6.2 \%$ and $2.24 \%$ respectively. Teepak also obtained a plot of $\mathrm{H}_{2} \mathrm{O}$ loading on $\mathrm{GBAC}$ carbon as a function of $\mathrm{RH}$ at $32^{\circ} \mathrm{C}$ from the German firm Lurgi. This is given in Figure 4.27, the lower curve. Note that at 100\% RH the $\mathrm{H}_{2} \mathrm{O}$ loading is $31 \%$. 


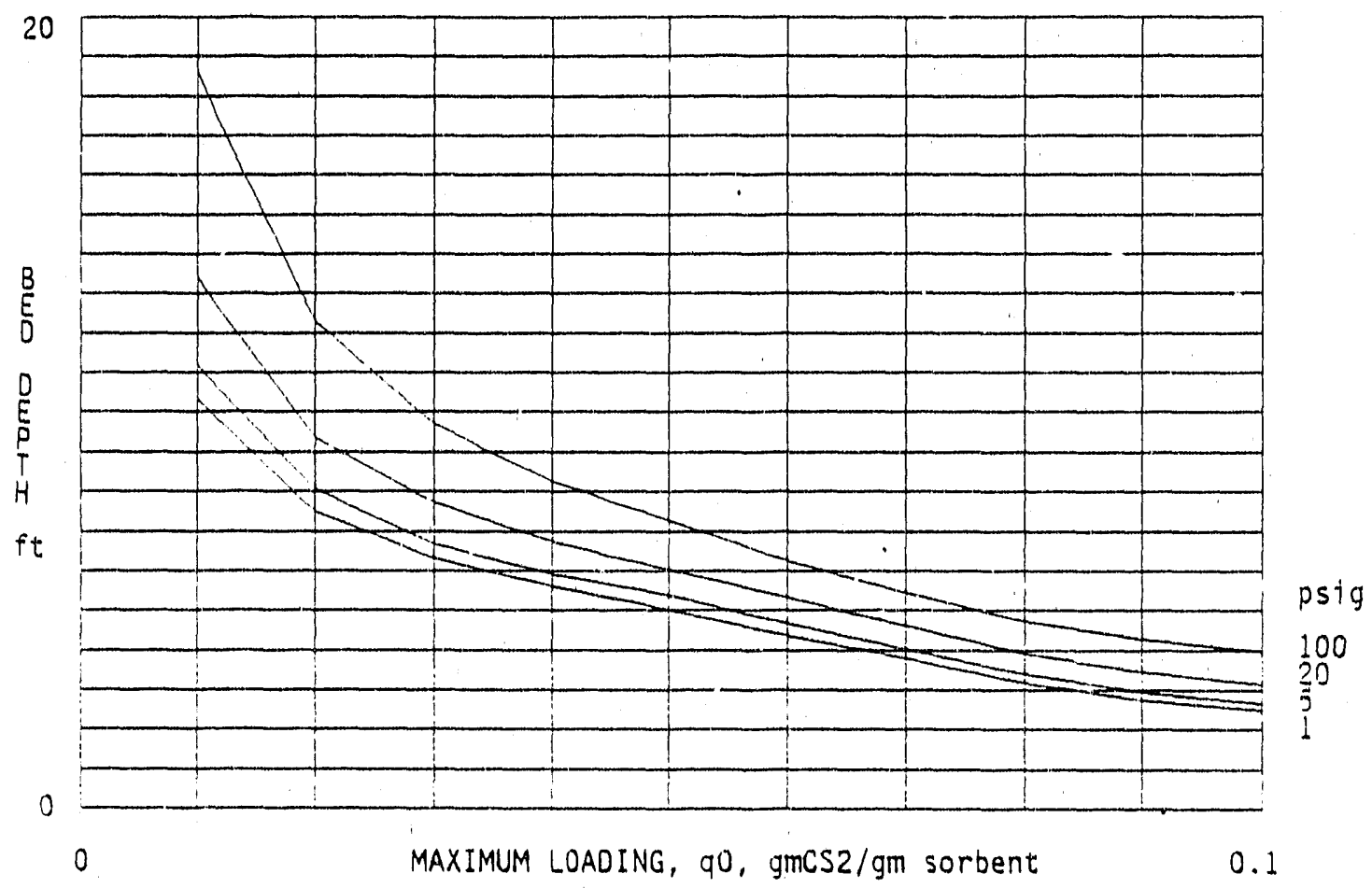

FIGURE 4.26a Adsorption Bed Depth vs. Maximum Loading $\left(q_{0}\right)$

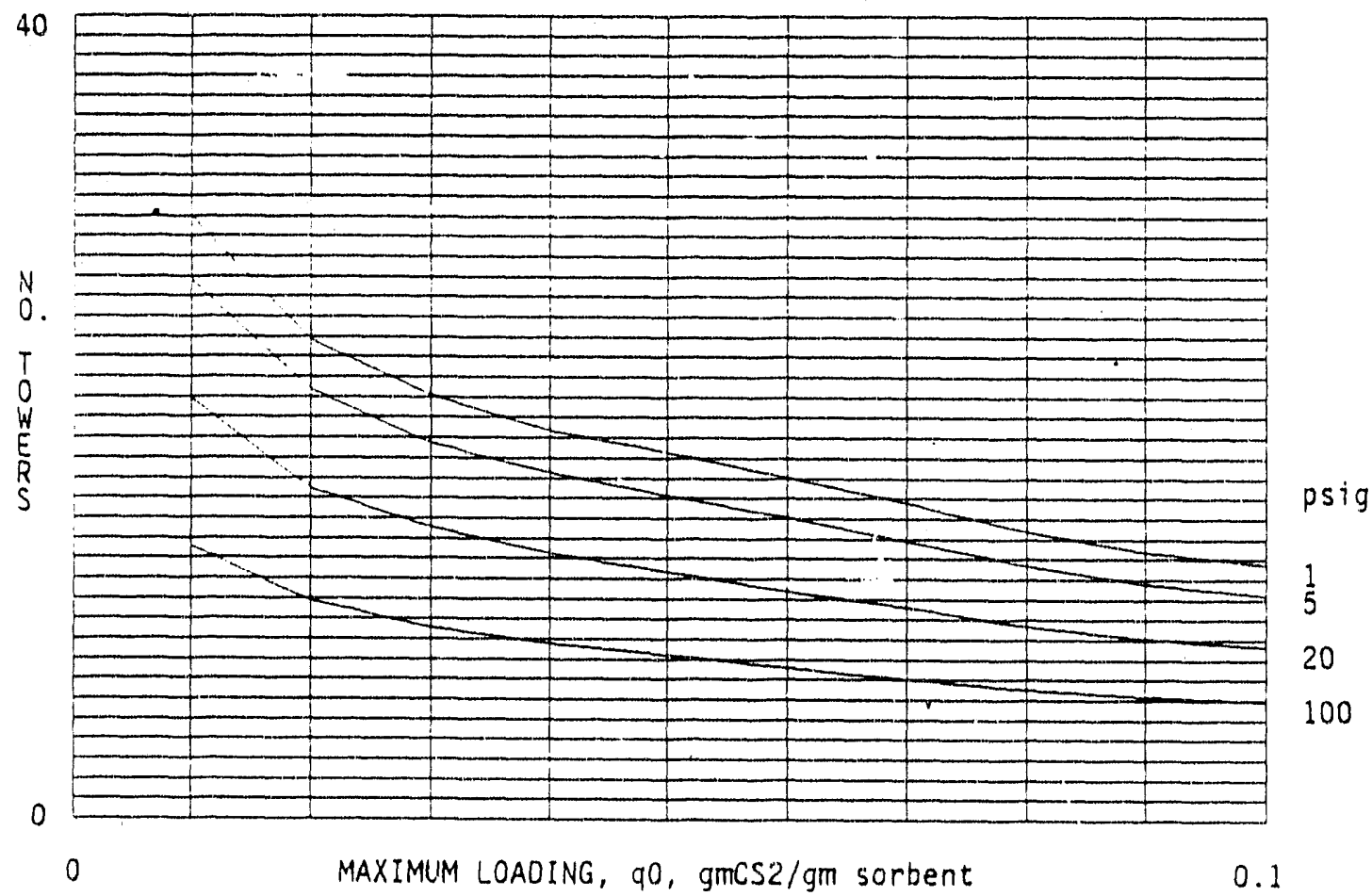

FIGURE 4.26b Number of Adsorption Towers vs. Maximum Loading $\left(\mathrm{q}_{o}\right)$ 


\section{5}

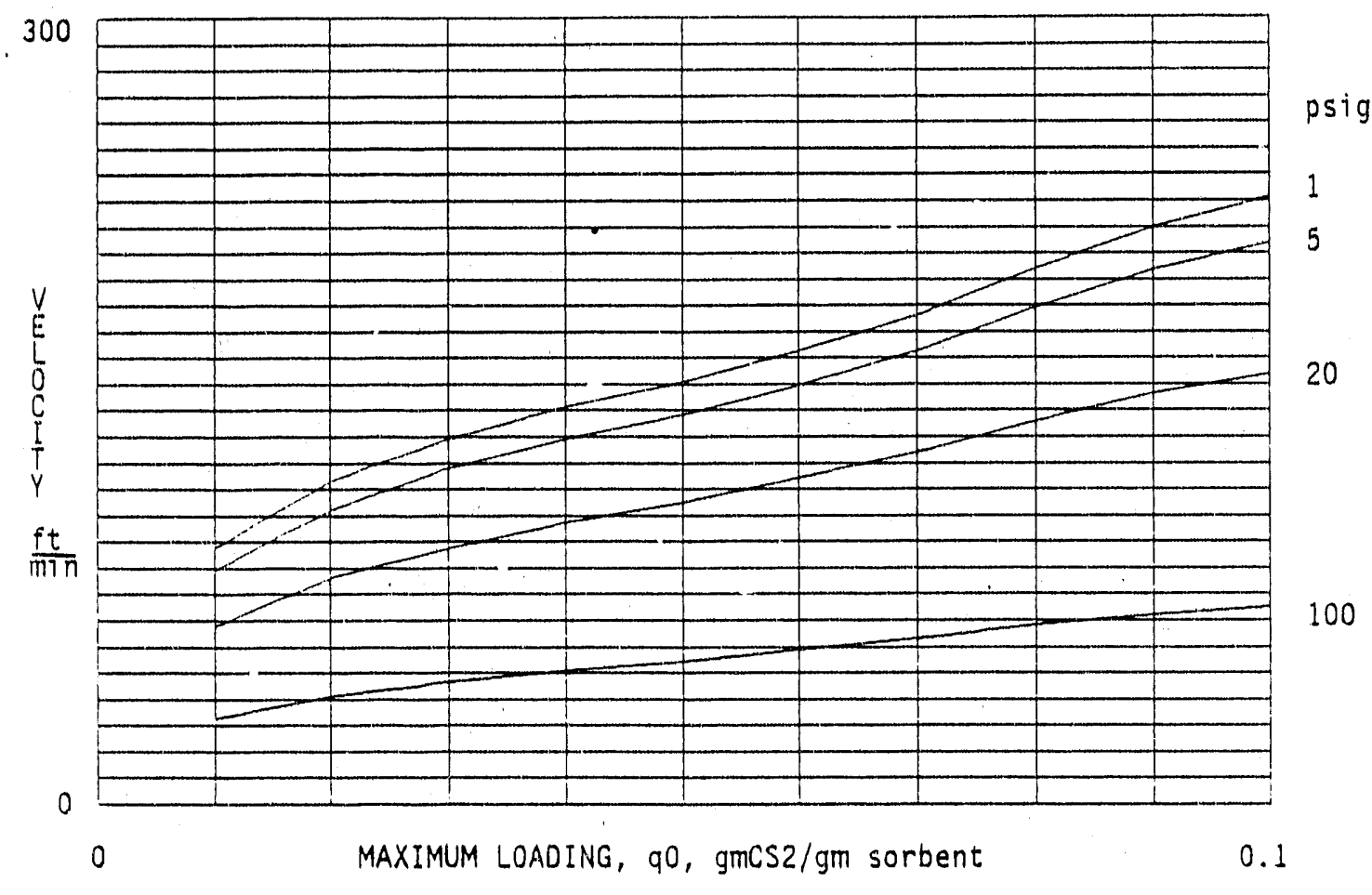

FIGURE 4.26c Superficial Velocity vs. Maximum Loading $\left(q_{0}\right)$

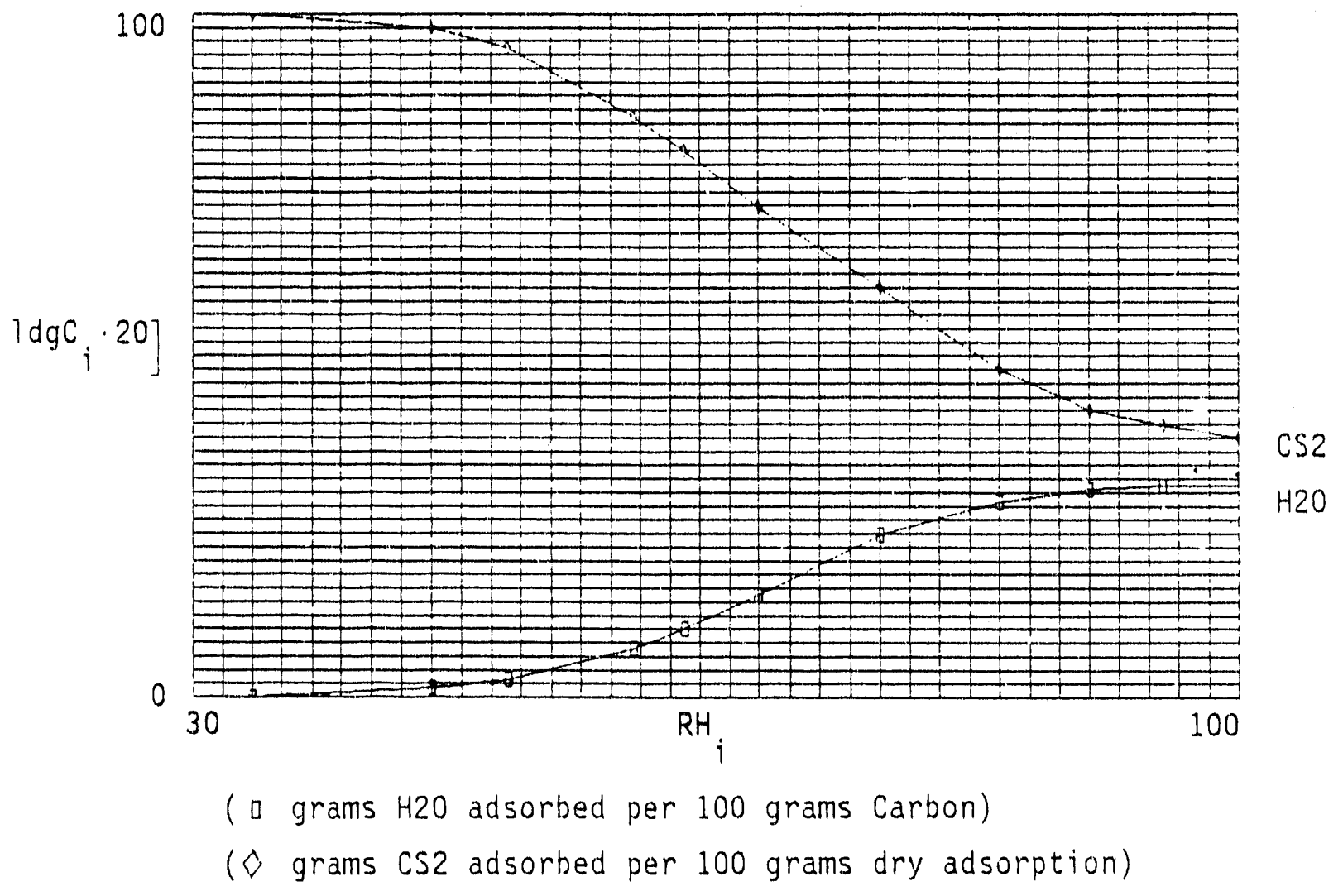

FIGURE 4.27 Estimated Effect of Relative Humidity on $\mathrm{H}_{2} \mathrm{O}$ and $\mathrm{CS}_{2}$ Loading 
With the following assumptions the $\mathrm{CS}_{2}$ loading, at $32^{\circ} \mathrm{C}$, can be estimated over the range of $\mathrm{RH}$ from 0 to $100 \%$.

1. The loading $6.2 \%$ at $0 \% \mathrm{RH}$ represents $1.00 \%$ occupation of the $\mathrm{CS}_{2}$ adsorption sites on carbon.

2. The loading $2.24 \%$ at $100 \% \mathrm{RH}$ represents $(2.24 / 6.2) 100=36 \%$ occupation of the $\mathrm{CS}_{2}$ adsorption sites on carbon.

3. The $\mathrm{H}_{2} \mathrm{O}$ blocking of $\mathrm{CS}_{2}$ adsorption sites is given by:

$$
\frac{100-36 \text { sites blocked by } \mathrm{H}_{2} \mathrm{O}}{31 \mathrm{H}_{2} \mathrm{O} \text { sites occupied }}=\frac{64}{31}=2.06 \frac{\mathrm{CS}_{2} \text { sites }}{\mathrm{H}_{2} \mathrm{O} \text { sites }}
$$

4. The ratio 2.06 holds ov"er the adsorption range and applies to carbon adsorbents in general.

Given the above assumptions, Table 4.3 is constructed for carbon adsorption. Figure 4.27 is constructed from the table. Figures $4.27,4.26 \mathrm{a}$ and $4.26 \mathrm{~b}$ can be used to estimate the requirements for a wet gas. For example, as seen in Table 4.1, the $\mathrm{q}_{0}$ measurements for the carbons tested range from $4 \%$ to $11 \%$. Thus, from Figure 4.27 we estimated maximum loading ( $39 \%$ of the dry case for $100 \% \mathrm{RH}$ ) and from Figures $4.26 \mathrm{a}$ and $4.26 \mathrm{~b}$, we estimated the required bed depth and number of towers for each of the carbons. The results for the $100 \%$ RH case are shown in Table 4.4, which also presents comparable data for the best noncarbon adsorbent tested, the "hydrophobic zeolite" Silicalite. This material was thought to be water-repellent, but when it was tested with wet gas its maximum loading was found to diminish by $50 \%$. Figures $4.26 \mathrm{a}$ and $4.26 \mathrm{~b}$ were not prepared for maximum loading less than 0.01, as required for the wet Silicalite case, but by extrapolating to the left a rough estimate was ubtained. Comparison of the Silicalite data in Table 4.4 with the carbon data indicates that the noncarbon adsorbents tested, including Silicalite, are of little interest for the Teepak application.

\subsubsection{Effect of System Pressure}

If the Teepak gas were pressurized before being sent to adsorption towers for $\mathrm{CS}_{2}$ removal, the volumetric flow rate would be proportionally reduced, and $q_{0}$ would increase due to the increased $\mathrm{CS}_{2}$ partial pressure. This reduced flow would require fewer towers but increased bed depth. For example, if $\mathrm{q}_{t)}=0.06$, compression from 1 psig to 100 psig would reduce the number of towers from 18 to 7.6, as seen in Figure 4.26b, but would increase bed depth from $5 \mathrm{ft}$ to $6.4 \mathrm{ft}$ (see Figure $4.26 \mathrm{a}$ ). Although the 1.0-tower reduction would reduce tower cost significantly, the required compressors would be an added expense. Figure 3.4 shows that the cost of compressors for 100 psig is $\$ 8$ million, much higher than the cost of 10 towers. Compression to 20 psig would reduce the number of towers to 12 (6-ft bed depth) 
TABLE 4.3 Carbon Disulfide Loading at $100 \mathrm{ppm}$ Vapor Concentration as a Function of Relative Humidity

\begin{tabular}{ccccc}
\hline $\mathrm{H}_{2} \mathrm{O} \begin{array}{c}\text { Loading } \\
(\%)\end{array}$ & $\begin{array}{c}\mathrm{RH} \\
(\%)\end{array}$ & $\begin{array}{c}\text { Surface } \\
\text { Blockage } \\
(\%)\end{array}$ & $\begin{array}{c}\text { Surface } \\
\text { Available } \\
(\%)\end{array}$ & $\begin{array}{c}\mathrm{CS}_{2} \text { Loading } \\
(\% \text { of dry case })\end{array}$ \\
\hline 0.06 & 34.0 & 0 & 100 & 100 \\
1.4 & 46.0 & 2 & 98 & 98 \\
2.5 & 51.1 & 5 & 95 & 95 \\
7.2 & 59.5 & 15 & 85 & 85 \\
10.0 & 63.0 & 20 & 80 & 80 \\
15.0 & 68.0 & 28 & 78 & 78 \\
23.8 & 76.0 & 40 & 60 & 60 \\
28.7 & 84.0 & 52 & 48 & 48 \\
30.0 & 90.0 & 58 & 42 & 42 \\
30.9 & 95.0 & 60 & 40 & 40 \\
31.0 & 100.0 & 62 & 38 & 38 \\
\hline
\end{tabular}

TABLE 4.4 Estimated Tower and Bed Depth Requirements for Activated Carbon and Hydrophobic Zeolite for Dry and Wet Gas Cases

\begin{tabular}{|c|c|c|c|c|c|c|}
\hline \multirow[b]{2}{*}{$\begin{array}{c}\text { Carbon } \\
\text { Adsorbent }\end{array}$} & \multicolumn{2}{|c|}{$\begin{array}{l}\text { Maximum Loading, } \\
\mathrm{q}_{\mathrm{b}} \\
\end{array}$} & \multicolumn{2}{|c|}{ Dry Gas } & \multicolumn{2}{|c|}{ Wet, Gas } \\
\hline & Dry & $\begin{array}{c}\text { Wet } \\
\text { (39\% of dry) }\end{array}$ & $\begin{array}{c}\text { Number } \\
\text { of } \\
\text { Towers }\end{array}$ & $\begin{array}{l}\text { Bed } \\
\text { Depth }\end{array}$ & $\begin{array}{c}\text { Number } \\
\text { of } \\
\text { Towers }\end{array}$ & $\begin{array}{c}\text { Bed } \\
\text { Depth }\end{array}$ \\
\hline Extrusorb & 0.0525 & 0.0205 & 17.9 & 4.8 & 25 & 7.5 \\
\hline BPL & 0.0600 & 0.0234 & 17.0 & 4.4 & 23 & 7.2 \\
\hline Kureha & 0.0750 & 0.0293 & 15.0 & 3.5 & 21 & 6.4 \\
\hline PCB & 0.0995 & 0.0388 & 12.8 & 2.5 & 19 & 5.7 \\
\hline Silicalite & 0.0127 & 0.0064 & 29.0 & 9.5 & $>35$ & $>12$ \\
\hline
\end{tabular}


but would require $\$ 4.25$ million for compressors, again a high cost. Compression to 5 psig only lowers the number of towers by two, but the cost is not given in Figure 3.4.

It is concluded that pressurization for the sole purpose of reducing volumetric flow and thus the required number of towers is not useful. More details relative to this are given in Section 5.

\subsubsection{Effect of Breakthrough Time}

As shown in Table 4.2, the nominal gas adsorption case assumes a 16-hr breakthrough time. However, if the breakthrough time were longer, the adsorption towers would require adcitional bed depth to accommodate the extra required adsorption capacity. The deeper beds would produce additional resistance to flow and decrease the gas throughput per tower, so that additional towers would be required. Therefore, attaining the lowest capital costs would require minimal breakthrough time. However, very short breakthrough time probably would incur excessive labor and operating costs. In the absence of an analysis to define the optimum breakthrough time, we have chosen $16 \mathrm{hr}$ (two 8-hr labor shifts).

To define the specific effect of different breakthrough times, Figures $4.28 \mathrm{a}, 4.28 \mathrm{~b}$, and $4.28 \mathrm{c}$ were prepared. For a 3 -hr breakthrough time, 13.4 towers of 2.75 -ft bed depth would be required at $1 \mathrm{psig}$, and the bed superficial velocity would be $220 \mathrm{ft} / \mathrm{min}$. A 30 -hr breakthrough time requires 21.8 towers of 6.6 -ft bed depth and produces a superficial velocity of $135 \mathrm{ft} / \mathrm{min}$. The nominal case of 18 towers of 5 -foot bed depth is obtained from the figures for a 16-hr breakthrough time. Pressurizing the gas will reduce the number of towers but increase bed depth as shown. However, as mentioned in the previous section, pressurization is not likely to result in an overall economic advantage because of the cost of compressors.

\subsubsection{Effect of Tower Diameter and Total Pressure}

The nominal case in Table 4.2 assumes that the towers are $12 \mathrm{ft}$ in diameter because this diameter is the largest standard size and larger towers would require special fabrication at a much higher cost.

At a given pressure and pressure drop, the Teepak gas flow will maintain constant bed depth and superficial velocity, both independent of tower diameter. Under these conditions, the number of towers varies as the inverse square of tower diameter. Figures $4.29 \mathrm{a}, 4.29 \mathrm{~b}$, and $4.29 \mathrm{c}$ show how bed depth, number of towers, and superficial velocity vary with tower diameter at different total pressures. 


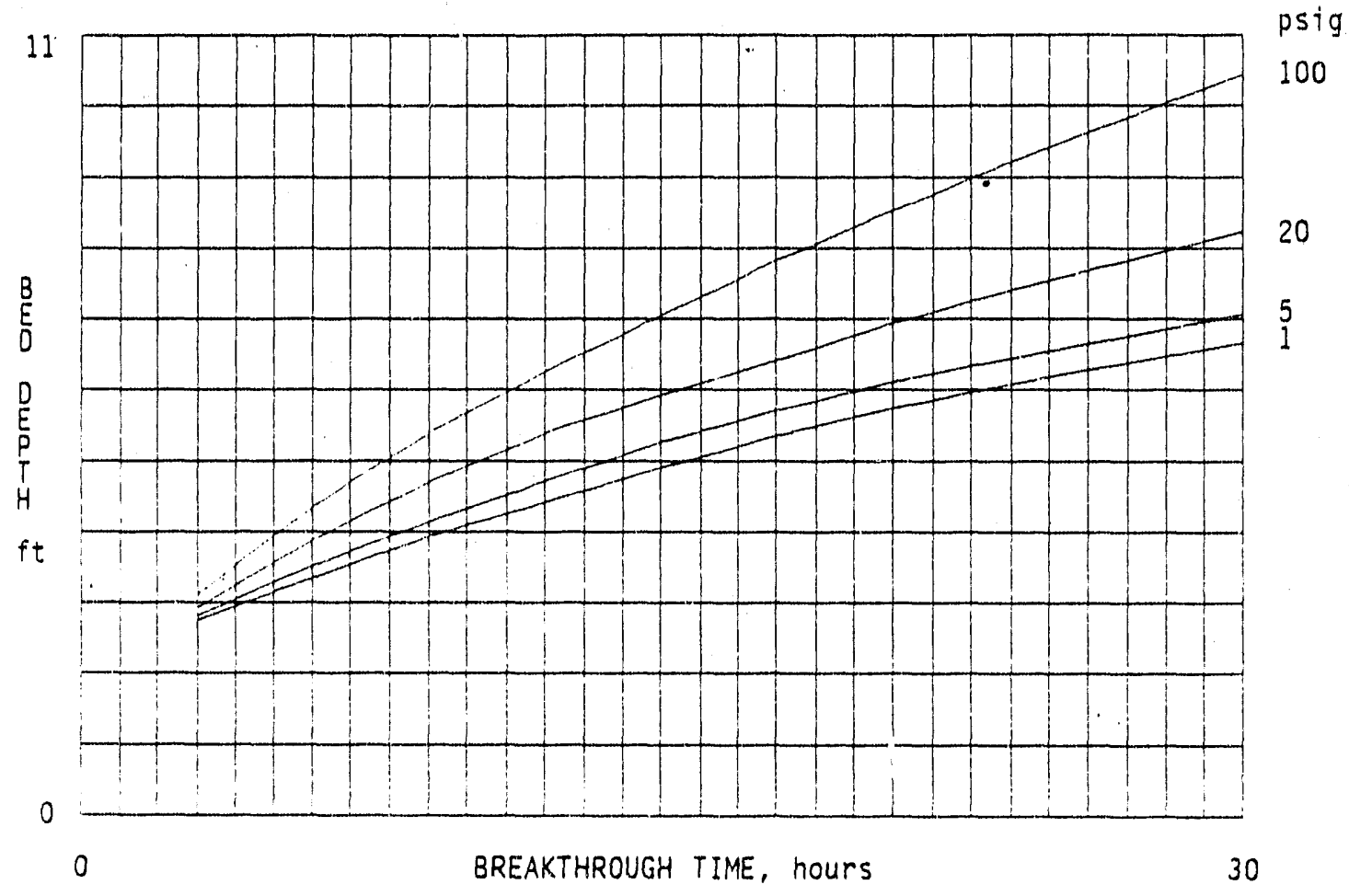

\section{FIGURE 4.28a Adsorption Bed Depth vs. Breakthrough Time}

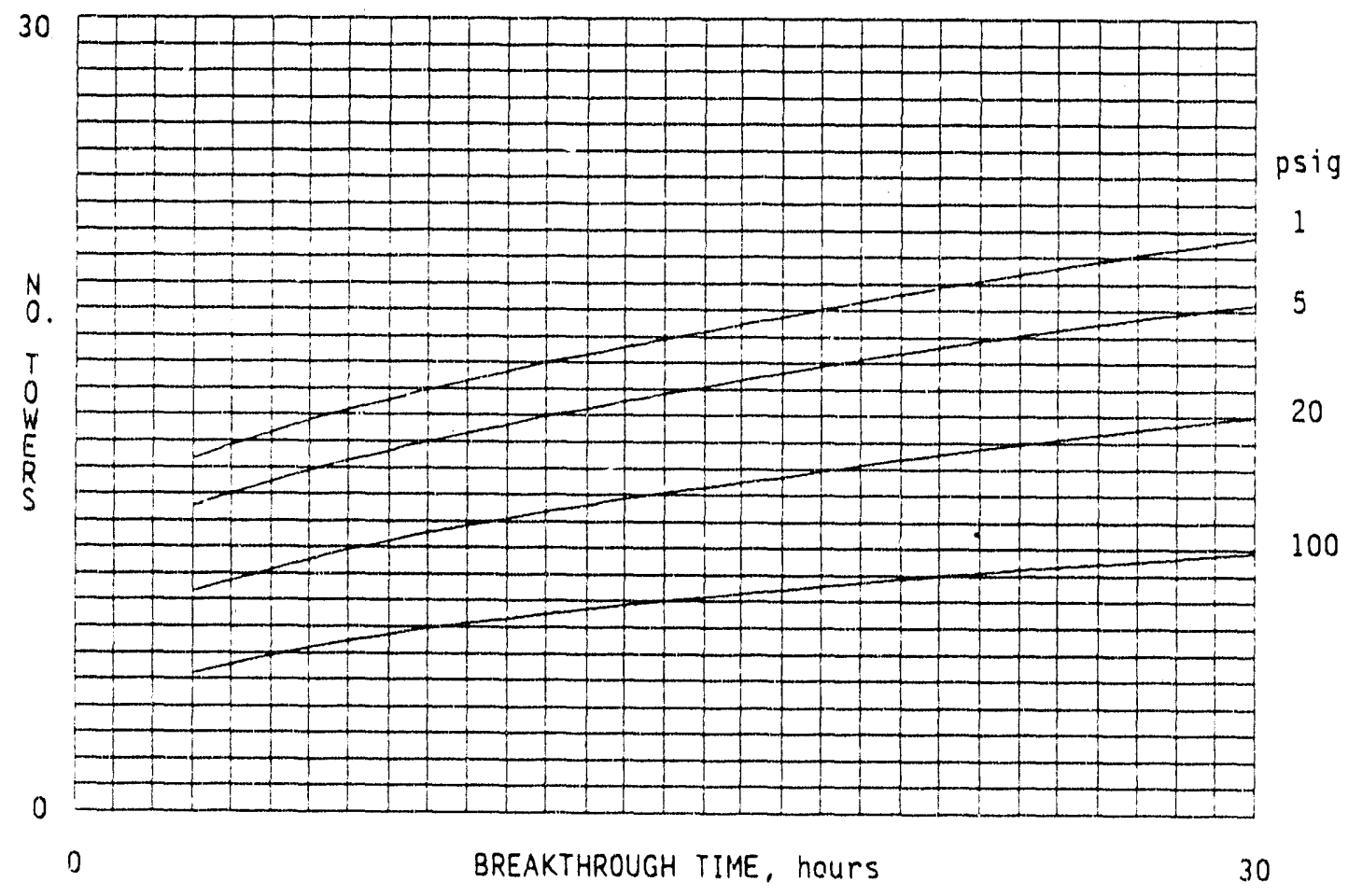

FIGURE 4.28b Number of Adsorption Towers vs. Breakthrough Time 


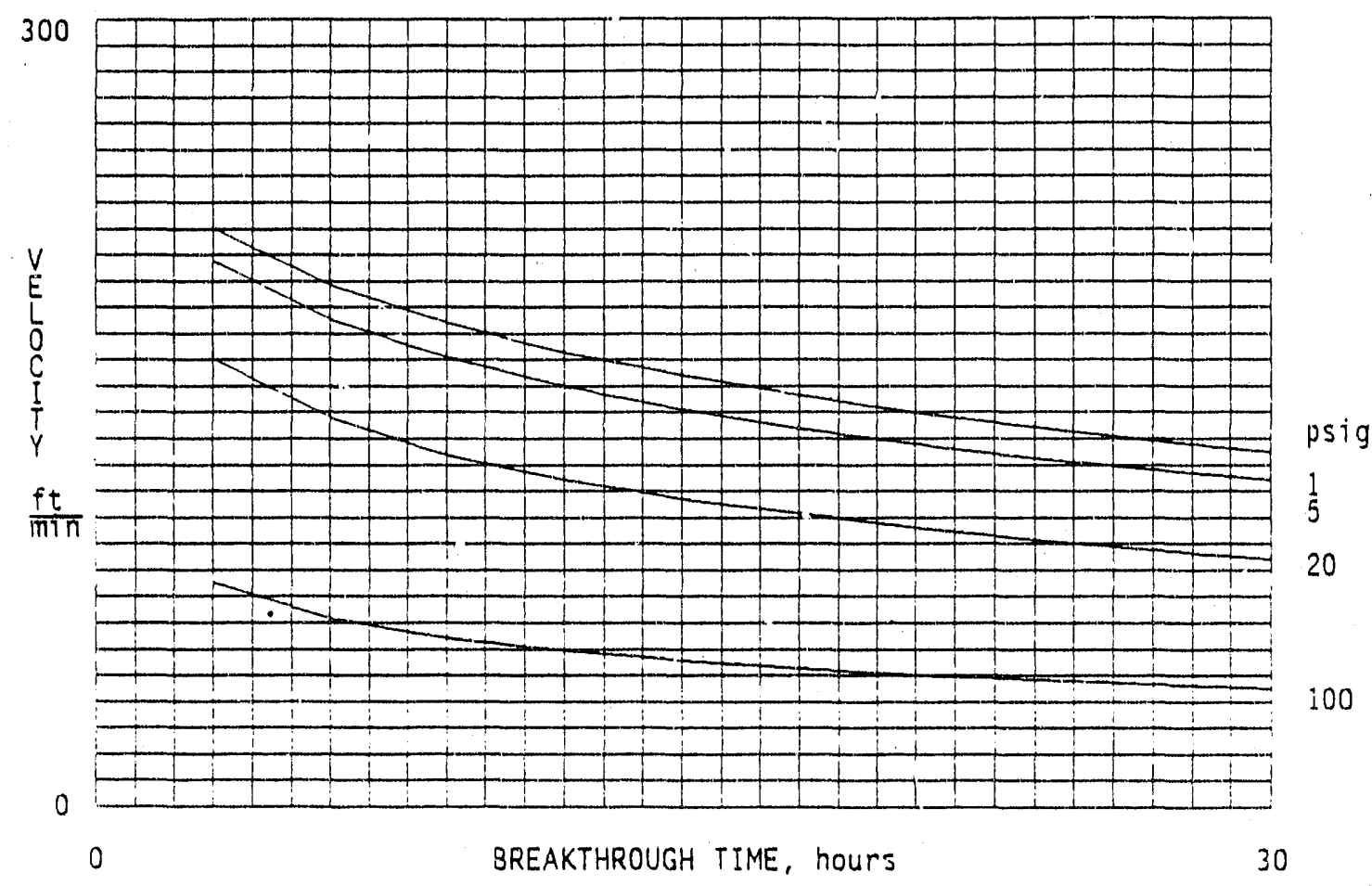

FIGURE 4.28c Superficial Velocity vs. Breakthrough Time

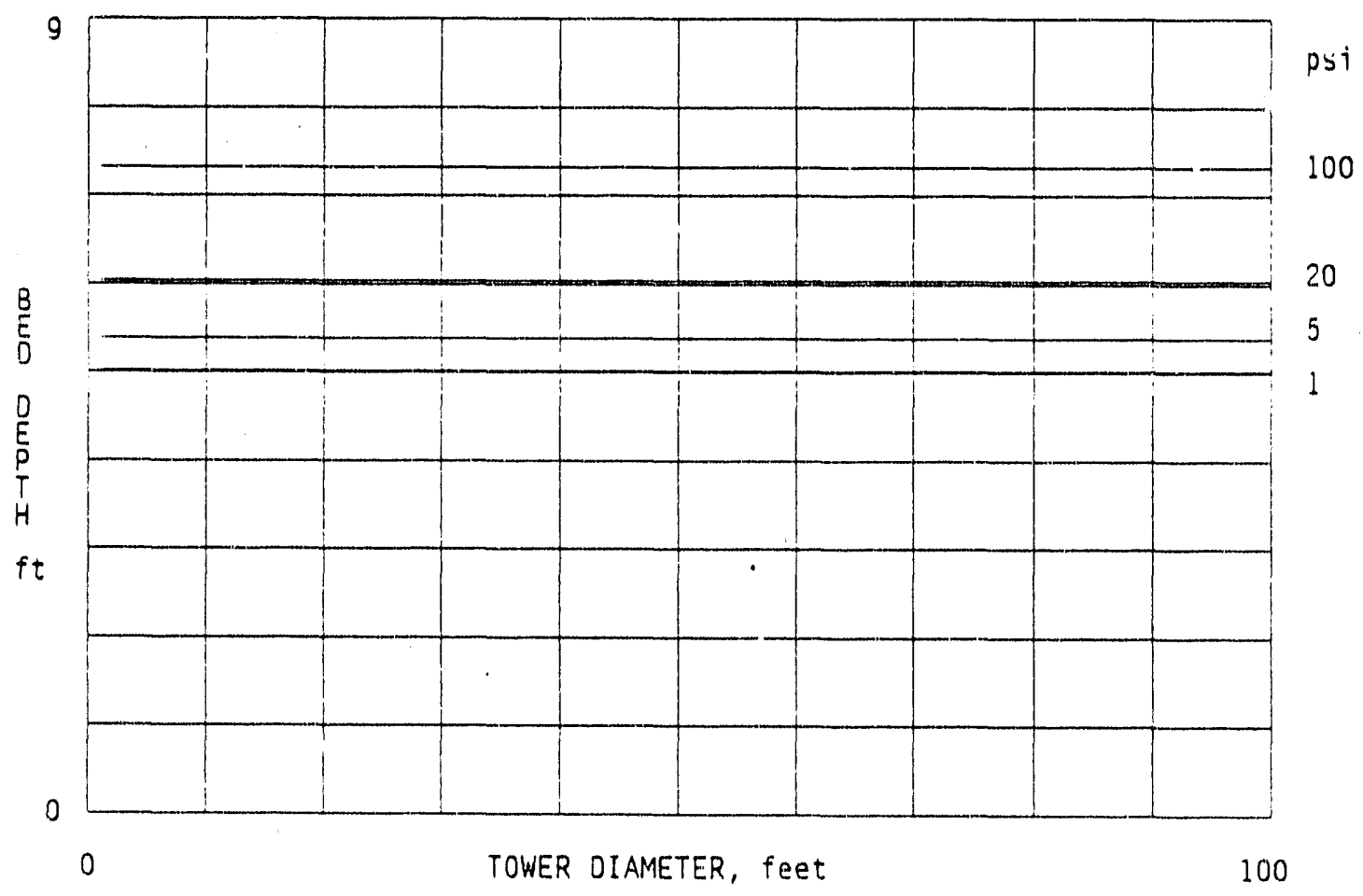

FIGURE 4.29a Adsorption Bed Depth vs. Tower Diameter 


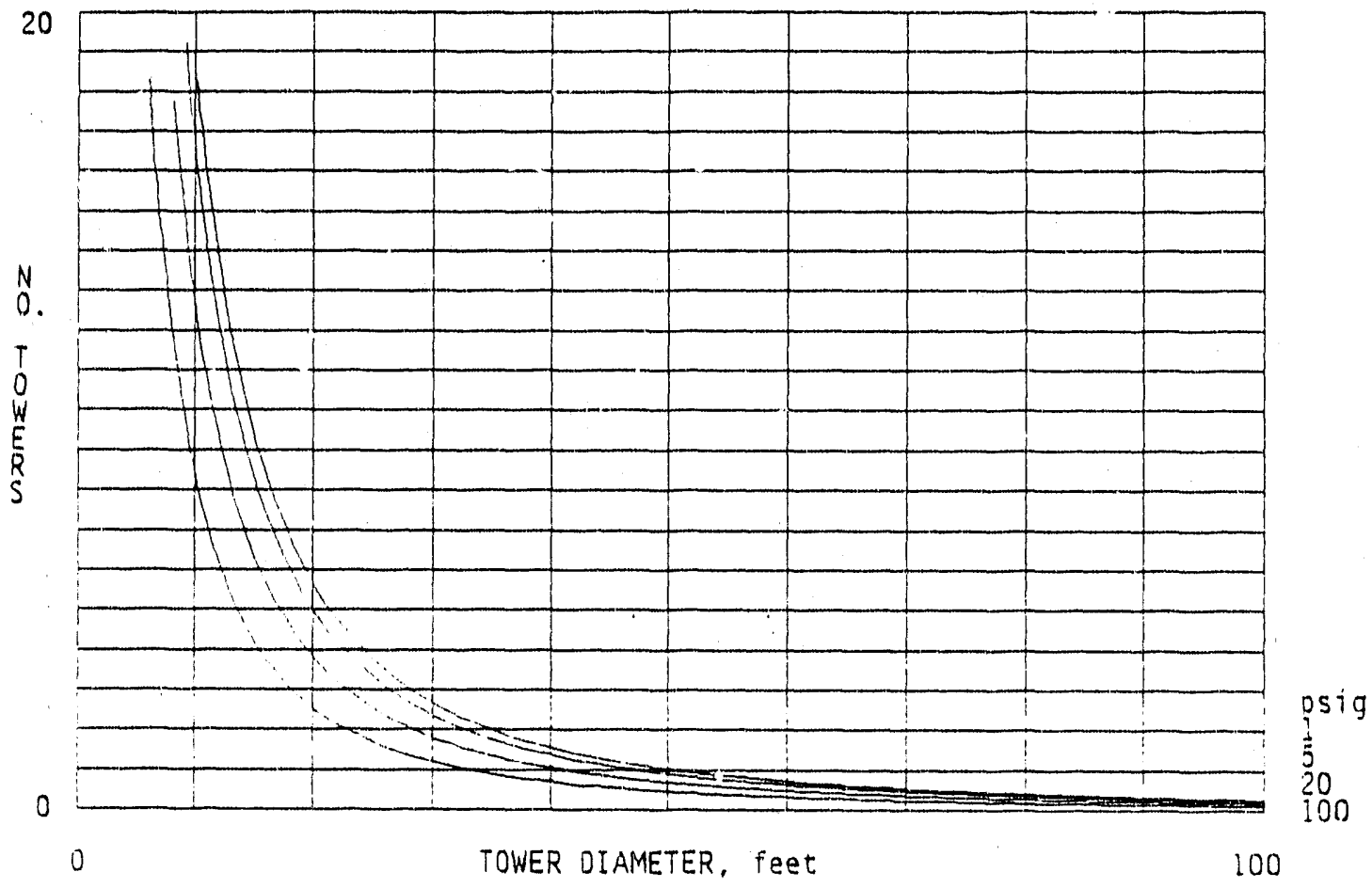

FIGURE 4.29b Number of Adsorption Towers vs. Tower Diameter

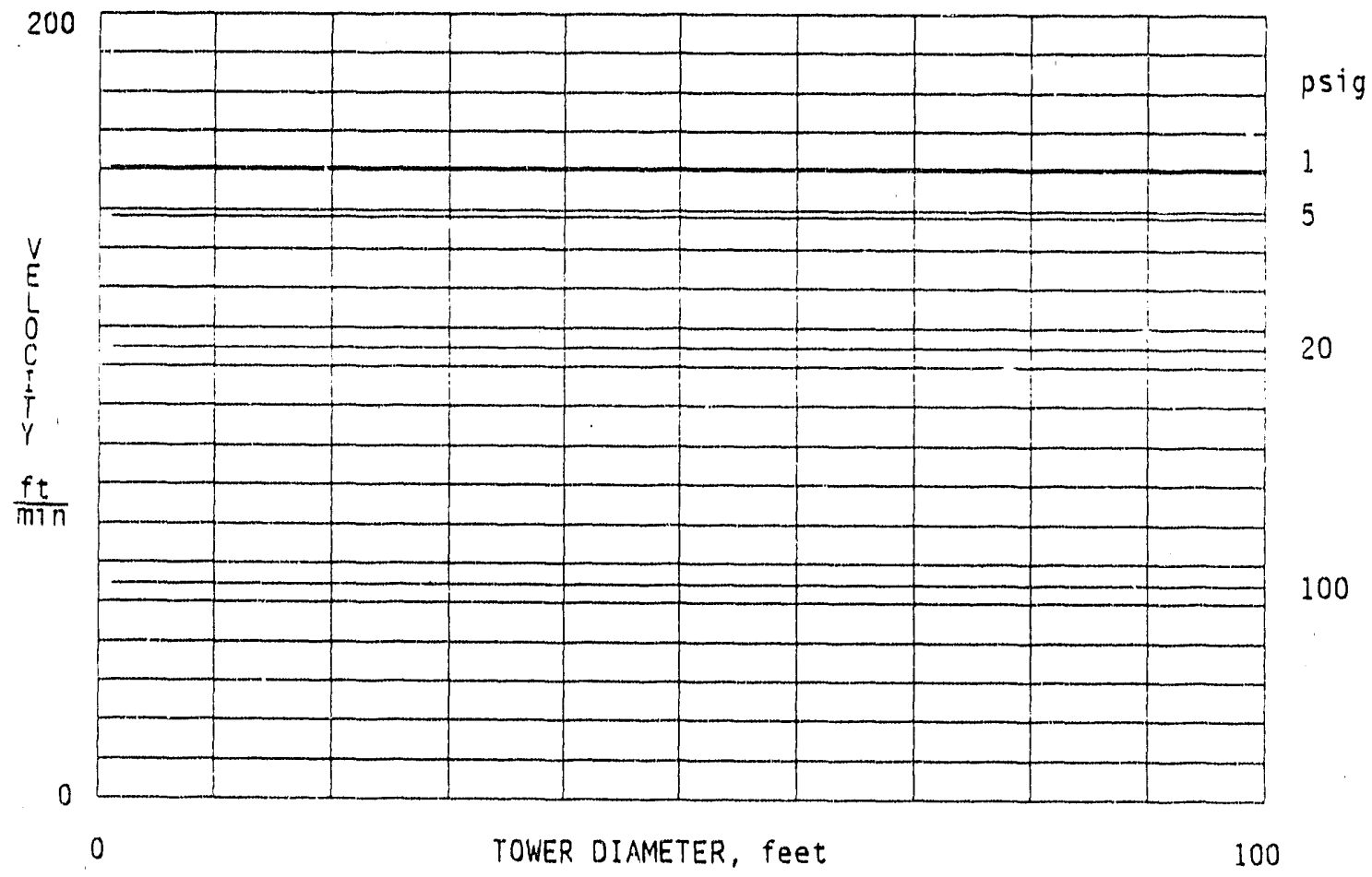

FIGURE 4.29c Superficial Velocity vs. Tower Diameter Time 


\subsubsection{Effect of Pressure Drop}

Previous adsorption plant calculations assumed a constant 2-psi pressure drop over the bed depth of the towers, as given in Table 4.2. Because of this assumption, the bed depth and number of towers for the nominal case were $5 \mathrm{ft}$ and 18 towers, respectively, on the basis of a superficial velocity of $160 \mathrm{ft} / \mathrm{min}$. However, if additional pressure drop were supplied, the flow of gas through the towers would increase, thereby lowering the required number of towers. Thus, to some extent, tower requirements can be reduced at the cost of gas compression and additional process complexity. A detailed analysis to define the cost optimum is beyond the scope of this study, but some general conclusions can be drawn from Figures $4.30 \mathrm{a}, 4.30 \mathrm{~b}$, and 4.30c. Figure $4.30 \mathrm{~b}$ shows clearly that if total pressure is $1 \mathrm{psig}$, much of the advantage of pressure drop occurs in the first 5 psi. For example, if pressure drop is raised from 2 psi to 5 psi, the required number of towers drops by five (from 18 to 13 ). Further increase of pressure drop hás much less effect. A 10-psi elevation of pressure drop, from 5 psi to 15 psi, only reduces the tower requirement by four (from 13 to 9). Raising pressure drop to more than about 5 psi probably would not be worth the added process complexity. We have chosen 2 psi as an inexpensively low but adequate pressure drop.

When pressure drop increases, superticial velocity increases; therefore, the adsorption tower mass-transfer zone tends to elongate, thus increasing the required bed depth. Figure $4.30 \mathrm{c}$ shows the rise of superficial velocity with pressure drop. An increase of 14 psi (from 1 to $15 \mathrm{psi}$ ) causes an increase in superficial velocity of $200 \mathrm{ft} / \mathrm{min}$ (from 120 to $320 \mathrm{ft} / \mathrm{min}$ ). Figure $4.30 \mathrm{a}$ shows how this difference in tower velocity translates into increased bed depth. That is, the 14-psi increase in pressure drop will result in a 6 -ft bed depth increase (from $4 \mathrm{ft}$ to $10 \mathrm{ft}$ ). However, as mentioned above, a large fraction of the tower requirement reduction occurs when pressure drop is increased from 1 psi to 5 psi. So, although the number of towers is reduced from 24 at 1 psi to 13 at 5 psi, bed depth only increases by $3 \mathrm{ft}$, from $4 \mathrm{ft}$ at 1 psi to $7 \mathrm{fl}$ at 5 psi. This contrast is an additional reason to restrict imposed pressure drop to less than 5 psi.

Figures $4.30 \mathrm{a}, 4.30 \mathrm{~b}$, and $4.30 \mathrm{c}$ also show the effect of increased total pressure level, which tends to reduce tower requirements and increase bed depth requirements.

From these figures, it may be concluded that supplying a pressure drop of a few psi will have a beneficial effect on tower requirements at the expense of some additional bed depth. However, pressure drop increases from 1 psi to above about 5 psi will not be as beneficial as increases from 1 psi to pressure drops 5 psi or below.

Of course, the particular response to pressure drop shown in the figures depends on the bed characteristics, especially bed particle size and shape, and on the adsorptive and mass-transfer characteristics of the particular adsorbent. The present case involves a $4 \times 6$ mesh BPL carbon bed. Other bed materials would exhibit different numerical values, but the general conclusions would be the same. 


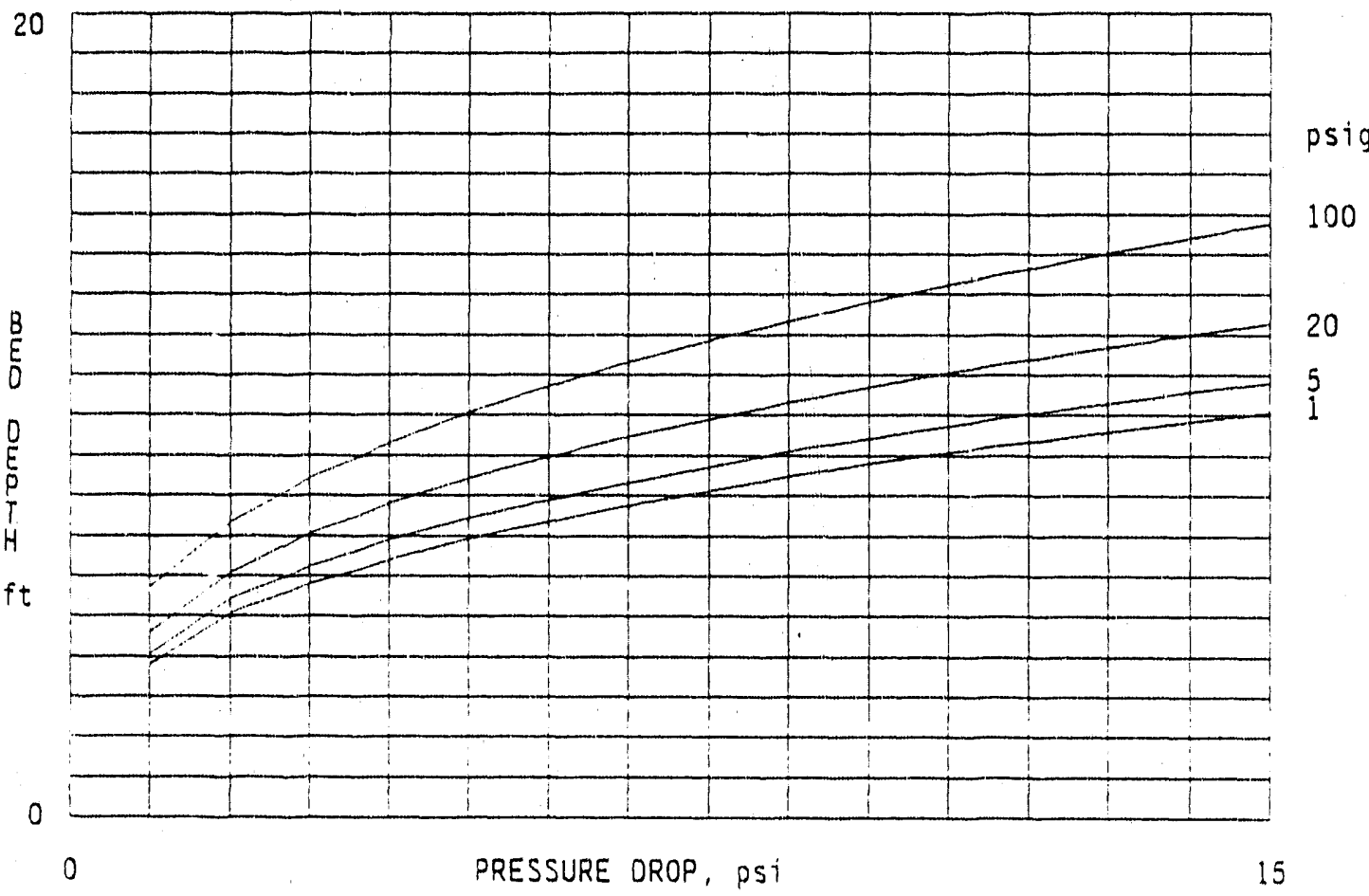

FIGURE 4.30a Adsorption Bed Depth vs. Pressure Drop

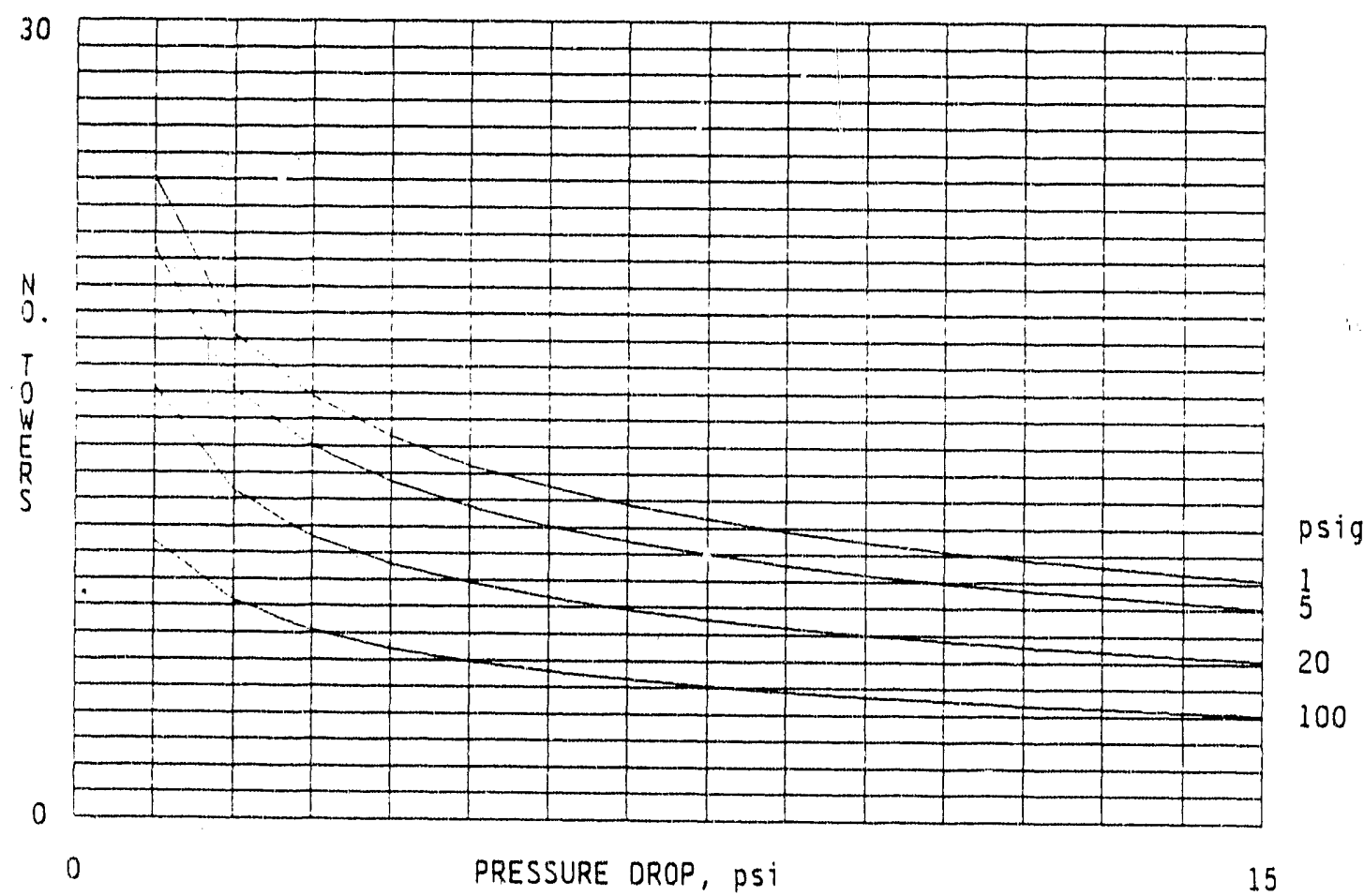

FIGURE 4.30b Number of Adsorption Towers vs. Pressure Drop 


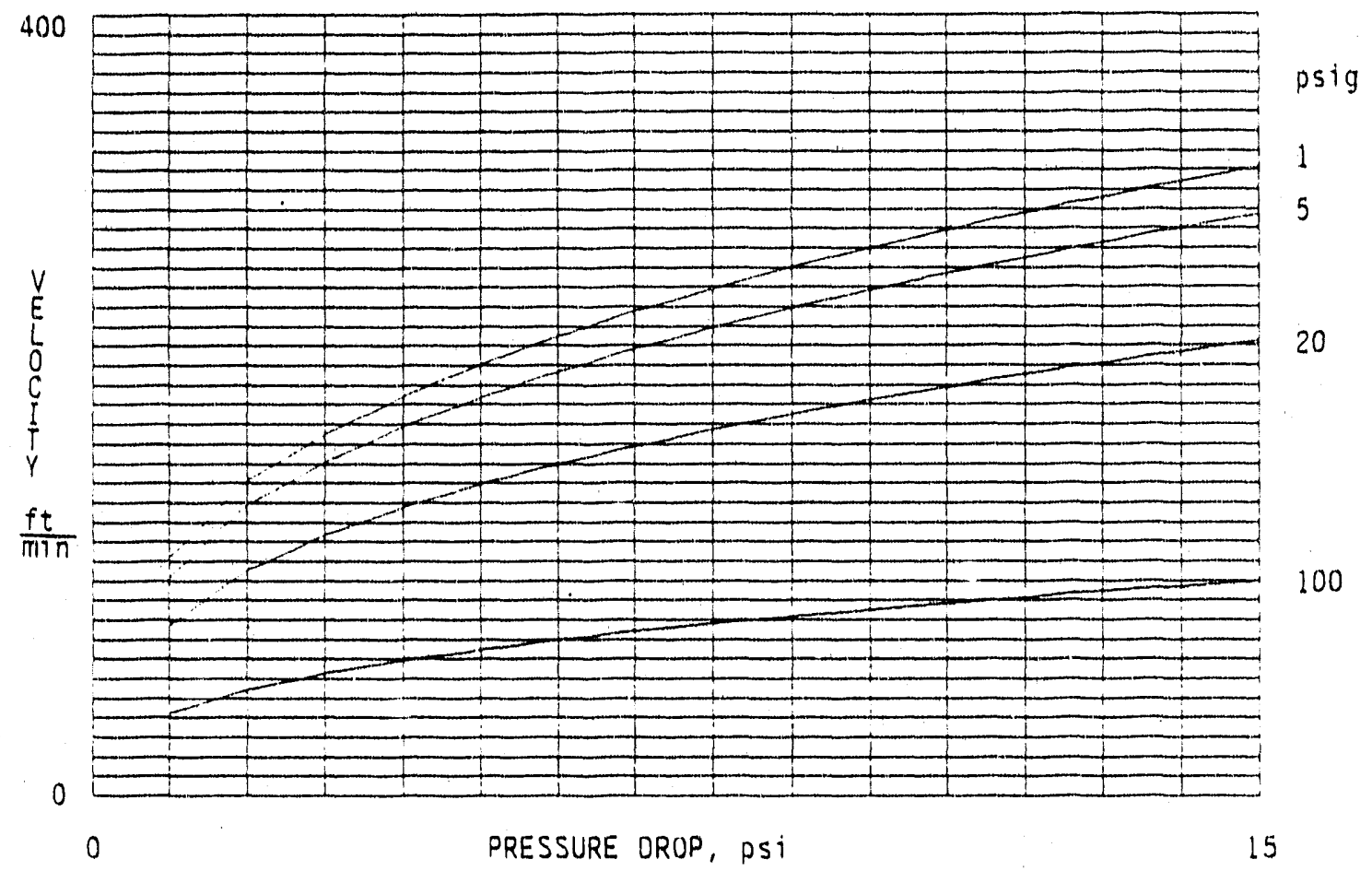

FIGURE 4.30c Superficial Velocity vs. Pressure Drop Time

\subsubsection{Effect of Transport Resistance}

The nominal case of Table 4.2 assumes a particle diffusion coefficient $\left(\mathrm{D}_{\mathrm{p}}\right.$ ) of $1.01 \times 10^{-3} \mathrm{ft}^{2} / \mathrm{min}$. This value was estimated for the BPL carbon by using generalized correlations. The details of this estimation are given in Appendix $B$. Because $D_{p}$ is estimated, not measured, it is assumed to have some error. We have not been able to evaluate the likely error band for these estimates. Therefore, we now present dependent variable calculations based on a broad variation of $D_{p}$.

As pointed out by Basmadjian, ${ }^{49}$ the value of $D_{p}$ used in developing adsorbent behavior can be considered an overall transpnrt resistance. Thus, variation of $D_{p}$ can account for not only pore diffusion resistance but also film resistance and axial dispersion:

$$
1 /\left(15 D_{p o} / R^{2}\right)=1 /\left(k_{d} a\right)+1 /\left(k_{f} a\right)+1 /\left(15 D_{p} / R^{2}\right)
$$

where $D_{p o}$ is the effective overall diffusivity, $D_{p}$ is the particle pore diffusivity, $k_{f}$ is film transfer coefficient, $1 / \mathrm{k}_{\mathrm{d}} \mathrm{a}$ is axial dispersion resistance, and a is transport surface area. 
With all inputs from Table 4.2 constant except $D_{p o}$, the adsorption tower model was run to evaluate the effect of combined transport resistance on bed depth, superficial velocity, and number of towers. The results are shown in Figure 4.31. $D_{p o}$ was varied from $10^{-4} \mathrm{ft} / \mathrm{min}$ to $200 \times 10^{-4} \mathrm{ft} / \mathrm{min}$, and the three dependent variables (bed depth, number of towers, and velocity) were plotted on the same graph. In the figure, the nominal case $\left(0.001 \mathrm{ft}^{2} / \mathrm{min}\right)$ represents the first mark after the origin. From the figure, it is clear that transport resistance greater than that ir the nominal case (i.e., lower $D_{p o}$ ) could have a significant adverse effect on the cost, because both bed depth and number of towers rise shart'y to the left from the nominal case. Likewise, it is clear that reduction of transport resistance would have a small advantage in terms of reduced bed depth and number of towers. The practical conclusion is that mass transfer resistance must be minimized when designing a gas adsorption column for Teepak. Controllable factors that will help reduce resistance are superficial velocity, particle size, packing, and pore characteristics of the adsorbent. These factors can be studied most effectively in a small adsorption pilot facility.

\subsection{CONCLUDING REMARKS ON ADSORPTION}

This Section has given the detailed results from a program intially designed to find an adsorbent that would have optimal characteristics relative to $\mathrm{CS}_{2}$ recovery. The program was undertaken with the hope that an effective absorbent could be found or developed that was nonflammable and could not be poisoned easily by $\mathrm{H}_{2} \mathrm{O}$ and $\mathrm{H}_{2} \mathrm{~S}$. Without the resources to conduct an expensive and very uncertain adsorbent development program, we are forced

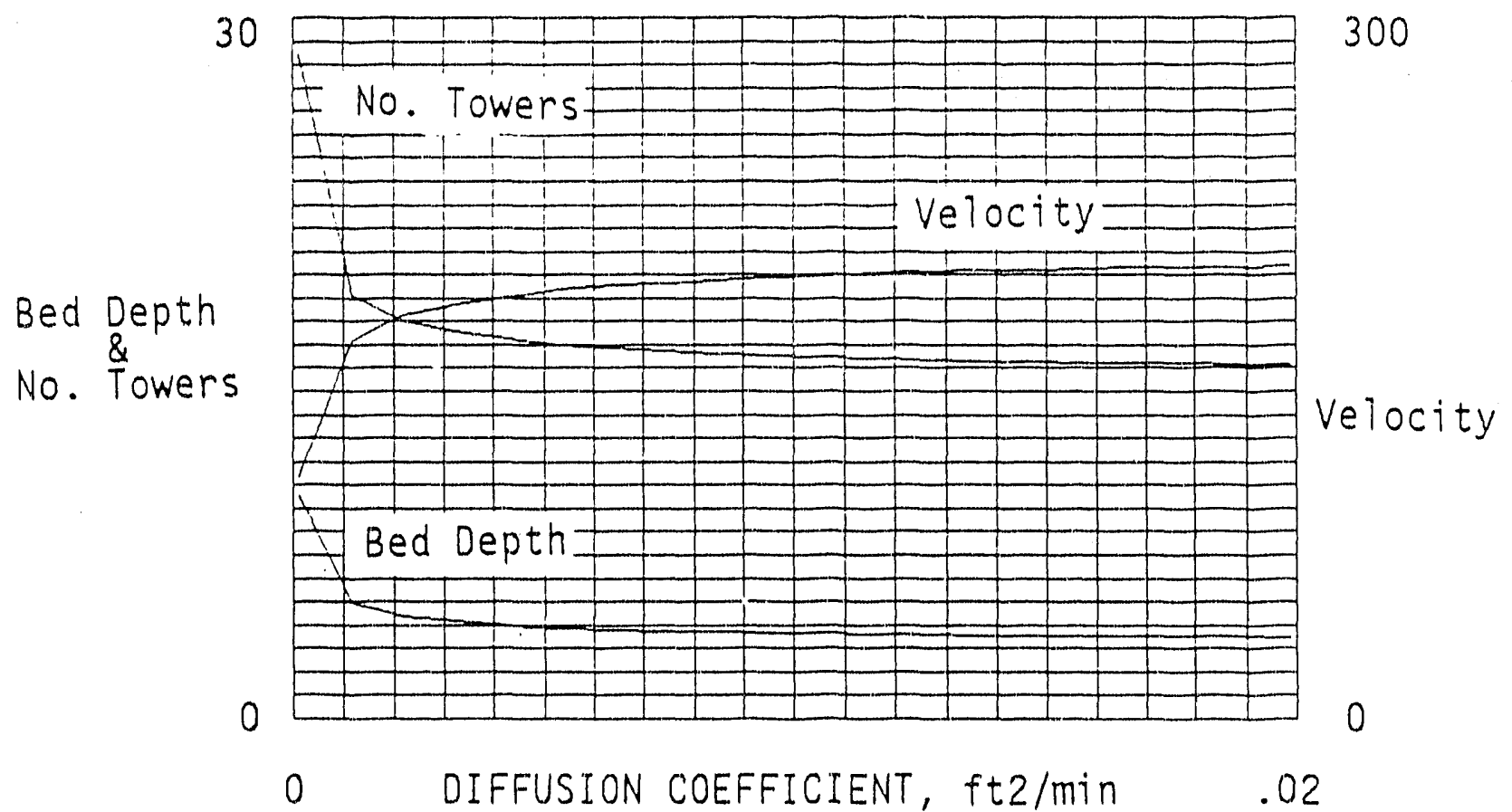

FIGURE 4.31 Bed Depth, Number of Towers, and Superficial Velocity vs. Particle Diffusion Coefficient (total pressure $=1$ psig) 
to conclude that no such adsorbent exists or will be developed. We are further forced to conclude that flammable, poisonable activated carbon is a very efficient adsorbent for $\mathrm{CS}_{2}$, exceeding all others tested. The practical conclusion is that carbon represents the best hope for an adsorptive solution at Teepak. We have evaluated the temperature swing adsorption process and found it to be a possibility (see also Section 5), provided the flammability and poisoning issues can be overcome. Process evaluations of other types of carbon adsorption plants, such as moving bed systems, will be conducted separately. A pilot plant project to optimize a carbon process for Teepak is envisioned. 


\section{GAS ADSORP'TION COST STUDY}

In Section 4 and Appendix B, gas adsorption was analyzed as a unit operation. Graphs were presented to show the bed depth, number of towers, and superficial velocity obtained for a variety of cases. These results suggest that gas adsorption with carbon adsorbent is a possibility for use at Teepak. However, the ultimate criterion must be cost. To provide Teepak with additional information for assessing the possibility of implementating this technology, capital costs were developed for several variations of temperature-swing adsorption (TSA) plants receiving the 400,000-cfm flow of Teepak air contaminated with 100 ppm $\mathrm{CS}_{2}$.

Figure 5.1 gives details of the adsorption plant used as a reference or base case; the other cases vary as shown in Table 5.1. The data given in Table 5.1 on number of towers, bed depth, and velocity were taken directly from Figures 4.26a through 4.30c. Other assumptions were given in Table 4.2, except for total pressure. The base case of Table 5.1 is for 5 psig, wather than 1 psig as shown in Table 4.2 .

As seen for the base case in Figure 5.1 , the Teepak flow of contaminated air is split into four equal flows, and each is sent to a large blower for boosting pressure to 5 psig. The air then enters four refrigerant dryers that cool the gas with cold glycol refrigerant in coils and remove moisture to less than $10 \%$ relative humidity $(\mathrm{RH})$. The dry air is then combined into a single manifold and sent to the adsorption towers, which are housed in a prefabricated building. The air is split into 16 equal streams, each of which enters a single adsorption tower with carbon bed depth of $5.4 \mathrm{ft}$. In the towers, $\mathrm{CS}_{2}$ is removed and the clean air is discharged to the atmosphere. As shown in Table 4.2, the breakthrough time is $16 \mathrm{hr}$; therefore, after a given adsorption tower has been operating for $16 \mathrm{hr}$, the $\mathrm{CS}_{2}$ concentration of the existing air will rise to $10 \mathrm{ppm}$, the breakpoint. The flow will then be directed to a freshly desorbed and cooled tower, and the old tower will be desorbed. As shown, each tower can be cooled with chilled water or heated with 150)psig steam by internal bed coils.

Desorption will be accomplished first by sealing the tower and flushing with $\mathrm{N}_{2}$, and then by using steam coils to heat the bed to the desorption temperature (typically $300^{\circ} \mathrm{F}$ ) and flooding the tower with $300^{\circ} \mathrm{F}$ steam, which will carry off the $\mathrm{CS}_{2}$. This preheating action will prevent the desorption steam from initially exiting the tower with low $\mathrm{CS}_{2}$ concentration while the bed is being heated and will allow more efficient condensation and recovery of $\mathrm{CS}_{2}$. When the desorption is completed, the hot bed must be cooled to less than $200^{\circ} \mathrm{F}$ before admitting $\mathrm{CS}_{2}$ to avoid the possibility of fire. The $\mathrm{CS}_{2}$ /steam mixture from desorption flow is sent to a chilled water condenser where the steam is condensed. Then the resulting $\mathrm{CS}_{2} / \mathrm{H}_{2} \mathrm{O}$ vapor is further condensed in a refrigerant condenser and the liquid $\mathrm{CS}_{2}$ decanted und stored.

Costs of several other cases in addition to the base case described above were estimated to allow comparisons and to determine the advantages of various options. These other cases are shown in Table 5.1. Tables 5.2 through 5.9 give the results of individual cost 


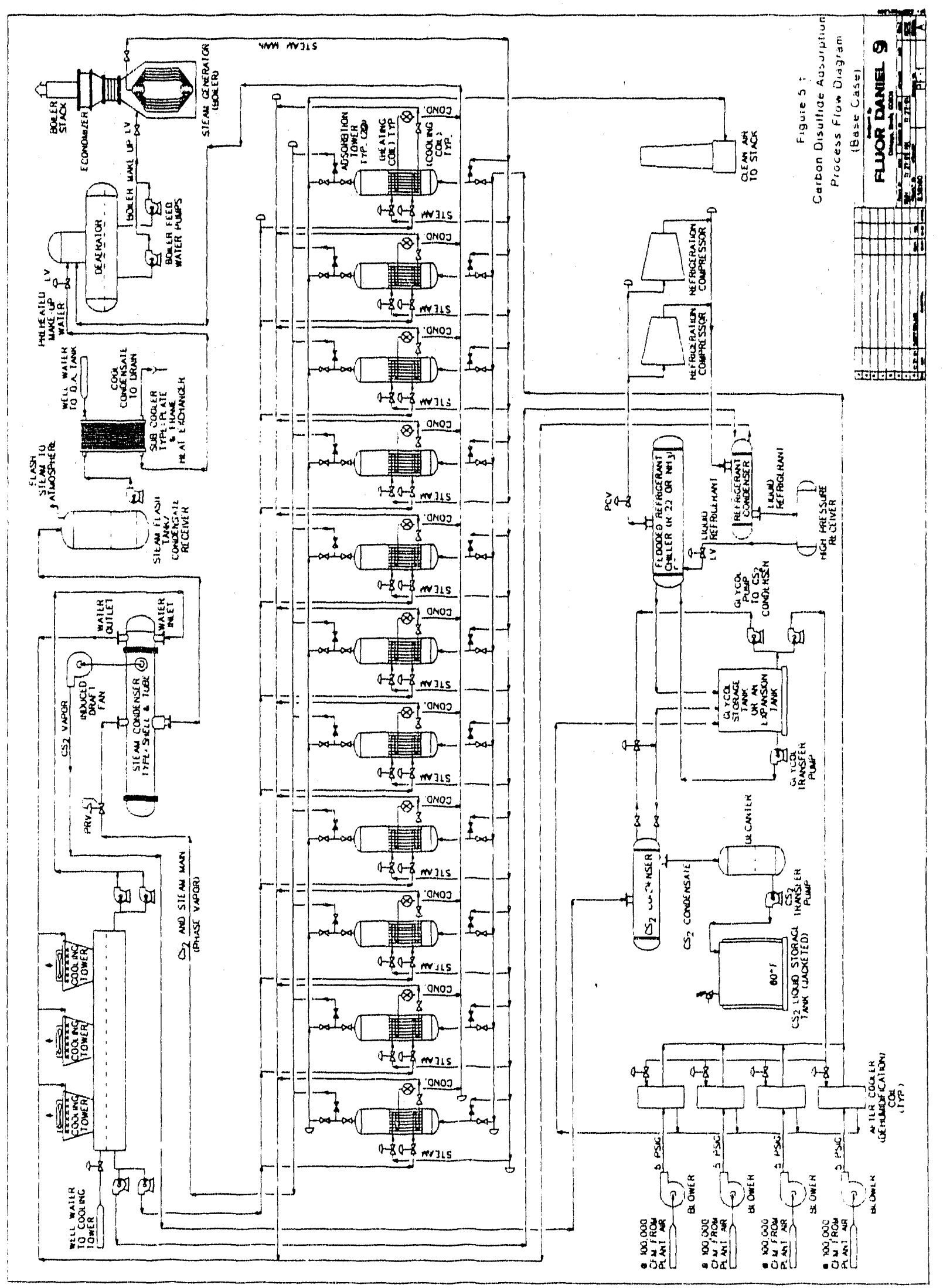

告 
TABLE 5.1 Cases Assumed for TSA Cost Study

\begin{tabular}{|c|c|c|c|c|c|c|c|c|}
\hline Case & Description & $\begin{array}{c}\text { Number } \\
\text { of } \\
\text { Towers }\end{array}$ & $\begin{array}{c}\text { Bed } \\
\text { Dupth } \\
\text { (ft) }\end{array}$ & $\begin{array}{l}\text { Superficial } \\
\text { Volocity } \\
\text { (ft/min) }\end{array}$ & Desorption & $\begin{array}{c}\text { Moisture } \\
\text { In Gas }\end{array}$ & $\begin{array}{c}\text { Prossuro } \\
\text { (psig) }\end{array}$ & $\begin{array}{c}\Delta p \\
(p s i)\end{array}$ \\
\hline 1 & Base & 16 & 5.4 & 148 & Steam & Dry & $\tilde{b}$ & 2 \\
\hline 2 & $\mathrm{~N}_{2}$ desorption & 16 & 5.4 & 148 & $\mathrm{~N}_{2}$ & Dry & 5 & 2 \\
\hline 3 & Wet gas & 16 & 5.5 & 146 & $\mathrm{~N}_{2}^{4}$ & $\tilde{b} 0 \% \mathrm{RH}$ & 5 & 2 \\
\hline 4 & Wet gas & 16 & 5.5 & 146 & Steam & $50 \% \mathrm{RH}$ & 5 & 2 \\
\hline $\bar{n}$ & Very wet gas & 20 & 7.5 & 110 & $\mathrm{~N}_{2}$ & $80) \% \mathrm{RH}$ & 5 & 2 \\
\hline 6 & Very wet gas & 20 & 7.5 & 116 & Steam & $80 \% \mathrm{RH}$ & 5 & 2 \\
\hline 7 & High pressure & 10 & 6.1 & 80 & Stram & Dry & 50 & 2 \\
\hline 8 & High pressure & 6 & 11 & 135 & Stenm & Dry & ถั) & 8 \\
\hline
\end{tabular}

estimates and provide some additional details pertaining to the assumptions made. Table 5.10 summarizes the information in Tables 5.2 through 5.9, and Figure 5.2 shows this information in graphic form.

Table 5.10 and Figure 5.2 make it clear that certain capital items, such as the steam plant. water cooling, CSn separation, and piping and fitting, do not vary from case to case. However, other items vary significantly and are helpful in understanding how best to optimize the process and minimize cost. The major cost change when using nitrogen desorption is the additional $\$ 950,000$ cost of the nitrogen feeding and heating system. Thus, we may conclude that steam desorption is less costly. It also may be mcre prartical for recovery, as discussed in Section 4.4.1.

Comparing cases 1,4 , and 6 indicates that drying the air before adsorption is very costly if the aim is a completely dry gas. However, partial drying to about $50 \% \mathrm{RH}$ results in substantial savings in dryer capital, while the additional adsorption tower cost reflected by the bed depth requirement is not significant. This savings is the reason partial drying (case 4) shows the lowest capital costs of all cases studied. Case 6 (no drying) results in lower drying capital costs, but additional tower and installation costs more than compensate for this savings.

Comparing cases 1 and 7 shows that an increase in total pressure (case 7) significantly reduces adsorption tower costs and installation charges but compensates for this reduction with the need for compressors. The compressors cost much more than the blowers used in case 1. Comparing cases 7 and 8 shows that if additional pressure drop is supplied, the velosity through the tower greatly increases, which allows a significant reduction in the number of required towers and therefore in tower costs. Unfortunately, these reductions are negated because the bed depth increases so much that the towers become too tall for the prefabricated buildings. Taller buildings, at greater cost, would be required. This factor, along with more complex installation and higher condenser costs, cancel the advantage of high pressure drop. 
TABLE 5.2 Carbon Disulfide Recovery System Cost Estimate: Base Case (case 1)

\begin{tabular}{|c|c|}
\hline Item & Cost (\$) \\
\hline $\begin{array}{l}\text { Steam generator plant } \\
40,000 \mathrm{lb} / \mathrm{hr} \text { at } 150 \mathrm{psig} \\
\text { Complete package, gas fired }\end{array}$ & 375,000 \\
\hline $\begin{array}{l}\text { Air blowers ( } 8 \text { units) } \\
400,000 \mathrm{cfm} \text { at } 5 \text { psig } \\
\text { Including full-flow (100\%) } \\
\text { air dryer }\end{array}$ & $4,000,000$ \\
\hline $\begin{array}{l}\text { Carbon towers ( } 20 \text { units) } \\
\text { Complete package including } \\
\text { control panel }\end{array}$ & $5,200,000$ \\
\hline Steam condensers & 150,000 \\
\hline $\begin{array}{l}\text { Cooling tower and chilled } \\
\text { water system }\end{array}$ & 800,000 \\
\hline Water/CS 2 separator & 200,000 \\
\hline Piping and fitting & $1,200,000$ \\
\hline $\begin{array}{l}\text { Process building } \\
15,000 \mathrm{ft}^{2}, \text { prefabricated } \\
\text { Without foundation }\end{array}$ & 750,000 \\
\hline Installation cost & $3,200,000$ \\
\hline Subtotal & $15,875,000$ \\
\hline $\begin{array}{l}\text { Engineering and } \\
\text { construction management }\end{array}$ & $2,858,000$ \\
\hline Contingency at $25 \%$ & $4,683,000$ \\
\hline Total estimated cost & $23,416,000$ \\
\hline
\end{tabular}


TABLE 5.3 Carbon Disulfide Rocovery System Cost Estimate: Nitrogen Desorption (case 2)

\begin{tabular}{|c|c|}
\hline Item & $\operatorname{Cost}(\$)$ \\
\hline $\begin{array}{l}\text { Steam generator plant } \\
40,000 \mathrm{lb} / \mathrm{hr} \text { at } 150 \mathrm{psig} \\
\text { Complete package, gas tired }\end{array}$ & 375,000 \\
\hline $\begin{array}{l}\text { Nitrogen heating and } \\
\text { feed system }\end{array}$ & 950,000 \\
\hline $\begin{array}{l}\text { Air blowers ( } 8 \text { units) } \\
400,000 \mathrm{cfm} \text { at } 5 \mathrm{psig} \\
\text { Including full-flow (100\%) } \\
\text { air dryer }\end{array}$ & $4,000,000$ \\
\hline $\begin{array}{l}\text { Carbon towers (20 units) } \\
\text { Complete package including } \\
\text { control panel }\end{array}$ & $\tilde{5}, 200,000$ \\
\hline $\begin{array}{l}\text { Gas mixture cooling } \\
\text { condensers }\end{array}$ & 200,000 \\
\hline $\begin{array}{l}\text { Cooling tower and chilled } \\
\text { water system }\end{array}$ & 800,000 \\
\hline Water $/ \mathrm{CS}_{2}$ separator & 200,000 \\
\hline Piping and fitting & $1,200,000$ \\
\hline $\begin{array}{l}\text { Process building } \\
15,000 \mathrm{ft}^{2}, \text { prefabricated } \\
\text { Without foundation }\end{array}$ & 750,000 \\
\hline Installation cost & $3, \ddot{0} 00,000$ \\
\hline Subtotal & $17,175,000$ \\
\hline $\begin{array}{l}\text { Engineering and } \\
\text { construction management }\end{array}$ & $3,091,000$ \\
\hline Contingency at $25 \%$ & $5,066,000$ \\
\hline Total estimated cost & $25,332,000$ \\
\hline
\end{tabular}


TABLE 5.4 Carbon Disulfide Recovery System Cost Estimate: Wet Gas at 50\% Relative Humidity (case 3)

\begin{tabular}{|c|c|}
\hline Item & Cost $(\$)$ \\
\hline $\begin{array}{l}\text { Steam generator plant } \\
40,000 \mathrm{lb} / \mathrm{hr} \text { at } 150 \mathrm{psig} \\
\text { Complete package, gas fired }\end{array}$ & 375,000 \\
\hline $\begin{array}{l}\text { Nitrogen heating and feed } \\
\text { system }\end{array}$ & 950,000 \\
\hline $\begin{array}{l}\text { Air blowers ( } 8 \text { units) } \\
400,000 \text { cfm at 5 psig } \\
\text { Including full-flow }(50 \%) \\
\text { air dryer }\end{array}$ & $3,600,000$ \\
\hline $\begin{array}{l}\text { Carbon towers ( } 20 \text { units) } \\
\text { Complete package including } \\
\text { control panel }\end{array}$ & $5,200,000$ \\
\hline $\begin{array}{l}\text { Gas mixture cooling } \\
\text { condensers }\end{array}$ & 200,000 \\
\hline $\begin{array}{l}\text { Cooling tower and chilled } \\
\text { water system }\end{array}$ & 800,000 \\
\hline Water/CS ${ }_{2}$ separator & 200,000 \\
\hline Piping and fitting & $1,200,000$ \\
\hline $\begin{array}{l}\text { Process building } \\
15,000 \mathrm{ft}^{2}, \text { prefabricated } \\
\text { Without foundation }\end{array}$ & 750,000 \\
\hline Installation cost & $3,500,000$ \\
\hline Subtotal & $16,775,000$ \\
\hline $\begin{array}{l}\text { Engineering and } \\
\text { construction management }\end{array}$ & $3,019,000$ \\
\hline Contingency at $25 \%$ & $4,948,000$ \\
\hline Total estimated cost & $24,742,000$ \\
\hline
\end{tabular}


TABLE 5.5 Carbon Disulfide Recovery System Cost Estimate: Wet Gas with Steam Desorption (case 4)

\begin{tabular}{|c|c|}
\hline Itern & Cost $(\$)$ \\
\hline $\begin{array}{l}\text { Steam generator plant } \\
40,000 \mathrm{lb} / \mathrm{hr} \text { at } 150 \mathrm{psig} \\
\text { Complete package, gas fired }\end{array}$ & 375,000 \\
\hline $\begin{array}{l}\text { Air blowers ( } 8 \text { units) } \\
400,000 \mathrm{cfm} \text { at } 5 \text { psig } \\
\text { Including full-flow }(50 \%) \\
\text { air dryer }\end{array}$ & $3,600,000$ \\
\hline $\begin{array}{l}\text { Carbon towers (20 units) } \\
\text { Complete package including } \\
\text { control panel }\end{array}$ & $5,200,000$ \\
\hline Steam condensers & 150,000 \\
\hline $\begin{array}{l}\text { Cooling tower and chilled } \\
\text { water system }\end{array}$ & 800,000 \\
\hline Water/CS 2 separator & 200,000 \\
\hline Piping and fitting & $1,200,000$ \\
\hline $\begin{array}{l}\text { Process building } \\
15,000 \mathrm{ft}^{2}, \text { prefabricated } \\
\text { Without foundation }\end{array}$ & 750,000 \\
\hline Installation cost & $3,200,000$ \\
\hline Subtotal & $15,475,000$ \\
\hline $\begin{array}{l}\text { Engineering and } \\
\text { construction management }\end{array}$ & $2,785,000$ \\
\hline Contingency at $25 \%$ & $4,565,000$ \\
\hline Total estimated cost & $22,825,000$ \\
\hline
\end{tabular}


TABLE 5.6 Carbon Disulfide Recovery System Cost Estimate: Very Wet Gas with Nitrogen Desorption and 80\% Relative Humidity (case 5)

\begin{tabular}{|c|c|}
\hline Item & Cost $(\$)$ \\
\hline $\begin{array}{l}\text { Steam generator plant } \\
40,000 \mathrm{lb} / \mathrm{hr} \text { at } 150 \mathrm{psig} \\
\text { Complete package, gas fired }\end{array}$ & 375,000 \\
\hline Nitrogen feed and heating system & 950,000 \\
\hline $\begin{array}{l}\text { Air blowers ( } 8 \text { units) } \\
400,000 \mathrm{cfm} \text { at } 5 \mathrm{psig}\end{array}$ & $3,000,000$ \\
\hline $\begin{array}{l}\text { Carbon towers (24 units) } \\
\text { Complete package including } \\
\text { control panel }\end{array}$ & $6,000,000$ \\
\hline Gas mixture cooling condensers & 200,000 \\
\hline $\begin{array}{l}\text { Cooling tower and chilled } \\
\text { water system }\end{array}$ & 800,000 \\
\hline Water/CS ${ }_{2}$ separator & 200,000 \\
\hline Piping and fitting & $1,200,000$ \\
\hline $\begin{array}{l}\text { Process building } \\
15,000 \mathrm{ft}^{2} \text {, prefabricated } \\
\text { Without foundation }\end{array}$ & 750,000 \\
\hline Installation cost & $3,800,000$ \\
\hline Subtotal & $17,275,000$ \\
\hline $\begin{array}{l}\text { Engineering and } \\
\text { construction management }\end{array}$ & $3,109,000$ \\
\hline Contingency at $25 \%$ & $5,096,000$ \\
\hline Total estimated cost & $25,480,000$ \\
\hline
\end{tabular}


TABLE 5.7 Carbon Disulfide Recovery System Cost Estimate: Very Wet Gas with Steam Descrption (case 6)

\begin{tabular}{|c|c|}
\hline Item & Cost (\$) \\
\hline $\begin{array}{l}\text { Steam generator plant } \\
40,000 \mathrm{lb} / \mathrm{hr} \text { at } 150 \mathrm{psig} \\
\text { Complete package, gas fired }\end{array}$ & 375,000 \\
\hline $\begin{array}{l}\text { Air blowers ( } 8 \text { units) } \\
400,000 \mathrm{cfm} \text { at } 5 \text { psig } \\
\text { Including full-flow (100\%) } \\
\text { air dryer }\end{array}$ & $3,000,000$ \\
\hline $\begin{array}{l}\text { Carbon towers ( } 24 \text { units) } \\
\text { Complete package including } \\
\text { control panel }\end{array}$ & $6,000,000$ \\
\hline Steam condensers & 200,000 \\
\hline $\begin{array}{l}\text { Cooling tower and ihilled } \\
\text { water system }\end{array}$ & 800,000 \\
\hline Water/CS ${ }_{2}$ separator & 200,000 \\
\hline Piping and fitting & $1,200,000$ \\
\hline $\begin{array}{l}\text { Process building } \\
15,000 \mathrm{ft}^{2} \text {, prefabricated } \\
\text { Without foundation }\end{array}$ & 750,000 \\
\hline Installation cost & $3,800,000$ \\
\hline Subtotal & $16,325,000$ \\
\hline $\begin{array}{l}\text { Engineering and } \\
\text { construction management }\end{array}$ & $2,939,000$ \\
\hline Contingency at $25 \%$ & $4,816,000$ \\
\hline Total estimated cost & $24,080,000$ \\
\hline
\end{tabular}


TABLE 5.8 Carbon Disulfide Recovery System Cost Estimate: High Pressure with Dry Gas (case 7)

\begin{tabular}{|c|c|}
\hline Item & Cost (\$) \\
\hline $\begin{array}{l}\text { Steam generator plant } \\
40,000 \mathrm{lb} / \mathrm{hr} \text { at } 150 \mathrm{psig} \\
\text { Complete package, gas fired }\end{array}$ & 375,000 \\
\hline $\begin{array}{l}\text { Compressors (8 units) } \\
400,000 \mathrm{cfm} \text { at } 50 \text { psig } \\
\text { Including full-flow }(100 \%) \\
\text { air dryer }\end{array}$ & $6,000,000$ \\
\hline $\begin{array}{l}\text { Carbon towers ( } 12 \text { units) } \\
\text { Complete package including } \\
\text { control panel }\end{array}$ & $3,800,000$ \\
\hline Steam condensers & 200,000 \\
\hline $\begin{array}{l}\text { Cooling tower and chilled } \\
\text { water system }\end{array}$ & 800,000 \\
\hline Water/CS ${ }_{2}$ separator & 200,000 \\
\hline Piping and fitting & 900,000 \\
\hline $\begin{array}{l}\text { Process building } \\
15,000 \mathrm{ft}^{2}, \text { prefabricated } \\
\text { Without foundation }\end{array}$ & 750,000 \\
\hline Installation cost & $3,000,000$ \\
\hline Subtotal & $16,025,000$ \\
\hline $\begin{array}{l}\text { Engineering and } \\
\text { construction management }\end{array}$ & $2,885,000$ \\
\hline Contingency at $25 \%$ & $4,727,000$ \\
\hline Total estimated cost & $23,637,000$ \\
\hline
\end{tabular}


TABLE 5.9 Carbon Disulfide Recovery System Cost Estimate: High Pressure with Deep Towers (case 8)

\begin{tabular}{|c|c|}
\hline Item & Cost $(\$)$ \\
\hline $\begin{array}{l}\text { Steam generator plant } \\
40,000 \mathrm{lb} / \mathrm{hr} \text { at } 150 \mathrm{psig} \\
\text { Complete package, gas fired }\end{array}$ & 375,000 \\
\hline $\begin{array}{l}\text { Air blowers (8 units) } \\
400,000 \text { cfm at } 50 \text { psig } \\
\text { Including full-flow }(50 \%) \\
\text { air dryer }\end{array}$ & $6,000,000$ \\
\hline $\begin{array}{l}\text { Carbon towers (10 units) } \\
\text { Complete package including } \\
\text { control panel (tall) }\end{array}$ & $2,500,000$ \\
\hline Steam condensers & 400,000 \\
\hline $\begin{array}{l}\text { Cooling tower and chilled } \\
\text { water system }\end{array}$ & 800,000 \\
\hline Water $/ \mathrm{CS}_{2}$ separator & 200,000 \\
\hline Piping and fitting & 800,000 \\
\hline $\begin{array}{l}\text { Process building } \\
15,000 \mathrm{ft}^{2}, \text { prefabricated } \\
\text { Without foundation }\end{array}$ & $1,500,000$ \\
\hline Installation cost & $3,200,000$ \\
\hline Subtotal & $15,775,000$ \\
\hline $\begin{array}{l}\text { Engineering and } \\
\text { construction management }\end{array}$ & $2,840,000$ \\
\hline Contingency at $25 \%$ & $4,654,000$ \\
\hline Total estimated cost & $23,269,000$ \\
\hline
\end{tabular}


TABLE 5.10 Summary of all $\mathrm{CS}_{2}$ Recovery System Cost Estimates $(\$ 1,000 \mathrm{~s})$

\begin{tabular}{|c|c|c|c|c|c|c|c|c|}
\hline Item & Case 1 & Case 2 & Caso 3 & Case 4 & Case 5 & Case 6 & Case 7 & Case 8 \\
\hline $\begin{array}{l}\text { Steam plant } \\
4(0,000 \mathrm{lb} / \mathrm{hr} \\
150 \mathrm{psig}, \text { gas fired }\end{array}$ & 375 & 375 & 375 & 375 & 375 & 375 & 375 & 375 \\
\hline $\begin{array}{l}\mathrm{N}_{2} \text { feed and } \\
\text { heating system }\end{array}$ & . & 960 & 950 & - & 950 & - & . & . \\
\hline $\begin{array}{l}\text { Air compressors } \\
\text { and dryer } \\
\text { E) psig, } 400,000 \mathrm{~cm}\end{array}$ & . & . & - & . & . & . & 6,0000 & 6,0000 \\
\hline $\begin{array}{l}\text { Air blowers and dryer } \\
5 \text { psig, } 400,0 \text { no efrn }\end{array}$ & 4,000 & 4,000 & 3,600 & 3,6100 & 3,000 & 3,0000 & . & - \\
\hline Adsorption towers & 5,200 & 5,200 & 5,200 & 5.200 & 6,0000 & 6,0000 & 3,800 & 2.500 \\
\hline $\begin{array}{l}\text { Condensers (steam or } \\
\mathrm{N}_{2} \text { cooling) }\end{array}$ & 150 & 200 & 200 & 150 & 200 & $2(10)$ & 200 & $+(1)$ \\
\hline $\begin{array}{l}\mathrm{H}_{2} \mathrm{O} \text { conling and } \\
\text { thilling }\end{array}$ & 8011 & 800 & 3010 & 800 & 800 & $3(10)$ & 800 & $3(10)$ \\
\hline $\mathrm{CS}_{2}$ separator & 200 & 200 & 200 & 200 & 200 & 200 & 200 & 200 \\
\hline Piping and fitting & 1,200 & 1,200 & 1,200 & 1,200 & 1,200 & 1,200 & $9(1) 0$ & 800 \\
\hline $\begin{array}{l}\text { Building } \\
15,000 \mathrm{ft}^{2} \\
\text { Prefabricated }\end{array}$ & 750 & 750 & 750 & 750 & 750 & 750 & 750 & $1,50()$ \\
\hline Installation & 3,200 & 3,500 & 3,500 & 3,200 & 3,800 & $3,800)$ & $3,00(0)$ & 3,200 \\
\hline $\begin{array}{l}\text { Engineering and } \\
\text { construction } \\
\text { management }\end{array}$ & 2,358 & 3,091 & 3,019 & 2,785 & 3,109 & 2,2339 & $2,3 \times 5$ & 2,840 \\
\hline Contingency $(25 \%)$ & 4,683 & $5 . u t i 6 i$ & 4,948 & 4.565 & 5,096 & $4,8 \perp f i$ & 4,727 &,$+ 65 \overline{4}$ \\
\hline Total & $\$ 23,416$ & $\$ 25,332$ & $\$ 24,742$ & $\$ 22,825$ & $\$ 25,480$ & $\$ 24,080$ & $\$ 23.637$ & $\$ 23,2639$ \\
\hline
\end{tabular}


$\left[\begin{array}{l}1 \\ \vdots \\ \vdots \\ 3\end{array}\right.$
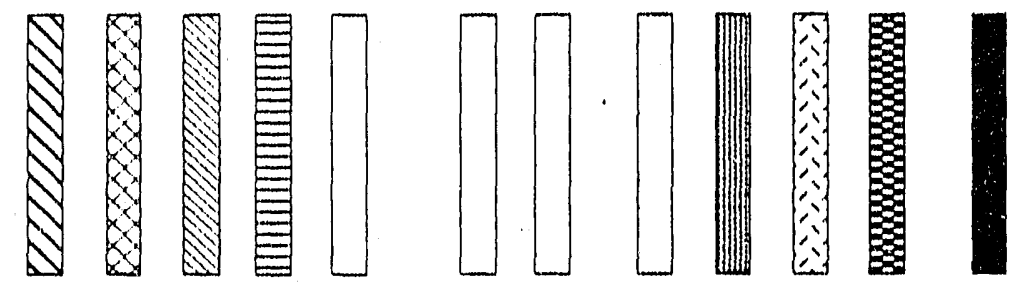

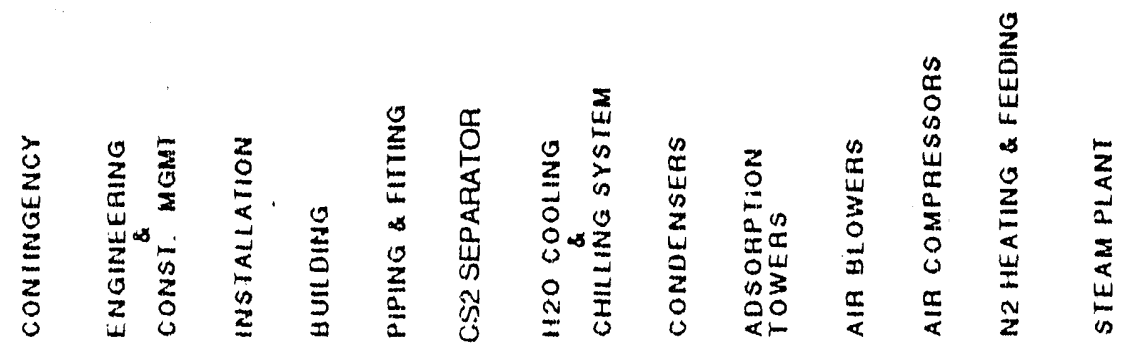

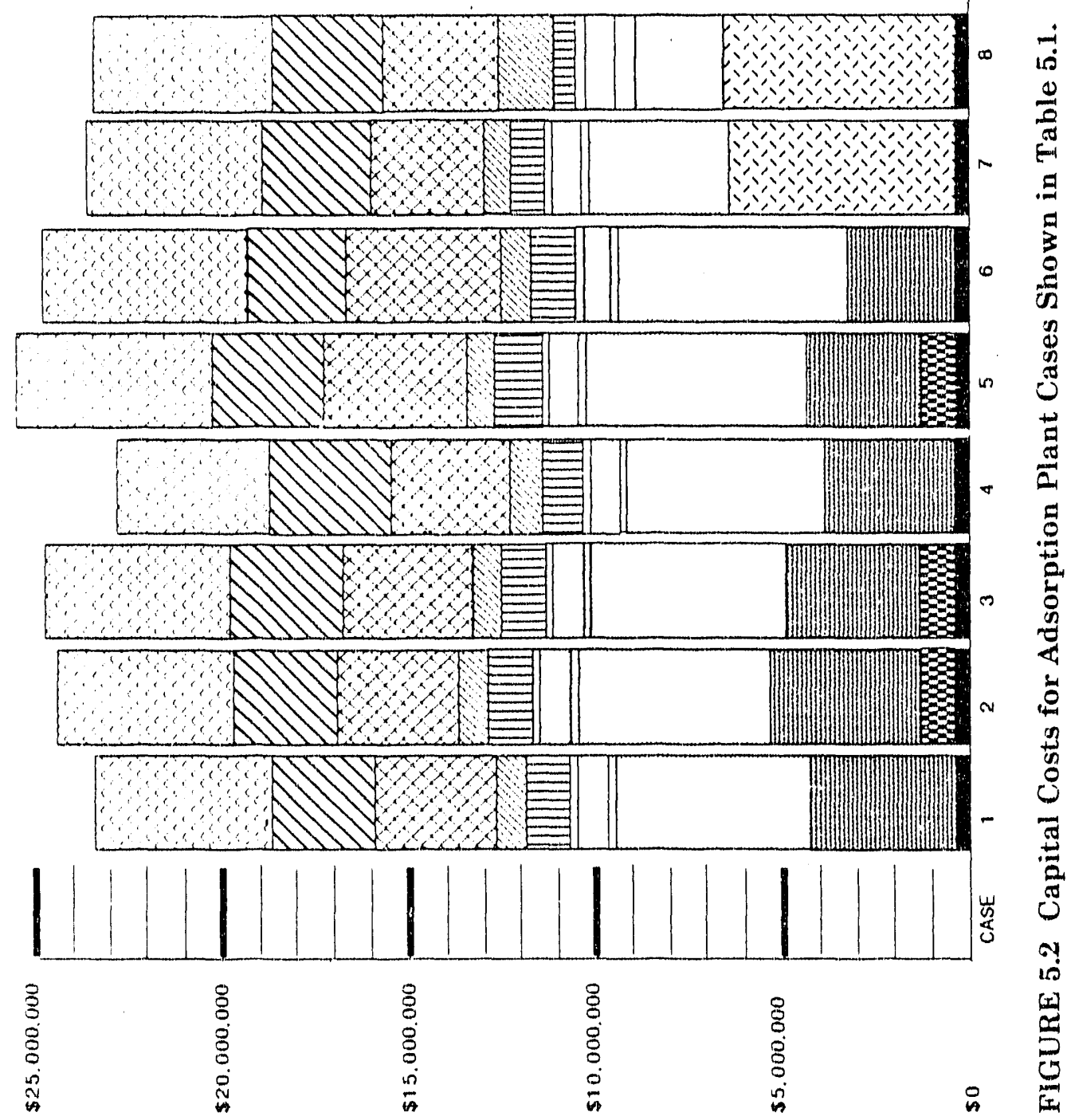


From the above data, it is concluded that:

- Steam desorption is preferred to $\mathrm{N}_{2}$ desorption.

- Partial drying is preferred to no drying or total drying.

- Minimum pressure (5 psig) is preferred to high pressure (50 psig).

- There is no advantage in supplying high pressure drop.

- The installed cost of a TSA plant at Teepak will be about $\$ 23$ million. 


\section{REFERENCES}

1. Kachanak, S., A. Moncinanova, and J. Valtyni, 1972, Carbon Disulfide Adsorption on Type 5a Molecular Siene, Zb. Pr. Chemickotechnol. Fak. SVST, pp. 293-300.

2. Kuropka, J., and M. Gostomczyk, 1978, Investigation of the Kinetics of Carbon Disulfide Sorption on Anion Exchangers, Environ. Prot. Eng., 4(2):87-99.

3. Richardson, I.M.J., and J.P. O'Oonnell, 1975, Some Generalizations about Processes to Absorb Acid Gases and Mercaptans, Int. Eng. Chem., Proc. Dev., 14(4):467-470.

4. Wolf, F, and S. Lindan, 1976, A6sorption of Carbon Disulfide, East Germany DD 117866 , Feb. 5.

5. Strazhesko, D., Ad., 1979, Adsorption and Adsorbents, No. 1, Halstead Press, Jnhn Wiley and Sons, New York, p. 159.

6. Grrefted Resins Adsorb Pollutants, 1991, Chem. Eng., p. 17, Jan.

7. Lee, M., Y. Nai, and R. Schoofs, 1969, Purification of Gases by Ammonia-Modified Molecular Sieves, Ger. Offen., DE 1911670, Oet. 9.

8. Storp, K., H. Wirth, and G. Rittinger, 1.976, Separation of Organic Sulfur Compounds from Gases, Ger. Offen., DE 2511976, Sept. 30.

9. Huschenbett, R., et al., 1985, Absorption of $\mathrm{H}_{2} \mathrm{~S}$ and $\mathrm{CS}_{2}$ on Activated Carbons, LuftKaeltetech, 213(3):151-153.

10. Goworek, J., A. Swiatkowski, and S. Zietek, 1989, Studies on the Adsorption Process of Benzene Methanol Mixtures on Carbon Blocks Containing Chemically Bonded Sulfiur. Mater. Chem. Phys., 21(4):357-365.

11. Biewald, H. and H. Riebold, 1988, Waste Treatment in Viscose Production Plants, Viscose Fibers Conf., Budapest, Hungary, Sept.

12. Shinko, I., et al., 1988, Development of Low Waste Techinology in Units for Removal of $\mathrm{H}_{2} \mathrm{~S}$ and $\mathrm{CS}_{2}$ from Gas-Air Mixtures, Kim. Volokna, 6:3-5.

13. Grochowski, R., and A. Kapuscinski, 1986, Methods of Removing $\mathrm{CS}_{2}$ from Air, Polish Patent PL 134594 B1, ICM B01J019-08, Oct. 31.

14. Hanan, I., et al., 1979, Possibilities of $C_{2}$ Removal from Some Industrial Gases, Rev. Chim. (Bucharest, Romania), 30(4):346-348.

15. Tantz, B., and D. Baehr, 1984, Energy and Material Recovery from Exhaust Giases of the Viscose Industry in a Gas Mixture with a Carbon Disulfide Content of less than $550 \mathrm{~g} / \mathrm{m}^{3}$, East German Patent DD 214866 A1, Oct. 24. 
16. Rybicki, Z., et al., 1987, Ventilation Air Purification in Viscose Fiber Plants, Pol. Tech. Rev, 5:12-13.

17. Majewska, J., V. Grams, and Z. Rybicki, 1977, New Wet Method for the Purification of Rayon Fiber Production Dilute Ventilation Discharges from Sulfur, Mezhdunar. Simp. Khim. Voloknam, 2nd, 6:69.74.

18. Majewski, J, et al., 1976, Renoval of Gaseous Sulfur Compounds from Waste Gas, Especially from Viscose Fiber Production, Ger. Offen. DE 2543630, April 22.

19. Nakanishi, V., and Y. Harada, 1977, Refining of Gases Containing Organic Sulfur Compounds, Japan Kokai JP 52111905, Sept. 20.

20. Shimada, MI., S. Hahimoto, and K. Lisui, 1975, Recovery of Carbon Disulfide from Waste Gases, Japan Kokai JP 50003997, Jan. 16.

21. Portnov, D., V. Astakhov, and R. Mokhnatkin, 1977, Neu Process for the Removal of Carbon Disulfide from Ventilation Discharges, Mezhdunar. Simp. Khim. Voloknam, and. $5: 5-6$.

22. Leszczynski, Z., et al., 1973, Separation of Pure Carbon Disulfide from Reaction Gases, Polish PL 66433, Nov. 15.

23. Selim, A., and V. Kim, 1988, Secondary Energy Sources in Rayon Manufacture, Khim. Volokna, 6:18-20.

24. Luethi, F., and G. Hechler, 1976, Purifying the Exhaust Air from Viscose Spinning Machines, Ger. Offen. DE 2514798, Sept. 16.

25. Liang, Y., and D. Qu, 1985, Cost-Benefit Analysis of the Recovery of Carbon Disulfide in the Manufacturing of Viscose Rayon, Scand. J. Work, Environ., Health, 11(4):60-633.

26. Shinko, I., et al, 1982, Removal of $\mathrm{CS}_{2}$ and $\mathrm{H}_{2} \mathrm{~S}$ from Rayon Fiber Production Ventilation Gases of Low Concentration, Khim. Volokna, 6:165-169.

27. Gizinksi, W., 1982, Sorne Aspects of the Treatment of Waste Gases from Rayon Fiber Plants, Wolokna Chem., 8(2):165-169.

28. Rybakov, L., I. Pushkova, and Y. Afanas'ev, 1984, Spontaneous Combustion of Activated Carbon during Recovery of Carbon Disulfide from Rayon Fiber Production Ventilation Air, Khim. Volokna, 6:11-12.

29. Hirata, M., et al., 1975, Computer-Aided Data Book of Vapor-Liquid Équilibria, Elsevier Scientific, Amsterdam.

30. Lekae, V., A. Golovko, and V. Polyak, 1973, Static Characteristics of the Carbon Disulfide-Mineral Oil System, Tr. Mosk. Tekhnol. Inst, 72:182-184. 
31. Hansen, C., and B. Anderson, 1988, The Affinities of Organic Solvents in Biological Systems, Am. Ind. Hyg. Assoc. J., 49(6):301-308.

32. Pransnitz, J., 1969, Molecular Thermodynamics of Fluld-Phase Equilibria, Prentice-Hall, Inglowood Cliffs, N.J., pp. 269-278.

33. Pohl, G., 1989, Biological Waste-Gas Cleaning at Viscose Processing Plants, CLB, Chem. Labor Betr., $40(4): 188-189$.

34. Berzaczy, L., et al., 1988, Biological Exhaust-Gas Purification in the Rayon Fiber Manufacture, Chem. Biochem. Eng, Q., 2(4):201-203.

35. Privalov, V., et al., 1981, Removal of Acid Components and Carbon Disulfide from Coke Gas, Otkrytiya, Izobret., Prom. Obraztsy, Tovarnye Zinaki, 3:25.

36. Vanderheyden, E., E. Vausant, and J. Philippaerts, 1987, FVIR-PAS Analysis of Silica Gel Modified with Amines for the Treatment of Natural Gases Contaminated with Silulfur Compounds, Milurochim Acta, 2(1-6):163-166.

37. Belyakov, V., et al., 1976, Removing Carbon Disulfide from Gases, Otkrytiya, Izobret., Prom. Obraztsy, Tovarnye Znaki, 53(29):17.

38. Denbigh, K., 1968, The Principles of Chemical Equilibrium, 2nd Ed., Cambridge University Press, United Kingdom.

39. Hansen. C.M., 1969, The Universality of the Solubility Parameter, Ind. Eng. Chem. Prod. Res. Div., 8:2-11.

40. Hildebrand, J., and R. Scott, 1.971, Solubility of Non-Electrolytes, 3rd Ed., Reinhold, New York.

41. Prausnitz, J.M., 1969, Molecular Thermodynamics of Fluid-Phase Eqquilibria, PrenticeHall, Inglewood Cliffs, N.J.

42. Bird, R., W. Stewart, and E. Lightfoot, 1960, Transport Phenomena, John Wiley and Sons, New York, p. 692.

43. Ferry, G.H., and C.H. Chilton, 1973, Chemical Engineers' Handbook, 5th Ed., McGrawHill, New York.

44. Hall, B., 1991, Union Carbide, Separations Skill Center, S. Charleston, W. Va., personal communication, June.

45. Weitekamper, F., 1991, Ingersoll-Rand, Air Compression Group, Elmhurst, Ill, personal communication, June.

46. Taecker and Ilougen, 1948, Chem. Eng. Progr., pp. 44 and 529. 
47. Shulman et al., 1955, Am. Inst. Chem. Engr. J., pp. 1 and 253.

48. Kohl, A., and P. Buckingham, 1960, Petroleum Refiner, 3̈ง:193-196, May.

49. Basmadjian, D., 1980, Rapid Procedures for the Prediction of Fixed-Bed Adsorber Behavior, Ind. Eng. Chem. Proc. Des. Devel., 19:129.137.

50. Leyden, D.E., 1986, Silanes, Surfaces and Interfaces, Gordon and Breach, New York.

51. Calgone Data Sheet 27.118a, 1987, Calgon Carbon Corp., Pittsburgh, Penn., June. 


\section{APPENDIX A}

\section{GAS ABSORPTION TOWER: SAMPLE CALCULATION}

The calculations for the gas absorption towers make the following assumptions:

- Air flow: 400,000 cfm

- Inlet air: $100 \mathrm{ppm} \mathrm{CS}_{2}, 5 \mathrm{psig}$

- Outlet air: 10 ppm $\mathrm{CS}_{2}, 4.9639$ psig

- Countercurrent contact of inlet air is with a liquid with the properties of propylene carbonate:

- $p_{1}=74.5 \mathrm{lb} / \mathrm{ft}^{3}$

- Molecular weight $=102$

- Viscosity $=0.3 \mathrm{cp}$ or $0.73 \mathrm{lb} / \mathrm{ft} \cdot \mathrm{hr}$

- Diffusivity of $\left(C S_{2}\left(D_{1}\right)=5 \times 10^{-5} \mathrm{ft}^{2} / \mathrm{hr}\right.$

- Bed properties: packing 1.0.in. ceramic Rashig rings

- Tower properties: 12-ft diameter

\section{A.1 VAPOR/LIQUTD EQUILIBRIUM ASSUMPTION}

For a sample calculation, assume $\mathrm{K}=0.48$, where $\mathrm{y}=\mathrm{Kx}$.

\section{A.2 LIQUTD RATE IN TOWER}

The optimum liquid rate is approximately that required to give 1.5 times the rate for equilibrium at the tower bottom. Let $\mathrm{L}_{\mathrm{M}}$ and $\mathrm{G}_{\mathrm{M}}$ be the total liquid sorbent (excluding $\mathrm{CS}_{2}$ ) and total gas rates in moles $/ \mathrm{hr}$. A material balance on the complete system (possibly more than one tow/er) gives:

$$
L_{M}=G_{M}\left(y_{1}-y_{2}\right) /\left(x_{1}-x_{2}\right)
$$

where 1 and 2 represent the bottom and top of the tower, respectively, and $\mathrm{x}$ and $\mathrm{y}$ represent the mole fraction of $\mathrm{CS}_{2}$ in the liquid and gas, respectively, as shown in Figure A.1. For $100 \mathrm{ppm}$ teed, we have:

$$
\mathrm{y}_{1}=100 \text { mole } \mathrm{CS}_{2} /\left(10^{6} \text { mole air }+100 \text { mole } \mathrm{CS}_{2}\right) \equiv 10^{-4}
$$




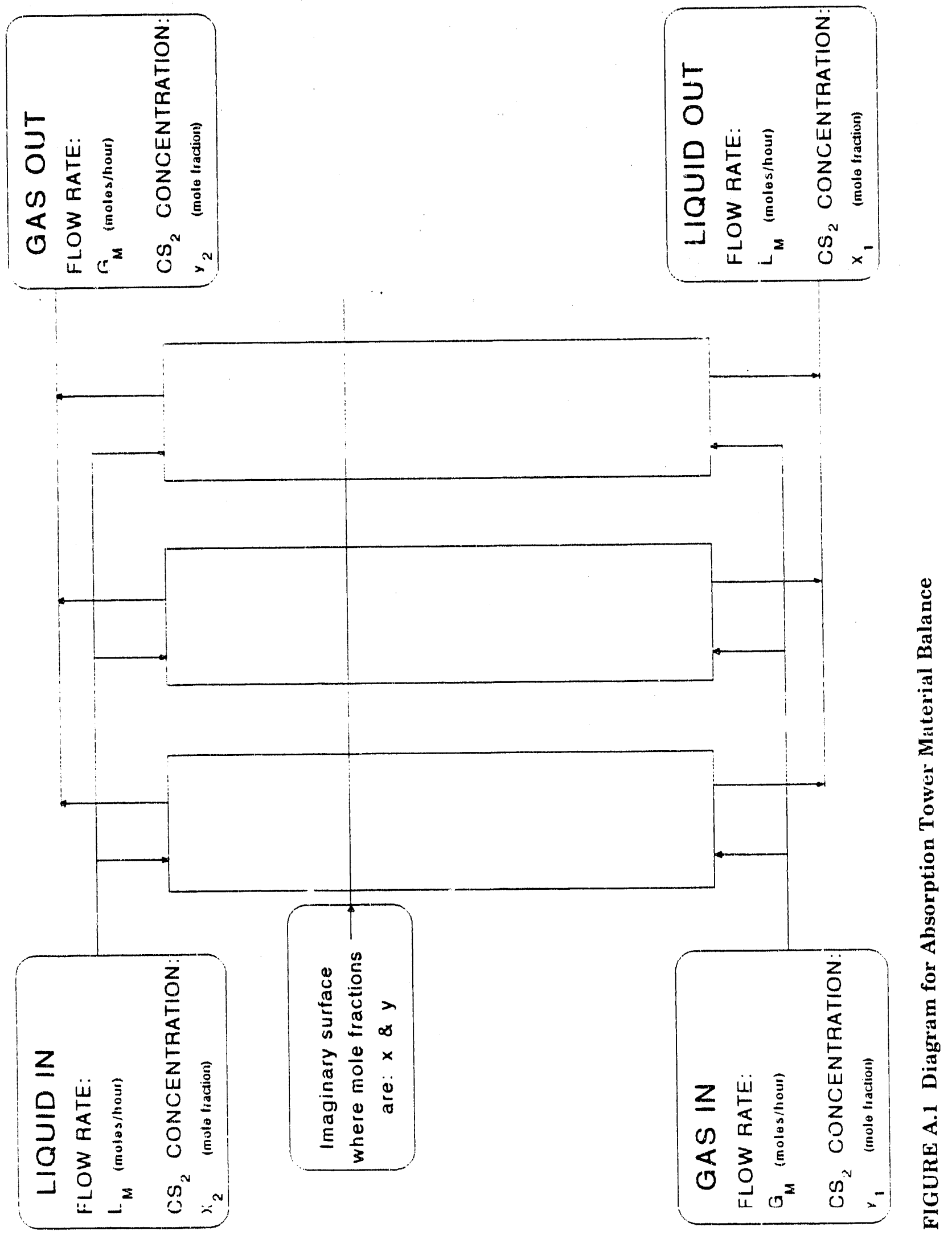


For 10 ppm outlet, we have:

$$
y_{2} \cong 10 / 10^{6}=10^{-5}
$$

For this balance, assume $\mathrm{K}=0.48$ and that equilibrium exists at the tower bottom. Thus, the concentration in the liquid $\left(\mathrm{x}_{1}\right)$ is the following:

$$
\mathrm{x}_{1}=\mathrm{y}_{1} / 0.48=2.08 \times 10^{1}
$$

Also assume the entering liquid is free of $\mathrm{CS}_{2}$ :

$$
x_{2}=0
$$

To get the moles in 400,000-cfm gas, use the ideal gas law:

$$
\begin{aligned}
\mathrm{G}_{\mathrm{M}}= & 4 \times 10^{5} \mathrm{P} / \mathrm{RT}=\left(4 \times 10^{5} \mathrm{ft}^{3} / \mathrm{min}\right)(1 \mathrm{~atm})(60 \mathrm{~min} / \mathrm{hr}) / \\
& \left(0.73 \mathrm{ft}^{3} \cdot \mathrm{atm}^{\mathrm{mole}} \mathrm{mol}^{\circ} \mathrm{R}\right)\left(537^{\circ} \mathrm{R}\right)=61,222 \mathrm{~mole} / \mathrm{hr}
\end{aligned}
$$

By using Equation A.1, the minimum liquid rate is calculated as follows:

$$
\mathrm{L}_{\mathrm{M}}=61,222 \mathrm{~mole} / \mathrm{hr}\left(10^{-4}-10^{-5}\right) /\left(2.08 \times 10^{-4}-0\right)=26,449 \mathrm{~mole} / \mathrm{hr}
$$

The optimum rate is usually taken to be 1.5 times the rate for equilibrium at the tower bottom. The optimum liquid rate is thus:

$$
\mathrm{L}_{\mathrm{M}}=1.5(26,449)=39,673 \mathrm{~mole} / \mathrm{hr}
$$

or, in terms of pounds:

$$
\mathrm{L}_{\mathrm{M}}=4,046,646 \mathrm{lb} / \mathrm{hr}
$$

The new $\mathrm{x}_{1}$ can be calculated from a rearranged form of Equation A.1:

$$
\mathrm{x}_{1}=\mathrm{G}_{\mathrm{M}}\left(\mathrm{y}_{1}-\mathrm{y}_{2}\right) / \mathrm{L}_{\mathrm{M}}=61,222\left(10^{-4}-10^{-5}\right) / 39,735=1.39 \times 10^{-4}
$$

\section{A.3 REQUIRED NUMBER OF TOWERS}

To obtain the required number of towers, we first must determine the allowable gas and liquid rates in towers filled with the particular packing to be used. In this case, we

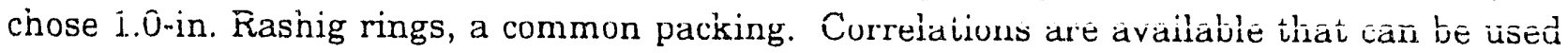


to determine the allowable gas flux into a tower of known diameter and liquid flow. Gas flux must be limited because, if the gas flow up the tower is too large, the liquid won't be able to flow downward easily and the tower will become flooded with liquid and require excessive pressure drop. Figure 18-39 of Perry and Chilton's Chemical Engineers' Handbook, a generalized pressure-drop curve, has been adapted for this purpose (see Figure 3.2, p. 20).

For a calculation with 1.0-in. Rashig rings, several factors are required. From Perry and Chilton (pp. 18-22*), we obtain the packing factor $\left(\mathrm{F}_{\mathrm{p}}\right)$ of 155 . The water-to-liquid density ratio is: $\Psi=62.4 / 74.5=0.84$. The input for the pressure-drop curve requires both the mass ratio of liquid to gas,

$$
\mathrm{L} / \mathrm{G}=39,735(102 \mathrm{lb} / \mathrm{mole}) /[(61,222)(29 \mathrm{lb} / \text { mole })]=2.28,
$$

and the density ratio of gas to liquid. The gas density can be obtained with the ideal gas law:

$$
\rho_{\mathrm{g}}=\mathrm{PM} / \mathrm{RT}=\mathrm{P}(29) / 0.73(537)=0.074 \mathrm{P}
$$

where $P$ is in atmospheres, absolute.

The required abscissa for the pressure-drop curve becomes:

$$
\mathrm{L}\left(\rho_{\mathrm{g}} / \rho_{1}\right)^{1 / 2} / \mathrm{G}=2.28(0.074 \mathrm{P} / 74.5)^{1 / 2}
$$

In order to proceed, we must know the pressure of the inlet gas. Because the tower requires some pressure drop, some gas pressurization equipment will be required. On the other hand, more extensive gas compression, although expensive, may have advantages. Because the volume to be treated is reduced, the number of required towers decreases and concentration increases, thus increasing the driving force for mass transfer. The trade-off must be based on costs. A thorough analysis of this trade-off is beyond the scope of this report, but some of the important effects of pressure are considered in Section 3.3.3. For the purposes of this example, we will assume that pressure is 5 psig and that 0.036 psig pressure drop is available. For a first iteration, we take bed depth (tower height) as $\mathrm{Z}=1.0 \mathrm{ft}$. This value results in a pressure drop per foot of bed depth of:

$$
\begin{gathered}
\mathrm{PD}=\left[(5 \text { psig }-4.9639 \text { psig }) 27.684 \text { in. } \mathrm{H}_{2} \mathrm{O} / \mathrm{psi}\right] / 1 \mathrm{ft} \text { bed } \\
\mathrm{PD}=1.0 \mathrm{H}_{2} \mathrm{O} / \mathrm{ft} \text { bed } \\
\mathrm{L}\left(\rho_{\mathrm{g}} / \rho_{1}\right)^{1 / 2} / \mathrm{G}=2.28[0.074(19.7 / 14.7) / 7,415]^{1 / 2}=0.0832
\end{gathered}
$$

\footnotetext{
“Perry, G.H., and C.H. Chilton, 1973, Chemical Engineers' Hardbook, 5th Ed., McGraw-Hill, New York.
} 
With these assumptions, the figure yields:

$$
\left(\mathrm{G}^{2} \mathrm{~F}_{\mathrm{p}} \psi \mathrm{\mu}^{0.2}\right) /\left(\mathrm{p}_{\mathrm{g}} \mathrm{p}_{1} \mathrm{~g}\right)=0.075
$$

This gives:

$$
\mathrm{G}=\sqrt{0.075[0.074(19.7 / 14.7)] 74.5(32.2) / 155(0.84)(0.3)^{0.2}}=0.413 \mathrm{lb} / \mathrm{s} \cdot \mathrm{ft}^{2}
$$

By using $G$, the total cross-sectional tower area can be calculated:

$$
\begin{gathered}
A_{\text {TOT }}=G_{M}\left(M_{\text {air }}\right) / G=(61,222 \mathrm{~mole} / \mathrm{hr})(29 \mathrm{lb} / \mathrm{mole}) / \\
\\
{\left[\left(0.413 \mathrm{lb} / \mathrm{s} \cdot \mathrm{ft}^{2}\right)(3,600 \mathrm{~s} / \mathrm{hr})\right]=1,1.94 \mathrm{ft}^{2}}
\end{gathered}
$$

To obtain the number of required towers, a tower diameter must be selected. We have chosen 12-ft-diameter towers, and:

$$
\left.\mathrm{N}_{\mathrm{T}}=1,194 \mathrm{ft}^{2} /\left(\pi(12 \mathrm{ft})^{2}\right) / 4\right)=10.56
$$

Now G becomes:

$$
\mathrm{G}=(61,222 \times 29) /(10.56)(\pi)(144 / 4)=1,487 \mathrm{lb} / \mathrm{hr} \cdot \mathrm{ft}^{2}
$$

\section{A.4 REQUIRED TOWER HEIGHT}

We must now calculate the required height of the 11 towers of 12 -ft diameter. The calculated height will be compared later with the assumed height, and the calculation will be iterated until agreement is reached. The height depends on the rate at which $\mathrm{CS}_{2}$ can be transferred from the gas to the bulk of the liquid. This rate depends on the driving force, the difference in $\mathrm{CS}_{2}$ concentration between the bulk gas and the bulk liquid. This will be quite small because the gas concentration at the tower bottom can be no larger than $y_{2}=10^{-4}$ and the liquid concentration will be zero only at the top of the tower and will increase to $\mathrm{x}_{2}=1.39 \times 10^{-4}$ at the tower bottom for the ideal liquid case, as shown in Section A.2 above.

Also, there is some resistance to transport of $\mathrm{CS}_{2}$ over the liquid/gas interface. Based on the available correlations for packed towers (see Perry and Chilton, pp. 18-33 and 18-38*). The interfacial mass-transfer coefficients are calculated as shown in the following sections.

*See footnote, p. 128. 


\section{A.4.1 Gas Side Mass-Transfer Coefficient}

For the gas side, we use the Taecker and Hougen correlation (CEP, pp. 44 and $529^{*}$ ). We first obtain the Chilton-Colburn "j factor" for Rashig ring packing:

$$
j_{p}=1.07\left(G\left(A_{p}\right)^{1 / 2 / \mu}\right)^{-0.41}=1.07\left[1,487(0.043)^{1 / 2} /\left(4.35 \times 10^{-2}\right)\right]^{-0.41}=0.0282
$$

where $G$ is the gas rate in $\mathrm{lb} / \mathrm{hr} \cdot \mathrm{ft}^{2}, \mathrm{~A}_{\mathrm{b}}$ is the packing surface area per ring, and $\mu_{\mathrm{f}}$ is gas viscosity in $\mathrm{lb} / \mathrm{hr} \cdot \mathrm{ft}$ (Perry and Chilton, p. $3-211^{\dagger}$ ). The mass-transfer coefficient for the partial-pressure driving force is given by:

$$
\left(k_{p} p_{a} M / G\right)\left(\mu_{g} / \rho_{D}\right)^{2 / 3}=j_{D}
$$

where $p_{a}$ is the partial pressure of air.

$$
\begin{gathered}
k_{p}=0.0282\left[\frac{\left(1.487 \mathrm{lb} / \mathrm{hr} \cdot \mathrm{ft}^{2}\right)}{\mathrm{p}_{\mathrm{a}}(29 \mathrm{lb} / \mathrm{mole})}\right]\left[\frac{4.35 \times 10^{-2} \mathrm{lb} / \mathrm{ft} \cdot \mathrm{hr}}{\left(0.0992 \mathrm{lb} / \mathrm{ft}^{3}\right)\left(0.62 \mathrm{ft}^{2} / \mathrm{hr}\right)}\right] \\
k_{\mathrm{p}}=\left(1.82 \mathrm{~mole} / \mathrm{hr} \cdot \mathrm{ft}^{2} \cdot \mathrm{atm}\right) / \mathrm{p}_{\mathrm{a}}
\end{gathered}
$$

where $\rho_{\mathrm{g}}=0.074 \mathrm{P}=0.074(19.7 / 14.7)=0.0992$.

Because the mass-transfer coefficient relative to mole fraction driving force is given by

$$
\mathrm{k}_{\mathrm{g}}=\mathrm{k}_{\mathrm{p}} \mathrm{P}_{\mathrm{t}}
$$

where $P_{t}$ is total pressure, and because, in the Teepak case $p_{a} \equiv P_{t}$ :

$$
\mathrm{k}_{\mathrm{g}}=1.88 \mathrm{~mole} / \mathrm{hr} \cdot \mathrm{ft}^{2}
$$

\footnotetext{
"Taecker and Hougen, 1948, Chem. Eng. Progr., pp. 44 and 529.

${ }^{\dagger}$ See footnote, p. 128.
} 


\section{A.4.2 Liquid Side Mass-Transfer Coefficient}

For the liquid side, the Shulman correlation (AIChE J., p. 255*) is used:

$$
k_{c}=\left(D_{1} 25.1 / D_{p}\right)\left(D_{p} L / \mu_{1}\right)^{0.45}\left(\mu_{e} / \rho_{1} D_{1}\right)^{0.50}
$$

where $\mathrm{k}_{\mathrm{c}}$ is the liquid side mass-transfer coefficient for concentration driving force, $\mathrm{L}$ is the liquid rate in $\mathrm{lb} / \mathrm{hr} \cdot \mathrm{ft}^{2}, \mathrm{D}_{1}$ is liquid diffusion coefficient in $\mathrm{lb} \cdot \mathrm{ft} / \mathrm{hr}$, and $\mathrm{D}_{\mathrm{p}}$ is the diameter of a sphere that has the same surface area as a unit of packing. For 1-in. Rashig rings, $D_{p}$ is 0.117 (R. Treybal, p. $168^{\dagger}$ ) and:

$$
\begin{gathered}
\left.\mathrm{L}=(4,046,646 \mathrm{lb} / \mathrm{hr}) /\left[(10.56 \text { towers }) \pi 12^{2} \mathrm{ft}^{2} / \text { tower }\right) / 4\right]=3,389 \mathrm{lb} / \mathrm{hr} \cdot \mathrm{ft}^{2} \\
\mathrm{k}_{\mathrm{c}}=\frac{5 \times 10^{-5} \mathrm{ft}^{2} / \mathrm{hr}}{0.117 \mathrm{ft}}(25.1)\left(\frac{(0.117 \mathrm{ft})\left(3389 \mathrm{lb} / \mathrm{hr} \cdot \mathrm{ft}^{2}\right)}{(0.73 \mathrm{lb} / \mathrm{ft} \cdot \mathrm{hr})}\right)^{0.45}\left(\frac{0.73 \mathrm{lb} / \mathrm{ft} \cdot \mathrm{hr}}{74.5 \frac{\mathrm{lb}}{\mathrm{ft}^{3}}\left(5 \times 10^{-5} \frac{\mathrm{ft}}{\mathrm{hr}}\right)}\right) \\
\mathrm{k}_{\mathrm{c}}=2.55 \mathrm{ft} / \mathrm{hr}
\end{gathered}
$$

The liquid side mass-transfer coefficient for mole fraction is given by:

$$
\begin{gathered}
\mathrm{k}_{1}=\mathrm{k}_{\mathrm{c}}\left(\rho_{\mathrm{liq}} / \mathrm{M}_{\text {liq }}\right)=(2.55 \mathrm{ft} / \mathrm{hr})\left(74.5 \mathrm{lb} / \mathrm{ft}^{3} / 102 \mathrm{lb} / \text { mole }\right) \\
\mathrm{k}_{1}=1.86 \mathrm{~mole} / \mathrm{hr} \cdot \mathrm{ft}^{2}
\end{gathered}
$$

\section{A.4.3 Absorption Tower Material Balances}

Figure A.2 shows an imaginary surface for material balances in the tower. Balancing $\mathrm{CS}_{2}$ in and out over the surface results in the relationship:

$$
y=\left(L_{M} / G_{M}\right) x+y_{2}
$$

Using the known values for $\mathrm{L}_{\mathrm{M}}, \mathrm{G}_{\mathrm{M}}$, and $\mathrm{y}_{2}$ in this equation allows the "operating line" to be plotted as shown in Figure A.2. Ir. addition, Henry's law gives another relationship between the liquid and gas concentrations, assuming equilibrium exists. This relationship is plotted on the figure as the "equilibrium curve."

"Shulman et al., 1955, Am. Inst. Chem. Engr. J., p. 255.

${ }^{\dagger}$ Treybal, R., 1968, Mass Transfer Operations, 2nd Ed., p. 168. 
Another important balance is obtained by noting that the flux of $\mathrm{CS}_{2}$ out of the gas is equal to the flux into the liquid. These fluxes can be written in terms of the liquid and gas side mass-transfer coefficient ( $\mathrm{k}_{\mathrm{g}}$ and $\mathrm{k}_{1}$ ), the interfacial concentrations ( $\mathrm{x}^{*}$ and $\mathrm{y}^{*}$ ), and the bulk concentrations ( $\mathrm{x}$ and $\mathrm{y}$ ). Equating the fluxes produces the following equation, which allows the interfacial concentrations to be written in terms of the bulk concentrations:

$$
\left(y-y^{*}\right) /\left(x-x^{*}\right)=-\left(k_{1} a\right) /\left(k_{g} a\right)
$$

For the present case:

$$
\left(y-y^{*}\right) /\left(x-x^{*}\right)=-1.86 / 1.82=-1.023
$$

So let the slope $(\mathrm{S})$ be -1.023 . This relationship is shown in Figure A.2 as lines of slope $S$ from the inlet conditions on the operating line to the interfacial conditions on the equilibrium line. The next balance gives the flux from the gas phase to the liquid phase over the interfacial surface contained in a very small segment $(\mathrm{dz})$ of the tower:

$$
-G_{M} d y=k_{g} a\left(y-y^{*}\right) A d z
$$

where $A$ is the tower cross-sectional area. If $\mathrm{y}^{*}$ were known as a function of gas phase mole fraction $(y)$, then this equation could be integrated to yield tower height.

\section{A.4.4 Log Mean Concentration Difference}

Because we are working with very dilute $\mathrm{CS}_{2}$ concentrations, we may assume that both the operating line and equilibrium curve of Figure A.2 are straight as shown. Given this assumption, and noting that Equation A.2 gives the slope (S) of the line connecting the operating condition with the equilibrium curve, Equation A.3 can be integrated to yield:

$$
z=G_{M}\left(y_{2}-y_{1}\right) /\left(A\left(k_{g} a\right)\left(y^{*}-y\right)_{l n}\right)
$$

where the log mean temperature difference is given by:

$$
\left(y^{*}-y\right)_{\ln }=\left(\left(y^{*}-y_{2}\right)_{2}-\left(y^{*}-y\right)_{1}\right) / \ln \left[\left(y^{*}-y\right)_{2} /\left(y^{*}-y\right)_{1}\right]
$$




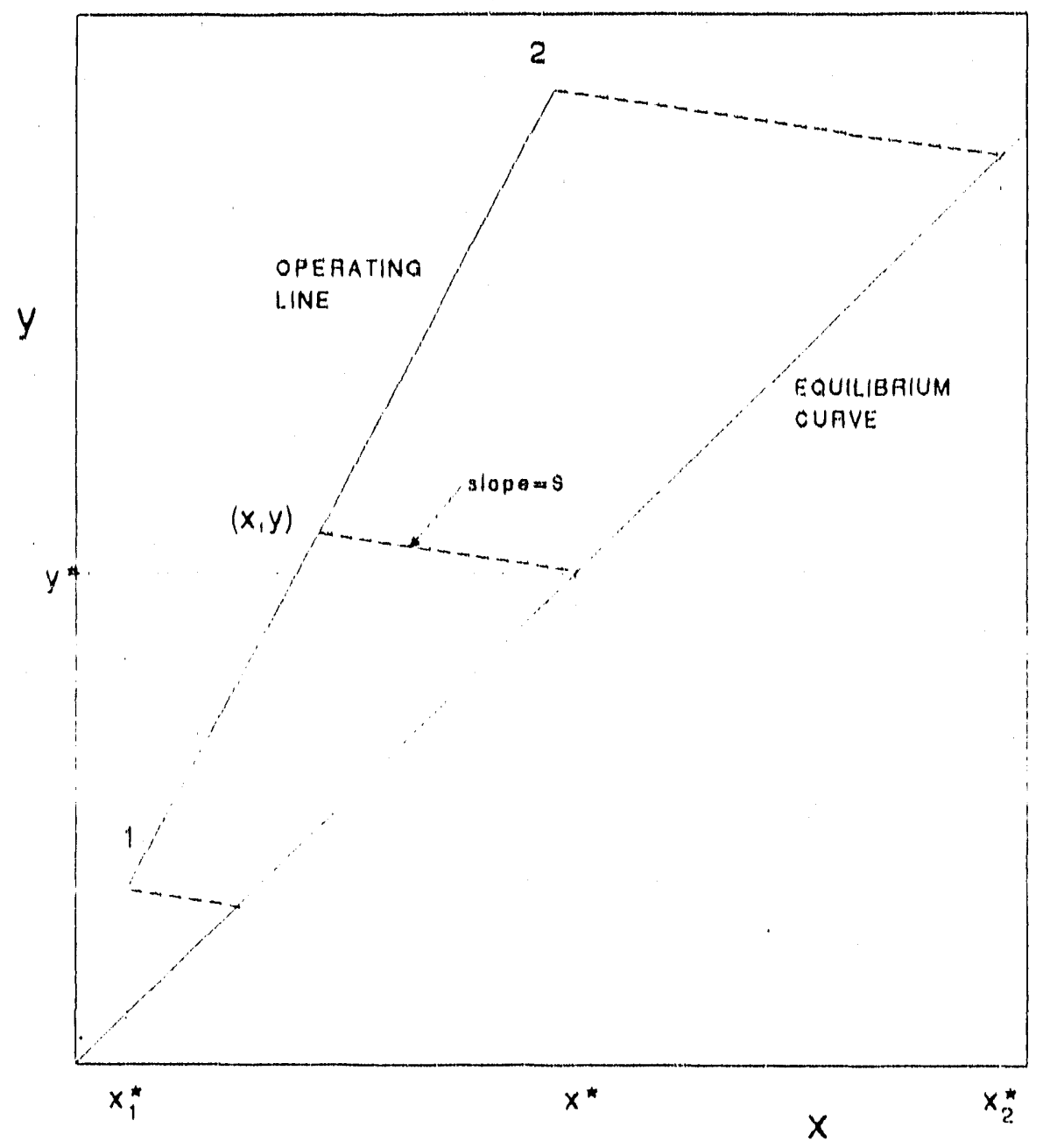

FIGURE A.2 Relationship of Interfacial Concentrations to Bulk Gas and Liquid Concentrations for $\mathrm{CS}_{2}$ Absorption Tower(s)

The relationship between interfacial and bulk concentrations and the equilibrium curve can then be used to calculate the tower height as follows:

$$
\begin{aligned}
& \left(y-y^{*}\right) /\left(x-x^{*}\right)=S \\
& y^{*}=K x^{*}
\end{aligned}
$$


We then solve for $x^{*}$ :

$$
\begin{aligned}
& y-K x^{*}=\left(x-x^{*}\right) S \\
& x^{*} S-K x^{*}=S x-y \\
& x^{*}=(S x-y) /(S-K)
\end{aligned}
$$

This value is the interfacial liquid concentration in terms of the bulk concentrations:

$$
\begin{aligned}
& x_{1}^{\prime \prime}=\frac{-1.015\left(1.39 \times 10^{-4}\right)-10^{-4}}{-1.015-0.48}=1.612 \times 10^{-4} \\
& x_{i}^{*}=\frac{-1.015(0)-10^{-5}}{-1 .(1) 15-10.48}=6.69 \times 10^{-5} \\
& \left(y-y^{\prime \prime}\right)_{1}=S\left(x-x^{*}\right) \\
& \left(y-y^{*}\right)_{1}=-1.015\left(1.39 \times 10^{-4}-1.612 \times 10^{-4}\right)=2.26 \times 10^{-5} \\
& \left(y-y^{*}\right)_{2}=-1.015\left(0-6.69 \times 10^{-6}\right)=6.79 \times 10^{-6} \\
& \left(y^{*}-y\right)_{\ln }=\left(\left(y-y^{*}\right)_{2}-\left(y-y^{*}\right)_{1}\right) /\left(\ln \left[\left(y-y^{*}\right)_{2} /\left(y-y^{*}\right)_{1} \mid\right)\right. \\
& \left.\left(y^{*}-y\right)_{\ln }=\left(6.79 \times 10^{-6}-2.26 \times 10^{-5}\right) /\left(\ln \mid 6.79 \times 10^{-6}\right) /\left(2.26 \times 10^{-5}\right)\right)=1.319 \times 10^{-5}
\end{aligned}
$$

\section{A.4.5 Calculation of Tower Height}

Equation A.4 can now be solved to give the required tower height:

$$
\begin{gathered}
\mathrm{Z}=\left(\mathrm{G}_{\mathrm{M}}\left(\mathrm{y}_{1}-2\right)\right) /\left(\mathrm{A}\left(\mathrm{k}_{\mathrm{gr}} \mathrm{a}\right)(\mathrm{y} *-\mathrm{y})_{\mathrm{ln}}\right) \\
\mathrm{Z}=\frac{(6122 \mathrm{~mole} / \mathrm{hr})\left(10^{-4}-10^{-5}\right)}{113.1 \mathrm{ft}^{2}\left(1.88 \frac{\mathrm{mole}}{\mathrm{hr}^{-5} \mathrm{ft}^{2}} \cdot 15 \mathrm{ft}^{-1}\right)\left(1.315 \times 10^{-5}\right)} .
\end{gathered}
$$




$$
\mathrm{Z}=13.1 \mathrm{ft}
$$

Because we assumed $\mathrm{Z}=1.0 \mathrm{ft}$ to begin this calculation, we must revise the estimate of $\mathrm{Z}$ and go through the procedure again. Six cycles produce convergence, as shown in Table A.1. These calculations have been programmed in Fortran (Microsofti version 4.1) and used to produce the figures shown in Section 3 of this report. Code listings with extensive comments are given in the following pages.

TABLE A.1 Iteration for Bed Depth of Absorption Tower

\begin{tabular}{|c|c|c|c|c|c|c|}
\hline $\begin{array}{c}\text { Estimated } \\
\text { Bed } \\
\text { Depth } \\
\left(t^{\prime} t\right)\end{array}$ & $\begin{array}{c}\text { Superficial } \\
\text { Cras } \\
\text { Velocity } \\
\text { (f't/min) }\end{array}$ & $\begin{array}{c}\text { Number } \\
\text { of } \\
\text { Towers }\end{array}$ & $\begin{array}{c}\text { Gas Side } \\
\text { Mass } \\
\text { Transfer } \\
\text { Coefficient } \\
\text { (mole/hr. } \mathrm{ft}^{2} \text { ) }\end{array}$ & $\begin{array}{c}\text { Liquid Side } \\
\text { Mass } \\
\text { Transfer } \\
\text { Coefficient } \\
\left.\text { (mole/hr.tit }{ }^{2}\right)\end{array}$ & $\begin{array}{c}\text { Log } \\
\text { Mean } \\
\text { Driving } \\
\text { Force } \\
\left(\times 10^{5}\right)\end{array}$ & $\begin{array}{c}\text { Calculated } \\
\text { Bed Depth } \\
\text { (ft) }\end{array}$ \\
\hline 1.0 & 249 & 10.6 & 1.82 & $\cdot 1.86$ & 1.32 & 12.8 \\
\hline 6.9 & 123 & 21.4 & 1.20 & 1.36 & 1.36 & 9.3 \\
\hline 8.1 & 115.8 & 22.8 & 1.16 & 1.16 & 1.3634 & 9.02 \\
\hline 8.56 & 113.3 & 23.3 & 1.14 & 1.31 & 1.3646 & 8.94 \\
\hline 8.75 & 1.12 .4 & $23 . \overline{5}$ & 1.1 .4 & 1.30 & $1.365 \mathrm{~L}$ & 8.90 \\
\hline 8.825 & 112 & 23.6 & 1.13 & 1.30 & 1.3653 & 8.89 \\
\hline
\end{tabular}


C PROGRAM TO ESTIMATE ABSORPTION TOWER HEIGET AND NUMBER OF TIOWERS AS A EUNCTION OF HENRYS LAW COEFEICIENT FOR VAPOR/LIQUID EQUIIIBRIUM. GIVEN: DIAMETER; FLOW RATE OF GAS TO BE TREATED; INLET AND OUTLET CONCENTRATIONS OF ABSORBATE; GAS, IIQUID AND PACKLNG PROPERIIES ; AND PRESSURE. THE CALCUTATION USES THE LOG MEAN DRIVING FORCE AND IS THEREFORE RESTRICIED TO LOW ABSORBATE CONCENTRATIONS. WRITTEN BY MICHAEL MCINTOSH, JUNE 1991

ABSORB. F'OR

FORMAT (1.X, 4F8.4)

FORMAT $(1 X, 5 \mathrm{~F} 8.4)$

FORMAT (1X, 4E8.4)

FORMAT $(1 \mathrm{X}, 54.3)$

FORMAT (1X,E8.4)

FORMAT $(1 \mathrm{X}$, F9.4)

FORMAT $(1 \mathrm{X}, 6 \mathrm{E} 8.4)$

$\operatorname{REAL} \operatorname{CL} 1(7), \operatorname{CL} 2(7), \operatorname{CL} 3(7), \operatorname{CL} 4(7), \operatorname{CL} 5(7), \operatorname{CL} 6(7)$

REAL MWL, KH, LCON1, LM, LCON2, JY, JL, KG, KL, LREN

REAI LMDE, JV, NI

$\operatorname{OPEN}(12, F I I E=$ 'C: $\backslash$ WP $\backslash A B D A T ')$

OPEN (13,FILE='A: (HT100.PRN')

OPEN (14,FILE='A: $\left.\backslash N T 100 . P R N^{\prime}\right)$

OPEN $\left(15, F I L E=\prime C: \backslash W P \backslash P D D A T^{\prime}\right)$

$\operatorname{OPEN}\left(16, F I L E=' A: \mid V S 100 . P R N^{\prime}\right)$

READ COORDINATES OF LINE SEGMENT ENDS

FOR FLOODING CURVE INTERPOLATION

DO $8, I=1,7$

$\operatorname{READ}(15,7) \operatorname{CL1}(\mathrm{I}), \operatorname{CL2}(I), \operatorname{CL} 3(I), \operatorname{CL} 4(I), \operatorname{CL} 5(I), \operatorname{CLG}(\mathrm{I})$

PRINT*, CL1(I), CI2(I), CL3(I), CL4(I), CL5(I), CL6(I)

CONTINUE

C INPUT LIQUID PROPERTIES

READ $(12,1) \quad D L, M W L, V I S L, D I F F L$

$\mathrm{C}$

$D I=D E N S I T Y$ OF LIQUID, LB/FT3

MWI = MOLECUIAR WEIGHT LIQUID

VISL=VISCOSITY OF LIQUID, CP

DIFFL=DIFFUSION COEFFICIENT, CS2 IN LIQ.,FT2/HR

PO=VAPOR PRESSURE OF CS2, 537 RANKIN

$P O=366$

PRINT*, 'DI, MWL, VISL, DIFFL

PRINT*, DL, MWL, VISL, DIFFL

INPUT TOWER PROPERTIES

READ $(12,2)$ DI, VCON2, VCON1, ICON2, OPLR

C DI=TOWER DIAMETER, ET

C

C

VCON2 $=$ CS2 INLET CONCENTRATION IN GAS, MOLE FRACTION

VCON $1=C S 2$ OUTIIET CONCENTRATION

LCON2=CS2 INLET CONCENTRATION IN LIQUID, MOLE FRACTION 


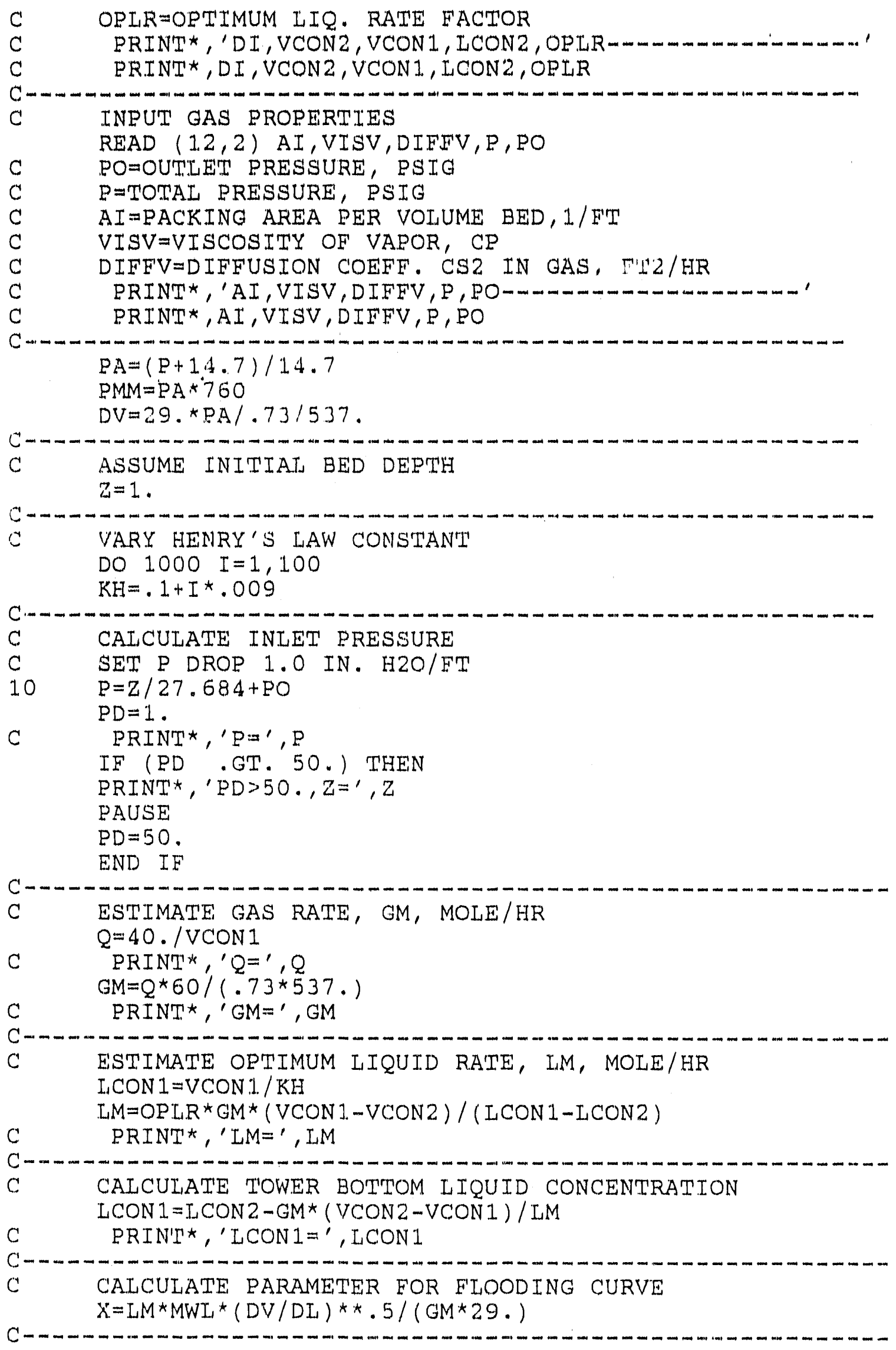




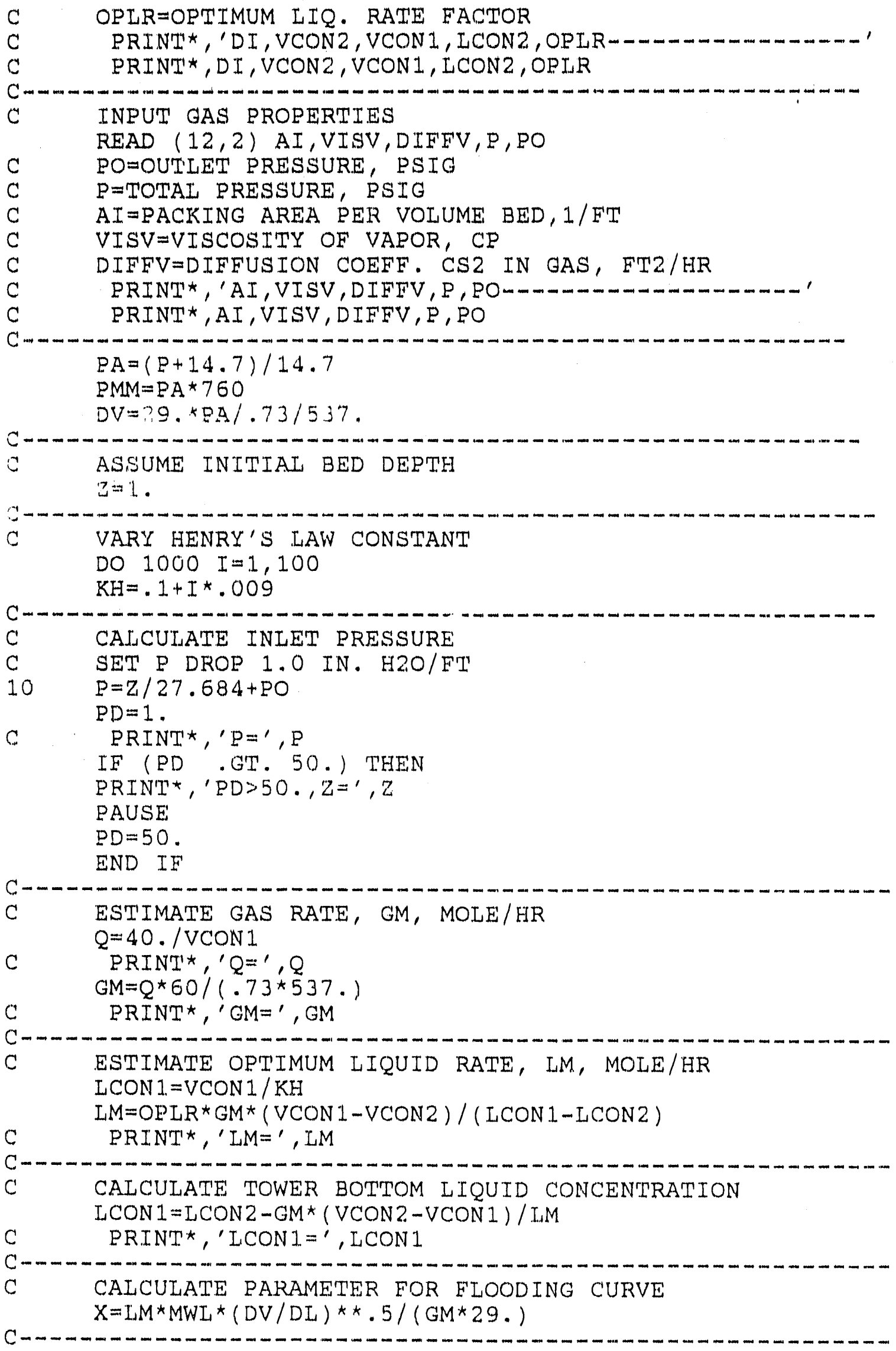




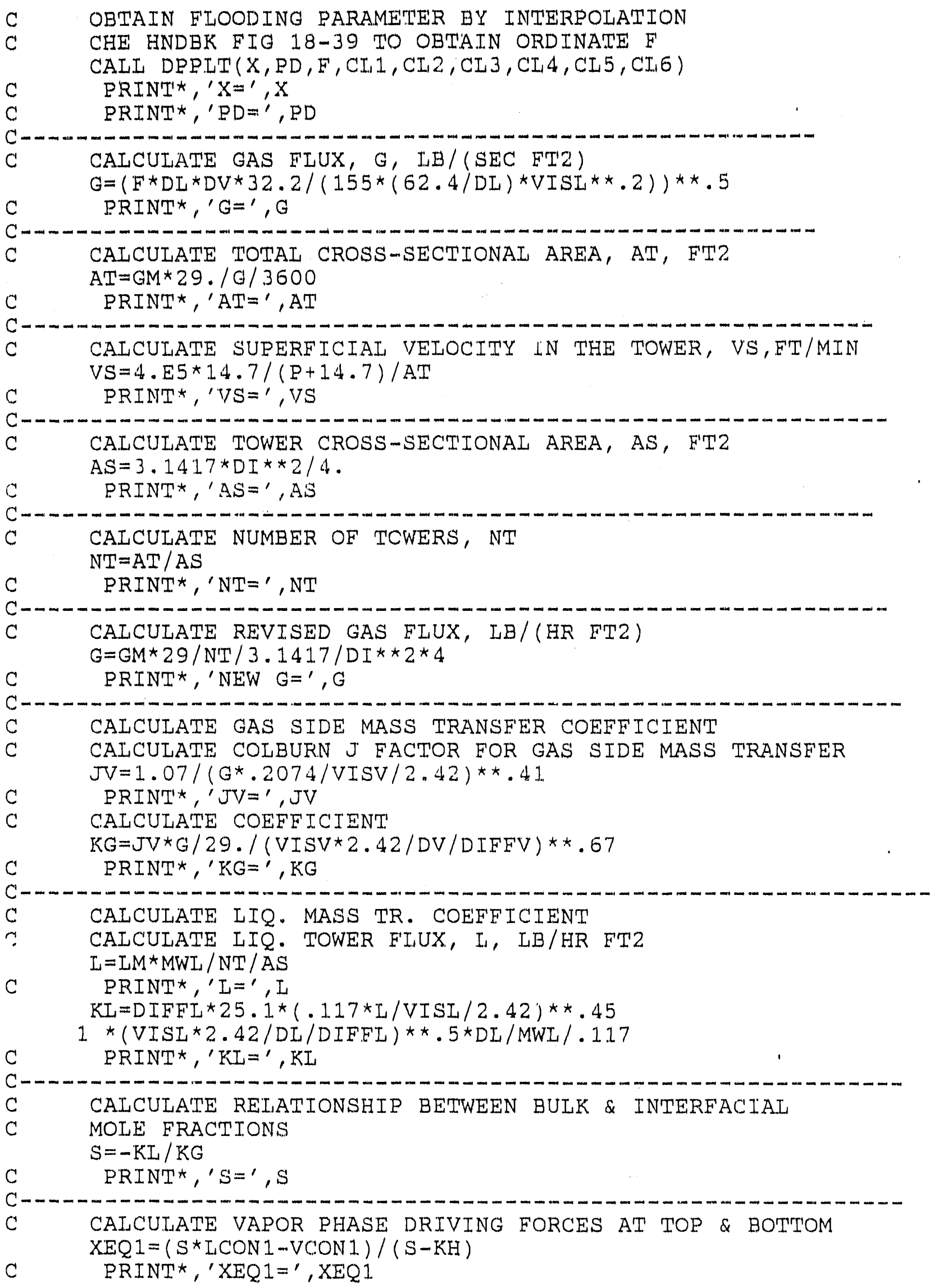




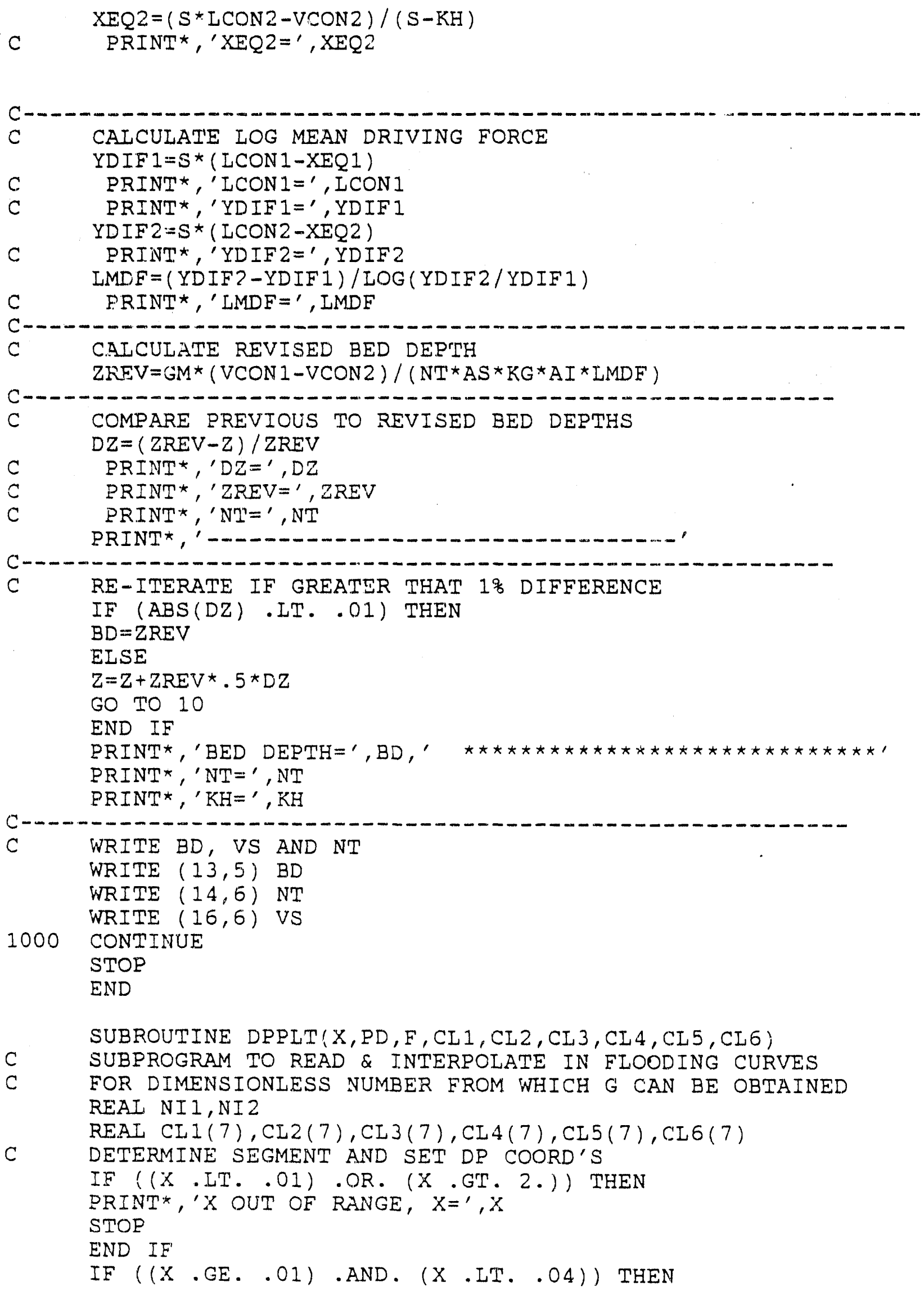




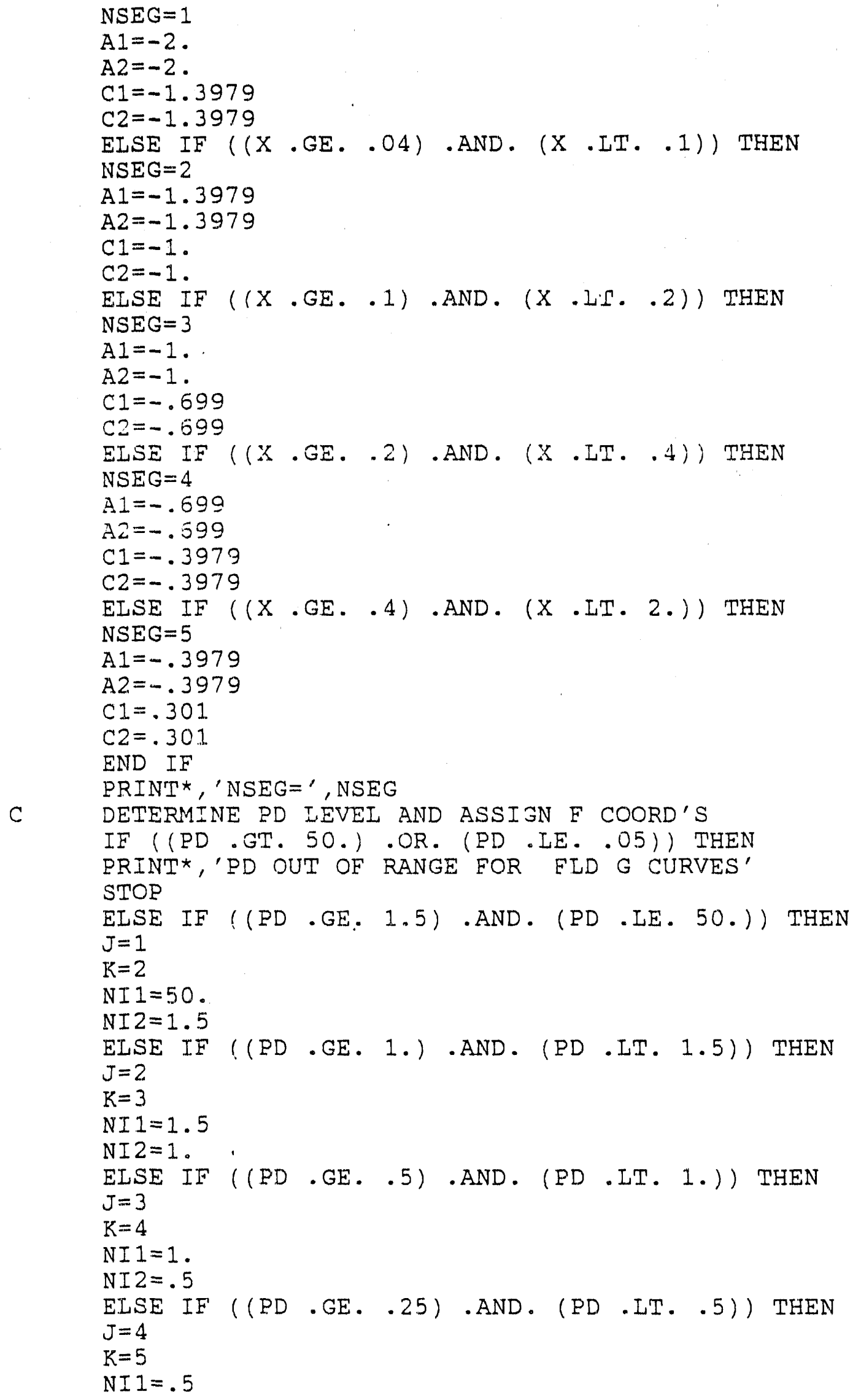




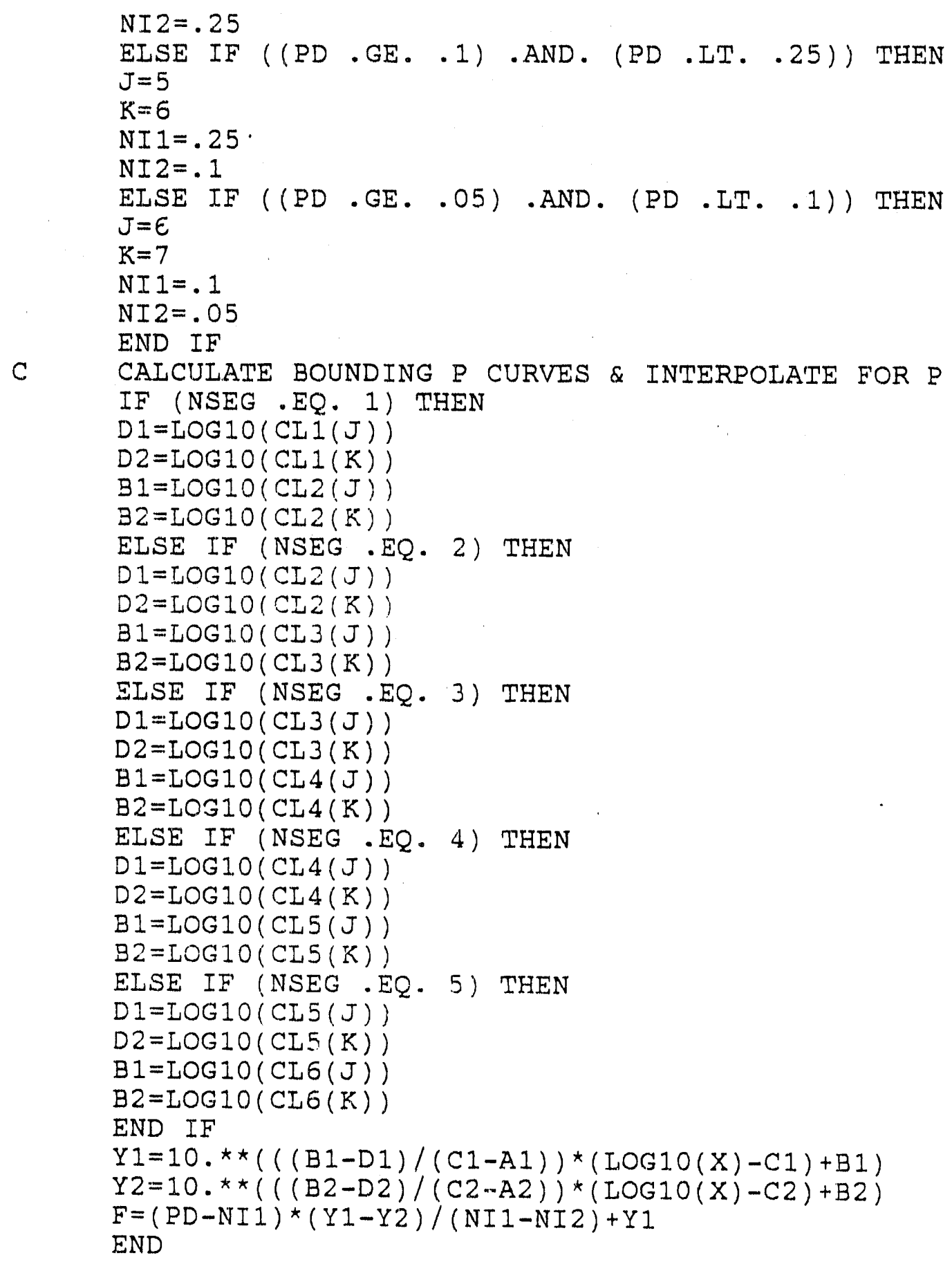




\section{APPENDIX B \\ GAS ADSORPTION TOWER: SAMPLE CALCULATION}

The calculations for the gas adsorption towers are made on the basis of the following assumptions:

- Air flow: $400,000 \mathrm{cfm}$

- Inlet air flow: 100 ppm $\mathrm{CS}_{2}, 5$ psig

- Breakthrough air flow: 10 ppm $\mathrm{CS}_{2}, 4.6 \mathrm{psig}$

- Adsorbent: isotherm shape similar to Calgon BPL carbon

- Bed properties: density $30 \mathrm{lb} / \mathrm{ft}^{3}$

- Average particle radius: $4 \times 6$ mesh $(\mathrm{R}=0.0065 \mathrm{ft})$

- Tower properties:

- Diameter: $12 \mathrm{ft}$

- Breakthrough time: $10 \mathrm{hr}$

- Total pressure drop: $0.4 \mathrm{psi}$

\section{B.1 SEPARATION FACTOR}

The adsorption isotherm for BPL activated carbon is shown in Figure B.1. The inlet gas has a $\mathrm{CS}_{2}$ concentration of $100 \mathrm{ppm}$, which in mole ratio (nearly identical to mole fraction for this small concentration) is!

$$
\mathrm{Y}=100 / 10^{\dot{6}}=10^{-4} \text { mole } \mathrm{CS}_{2} \text { per mole air }
$$

In weight ratio, the inlet concentration is:

$$
\begin{aligned}
\mathrm{Y}_{0} & =100 \text { mole } \mathrm{CS}_{2}\left(76 \mathrm{lb} / \text { mole } \mathrm{CS}_{2}\right) /\left(10^{6} \text { mole air }\right)(29 \mathrm{lb} / \text { mole air }) \\
& =2.62 \times 10^{-4} \mathrm{lb} \mathrm{CS}_{2} \text { per lb air }
\end{aligned}
$$

From the isotherm of Figure B.1, the maximum bed loading is:

$$
q_{0}=4.9 \times 10^{-2} \mathrm{lb} \mathrm{CS}_{2} \text { per lb sorbent }
$$




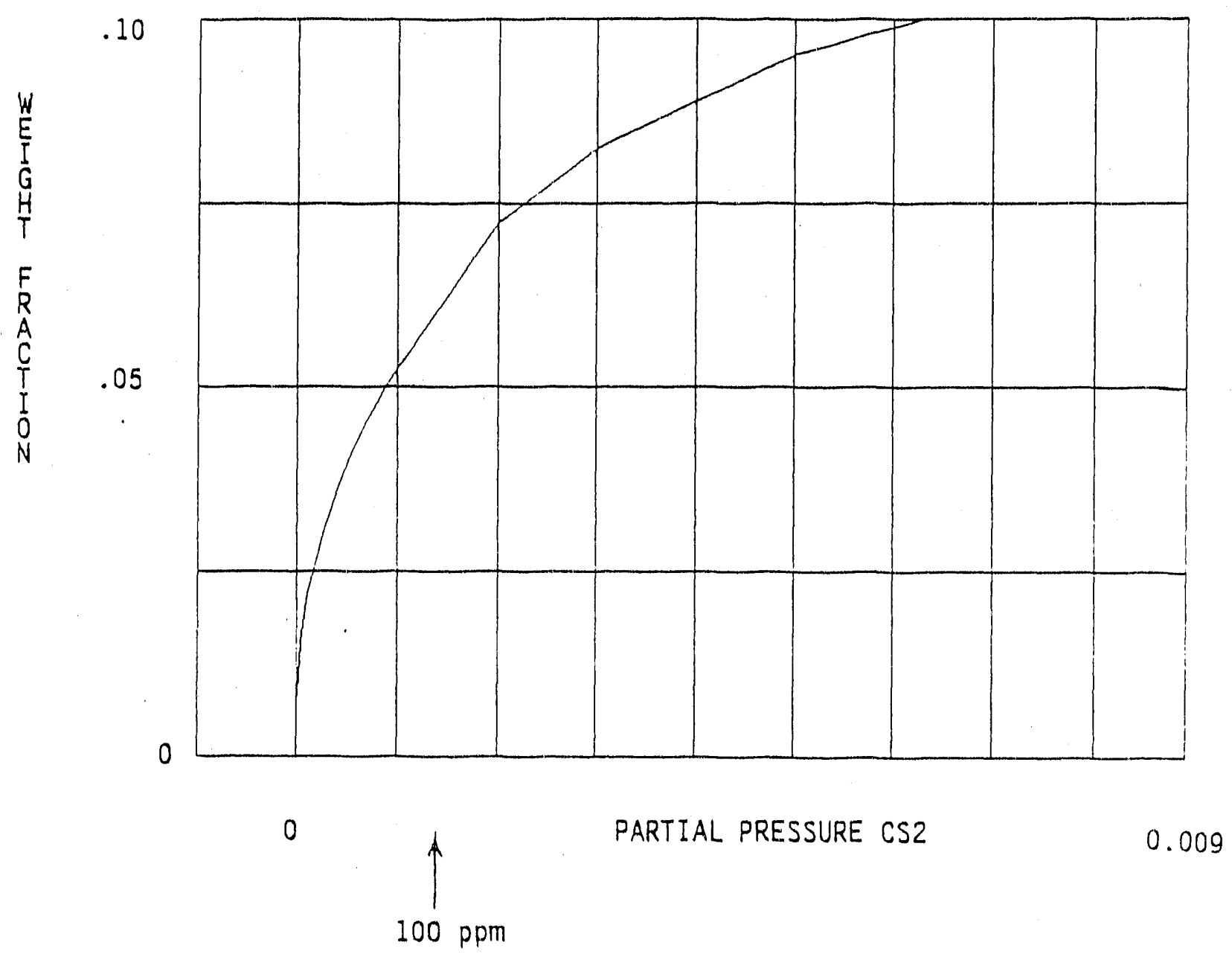

FIGURE B.1 Expanded View of Carbon Isotherm

Because breakthrough is defined as a gas concentration of $1.0 \mathrm{ppm} \mathrm{CS}_{2}$ (i.e., $\mathrm{y}=2.62 \times 10^{-5} \mathrm{lb}$ $\mathrm{CS}_{2}$ per $\mathrm{lb}$ air) from the isotherm, the corresponding equilibrium bed loading is:

$$
\mathrm{q}=8.5 \times 10^{-3} \mathrm{lb} \mathrm{CS}_{2} \text { per } \mathrm{lb} \text { sorbent }
$$

The ratios are:

$$
\begin{aligned}
& y / y_{0}=2.62 \times 10^{-5} / 2.62 \times 10^{-4}=0.1 \\
& q / q_{0}=8.5 \times 10^{-3} / 4.9 \times 10^{-2}=0.1735
\end{aligned}
$$


and the separation factor is:

$$
R=0.1(1-0.1735) / 0.1735(1-0.1)=0.5293
$$

\section{B.2 FLOW RATE AND PRESSURE DROP}

The flow rate of the gas (or its superficial velocity) through the adsorption bed depends on pressure drop from inlet to outlet and on packing characteristics. Figure B.2 shows superficial velocity at the tower inlet for a given pressure drop and inlet pressure. To use this graph, one must know the bed depth. Because the bed depth (or tower height) is the object of this design, the calculation must be iterative. An assumed bed depth is used in Figure B.2 to give velocity. The calculation then proceeds to obtain bed depth. The previously assumed bed depth is adjusted and the calculation iterated until the assumed and calculated bed depth agree.

For a first guess, let us take bed depth $(Z)$ to be $1.0 \mathrm{ft}$. Pressure drop now becomes:

$(5 \mathrm{psig}-4.6 \mathrm{psig})\left(27.684\right.$ in. $\left.\mathrm{H}_{2} \mathrm{O} / \mathrm{psig}\right) / 1.0 \mathrm{ft}=11.07$ in. $\mathrm{H}_{2} \mathrm{O} / \mathrm{ft}$

and, from Figure B.2, superficial velocity (VS) is:

$$
\mathrm{VS}=158 \mathrm{ft} / \mathrm{min}
$$

\section{B.3 NUMBER OF TOWERS}

After superficial velocity is known, it is possible to calculate the required number of towers. This is obtained by dividing the total volume of gas, which is approximated at 5 psia by using the pressure ratio factor $(14.7+5) / 5$, by the volume flow per tower. Note that the area of a 12 -ft-diameter tower is $113.1 \mathrm{ft}^{2}$.

$$
\left.\mathrm{NT}=4 \times 10^{5} \mathrm{ft}^{3} / \min (14.7 /(14.7+5)) / 158 \mathrm{ft} / \mathrm{min}\right) 113.1 \mathrm{ft}^{2}=16.8
$$

\section{B.4 PORE DIFFUSIVITY}

We now calculate the pore diffusivity for BPL carbon adsorbent. First we must obtain the fluid diffusivity $\left(D_{f}\right)$, which can be estimated from the Hirschfelder, Bird, and Spotz equation: 


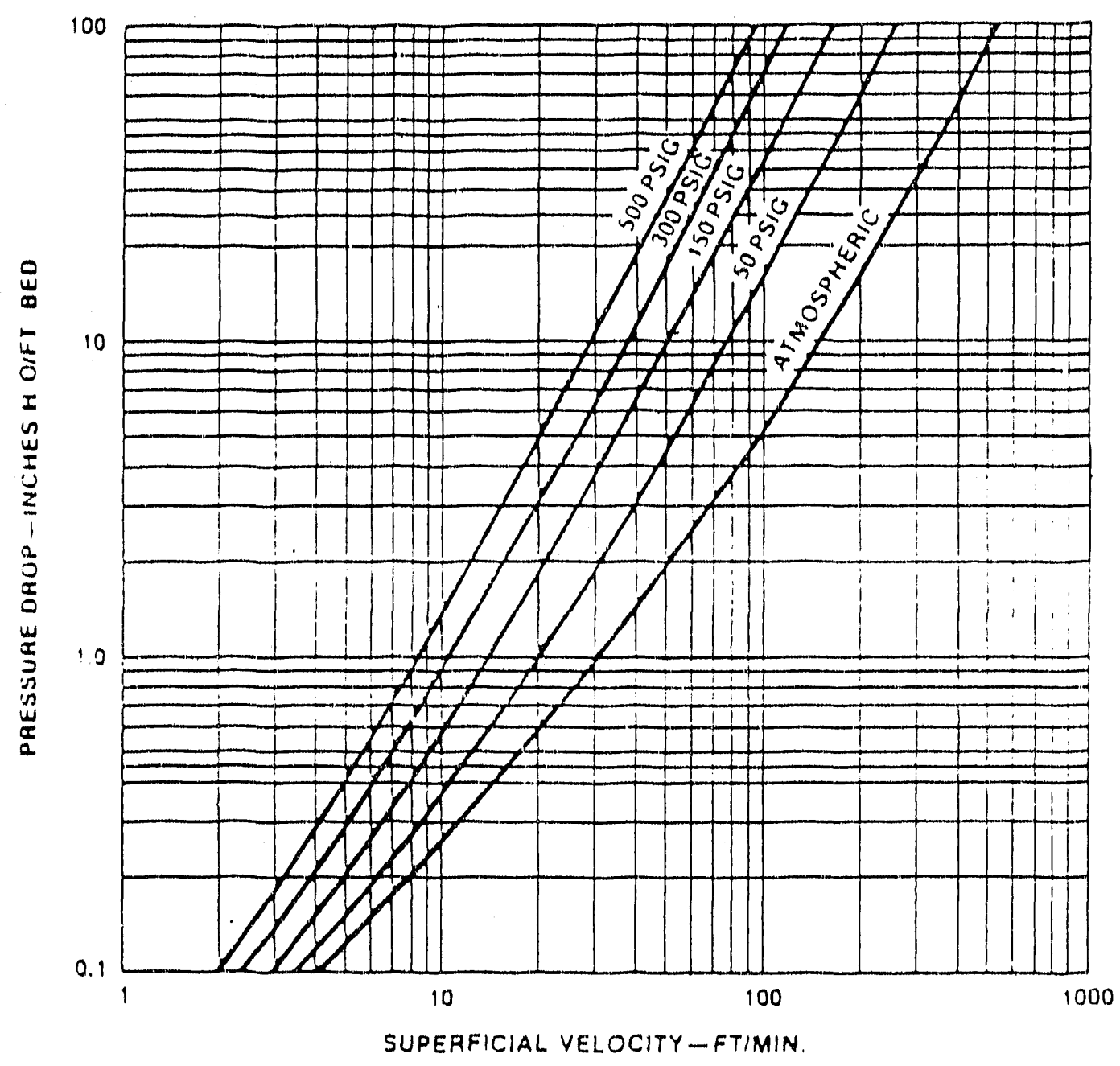

FIGURE B.2 Pressure Drop for Adsorption Towers Packed with Calgon BPL Activated Carbon ( $4 \times 6$ mesh)

$$
D_{f}=B T^{3 / 2} \frac{\sqrt{1 / M_{1}+1 / M_{2}}}{P_{r 12}^{2} I_{D}}
$$

(See Perry and Chilton's Chemical Engineers' Handbook, p. 3-232.")

An outline of the computations of the constants for this equation follows. To get $I_{D}$, first calculate:

'Perry, G.H., and C.H. Chilton, 1973, Chemical Engineers' Handbook, 5th Ed., McGraw-Hill, New York. 


$$
\begin{gathered}
\varepsilon_{\mathrm{CS} 2} / \mathrm{k}=1.15(319)=366 \\
\varepsilon_{12} / \mathrm{k}=\left\lfloor\left.\left(\varepsilon_{\mathrm{ail}} / \mathrm{k}\right)\left(\varepsilon_{\mathrm{CS} 2} / \mathrm{k}\right)\right|^{1 / 2} \equiv(190 \times 366)^{1 / 2}=264\right. \\
\mathrm{kT} / \varepsilon_{12}=298 / 264=1.13
\end{gathered}
$$

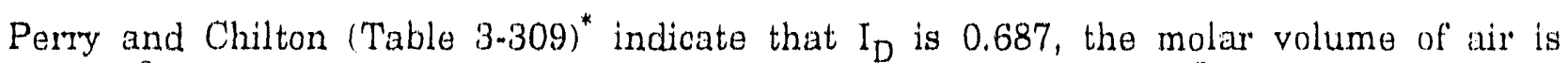
$29.9 \mathrm{~cm}^{3} /$ mole, and the molar volume of $\mathrm{CS}_{2}$ is $76 / 1.263$, or $60.2 \mathrm{~cm}^{3} /$ mole. The collision diameter is calculated:

$$
\begin{gathered}
r_{12}=(1 / 2) 1.18\left(60.2^{1 / 3}+29.9^{1 / 3}\right)=4.14 \AA \\
B=\{10.7-2.46 \sqrt{(1 / 76+1 / 29)}\rceil \times 10^{-4}=1.016 \times 10^{-3} \\
D_{f}=\frac{1.016 \times 10^{-33} \sqrt{1 / 76+1 / 29}(298)^{3 / 2}}{(1)(4.14)^{2}(0.687)}=0.0969 \mathrm{~cm}^{2} / \mathrm{s}
\end{gathered}
$$

With fluid diffusivity $\left(D_{f}\right)$ available, we can now proceed to estimate pore diffusivity $\left(D_{p}\right)$ (see Perry and Chilton, pp. 16-19):**

$$
D_{p}=\frac{\chi}{\tau}\left[\frac{3}{4 r}\left(\frac{\pi M}{2 R T}\right)^{1 / 2}+\frac{1}{D_{f^{\prime}}}\right]^{-1}
$$

We will use data for Calgon BPL carbon: internal porosity $(\chi)=64 \%$, tortuosity $(\tau)=4$, and average pore radius $(r)=30 \AA$. Thus:

$$
\begin{gathered}
D_{p}=0.16(0.025 \times 0.0881+10.322)^{-1}=0.0155 \mathrm{~cm}^{2} / \mathrm{s} \\
D_{p}=\left(0.0155 \mathrm{~cm}^{2} / \mathrm{s}\right)(60 \mathrm{~s} / \mathrm{min})(0.03295 \mathrm{ft} / \mathrm{cm})^{2} \\
D_{p}=1.01 \times 10^{-3} \mathrm{ft}^{2} / \mathrm{min}
\end{gathered}
$$

"See footnote, p. 145. 


\section{B.5 NUMBER OF REACTION UNITS}

The number of reaction units $\left(N_{R}\right)$ is a dimensionless group that is a measure of the diffusional resistance to adsorption. It defines the sharpness of the adsorption wave.

$$
\begin{aligned}
N_{R} & =\frac{15 D_{p}}{r^{2}} \cdot \frac{Z}{V S} \cdot \frac{2}{R+1} \\
& =\frac{30\left(1.01 \times 10^{-3} \mathrm{ft}^{2} / \mathrm{min}\right)}{\left(6.5 \times 10^{-3} \mathrm{ft}\right)^{2}} \cdot \frac{1.0 \mathrm{ft}}{158 \mathrm{ft} / \mathrm{min}} \cdot \frac{1}{0.529+1}=2.966
\end{aligned}
$$

The particle diameter $(2 \mathrm{r})$ is that of a 5 mesh opening, $0.156 \mathrm{in.}$

\section{B.6 GAS MASS FLUX}

Gas inass thux (G) can be obtained from the moliur tlow in area of tower and number of towerg $\left(\mathrm{N}_{\mathrm{T}}\right)$ :

$$
\begin{aligned}
G= & \left(4 \times 10^{\tilde{5}} \mathrm{ft}^{3} / \mathrm{min}\right)(1 \mathrm{~atm})(29 \mathrm{lb} / \text { mole }) / \\
& \left(0.73 \mathrm{~atm} \cdot \mathrm{ft}^{3} / \mathrm{mole}^{\circ} \mathrm{R}\right)\left(537^{\circ} \mathrm{R}\right)\left(113.1 \mathrm{ft}^{2}\right)(16.7) \\
= & 1.5 .67 \mathrm{lb} / \mathrm{ft}^{2} \cdot \mathrm{min}
\end{aligned}
$$

\section{B.7 THROUGHPUT PARAMETER}

Solutions of a reaction-kinetic model by Hiester and Vermeulen have been adapted by Basmadjian for graphical solution of throughput parameter ( $\left.Z_{1}\right){ }^{*}$ That is, given separation factor $(R)$ and number of reaction units $\left(N_{R}\right)$, Basmadjian has constructed graphs for obtaining throughput parameter. Figure B.3 shows the graph for the $90 \%$ removal case (e.g., inlet $\mathrm{CS}_{2}$ concentration $=100 \mathrm{ppm}$, outlet $\mathrm{CS}_{2}$ concentration $=10 \mathrm{ppm}$ ). For the present calculation, with $R=0.5293$ and $N_{R}=2.966$, Figure B.3 yields:

$$
1-Z=0.8193
$$

or

\footnotetext{
"Basmadjian, D., 1980, Rapid Procedures for the Prediction of Fixed-Bed Adsorber Behavior, Ind. Eng. Chem. Proc. Des. Devel., 19:129-137.
} 


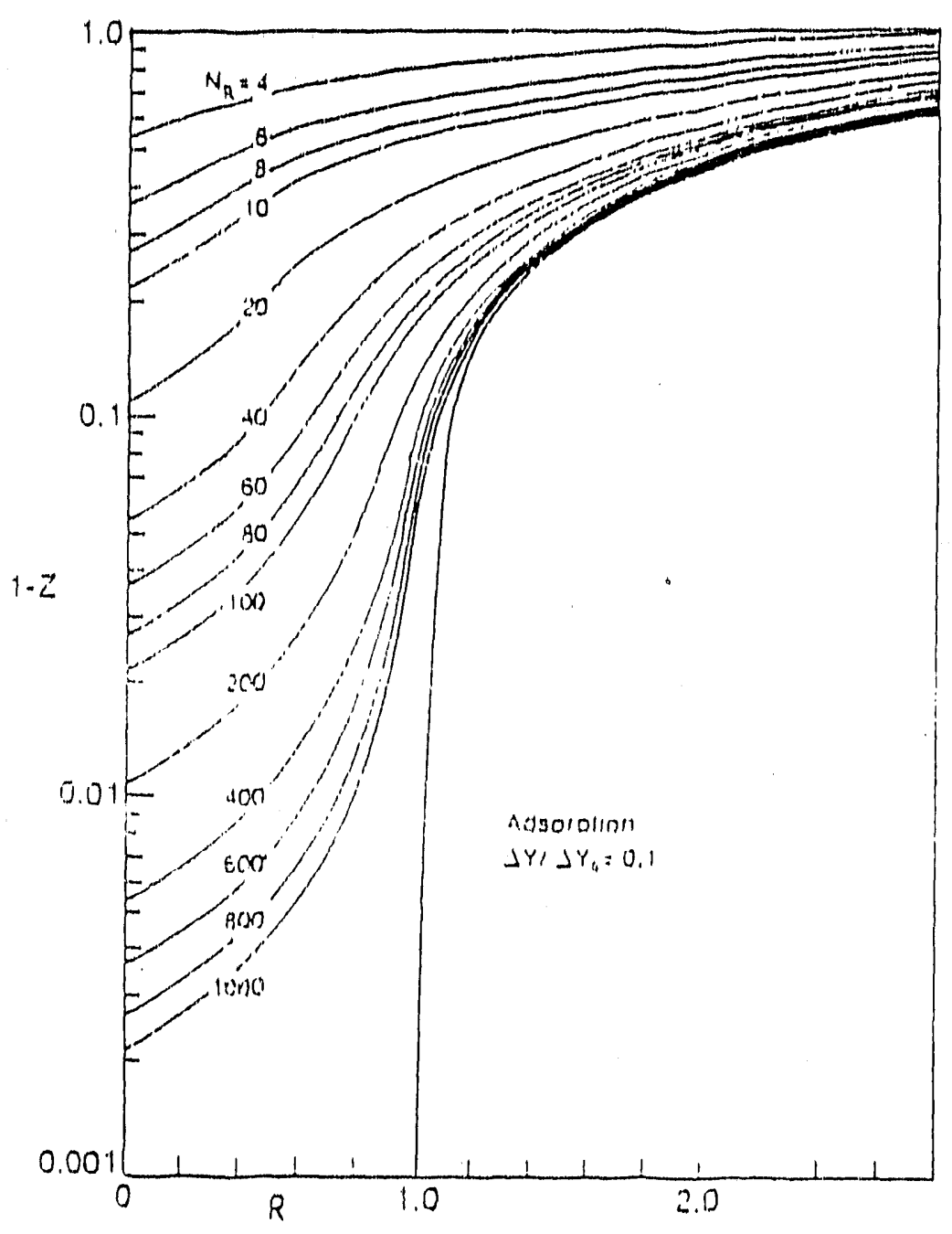

FIGURE B.3 Basmadjian Graph for Adsorption Bed Depth Design

$$
\mathrm{Z}=0.1807
$$

$\mathrm{Z}$ is defined as follows:

$$
\mathrm{Z}=\mathrm{y}_{0} \mathrm{Gt} / \mathrm{q}_{0} \mathrm{pz}
$$

where $t$ is breakthrough time, $p$ is bed density, and $z$ is bed depth. Bed depth (or tower height) can now be calculated from the above equation: 
$\left(2.62 \times 10^{-4} \mathrm{lb}\right.$ CS $_{2}$ per lb air $)\left(15.7 \mathrm{lb}\right.$ air per $\left.\mathrm{min} \cdot \mathrm{ft}^{2}\right)(60 \mathrm{~min} / \mathrm{hr}) 10 \mathrm{hr}$

$\left(4.9 \times 10^{-2} \mathrm{lb} \mathrm{CS}_{2}\right.$ per $\mathrm{lb}$ sorbent)(30 lh sorbent per $\left.\mathrm{ft}^{3}\right) 0.1807$

$$
z=9.29 \mathrm{ft}
$$

\section{B.8 ITERATION FOR BED DEPTH}

Because the initial guess for bed depth was $1.0 \mathrm{ft}$ and the calculation yielded $9.29 \mathrm{ft}$, it will be necessary to iterate until the assumed and calculated bed depths agree within a small tolerance. Let us take this tolerance as $1 \%$ of bed depth. The iteration is performed best by guessing a new value, repeating the steps above, and comparing the results. These calculations are easily done; the results are shown in Table B.1. Note that the new yuess for $\mathrm{z}$ is a point between the old and new values. Multiplying the converged value, 1.9 l't, by the number of towers gives the total bed depth:

$$
\text { Total } B D=(1.9 \text { tt })(25.9)=49.2 \text { tt }
$$

These calculations have been programmed in Fortran (Microsoft version 4.1) and used to produce the figures shown in Section 4 of this report. Code listings with extensive comments are given below.

TABLE B.1. Iteration for Bed Depth of Adsorption Tower

\begin{tabular}{ccccccc}
\hline $\begin{array}{c}\text { Estimated } \\
\text { Bed } \\
\begin{array}{c}\text { Depth } \\
\text { (ft) }\end{array}\end{array}$ & $\begin{array}{c}\text { Velocity } \\
\text { (ft/min) }\end{array}$ & $\begin{array}{c}\text { Number } \\
\text { of } \\
\text { Towers }\end{array}$ & $\begin{array}{c}\text { Reaction } \\
\text { Units }\end{array}$ & $\begin{array}{c}\text { Mass } \\
\text { Flux } \\
\text { (lb/ft-min) }\end{array}$ & $\begin{array}{c}\text { Throlght - } \\
\text { put } \\
\text { Parameters }\end{array}$ & $\begin{array}{c}\text { Calculated } \\
\text { Bed } \\
\text { Depth } \\
\text { (ft) }\end{array}$ \\
\hline 1.0 & 1.58 & 16.7 & 3.0 & 15.7 & 0.1807 & 9.3 \\
5.14 & 50.6 & 52.2 & 47.6 & 5.0 & 0.892 & 0.60 \\
2.87 & 76.7 & 34.4 & 1.7 .5 & 7.6 & 0.730 & 1.11 \\
1.99 & 99.1 & 26.6 & 9.4 & 9.8 & 0.588 & 1.79 \\
1.89 & 102.9 & 25.6 & 8.6 & 10.2 & 0.561 & 1.94 \\
1.917 & 101.9 & 25.9 & 8.8 & 10.1 & 0.568 & 1.901 \\
\hline
\end{tabular}




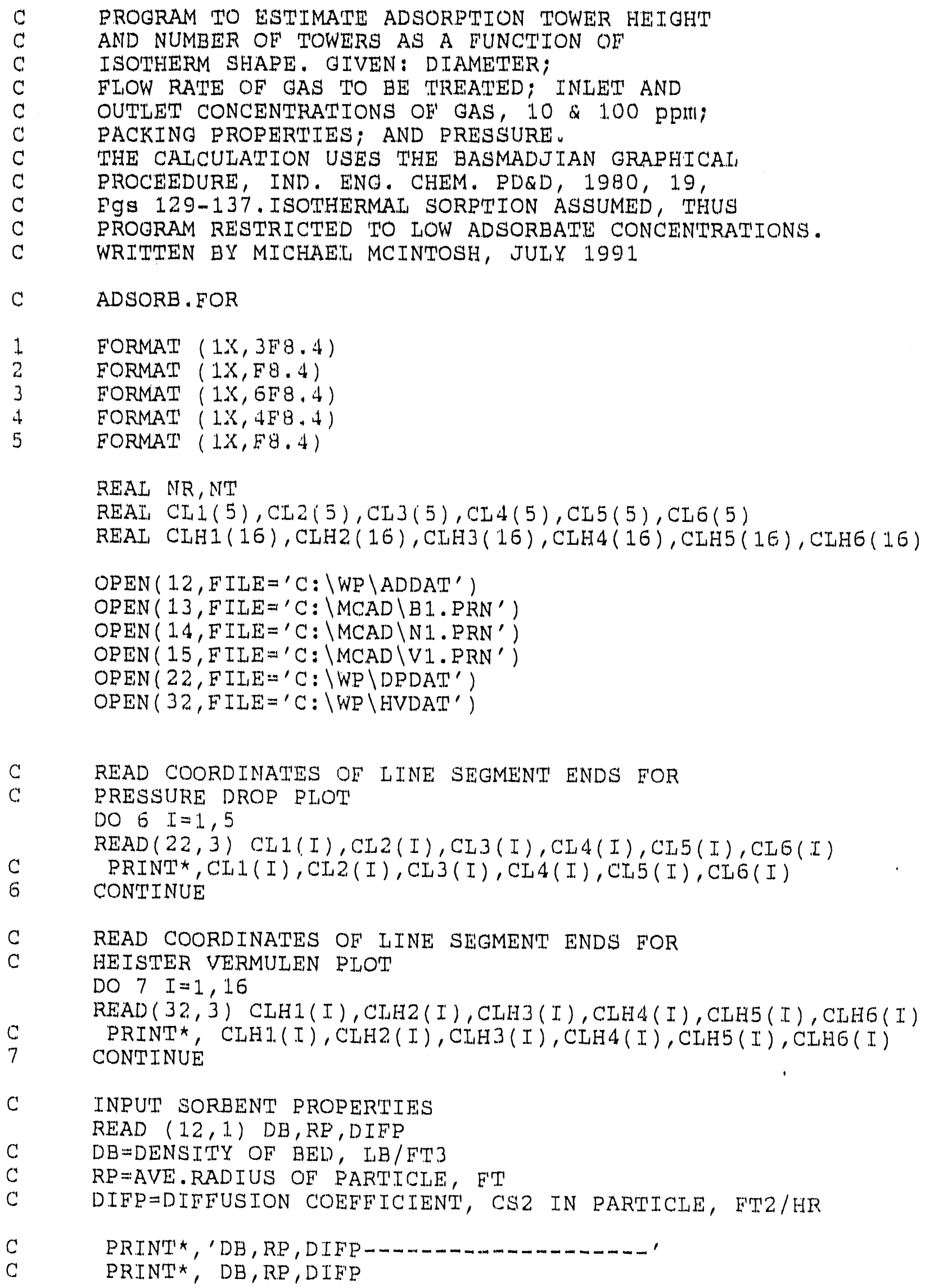




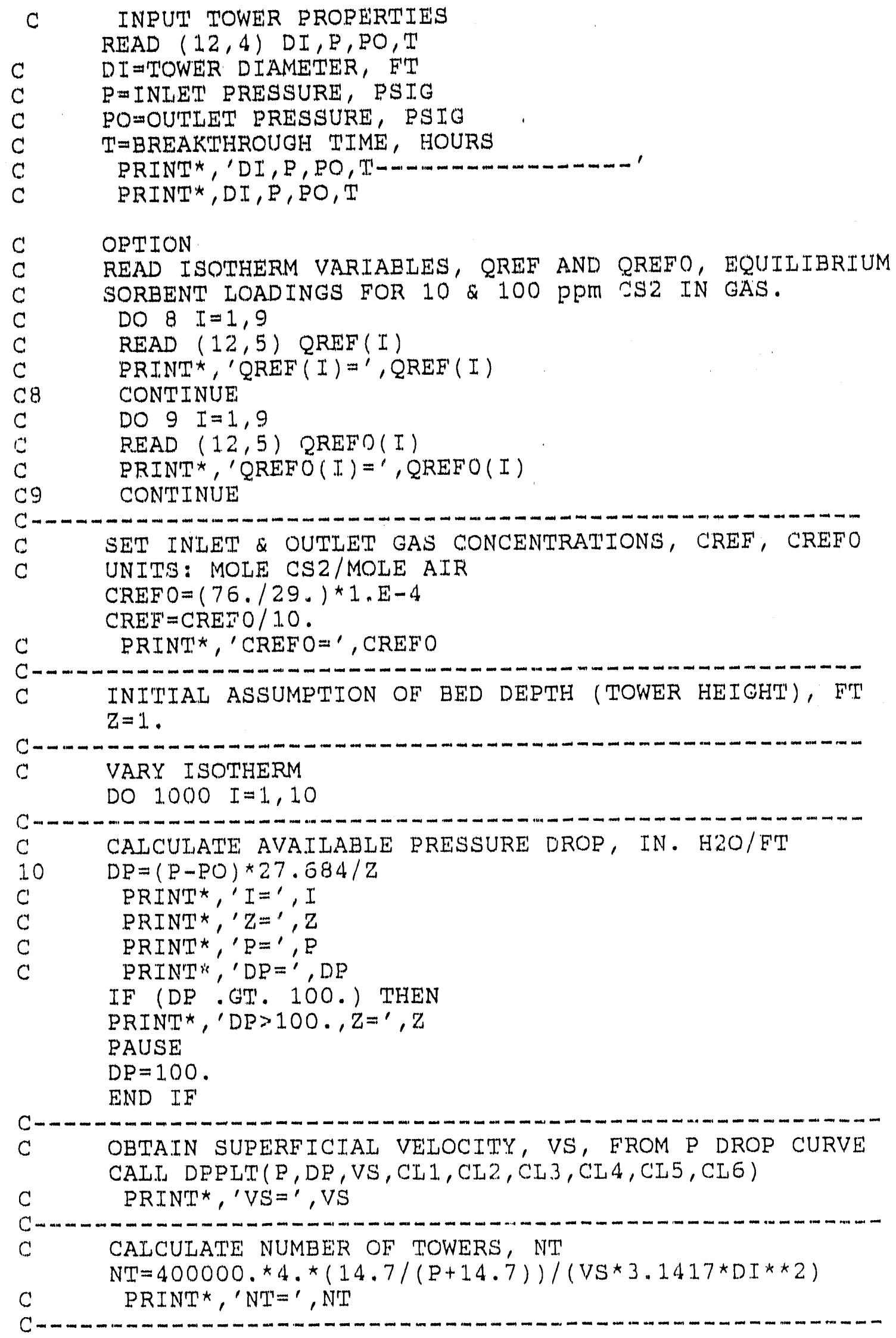




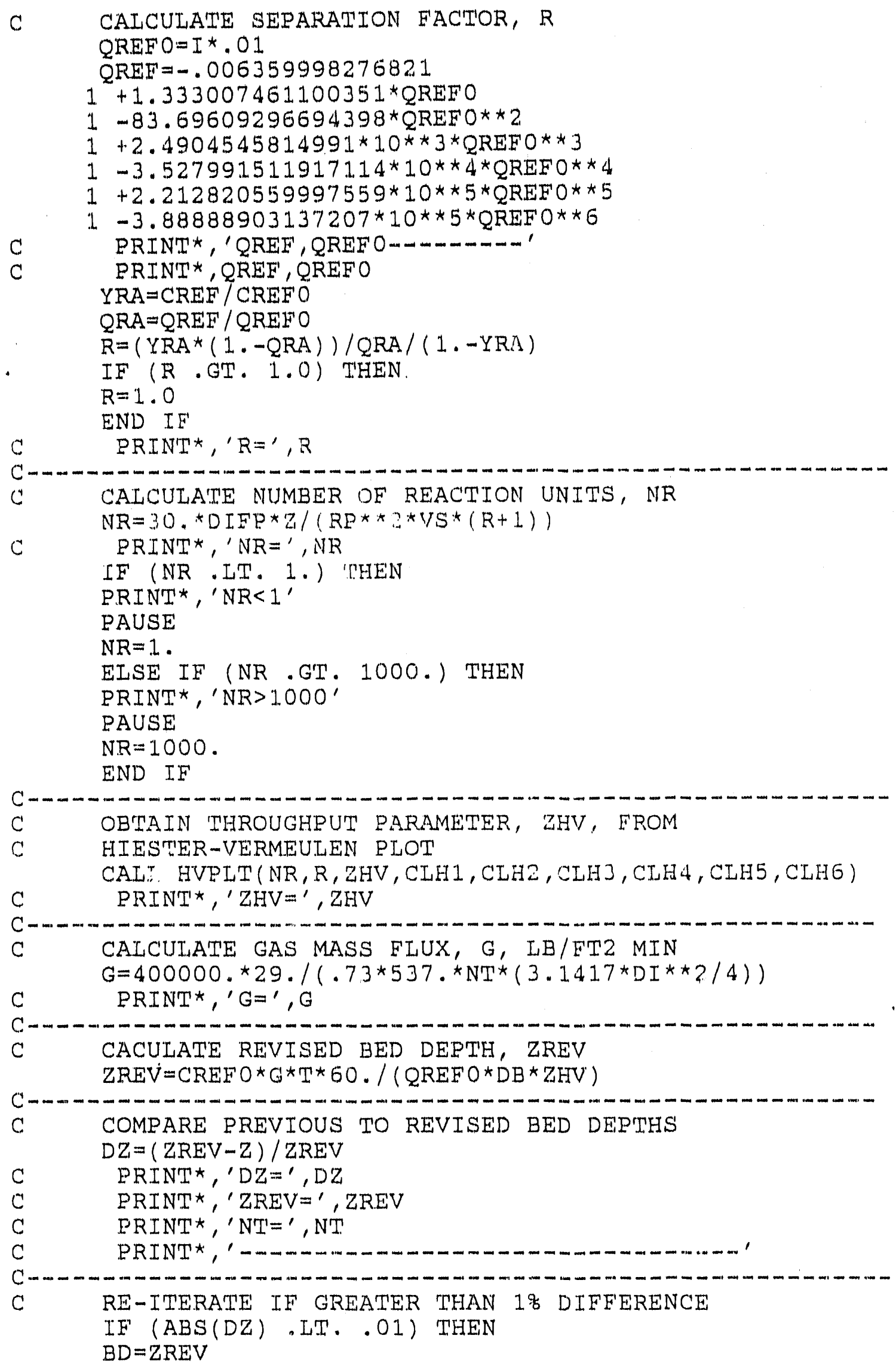




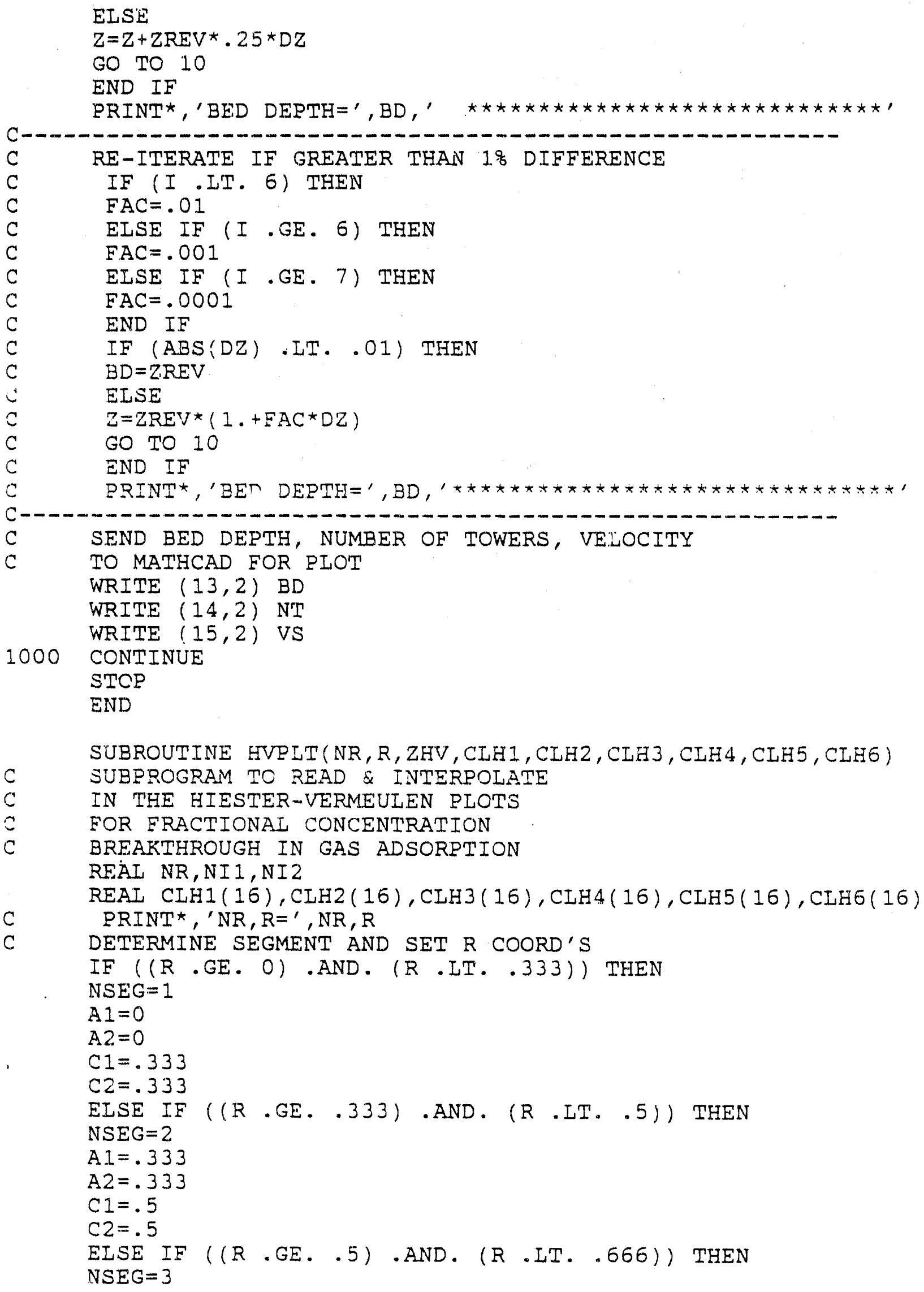




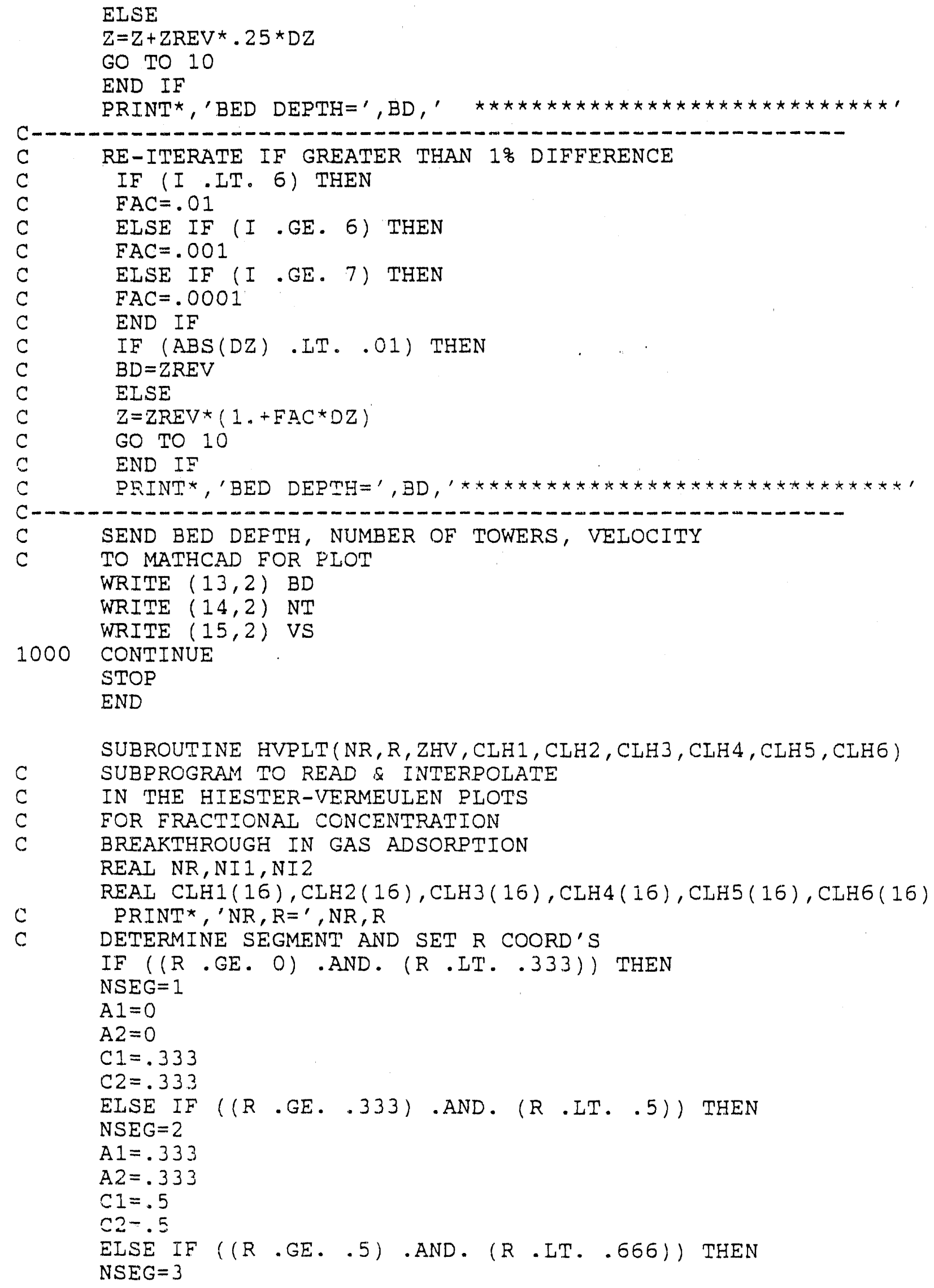




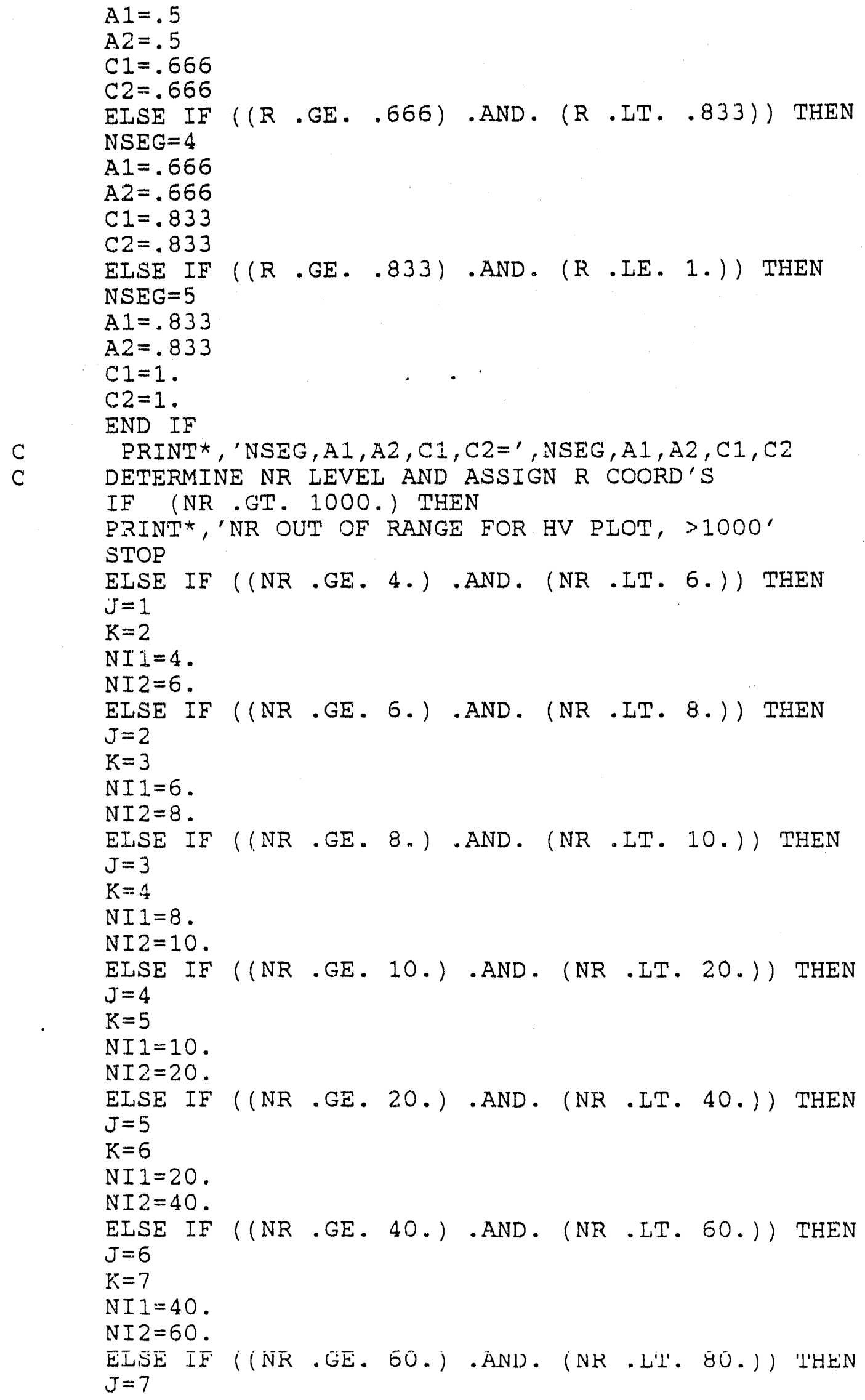




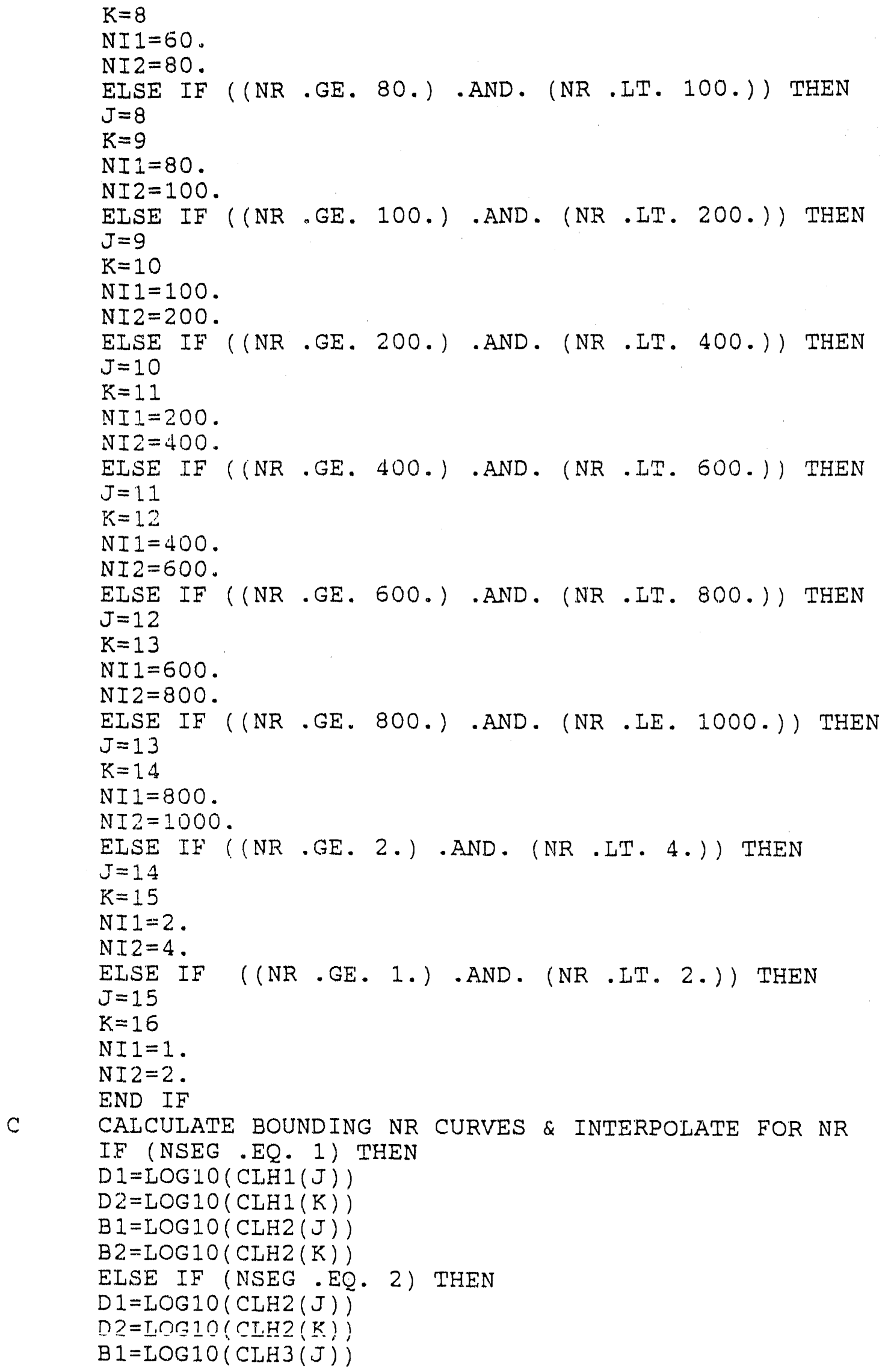




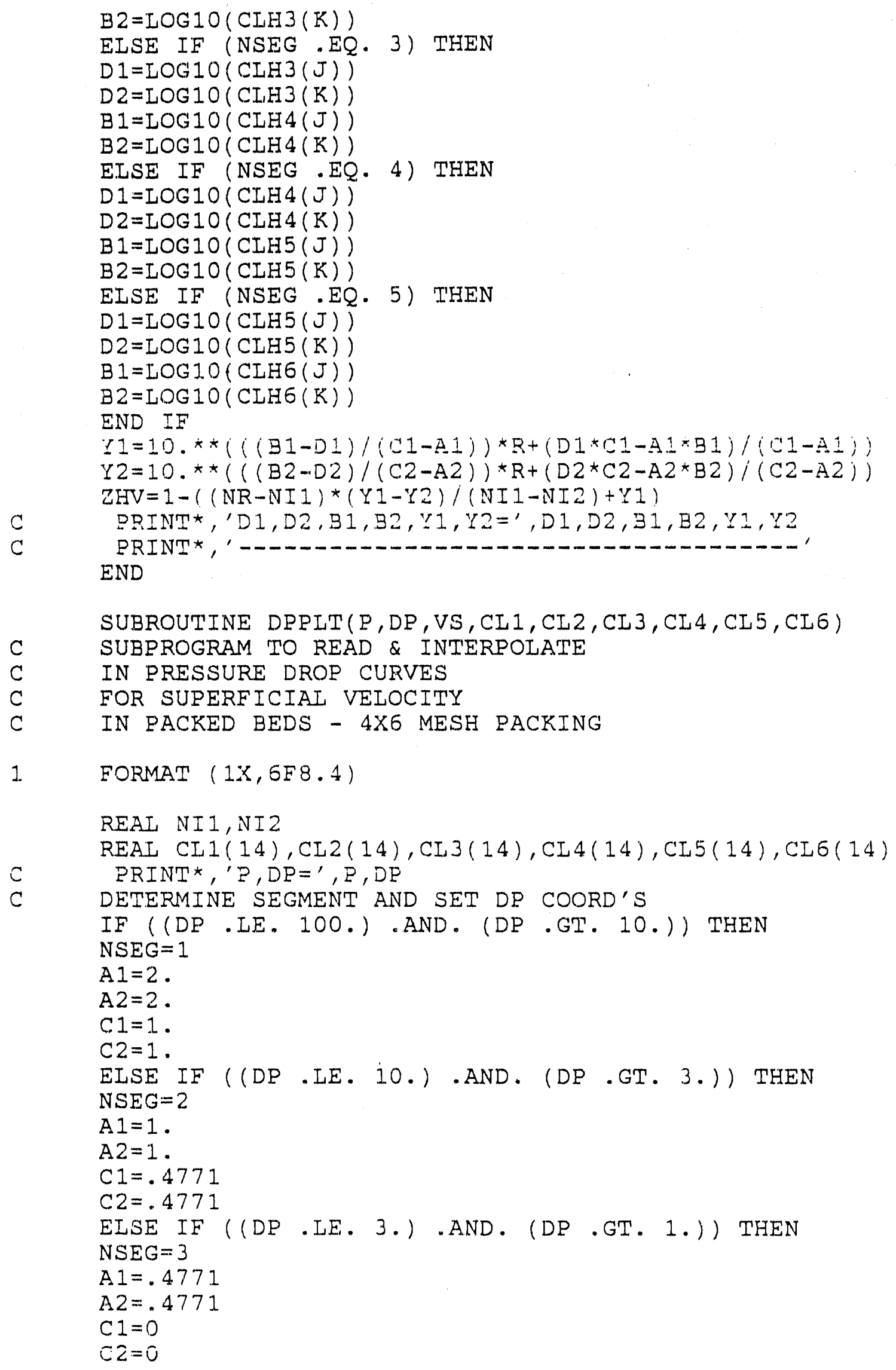




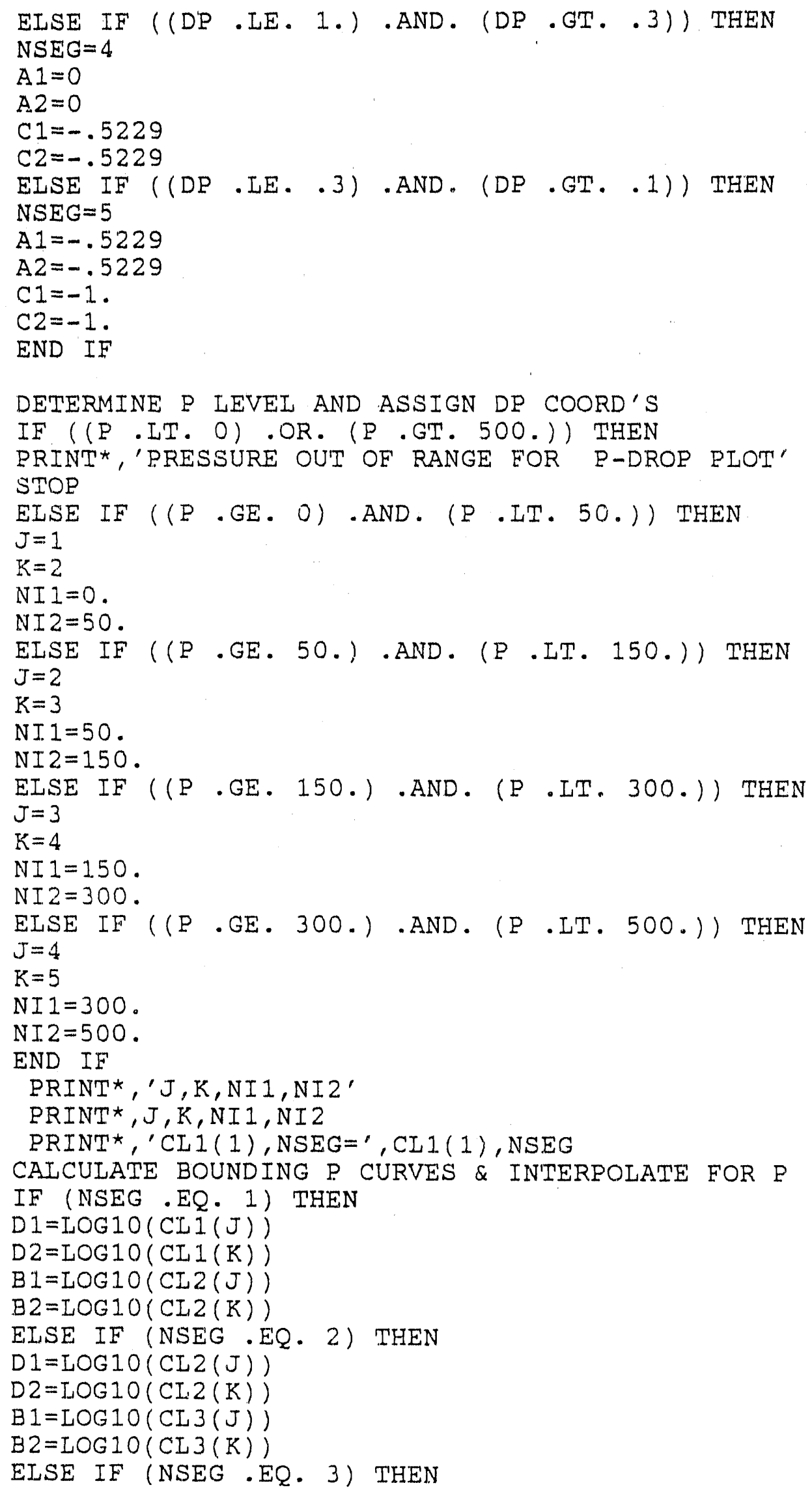




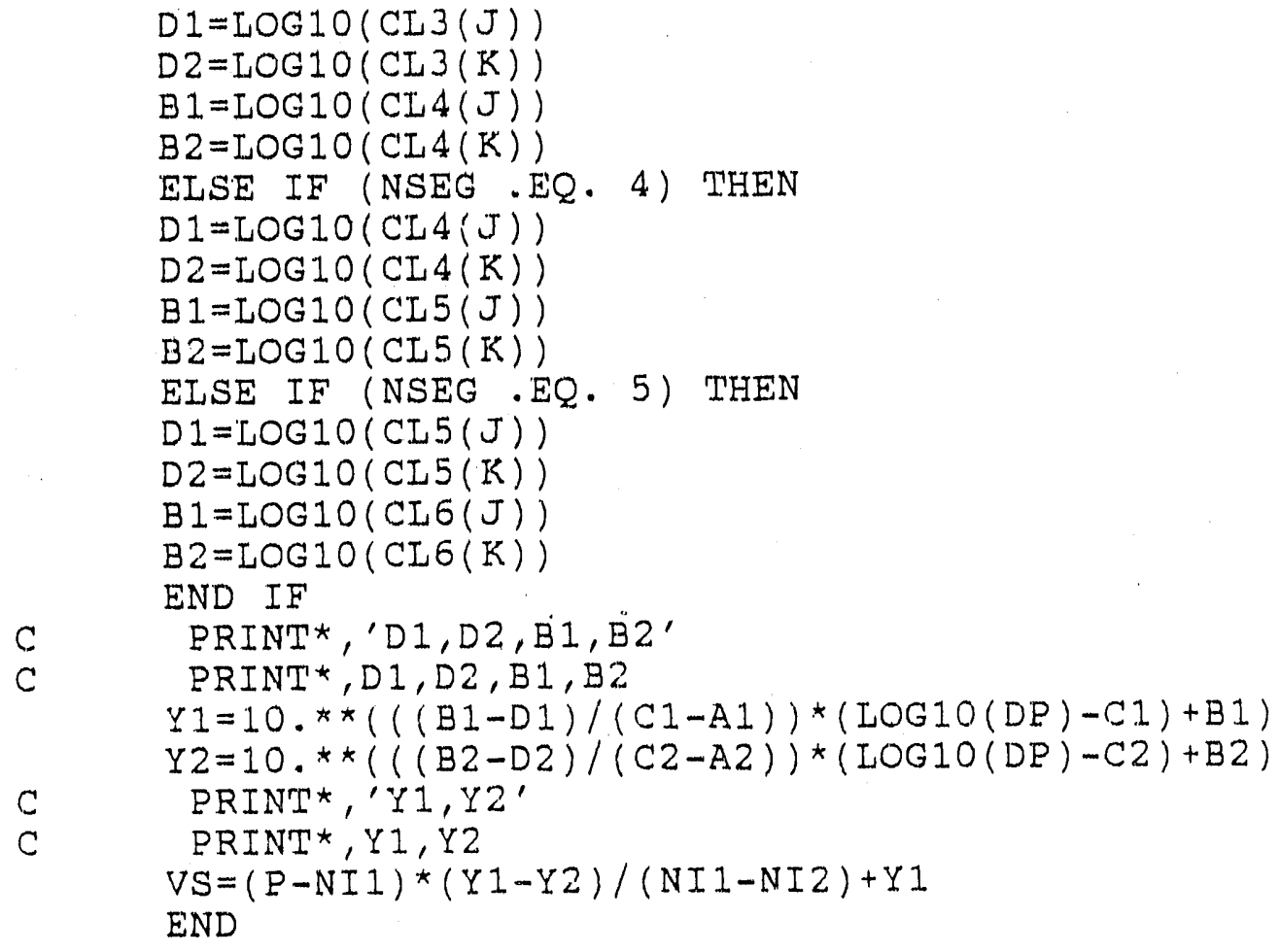




\section{APPENDIX C \\ PUBLICATIONS IDENTIFIED FROM LITERATURE SEARCH}

1. Rudling, J., Multicomponent adsorption isotherms for determination of recoveries in liquid desorption of mixtures of polar solvents adsorbed on activated carbon, American Industrial Hygienist Association Journal, 49(3):95-100 (1988).

2. Quemere, E., et al., Catalyst and process for removing sulfur compounds from waste gases, European Patent Application, 6 pp. (1989).

3. Karolewski, M.A., and R.G. Cavell, SIMS study of cesium/molybdenum disulfide (0001). II. Chemisorption of oxygen, water, formic acid, carbon dioxide, and carbon disulfide, Surface Science, 21.9( 1-2):261-76 (1989).

4. Machej, T, et al. A platinum catalyst for removing organic and non-organuc pollutcunts from gases, Polish, 11 pp. (1988).

5. Borsboom, J., and J.A. Layas, Process for converting and removing sulfur compouncts from a CO-containing gas, European Patent Application, 8 pp. (1989).

6. Thomas, J.C, et al., Selective removal of hydrogen sulfide from fluid mixtures using high-purity triethanolamine, European Patent Application, 11 pp. (1989).

7. Berzaczy, L., et al., Process for microbiological conversion of sulfur containing pollutants in off gases, European Patent Application, 7 pp. (1989).

8. Berzaczy, L., et al., Biological exhaust gas purification in the rayon fiber manufacture ithe Waagner-Biro/Glanzstoff Austria process), Chemistry and Biochemistry Engineering Quarterly, 2( 4):201-3 (1988).

9. Pohl, G., Biological waste gas cleaning at viscose processing plants, CLB, Chem. Labor Betr., 느(4):188-9 (1989).

10. Dawodu, O., and A. Meisen, Amine degradation by carbonyl sulfide and carbon disulfide, Proceedings of Laurance Reid Gas Conductivity Conference 9-71 (1989).

11. Bowman, D.F., Removal of sour components from a gas stream, European Patent Application, 6 pp. (1989).

12. Aracil, J., et al., Surface properties of mixtures of molecular fluids: an experimental and theoretical study of carbon disulfide + dichloromethane and carbon disulfide + carbon tetrachloride, Journal of Physical Chemistry, 93(8):3210-18 (1989). 
13. Shimko, I.G., et al., Development of low-waste technology in units for removal of hydrogen sulfide and carbon disulfide from gas-air mixtures, Khim. Volokna, (6):3-5 (1988).

14. Hudec, P., et al., Regeneration of activated charcoal used for removal of carbon disulfide and hydrogen sulfide from waste gases, Czechoslovakian, 5 pp. (1988).

15. Burkhardt, K., et al., Removal of carbon disulfide and hydrogen sulfide from waste gases for subsequent use, German (East), 3 pp. (1988).

16. Selin, A.N., and V.P. Kim, Secondary energy sources in rayon manufacture, Khim. Volokna, (6):18-20 (1988).

17. Grochowski, R., and A. Kapuscinski, Method of removing carbon disulfide from air, Polish, 2 pp. (1986).

18. Vanderheyden, E., et al., FTIR.PAS analysis of silica gel modified with umines for the treatment of natural gases contaminated with sulfur compounds, Mikrochim. Acta, 1987, ?(1-6):163-6 (1988).

19. Hansen, C.M., and B. H. Andersen, The affinities of organic solvents in biological systems, American Industrial Hygienist Association Journal, 49(6):301-8 (1988).

20. Hudec, P., and W. Berndt, Apparatus for removing carbon disulfide and hydrogen sulfide from wastewaters from viscose fiber manufacture, Czechoslovakian, 4 pp. (1988).

21. Brunelle, J.P., et al., Catalyst based on cerium oxide and process for the treatment of industrial gases containing sulfur compounds, European Patent Application, 9 pp. (1988).

22. McCoy, B.J., and J.M. Smith, Reply to "Determination of active sites on palladium by carbon disulfide titration", Journal of Catalysis, 110 (1):206-7 (1.988).

23. Rybicki, Z., et al., Ventilation air purification in viscose fiber plants, Polish Technical Review, (5):12-13 (1987).

24. Grams, W., et al., Method of removing hydrogen sulfide and carbon disulfide from the waste gases from a rayon fiber manufacturing plant, Polish, 5 pp. (1985).

25. Luengo, G., et al., Bulk and surface thermodynamic properties in mixtures of small rigid molecules: the carbon tetrachloride + carbon disulfide' system, Journal of Physical Chemistry, 92(1):228-34 (1988).

26. Raulinaitis, I., Carbon disulfide-formic acid: an efficient desorbant for industrial solvents, American Industrial Hygienist Association Journal, 48(11):A/708-A/709 ( 1987 ). 
27. Minhas, B.S., et al., Formation of asymmetric cellulose acetate membranes for the separation of carbon dioxide-methane gas mixtures, Industrial and Engineering Chemistry, Research, 26(11):2344-8 (1987).

28. Dai, S., Recovery of carbon disulfide with activated carbon, Huanjing Baohu (Beijing), (4):14-16 (1987).

29. Lutz, W., et al., Prevention of formation of carbonyl sulfide in sorptive processes, German (East), 5 pp. (1.986).

30. Burushkina, T.N., et al., Adsorption properties and structure of porous styrene-divinylbenzene copolymers, Khim. Tekhnol. (Kiev), (1):3-8 (1987).

31. Majewska, J., et al., Regeneration of redox-containing absorbent used for purification of sulfur-containing gases, in particular removal of carbon disulfide from air, Polish, $3 \mathrm{pp}$. (1985).

32. Majewska, J., et al., Removal of sulfur-containing gases, in particular carbon disulfide, from waste gases, Polish, 3 pp. (1985).

33. Fatkullina, A.F., et al., Absorption of sulfur-containing compounds on alumina-chromium-potassium catalyst, Neftekhimiya, 266(5):704-7 (1986).

34. Voirin, R., Removal of carbonyl sulfide and carbon disulfide from industrial gases, French Demande, 13 pp. (1986).

35. Voirin, R., Removing carbon oxysulfide and carbon disulfide compounds contained in an industrial gas, PCT Int. Application, 22 pp. (1986).

36. Mishra, S.C., and K. Samal, An ultrasonic study of absorption in a binary mixture of carbon disulfide with methyl iodide, Acoustics Letters, $\underline{8}(12): 203.7$ (1985).

37. Marakhovskii, L.F., et al., Removing acid components and carbon disulphide from coke oven gas, USSR. From: Otkrytiya, Izobret. 1985, (31):105 (1985).

38. Liang, Y., and D. Qu, Cost-benefit analysis of the recovery of carbon disulfide in the manufacturing of viscose rayon, Scandinavian Journal of Work, Environment, Health, 11(Suppl. 4):60-3 (1985).

39. Melvold, R, et al., Development of a guidance manual for the selection and use of sorbents for liquid hazardous substance releases, Proceedings, Technical Seminars on Chemical Spills, 2nd, 238-53. Environmental Protection Service: Ottawa, Ontario (1985).

40. Ito, M., Carbon disulfide from sulfur dioxide in flue gas, Japanese Kokai Tokkyo Koho, 4 pp. (1985). 
4.1. Huschenbett, R., et al., Adsorption of hydrogen sulfide and carbon disulfide on cattuated carbons, Luft-Kaeltetech., 21(3):151-3(1985).

42. Tautz, B., and D. Baehr, Energy and material recovery from exhaust gases of the viscose industry in a gas mixture with a carbon disulfide content of less than $550 \mathrm{~g} / \mathrm{m}^{3}$, German (East), 9 pp. (1984).

43. Westberg, H., at al., A charcoal sampling method and a colorimetric cunalytical procedure for carbon disulfide. Measurement data from aviscose rayon manufacturing plant, G. Ital. Med. Lav, 6(3-4):123-5(1984).

44. Konieczynski, J., and Z. Konaszynska, System for adsorption of carbon disulfide vapors, Ochr. Powietrza, 17(6):153-7 (1983).

45. Aleinikov, V.G., et al., Absorption of carbon disulfide from gas-vapor mixtures by carbon adsorbents, Khim. Tekhnul. (Kiov), (1):31-4 (1985).

46. Rybakov, L.A., et al., Spontaneous combustion of activated carbon during recovery of carbon disulfide from rayon fiber production ventilation air, Khim. Volokna, (6):1.1-1.2 (1984).

47. Shimko, I.G., et al,, Removal of carbon disulfide and hydrogen sulfide from rayon fiber production ventilation gases of low concentration, Khim. Volokna, (6):6-9 (1984).

48. Dupin, 'T., and $\mathrm{R}$. Voirin, Catalytic desulfurization of an acidic gas containing hydrogen sulfide and possibly a total quantity at the most $3 \%$ of the volume of carbon disulfide and/or carbon oxysulfide, French Demande, $15 \mathrm{pp}$. Addendum to French Demande Application Number 8123611 (1984).

49. Turchanenko, Y.T., and A.I. Suprunenko, Regeneration of carbon disulfide from exhaust fan wastes in the production of synthetic fibers, USSR. From: Otkrytiya, Izobret., Prom. Obraztsy, Tovarnye Znaki 1984, (30):60 (1.984).

50. Won, K.W., et al., Vapor-liquid equilibriums of sulfur-containing solutes in hydrocarbons, Proceedings, 63rd Annual Convention - Gas Processing Assuciation, pp. 187-91 (1984).

51. Derecka, B., and T. Wasag, Possible use of an absorption method for removal of carbon disulfide from ventilation gases, Ochr. Powietrza, 18(3):52-5 (1984).

52. Chou, C.L., and K. Li, Kinetic and structural studies of regeneration of sulfided dolomite in carbon dioxide. I. The first cycle regeneration, Chemical Engineering Communications, 29(1-6):153-79 (1984).

53. Gasyuk, L.A., Separation of carbon disulfide in apparatus for bath stretching of a synthetic fiber, Khim. Volokna, (4):56-7 (1984). 
54. Armagan, T., Adsorption measurements using a pulse concentration flow system for desulfurization reactions, Bull. Technical University of Istanbul, 36(4):475.85 (1.983).

56. Derecka, B., and T. Wasag, Absorption equilibriums for the system: air.carbon disulfide.liquict, Przem. Chem., 62(9):522-33 (1983).

56. Rybicki, Z., et al., Regeneration of an absorption bath for removing sulfur gases and carbon. disulfide from waste gases, Polish, 2 pp. (1983).

57. Mishra, S.C., and K. Samal, Ultrasonic absorption study in some binary mixtures of polar-nonpolar liquids, Acoustical Letters, 7(1):7-16 (1983).

58. Boka, L, et al., Treatment of waste gases from viscose plants, Hurgarian Teljes, 11. pp. (1983)。

59. Derecka, B., and T. Wasag, Studty of atarbon disulfide absorption by selected fluids. Ochr. Powietrza, 17(4):96-8 (1.983).

60. Kaiodorous gas adsorbents, Japanese Kokai Tokkyo Koho, a pp. 11983).

61. Ancerowicz, R., et al., Head control for metering oxidants to an adsorbent bath containing a redox system for removal of carbon disulfide and hydrogen sulficte from waste gases, Polish, 3 pp. (1982).

62. Zanevskaya, O.S., et al., Oxidation of carbon disulfide by ozonized air on a silver-manganese catalyst, Katal. Katal, 20:56-60 (1982).

63. Palilla, F.C., et al., Catalytic removal of toxic gases from gas streams, United States, 24. pp. Division of United States Serial Number 93,662, abandoned (1983).

64. Loskutov, A.I. and M.N. Khlopotov, Interaction of hydrogen sulficle and carbon disulficle with carbon adsorbents, Adsorbts. Adsorbenty, 10:28-32 (1982).

65. Lopatneva, Z.Y., et al., Effect of different factors on the separation of carbon disulfide from rubbers, Kauch. Rezina, (1):39-40 (1983).

66. Solozhenkin, P.M., and A.V. Ivanov, EPR of complexes prepared byadsorption by molybdenum oxide of sulfhydryl reagents and their disulfides, Sovrem. Metody YAMIR i EPR v Khimii Tverd. Tela. Materialy 3 Vses. Koordinats. Soveshch. Uchenykh i Spets. In-tov AN SSSR, Noginsk, 1-3 Iyunya, 1982, Chernogolovka 199.201 From: Ref. Zh., Khim. 1982, Abstract Number $21 B 320$ (1982).

67. Hlavacek, V., and O. Mikus, Deactivation of platinum catalysts by poisons: a study of behavior of afterburner convertors, Chemical Engineering Communications, 18( 1-4):1-14 (1982). 
68. Dupin, 'T., Catalyst for treating industrial waste gases that contain sulfur, European' Patent Application, 28 pp. (1982).

69. Dupin, T, Catalyst for the oxidation of hydrogen sulfide and/or organic sulfur compounds to sulfur dioxide, European Patent Application, 25 pp. (1982).

70. Gizinski, S., Some aspects of the treatment of waste gases from rayon fiber plants, Wlokna Chem., $8(2): 165-9$ (1982).

71. Zanevskaya, O.S., et al., Adsorption of carbon disulfide by active carbons from gas-air mixtures of low concentration, Khim. Telchnol. (Kiev), (4):55-7 (1982).

72. Wasag, T., and B. Derecka, Absorption of carbon disulfide from a model gas in aqueous solutions of hydroquinone, Ochr. Powietrza, 15(4):107-11(1981).

73. Epiluhin, V.N., et al., Vibrational relaxation in carbon disulfide carbon dioxide muxtures studied by the ultrasound absorption method, Deposited Document. VINITI 2949-80, 30 pp. Available VINITI (1980).

74. Aftanas'ev, Y.M., Removal of hydrogen sulfide und organosulfur compounds from gases, Prom. Sanit. Ochistka Gazov, (3):22«3 (1981).

75. Kuzmichev, G.V., et al., Petroleum sulfoxides as prospective sorbents for the purification of waste gases and recovery of sulfur-containing gases in the metallurgical industry, Tsvetn. Met., (6):21-2 (1981).

76. Hoppe, H., et al., Measurement of adsorption isotherms of some harmful atmospheric gases on activated carbons, Luft- Kaeltetech., 17(2):70-2 (1981).

77. Kiklas, J., ot al., Processing of a carbon disulfide fraction in hydrorefining of colie oven benzene, Polish, 2 pp. (1981).

78. Troitskii, V.N., et al., Removal of carbon disulfide from gases, USSR. From: Otkrytiya, Izobret., Prom. Obraztsy, Tovarnye Znaki 1981, (18):28 (1981).

79. Katushkin, V.P., and V.S. Minster, Removal of carbon: disulfide and hydrogen sulfide froin emissions, Khim. Prom-st., Ser.: Okhr. Okruzhayushchei Sredy Ratsion. Ispol'z. Prir. Resur., (6):1-5 (1980).

80. Brunekreef, B., and H. Harssema, Viscose odors in ambient air. A study of the relationship between the detectability of viscose odors and concentrations of hydrogen sulfide and carbon disulfide in ambient air, Water, Air, Soil Pollut., 13(4):439-46 (1980).

81. Wasag, T., and B. Derecka, Methods for the removal of carbon disulfide from gases, Ochr. Powietrza, 14(3):74-7 (1980). 
82. Privalov, V.E., et al., Removal of acid components and carbon disulfide from coke gas, USSR. From: Otkrytiya, Izobret., Prom, Obraztsy, T'ovarnye Znaki 1981., (3):26 (1981).

83. Dosouza, G.J., and H.D. Radford, Desulfurization of waste gases, United States, 9 pp. (1980),

84. Sasaki, A., Adsorbants of heauy metals having a high selectivity and adsorption methods, Beigium, 28 pp. (1980).

85. Hajek, J., Elimination of waste gases from the production of staple fibers at the Spolana plant in Neratoutce, Chem. Lide, (5):2.3 (1980).

86. Novinyuk, L.V., et al, Study of the removal of carbon disulfide and acetone from air in the synthetic fiber plants, Mezhvuz. Sb. Nauch. Tr. Leningr. Tekhnol. In-t, (2):81.7 From: Ref: Zh., Khim. 1980, Abstract Number 12I627 (1979).

87. Umemura, MI, et al., Emission factor of carbon disulfide and hydrogen sulfide from cellophane manufacturing plant, Gifu-ken Kogai Kenkyusho Nenpo, 7:23-5 (1979).

88. Slupin, D.Y, and A.P. Seleznev, Absorption of ethanethiol and carbon disulfïcle present in microconcentrations in methane-hydrogen sulfide-ethanethiol, methane-ethanethiol, and methane-carbon disulfide gaseous mixtures by an aqueous aerosol crystallizing in them, Zh. Prikl. Khim. (Leningrad), 53(4):944-6 (1980).

89. Stuchlsov, G.S., and O.P. Koval, Removal of carbon disulfide from carbon tetrachloride using synthetic zeolite CaA, Khim. Tekhnol. (Kiev), (6):19-21. (1979).

90. Batteux, J., et al., Purifying industrial waste gases containing small amounts of sulfur compounds, German, Offen., 11. pp. (1979).

91. Akimoto, M., and I.G.D. Lana, Reactivity of carbonyl sulfide and carbon disulfide in vapor-phase hydrolysis over an alumina catalyst, Nippon Kagaku Kaishi, (12):1662-7 (1979).

92. Gasyuk, L.A., and R.G. Nonezov, Determination of points of the greatest formation of carbon disulfide and hydrogen sulfide in rayon fiber production, Khim. Volokna, (4):48.9 (1979).

93. Sims, D.G., and S.E. Suniewski, Thermal oxidation of Claus tail gases in a plant producing carbon disulficle, Institute of Chemical Engineering Symposium Service, 57(Control Sulphur Other Gaseous Emissions):AA1-AA14 (1979).

94. Hoppe, H., et al., Adsorption studies on carbon disulfide-containing waste gases, LuftKaeltetech., 15(2):91-3 (1979).

95. Grebennikov, S.F., et al., Adsorption of carbon disulfide with carbon fiber adsorbents, Khim. Volokna, (3):50-2 (1979). 
96. Hancu, I., et al., Possibilities of carbon disulfide removal from some inilustrial gases, Rev. Chim. (Bucharest), 30(4):346-8 (1979).

97. Brager, N.N., et al., Removal of carbon disulfide, carbon oxysulfide, mercaptans, and thiophene from coke gas and an ethylene fraction, USSR. From: Otkrytiya, Izobret., Prom. Obraztsy, Tovarnye Znaki1979, (18):291 (1979).

98. Grams, W., and J. Majewska, Polarographic study of a bath for absorption of carbon disulfide and hydrogen sulfide, Hem. Vlakna, 18(4):3-6 (1978).

99. Kuropka, J., and M.A. Gostomczyk, Investigation of the kinetics of carbon disulfide sorption on anion exchangers, Environmental Protection Engineering, 4 (2):87-99 (1978).

100. Sadakane, Y., and C. Furutani, Removal of odorous materials and environmental pollution in rayon plants. Part 2. Desulfurization by alkali scrubbing and activated carón adsorption, Akushu no Kenkyu, 6(30):3-10 (1978).

101. Stevens, G.C., Desulfurization catalysts and their use in hydrocatalytic desulfurization, German, Offen., 15 pp. (1978).

102. Removing carbonyl sulfide, carbon disulfide and sulfur dioxide from industrial waste gases, Japanese, 6 pp. (1978).

103. Majewska, J., et al., New wet method for the purification of rayon fiber production dilute ventilation discharges from sulfur (carbon disulfide and hydrogen sulfide) compounds, Prepr. - Mezhdunar. Simp. Khim. Voloknam, 2nd, Volume 6, 69-74. Program. Kom. Mezhdunar. Simp. Khim. Voloknam: Kalinin, USSR. (1977).

104. Selin., A.N., and V.P. Kim, Utilization of hydrogen sulfide and carbon disulfide absorption with a setting tank and their forced desorption for rayon fiber production decontamination. Prepr. - Mezhdunar. Simp. Khim. Voloknam. 2nd. Volume 6, 23-8. Program. Kom. Mezhdunar. Simp. Khim. Voloknam: Kalinin, USSR. (1977).

105. Portnov, D.M., et al., New process for the removal of carbon disulfide from ventilation discharges, Prepr. -Mezhdunar. Simp. Khim. Voloknam, 2nd, Volume 6, 5-9. Program. Kom. Mezhdunar. Simp. Khim. Voloknam: Kalinin, USSR. (1977).

106. Korobochko, N.A., et al., Purification of ventilation air in staple production shop by carbon disulfide recovery, Prom. Sanit. Ochistka Gazov, (5):24-5 (1977).

107. Nakanishi, Y., and Y. Harada, Refining of gases containing organic sulfur compounds, Japanese Kokai, 5 pp. (1977).

108. Mori-Konig, G., Some procedures for the recovery of environment-polluting chemicals in the tisne process. Prenpr. - Mezhdunar. Simp. Khim. Voloknam. 2nd, Volume 6, 75-82. Program. Kom. Mezhdunar. Simp. Khim. Voloknam: Kalinin, USSR. (1977). 
109. Shimada, M., et al., Recovery of organic sulfur compounds from industrial u'aste gases, Japanese Kokai, 3 pp. (1977).

110. Hasegawa, K., et al., Desorption of adsorbed materials from activated carion "Japanesa Kokai, 4 pp. (1977).

111. Drumer, J., Improvements in or relating to a process for themanufacture of carbon disulfide, British, 3 pp. (1977).

112. Majewska, J., et al., New method for catalytic removal of sulfur compounds (carbon disulfide and hydrogen sulfide) from dilute ventilation gases of rayon factories, Hem. Vlakna, 17(1):3-6 (1977).

113. Joswig, H. J., et al., Orbital population and activity of metal phthalocyanine catalysts of the first transition period in heterogeneously catalyzed gas-phase reactions, Proceedings, International Congress of Catalysis, bth, Meeting Date 1976, Volume 1, 583-92. Edited by: Bond, G. C., et al., Chemical Society: Letchworth, England (1977).

114. Astakhov, V.A., and V.D. Lukin, Study of the recovery of carbon disuifide irom ventilation emissions. I. Study of equilibrium adsorption of caroon aisuificie on microporous active carbons, Zh. Prikl. Khim. (Leningrad), 50(5):1033-6 (1977).

115. Gostomczyk, M.A., and J. Kuropka, Hydrogen sulfide and carbon disulfide sorption on anion exchangers, Pr. Nauk. Inst. Inz. Ochr. Srodowiska Politech. Wroclaw., 41:95-104 (1976).

116. Astakhov, V.A., et al., Dynamics of carbon disulfide adsorption from solutions on erionite, Zh. Prikl. Khim. (Leningrad), 50(6):1243-7 (1977).

117. Hasui, H., et al., Carbon disulfide removal with chelated iron, Japanese Kokai, 6 pp. (1977).

118. Maier, F., Apparatus and method for using sulfur compounds contained in oxygen-containing gases with a high water vapor content, German, 6 pp. (1976).

119. Van Deraerschot, R., and J.P. Valentine, The SELEXOL Solvent Process for selective removal of sulfur compounds, Control Gaseous Sulphur Nitrogen Compound Emissions, Paper, International Conference, 2nd, Volume 2, VIII, 17 pp. University of Salford: Salford, England (1976).

120. Luethi, F., and G. Hechler, Purifying the exhaust air from viscose spinning machines, German, Offen., 13 pp. (1976).

121. Sefcik, M.D., et al., Characterization of the mordenite sorption sites by carbon-13 NMR, ACS Symposium Service, 40 (Molecular Sieves-2, International Conference, 4th):344-56 i1077;. 
122. Stoecker, U., Purification of gaseous effluenis in the production and processing of viscose products, Chem.-Ing.-Tech., 418(10):833-9(1976).

123. Aleksandrova, M.V., and E.G. Yaroshchuk, Gas.liquid phase equilibrium in the nitrogen-carbon disulfide-settling bath system at 50 degree $C$, Khim. Volokna, (1):45-7 (1977).

124. Kalinina, N.V., Catalytic combustion of the ventilated air of viscose production, Prom. Sanit. Ochistka Gazov, (2):6 (1976).

125. Storp, K., et al., Separation of organic sulfur compounds from gases, German, Offen., 10 pp. (1976).

126. Kuropka, J., and M.A. G'stomczyk, Methods for limiting the emission of hydrogen sulfide and carbon disulfide into the atmosphere, Gaz, Woda Tech. Sanit., 50(8):233-5 (1976).

127. Zubov, S.B., Recovery of carbon disuifide by activated carbons, Prom. Sanit. Ochistka Gazov, i2):6-7 (1976).

128. Serkov, A.T., et al., Viscose fibers, French Demande, 8 pp. (1976).

129. Majewska, J, et al., Removal of gaseous sulfur compounds from waste gas, especially from viscose fiber production, German, Offen., 15 pp. (1976).

130. Belyakov, V.P., et al., Removing carbon disulfide from gases, USSR. From: Otkrytiya, Izobret., Prom. Obraztsy, Tovarnye Znaki 1976, $\underline{53}$ (29)17 (1976).

131. Wolf, F., and S. Lindau, Adsorption of carbon disulfide, German (East), 3 pp. (1976).

132. Yasui, T., et al., Separation and recovery of carbon disulfide, Japanese Kokai, 8 pp. (1976).

133. Belokonev, S.V., et al., Kinetics of the process for distillation of carbon disulfide from the roving in the production of a high-modulus rayon fiber. (Brief communication), Khim. Volokna, (4):49-50 (1976).

134. Kachanak, S., et al., Study of the change in the mass-transfer coefficients in differential bed of a sorbent during its saturation with adsorhate, Chem. Zvesti, 29(5):637-44 (1975).

135. Sharkin, G.A., et al., Thermodynamics of reactions involving removal of sulfurous substances from gases, Zh. Prikl. Khim. (Leningrad), 49(2):329-33 (1976).

136. Wolf, D., and J. Fahrbach, Gas filter testing. Theoretical considerations on the separating capacity of adsorbents, Staub - Reinhalt. Luft, 36(1):39-43 (19'76).

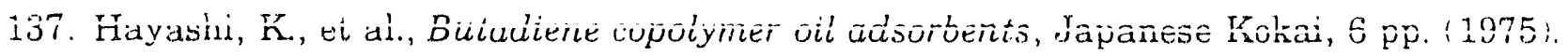


138. Nicklin, T., Catalytic production of sulfur from hydrogen sulfide and sulfur dioxide, Canadian, 16 pp. (1975).

139. Astakhov, V.A., et al., Displacement desorption of carbon disulfide from active carbons in apparcius with a moving bed of adsorbent, Zh. Prild. Khim. (Leningrad), $\underline{48}(9): 1978-82$ (1975).

140. Jerzykiewicz, W., et al., Removal of carbon disulfide from benzene products using higher aliphatic amines, Koks, Smola, Gaz, 20(3):66-8 (1975).

141. Kal'ko, V.I., et al., Interphase equilibrium in the carbon disulfide-organosilicon liquid system, Khim. Tekhnol. (Kiev), (4):61 2 (1975).

142. Aggarwal, V.C., and A.K. Gupta, Ultrasonic absorption and velocity measurements in a critical mixture of methyl alcohol and carbon disulfide, Indian Journal of Pure Applied Physics, 13(11):734-7 (1975).

143. Richardson, I.M.J., and J.P. O'Connell, Generalizations about processes to absorb acid. gases and mercaptans, Ind. Eng. Chem., Process Des. Dev., 14(4):467-70 (1975).

144. Shimada, M., et al., Recovery of carbon disulfide from waste gases, Japanese Kokai, 3 pp. (1975).

145. Norden, B., Linear dichroism technique on small molecules dissolved and oriented in a polymer matrix. I. Polarization for a few electronic transitions in sulfur dioxide, carbon disulfide, and nitrogen dioxide, Chem. Scr., I(4):167-72 (1975).

146. Sturc, J., Zinc oxide sorbent for the desulfurization of gases, Czechoslovakian, $5 \mathrm{pp}$. (1975).

147. Liberman, V.I., et al., Removal of suspended particles, carbon disulfide, and hydrogen sulfide from rayon manufacture spinning baths, USSR. From: Otlirytiya, Izobret., Prom. Obraztsy, Tovarnye Znaki 1974, 51(45):17 (1974).

148. Kachanak, S., et al., Carbon disulfide adsorption on type 5 a molecular sieves. Adsorption equilibriums and kinetics, Zb. Pr. Chemickotechnol. Fak. SVS'T, 1972 293-300 (1974).

149. Crow, J.H., and J.C. Baumann, Versatile process uses selective absorption, Hydrocarbon Process., 53(10):131-2 (1974).

150. Shimada, M., and K. Usui, Recovery of carbon disulfide from waste gas, Japanese Kokai, 3 pp. (1973).

151. Lekae, V.M., et al., Static charanteristics of the carbon disulfide-mineral oil system, Tr. Mosk. Khim.-Tekhnol. Inst., 72:182-4 (1973). 
152. Kawazoe, K., et al., Correlation of adsorption equilibrium data of various gases and vapors on molecular sieving carbon, Journal of Chemical Engineering of Japan, $\underline{7}(3): 158-62$ (1974).

153. Timofeev, D.P., et al., Dynamics of adsorption of carbon disulfied on moistered active charcoal, Prom. Sanit. Ochist. Gazov, Nauchno-Tekh. Sb., Number 3:17-20 From: Res. Zh., Khim. 1973, Abstract Number 221596 (1973).

154. Sharp, S.P., and L.F. Sudduth, Dehydration of wet gases, United States, 4 pp. (1974).

155. Kato, T., et al., Polluting gas-removing adsorbent, Japanese Kokai, 4 pp. (1974).

156. Gorin, E., et al., Removal of carbon disulfide from gas containing suifur dioxide, Japanese Kokai, 7 pp. (1973).

157. Puri; B. R., et al., Formation and properties of carbon-sulfur surface complexes. VII. Effect of the complexes on surface behavior of carbon blacks, Journal of Indian Chemistry Society, 50(7):473-8 (1973).

158. Nicklin, T., Recovery of suifur from waste gases containing hydrogen sulfide, British, 5 pp. (1973).

159. Mal'kov, V. A., et al., Start-up and repair of pilot-plant cleaning equipment at the Krasnoyarsk synthetic fiber manufacturing plant, Khim. Volokna, 15(4):34-7 (1973).

160. Chivilikhina, M.P., et al., The liberation of toxic gases in rayon cord production, Khim. Volokna, 15(4):24-6 (1973).

161. Chicherin, Y.I., et al., Annular adsorber for recovering of carbon disulfide and acetone from ventilation gases from synthetic fiber production, Khim. Volokna, 15( 4):21-4 (1973).

162. Zak, S.L., Detoxication of ventilation emissions containing carbon disulfide and hydrogen sulfide in rayon fiber manufacturing plants, Khim. Volokna, 15(4):14-16 (1973).

163. Telyal'kova, L.I., Testing the performance of apparatus for recovering carbon disulfide from exhaust gases at the Ryazan synthetic fiber complex, Khim. Volokna, 15(4):27-8 (1973).

164. Lazarev, V.I., et al., New purification processes for ventilation emissions in synthetic fiber production, Khim. Volokna, 15(4):9-12(1973).

165. Storp, K., and H. Kleemann, Removing organic sulfur compounds from gases, German, 3 pp. Addendum to German 1,277,817 (See British 903,612, CA 58;10014c) (1973).

166. Lazarev, V.I., and V.I. Kostrikov, Decomposition of carbon disulfide on different-grade active carbons, Prom. San. Ochistka Gazov., Ref. Sb., No. 1, 12-14 From: Ref. Zh., Khim. 1973, Abstract Number 11501 (1972). 
167. Jaenike, K., Problems of waste gas purification in the chemical fiber industry, Chem. Tech. (Leipzig), 25(6):370-1 (1973).

168. Koizumi, T., et al., Recovery of carbon disulfide, Japanese Kokai, 3 pp. (1973).

169. Leszczynski, Z., et al., Seporation of pure carbon disulfide from reaction gases, Polish, 2 pp. (1973).

170. Chervyakov, V.A., Automation of adsorption-desorption processes of carbon disulfide recovery apparatus, Khim. Volokna, 15(2):55-7 (1973).

171. Astakhov, V.A., et al., Adsorptive capability of zeolite suspensions during carbon disr:lfide absorption, Zh. Prikl. Khim. (Leningrad), 46(3):675-8 (1973).

172. Pearson, M.J., et al., Catalytic conversion of sulfur-containing organic compounds present in residual industrial gases, French Demande, 14 pp. (1972).

173. Antsypovich, I.S., and E.F. Shkatov, Modeling of the continuous thermal regeneration of active carbons, Khim. Prom. (Moscow), 49(3):217-18(1973).

174. Pearson, M.J., Developments in Claus catalysts, Hydrocarbon Process., 5212 (Sect. 1)):81-5 (1973).

175. Rabinowitz, J.R., Interaction theory for large molecules, $105 \mathrm{pp}$. Available University inicrofilms, Ann Arbor, Michigan, Order Number 73-5165 From: Dissertation Abstracts Int. B 1973, $\underline{33}(8): 3860$ (1972).

176. Lissant, K.J., Carbon disulfide emulsions, United States, 4 pp. (1972).

177. Lobanova, N.N., et al., Detoxification of exhaust gases and recovery of carbon disulfide in staple fiber production, Khim. Volokna,14(5):67-9 (1972).

178. Jones, T.R., Effluent treatment at man-made fiber production units, Effluent Water Treatment Journal, 12(7):352-5 (1972).

179. Beavon, D.K., Conversion of carbon disulfide and carbonyl sulfide to hydrogen sulfide in a modified Claus process, German, Offen., 15 pp. (1972).

180. Campiglio, A., Microdetermination of oxygen in sulfur-containing, organic compounds. III. Removal of carbon disulfide and carbonyl sulfide from cracked gases by thermal decomposition on metal, Mikrochim. Acta, (5):631-45 (1972).

181. Cognion, J.M., Influence of copper on the desulfurizing properties of zinc oxide, Chim. Ind., Genie Chim., 105(12):757-64 (1972).

182. Saleh, J.M., Adsorption and incorporation on copper, Journal of Chemical Society, Faraday Trans. 1, 68(Pt. 8):1520-7 (1972). 
183. Goodsel, A.J., and G. Blyholder, Adsorption of carbon dioxide, carbonyl sulfide, and carbon disulfide on manganese films, Journal of Catalysis, 26(1):11-17 (1972).

184. Dobrotin, R.B., et al., Adsorption-desorption equilibrium and kinetics in a three-phase system, Adsorbenty, Ikh Poluch., Svoistva Primen., Tr. Vses. Soveshch. Adsorbentam, 3rd, Meeting Date 1969, 229-32. Edited by: Dubinin, M. M. "Nauka", Leningrad. Otd.: Leningrad, USSR. (1971).

185. Samal, K., and S.C. Misra, Ultrasonic absorption in binary mixtures of carbon disulfide in comparison with Bauer's theory, Journal of Physics Society of Japan, 32(6):1615-18 (1972).

186. Schoofs, R.J., and R.J. Kulperger, Selectively adsorbir g acidic compounds from gas streams by using as the adsorbent a modified zeolitic molecular sieve, British, 3 pp. (1971).

187. Kim, V.P, et al., Operation of an experimental-industrial apparatus for the recovery of carbon disulfide, Khim. Volokna, 15i:66-8 (1971).

188. Mehta, N.C., et al., Cataiytic process for the removal of organuc sulfur compouncis from a gas stream, Technology, 7(4):239-45 (1970).

189. Pak, H., Statistical thermodynamic approach to the liquid-vapor interface of binary solutions, Daehan Hwahak Hwoejee, 15(3):133-45(1971).

190. Storp, $\mathrm{K}$,Purification of spent air from hydrogen sulfide and carbon disulfide, German, Offen., 10 pp. (1971).

191. Adamson, A.W., Physical adsorption of vapors, United States Clearinghouse Federal Science trechnical Information, AD, Number 724740, 10 pp. Available NTIS From: Government Rep. Announce. (U.S.) 1971, 71' 15):80 (1971).

192. Nikitenk, A.G., et al., Removal of carbon disulfide from carbon tetrachloride, Ukr. Khim. Zh., 37(4):374-6 (1971).

193. Saleh, JM., Chemisorption on platinum and tungsten, Trans. Faraday Society, 67(6):1830-6 (1971).

194. Storp, K, et al., Separation of hydrogen sulfide and carbon disulfide from industrial. waste gas, German, Offen., 14 up. (1971).

195. Hirst, D.G., and A. Parr, Recovery of carbon disulfide, German, Offer., 16 pp. (1971).

196. Kostrikov, V.I., et al., Removal of hydrogen sulfide and carbon disulfide from the viscose industry vented wastes with the use of activated carbons, Uglerodn. Adsorbenty Ikh. Primen. Prom., 2, 12-21 From: Ref. Zh.', Khim. 1969, Abstract Number 22I609 (1969).' 
197. Recovery of carbon disulfide from viscose process gases, French, 10 pp. (1970).

198. Campiglio, A., Unterzaucher method for the microdetermination of oxygen in organic compounds containing sulfur. II. Use of chemical methods for the removal of carbon disulfide and carbonyl sulfide from pyrolysis gas, Farmaco, Ed. Sci., 26(4):349-69 (1971).

199. Campiglio, A., Unterzaucher method for the microdetermination of oxygen in organic compounds containing sulfur. I. Use of physicalmethods for the removal of carbon disulfide and carbonyl sulfide from pyrolysis gas, Farmaco, Ed. Sci., 26(4):333-48 (1971).

200. Storp, K., Removal of sulfur from exhaust air and gases by adsorption and catalysis on activated carbon, DECHEMA (Deut. Ges. Chem. Apparatewesen) Monogr., 64(1144-1167):91-102 (1970).

201. Preusser, G., et al., Washing of carbonyl sulfide and carbon disulfide from industrial gases, German, Offen., 16 pp. (1970).

202. Astakhov, V.A., Adsorption of carbon dioxide and carbon disulfide by a suspension of CaA zeolite in toluene, Zh. Prikl. Khim. (Leningrad), 43 12):2655-8 (1970).

203. Levina, S.A., Adsorption of carbon disulfide on iron-substituted zeolites, Kolloid. Zh., $\underline{32}$ (ct):729-32 (1970).

204. Levit, R.M., and G.M. Belotserkovskii, Adsorption method for carbon disulfide recovery in carbon disulfide production waste gases, Uglerodn. Adsorbenty lkh Primen. Prom., 2, 31.43 From: Ref. Zh., Khim. 1970, Abstract Number 2L42 (1969).

205. Levina, S.A., Adsorption of carbon disulfide from solutions by granulated erionite, Dokl. Akad. Nauk Beloruss. SSR, 19(5):423-4 (1970).

206. Kel'tsev, N.V., et al., Change in the structure of activated carbon during the cleaning of waste gases from viscose production, Khim. Volokna, (1):37-8 (1970).

207. Denisov, N.S., et al., Degassing technological solutions of viscose manufacture in a sprayer, Khim. Volokna, (6):48-9 (1969).

208. Astakhov, V.A., et al., Multicycle adsorption-desorption process in a carbon disulfide-decalin-erionite system, Dokl. Akad. Nauk Beloruss. SSR, 13(11):998-1000 (1969).

209. Samal, K., and S.C. Misra, Ultrasonic absorption in binary mixtures of carbon disulfide, Indian Journal of Physics, $\underline{43}(4): 227-9$ (1969).

210. Lee, M.N.Y., and R.J. Schoofs, Purificction of gases by ammonia-modified molecular sieves, German, Offen., 11 pp. (1969). 
211. Thomas, W.J., and U. Ullah, Chemisorption of hydrogen sulfide and carbon disulfide on sulfided nickel oxide and vanadium pentoxide, Journal of Catalysis, 15(4):342-54 (1969).

212. Bubnova, G.P., and V.I. Kostrikov, Removal of hydrogen sulfide and carbon disulfide from air during viscose production, Zh. Vses. Khim. Obshchest., 14(4):399-405 (1.969).

213. Schoofs, R.J., and R.J. Kulpurger, Adsorption process for acid gases, German, Offen., $11 \mathrm{pp} .(1969)$.

214. Sinev, O.P., Removal of carbon disulfide and sulfide compounds by aeration from the total discharge from the production of viscose fibers, Khim. Volokna, (4):59-61 (1969).

215. Chicherin, Y.I., and V.S. Minster, Dynamic characteristics of new domestically produced activated carbons suitable for apparatus for the recovery of carbon disulfide, Khim. Volokna, 135-40. Edited by: Konkin, A. A. Izd. "Khimiya": Moscow, USSR. (1.968).

216. Astakhov, V.A., et al., Removal of carbon disulfide from ventilating air discharges, USSR. From: Otkrytiya, Izobr|at., Prom. Obraztsy, Tovarnye Znaki 1969, 46(14):15 (1969).

217. Zhukov, A.I., et al., Purificatid" of waste waters from viscose fiber plants, Tr., Vses. Nauch.-Issled. Inst. Vodosnabzil., Kanaliz., Gidrotelsh. Sooruzhenii Inzh. Gidrogeol., Number 20:67-70 (1967).

218. Tanaka, R., and T. Iida, Recoviry of carbon disulfide and sodium hydrosulfide from collector gas in viscose spinning. Japanese, 5 pp. (1968).

219. Baranowska-Gulik, B., and Z. Banasiak, Comparison of the binding rate of carbon disulfide in some solutions used tor the absorption of carbon disulfide vapors, Chemical Analysis (Warsaw), 13(4):823-6 1968).

220. Voiskoboinik, A.I., et al., Purify, ng gases of the viscose industry by removal of carbon disulfide, USSR. From: Izobret.., Prom. Obraztsy, Tovarnye Znaki 1968, 45(29):1.3 (1968).

221. Belotserkovskii, G.M., and R.M. Levit, Adsorption of carbon disulfide from waste gases from carbon disulfide preparation. VII. Dynamics of the adsorption of carbon disulfide from concentrated mixtures with hydrogen sulfide on moist activated carbon, Khim. Volokna, (5):43-5(1968).

222. Hert1, W., and M.L. Hair, Hydrogen bonding between adsorbed gases and surface hydroxyl groups on silica, Journal of Physical Chemistry, 72(13):4676-82 (1968).

223. Levina, S.A., et al., Carbon disulfide adsorption on zeolite from solutions, Dokl. Akad. Nauk Beloruss. SSR, 12(10):908-10 (1968). 
224. Kloeclener, L., et al., Recovery of carbon disulfide from gas and steam mixtures, German, 2 pp. (1968).

225. Kloeckner, L., Removal of carbon disulfide and hydrogen sulfide from exhaust air, German, 2 pp. (1968).

226. Braeuer, H.W., and F. Fischer, Recovery of carbon disulfide with simultaneous removal of hydrogen sulfide, DECHEMA Monogr, 59(1045-1069):173-89 (1968).

227. Nabivach, V.M., et al., Comparison of th: absorption capacity of absorption oils with the aid of gas chromatography, Koks Khim., (8):35-8 (1968).

228. Kostrikov, V.I., et al., Use of one sorbent to remove both hydrogen sulfide and carbon disulfide from rayon-industry waste gases, Khim. Volokna, (2):45-7 (1968).

229. Kostrikov, V.I., et al., Removal of hydrogen sulfide and carbon disulfide from gases, USSR. From: Izobret., Prom. Obraztsy, Tovarnye Znaki 1967, 44(21):20.

230. Fridman, S.D., et al., Purification and removal of gas from settling tanks in the preparation of viscose fibers and films by flotation. III. Continuous purifïcation and removal of gas from settling tanks by flotation with the recovery of carbon disulfide, Legka Prom-st., (3):37-40 (1967).

231. Venkateshwarlu, M., and G.S. Sastry, Ultrasonic studies of binary liquid mixtures: aniline-benzene and aniline-carbon disulfide, Current Science, 36(22):602-3 (1.967).

232. Landau, M., et al., Method of breaking carbon-sulfur bonds, British, 21 pp. (1967).

233. Stephens, A., Improved method for the recovery of carbon disulfide and other solvents, French, 17 pp. (1967).

234. Romovacek, J., et al., Desulfurization of gas with wash oil, Sb. Vys. Sk. Chem.-Technol. Praze, Technol. Paliv, 12:139-57 (1966).

235. Ivanovskii, F.P., et al., Catalytic removal of organic sulfur impurities in coking gas, Khim. Prom-st. (Moscow), 42(11):845-6 (1966). 

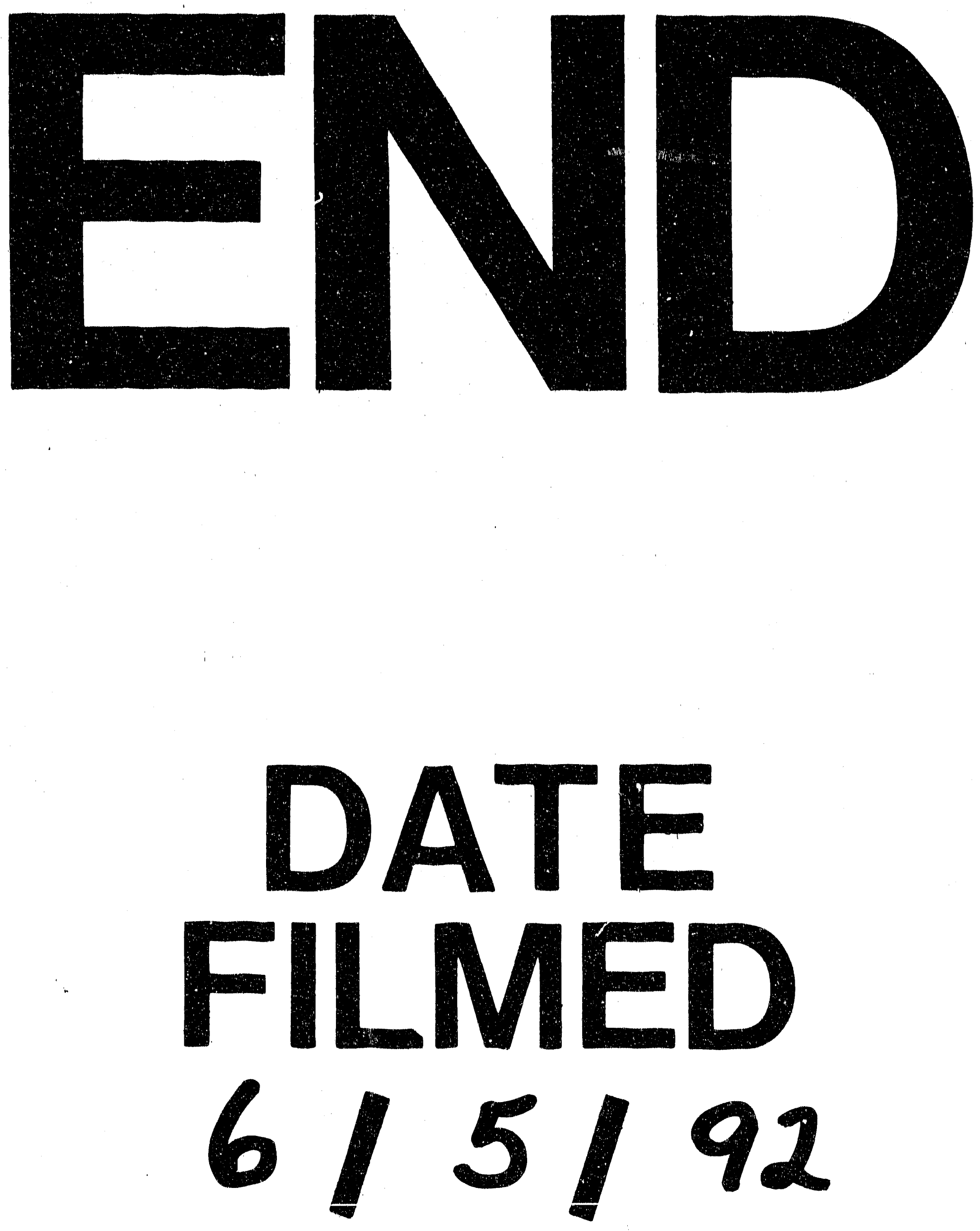

1 
